\title{
Identifying patients with axial spondyloarthritis: on a mission to achieve timely recognition
}

Citation for published version (APA):

van Onna, M. (2015). Identifying patients with axial spondyloarthritis: on a mission to achieve timely recognition. [Doctoral Thesis, Maastricht University]. Datawyse / Universitaire Pers Maastricht. https://doi.org/10.26481/dis.20151120mo

Document status and date:

Published: 01/01/2015

DOI:

10.26481/dis.20151120mo

Document Version:

Publisher's PDF, also known as Version of record

\section{Please check the document version of this publication:}

- A submitted manuscript is the version of the article upon submission and before peer-review. There can be important differences between the submitted version and the official published version of record.

People interested in the research are advised to contact the author for the final version of the publication, or visit the DOI to the publisher's website.

- The final author version and the galley proof are versions of the publication after peer review.

- The final published version features the final layout of the paper including the volume, issue and page numbers.

Link to publication

\footnotetext{
General rights rights.

- You may freely distribute the URL identifying the publication in the public portal. please follow below link for the End User Agreement:

www.umlib.nl/taverne-license

Take down policy

If you believe that this document breaches copyright please contact us at:

repository@maastrichtuniversity.nl

providing details and we will investigate your claim.
}

Copyright and moral rights for the publications made accessible in the public portal are retained by the authors and/or other copyright owners and it is a condition of accessing publications that users recognise and abide by the legal requirements associated with these

- Users may download and print one copy of any publication from the public portal for the purpose of private study or research.

- You may not further distribute the material or use it for any profit-making activity or commercial gain

If the publication is distributed under the terms of Article $25 \mathrm{fa}$ of the Dutch Copyright Act, indicated by the "Taverne" license above, 


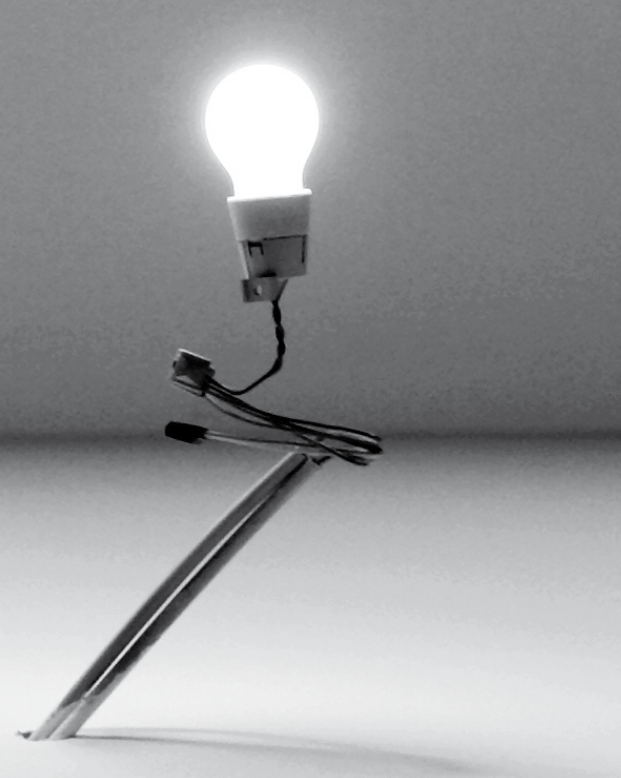

Identifying patients with axial spondyloarthritis On a mission to achieve timely recognition

\section{Marloes van Onna}


ISBN: 9789461594877

Printing was financially supported by Abbvie, Pfizer B.V, UCB Pharma B.V, Janssen-Cilag B.V.

Cover design: Getty images, Raphael Schneider Layout: Tiny Wouters

Production: Datawyse, Universitaire Pers M aastricht 


\title{
Identifying patients with axial spondyloarthritis: on a mission to achieve timely recognition
}

\author{
PROEFSCHRIFT \\ Ter verkrijging van de graad van doctor aan de Universiteit Maastricht, \\ op gezag van de Rector Magnificus, Prof. Dr. L.L.G Soete \\ volgens het besluit van het College van Decanen, \\ in het openbaar te verdedigen \\ op vrijdag 20 november 2015 om 12.00 uur
}

door

Marloes Gertrude Berdiene van Onna

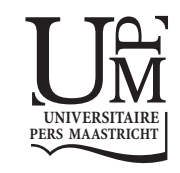




\section{Promotores}

Prof. dr. A.E.R.C.H Boonen

Prof. dr. R.B.M . Landewé, Academisch Medisch Centrum, Amsterdam \& Zuyderland Ziekenhuis, Heerlen-Sittard

\section{Copromotor}

Dr. A.M. van Tubergen

\section{Leden van de beoordelingscommissie}

Prof. dr. J.E. Wildberger (voorzitter)

Prof. dr. R.A. de Bie

Prof. dr. F. van den Bosch, Universitair Ziekenhuis, Gent

Prof. dr. J.A. Knottnerus

Dr. A.E.A.M Weel, M aasstad Ziekenhuis, Rotterdam 
"In the beginning there was nothing.

God said, 'Let there be light!'

And there was light.

There was still nothing, but you could see it a whole lot better."

Ellen DeGeneres 



\section{Contents}

$\begin{array}{lll}\text { Chapter } 1 \text { General introduction } & 9\end{array}$

$\begin{array}{lll}\text { Part I Epidemiology of spondyloarthritis } & 25\end{array}$

$\begin{array}{lll}\text { Chapter } 2 & \text { The global prevalence of spondyloarthritis: a systematic } & 27\end{array}$ review and meta-regression analysis submitted

$\begin{array}{lll}\text { Part II } & \text { The use of M RI in detection of early axial spondyloarthritis } & 71\end{array}$

Chapter 3 HLA-B27 and gender independently determine the likelihood of a positive M RI of the sacroiliac joints in patients with early inflammatory back pain: a two-year M RI follow-up study Ann Rheum Dis 2011:70;1981-5

Chapter 4 Bone marrow edema on M Rl of the sacroiliac joints is associated with development of fatty lesions on M RI over a one-year interval in patients with early inflammatory low back pain: a 2-year follow-up study J Rheumatol 2014;41:1088-94

Chapter 5 Gadolinium contrast-enhanced M RI sequence does not have an incremental value in the assessment of sacroiliitis in patients with early inflammatory back pain by using $\mathrm{MRI}$ in combination with pelvic radiographs: a 2 year follow-up study Clin Exp Rheumatol 2014;32:225-30

Chapter $6 \quad$ Natural course of bone marrow edema on magnetic resonance imaging of the sacroiliac joints in patients with early inflammatory back pain: a 2-year follow-up study Scand J Rheumatol 2015;44:129-34

$\begin{array}{lll}\text { Part III } & \text { Timely identification of spondyloarthritis in primary care } & 127\end{array}$

Chapter 7 General practitioners' perceptions of their ability to identify and $\quad 129$ refer patients with suspected axial spondyloarthritis:

a qualitative study J Rheumatol 2014;41:897-901

Chapter $8 \quad$ Education improves referral of patients suspected of having spondyloarthritis by general practitioners. A study with unannounced standardized patients in daily practice Accepted for publication in RMD Open

Chapter 9 Summary and general discussion

Samenvatting in het Nederlands

Valoriation addendum

Dankwoord

Curriculum vitae 




\section{INTRODUCTION}

Spondyloarthritis comprises a group of clinically and genetically closely related inflammatory rheumatic disorders, including ankylosing spondylitis (AS), psoriatic arthritis, reactive arthritis and arthritis and/or spondylitis associated with inflammatory bowel disease (IBD).[1]

Depending on the location of the predominant clinical features, SpA is nowadays also divided into axial and peripheral disease.[2] Axial SpA (axSpA) can be further subdivided into AS and non-radiographic (nr)-axSpA, depending on presence of abnormalities on pelvic radiographs.[2] In $\mathrm{nr}$-axSpA inflammation may already be detected on an MRI of the sacroiliac joints (SIJs). Patients with nr-axSpA may eventually progress to a radiographic stage, with an average progression rate of $10 \%$ after 2 years, and up to $60 \%$ after 10 years.[3-5]

The field of spondyloarthritis (SpA) has experienced major progress in the last decade, especially with regard to development of new therapeutic options and the use of magnetic resonance imaging (M RI) to establish an early diagnosis of SpA.[6] The recent developments in the field of SPA increased the need to timely recognize patients having the disease. However, several priorities on the research agenda to improve earlier diagnosis remain, such as further refining the role of MRI in the diagnosis, follow-up and prognosis of patients with SpA. Also, improving recognition and referral of patients with early SpA in primary care is an important challenge. The aim of this thesis is to provide more insight into the role of MRI in SpA and recognition of this disease in primary care. This chapter first provides an overview of the current knowledge about SpA and then elaborates on the specific objectives of this thesis.

\subsection{Clinical features of spondyloarthritis}

In patients with axSpA, the most important clinical feature is inflammatory back pain (IBP) caused by sacroiliitis and spondylitis.[7] IBP is typically characterized by awakening night pain, improvement of pain with exercise, no improvement with rest and a favourable response to non-steroidal anti-inflammatory drugs (NSAIDs).[8] Peripheral $\mathrm{SpA}$ is characterized by peripheral arthritis (predominantly of the lower limbs), enthesitis and dactylitis, as presenting symptom.[1] Extra-articular manifestations related to axial and peripheral SpA include psoriasis, anterior uveitis and IBD.[1] The main features of both axial and peripheral SpA are listed in Box 1.[9] 


\subsection{Pathophysiology}

Although the clinical symptoms of the SpA are typically heterogeneous, there is evidence of shared genetic markers and linkage.[10] The strongest known contributing genetic factor for SpA is the major histocompatibility complex (M HC) class I molecule human leukocyte antigen (HLA)-B27. HLA-B27 is most strongly associated with axSpA. The risk of developing axSpA in HLA-B27-positive individuals is as high as 5-7\%.[11,12] Approximately $80-90 \%$ of Northern European patients with axSpA are HLA-B27 positive.[11] Other subtypes of SpA have lower degrees of association with HLA-B27. For instance, the frequency of HLA-B27 in patients with psoriatic arthritis and peripheral arthritis is around $20 \%$, but this increases to $60 \%$ in patients with associated sacroiliitis.[13] More recently, additional genetic links that contribute to the pathogenesis of SpA have been identified, e.g. polymorphisms of the interleukin-23 receptor (IL-23R) gene and endoplasmic reticulum aminopeptidase 1 (ERAP-1) gene. Genetic variants of IL-23R are also linked to concomitant psoriasis and IBD.[11,12] In patients with SpA, the genetic susceptibility is, at least in part, responsible for an 'auto-inflammatory status'. This auto-inflammatory reaction may eventually initiate tissue remodelling which may eventually lead to ankylosis (immobilisation and consolidation of a joint).[12]

\subsection{Epidemiology}

The prevalence of SpA in Western European countries is estimated to be approximately $0.5-1 \%$, similarly to that of rheumatoid arthritis.[14] The estimated prevalence of AS, the most frequent subtype of SpA, ranges from $0.1-0.9 \%$.[14] The incidence and prevalence rates of SpA are strongly dependent and directly correlated to the prevalence of HLA-B27 in a given population.[14] Other important contributors to variation in prevalence of SpA include differences in selection of the target population, variation in the criteria used for case definition and study design.[9]

Unlike most other forms of arthritis, the first symptoms of SpA usually appear before the fourth decade of life.[15] M ales are about three times more often affected with AS than females.[1] However, in the whole group of axSpA, the male : female ratio approaches 1:1.[1,16] 
Box 1. SpA features

- Inflammatory back pain

- Good response to NSAIDs

- HLA-B27 positive

- A positive family history for SpA

- Increased CRP concentration

- Enthesitis

- $\quad$ Peripheral arthritis

- Dactylitis

- Prior urogenital or gastrointestinal infection

- Inflammatory bowel disease

- Psoriasis

- Acute anterior uveitis

- Sacroiliitis detected by imaging (conventional radiography or M RI)

SpA=spondyloarthritis; NSAID=non-steroidal anti-inflammatory drug; $C R P=C$-reactive protein; HLAB27=human leukocyte antigen B27; M RI=magnetic resonance imaging.

\section{CLASSIFICATION CRITERIA FOR SPONDYLOARTHRITIS}

The idea that the disorders belonging to SpA were different from other rheumatological disorders e.g. rheumatoid arthritis was first described by the American Rheumatism Association in the "Nomenclature and Classification of Rheumatic diseases" in 1963.[17,18] The unifying concept of "seronegative spondyloarthritides", now known as "spondyloarthritis or SpA", was first introduced by Moll and Wright in 1974.[19] Over the last decades, several sets of classification criteria for SpA have been developed in an attempt to define subgroups of patients to facilitate research studies. Figure 1 shows a historical timeline in which several classification criteria for SpA in general, for AS, and for axial and peripheral SpA are presented.[7,20-23]

The modified New York ( $\mathrm{mNY}$ ) criteria for the classification of AS rely on clinical and radiological findings (Figure 1.1).[20] Patients fulfil the $\mathrm{mNY}$ criteria when sacroiliitis on a conventional radiograph is present and at least one clinical criterion is present.[20] A major disadvantage of the mNY criteria is that advanced sacroiliitis on conventional radiography is required for fulfilment. Development of radiographic sacroiliitis may take up to several years. Some patients, especially females, may never develop radiographic sacroiliitis.[15] This means that the mNY criteria lack sensitivity especially at the early disease stage, which may result in a diagnostic delay up to 9 years.[15] 


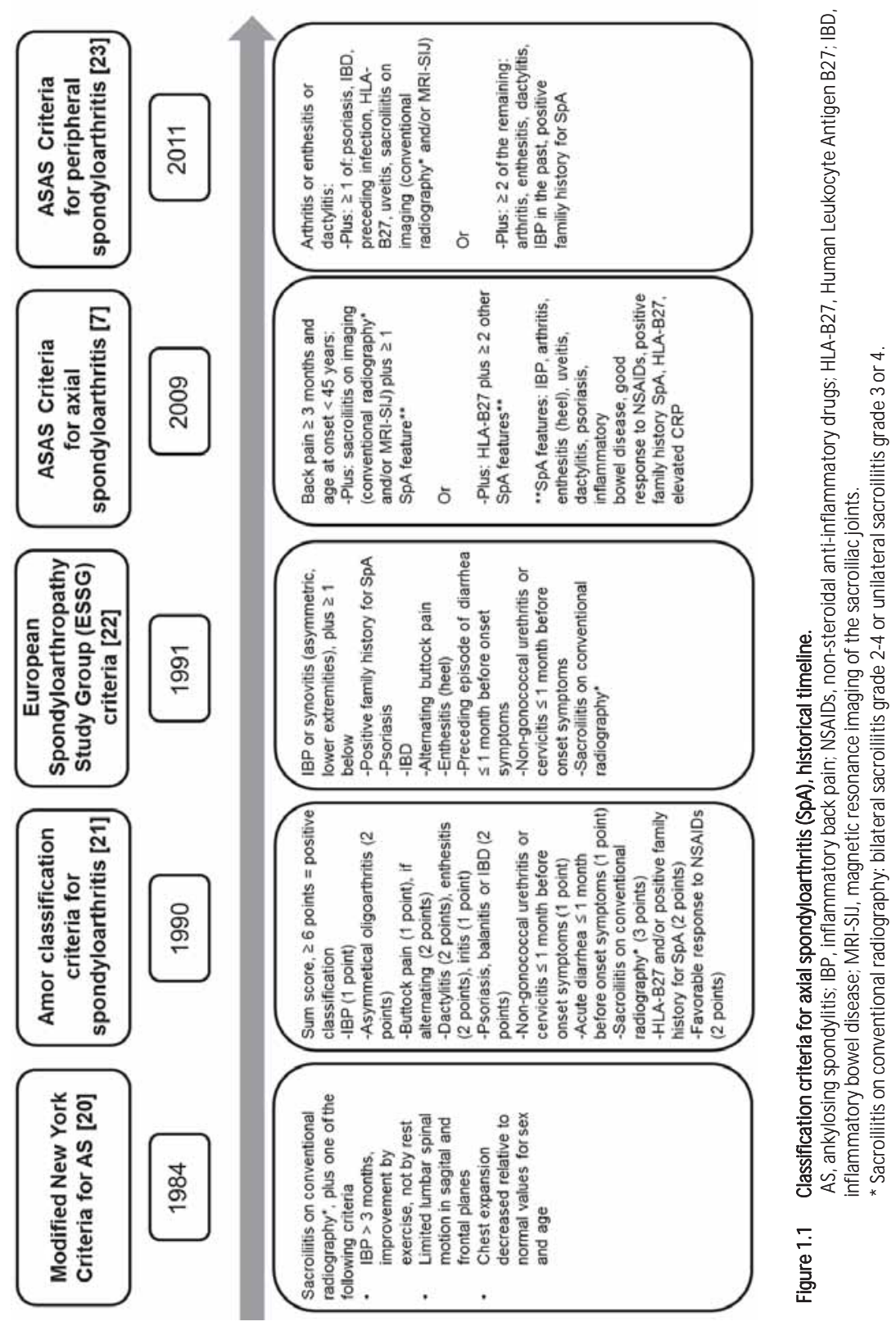


The Amor and European Spondyloarthropathy Study Group (ESSG) criteria were both developed in the 1990s, in order to encompass the entire spectrum of SpA, including the axial and peripheral manifestations, and early as well as mild disease stages.[21,22] Notwithstanding, the Amor and ESSG criteria lacked sensitivity and specificity, especially in patients with early disease. $[24,25]$ In addition, these criteria do not allow for a clear differentiation between axial and peripheral disease, while this distinction is important for etiologic studies and testing treatment strategies. $[9,26]$

To overcome the limitations of the mNY, ESSG and Amor criteria, it was necessary to develop new criteria sets. The most recently developed criteria sets are the Assessment of SpondyloArthritis international Society (ASAS) classification criteria for axial and peripheral SpA.[7,23] The entry criterion for the ASAS axSpA criteria is back pain $\geq 3$ months and age at onset $<45$ years (Figure 1.1). There are two arms in the ASAS axSpA criteria, an "imaging" and "clinical" arm. The imaging arm includes both sacroiliitis detected either by MRI or on a conventional radiograph; for classification one other additional SpA feature also needs to be present. HLA-B27 is the main criterion of the clinical arm; for classification two other additional SpA features also need to be present (Figure 1.1).[4] The entry criteria for the ASAS peripheral SpA criteria are arthritis, enthesitis, and/or dactylitis. For classification purposes, presence of additional features is needed (Figure 1). These additional features may include either one or more from the following list: psoriasis, IBD, preceding infection, HLA-B27, uveitis and sacroilitis on imaging or two or more of the following list: arthritis (past or present), enthesitis (past or present), dactylitis (past or present), history of previous IBP and a positive family history of SpA.[23]

\section{CRITERIA FOR INFLAM M ATORY BACK PAIN}

IBP is a key feature for the ESSG and ASAS axSpA classification criteria. To define this feature several criteria sets have been developed over the last years. $[8,27,28]$ Single parameters lack sufficient discriminative ability to define IBP, because all parameters may also be present in patients with other causes of back pain.[27] The most recent criteria set for IBP is the ASAS classification criteria set for IBP, established in 2009 (Figure 1.2).[27] The ASAS IBP criteria were tested in a validation cohort and have a sensitivity of $77.6 \%$ and specificity of $72.4 \%$, when at least four out of five parameters were fulfilled.[27] Other criteria sets for IBP are the Calin criteria and Berlin criteria (Figure 1.2).[8,28] 


\section{Inflammatory Back Pain (IBP) According to Various Criteria}

Calin et al. ${ }^{1}$

- age at onset < 40 yrs
- duration of back pain
$>3$ months
- insidious onset
- moming stiffness
- improvement with exercise

IBP if $4 / 5$ are

present.
Rudwaleit et al. ${ }^{2}$

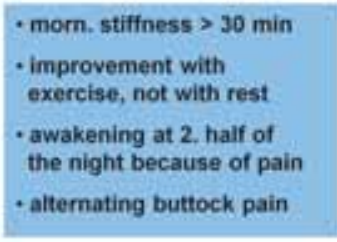

IBP if $2 / 4$ are

present.
IBP experts (ASAS) ${ }^{3}$

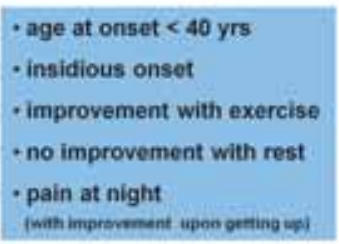

IBP if $4 / 5$ are present.

1 CalinA et al. JAMA 1977:237 261;2 Ructwainit M et al. Arthritis Rheum 2006:54:569,78, 3 Sieper J et at. Ann Rheum Dis. $2009.68 .784-788$

Figure 1.2. Classification criteria for inflammatory back pain (IBP). morn., morning; ASAS, Assessment of SpondyloArthritis international Society.

\section{IM AGING IN AXIAL SPONDYLOARTHRITIS}

\subsection{Conventional radiography}

Conventional radiography is the most widely used imaging technique for assessing structural changes of the SIJs.[29,30] Radiographs of the SIJs can demonstrate sclerosis, erosions and ankylosis.[31] The presence of sacroiliitis is graded from 0 (normal) to 4 (ankylosis) (Table 1.1).[20]

The main disadvantage of conventional radiography in the clinical assessment of patients suspected for having axSpA is its low sensitivity, especially in early disease. $[7,29]$ In addition, only structural damage of the SIJs, which is the consequence of inflammation, can be detected. Other major challenges when using conventional radiographs of the SIJs for detection of sacroiliitis are the low intra- and inter-observer agreement, projection artefacts and poor visibility.[29-33] 


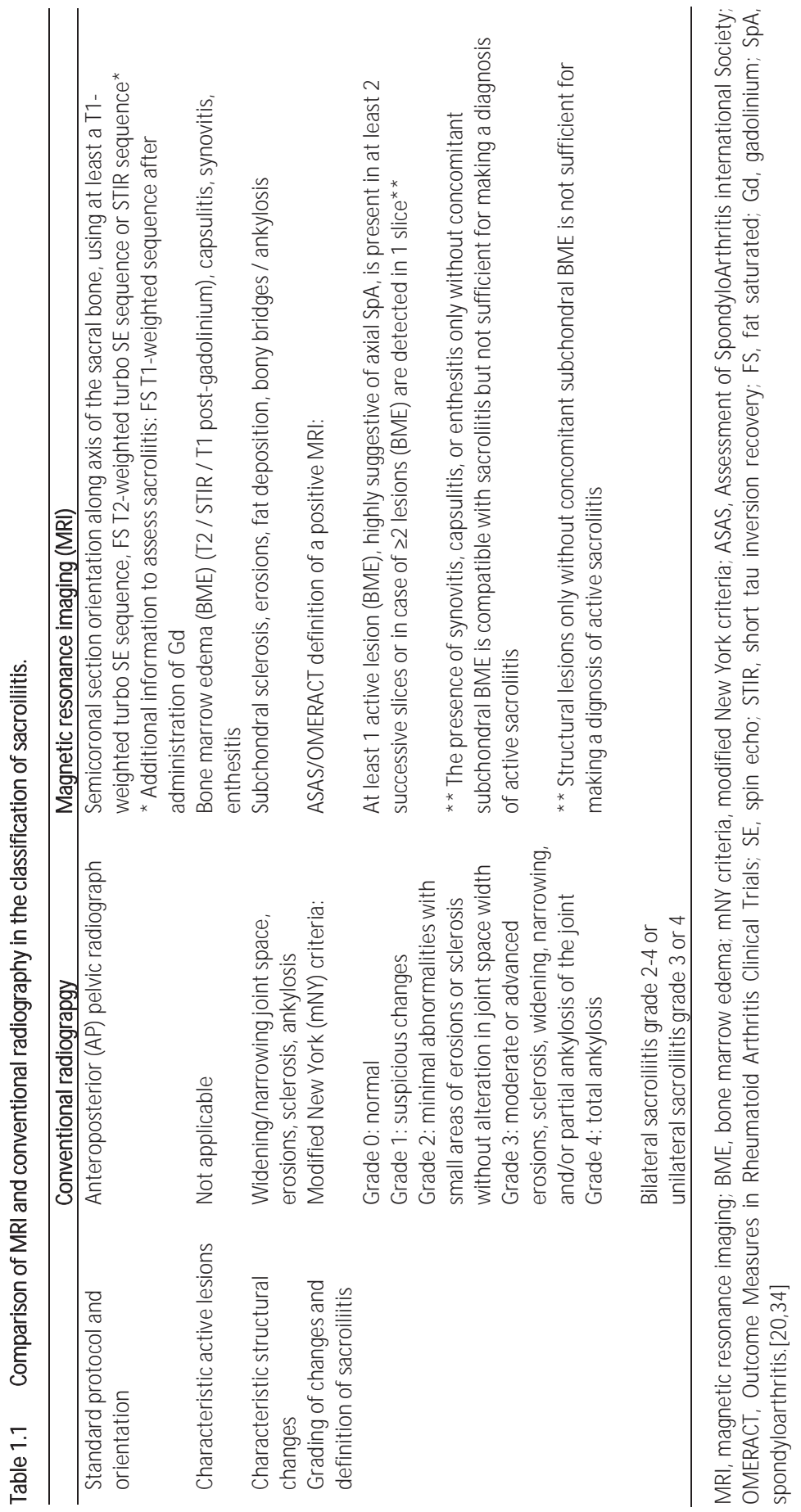




\subsection{Magnetic resonance imaging}

Nowadays, MRI of the SIJs is considered an important imaging technique for making a diagnosis of axial SpA.[34] By using MRI, both active (inflammatory) lesions and structural changes can be visualized (Table 1.1).[34] Typical active lesions in the SIJs are subchondral bone marrow edema (BME) / osteitis, and to a lesser extent synovitis, enthesitis and capsulitis.[34] Active lesions are best visualised on T2 fat saturated (FS)weighted spin-echo (SE) sequence, T1 FS gadolinium contrast-enhanced sequence or the short tau inversion recovery (STIR) sequence. Structural changes that can be detected by MRI are erosions, fat deposition (fatty lesions), sclerosis and ankylosis. These structural lesions are best detected on the T1-weighted SE sequence.[34]

A positive MRI of the SIJs in the context of identifying sacroiliitis, is defined as the presence of subchondral BME that is highly suggestive of axial SpA, and appears as two or more distinguishable lesions on one slice, or as one lesion on at least two successive slices (ASAS/ Outcome Measures in Rheumatoid Arthritis Clinical Trials (OMERACT) definition).[34] The presence of synovitis, enthesitis or capsulitis without BME does not suffice. Only active lesions (BME) are currently considered for fulfilment of the ASAS/OM ERACT definition.[34] Structural changes may also occur in conjunction with $B M E$, or without BME as a sequel of previous inflammation.[34]

Several scoring methods for assessment and quantification of active lesions on MRI have been proposed throughout the years.[36-38] However, there is no preferred scoring system.[34] All of these scoring systems are primarily confined to the research setting.

\section{EARLY REFERRAL AND RECOGNITION OF SPONDYLO- ARTHRITIS IN PRIM ARY CARE}

$\mathrm{SpA}$ is among the inflammatory rheumatic disorders with the longest delay between the onset of symptoms and the making of a diagnosis. Specifically in the case of AS, the delay up is up to 9 years.[15] An early diagnosis of axSpA is important not only to avoid unnecessary diagnostic procedures and inappropriate treatments, but a short disease duration is also associated with a favourable response to NSAIDs and anti-TNF-alpha therapy.[39] Furthermore, several studies have shown that effective treatment of active axSpA is associated with improved work capacity and quality of life [40-43]. Providing an early diagnosis can provide reassurance to patients and may optimise the 
benefit of education and lifestyle modifications. Recognizing patients with axSpA early in the disease course is therefore important.

The general practitioner (GP) is a key role player in the identification and referral of patients suspected of having SpA.[44] However, knowledge and awareness about SpA and the associated extra-articular manifestations is low among GPs, resulting in poor recognition and delayed referral of patients.[45] A recent study has shown that 1 in 4 patients with chronic back pain of $\geq 3$ months that had started before the age of 45 years and who were recruited from primary care, can be classified as having axSpA after careful evaluation.[46] These patients had not been recognized as such by the GP. Several referral tools for patients with chronic back pain have been proposed a few years ago, in order to improve recognition and hence referral of patients suspected for axSpA in primary care.[47-51] These tools included parameters such as IBP, sacroiliitis on imaging and / or HLA-B27. When patients fulfilled the referral criteria and were actually referred to the rheumatologist, up to $45 \%$ patients were found to have axSpA after a diagnostic work-up.[48-52]

\section{THE CONTEXT OF RESEARCH IN THE FIELD OF SPONDYLOARTHRITIS AT THE START OF THIS THESIS}

This thesis describes our research with regard to assessing the global prevalence of SpA and the early identification of patients with $\mathrm{SpA}$, both in primary and secondary care. Until about the turn of the millennium, SpA took the back seat in rheumatology, because of limited therapeutic options. Early diagnosis was simply not an area of major concern. This dramatically changed with the introduction of the highly effective TNFalpha blockers that significantly improved quality of life of patients dealing with SpA.[53] The expansion of therapeutic armamentarium makes it necessary to provide reliable data on the prevalence of $\mathrm{SpA}$, in order to gain insight in the societal impact and costs associated with SpA.

In addition, new and effective therapeutic options make it even more important to diagnose SpA at an early stage. In the light of these developments, the Early SpondyloArthritis Clinic (ESpAC) was established in 2000.[54] Sixty-eight patients with IBP of less than two years duration were included in this prospective cohort study and followed for two years with repeated clinical and radiological examinations. In 2009, when starting this PhD program, MRI had already evolved as an important imaging modality for diagnosis and classification of early axSpA but several research questions 
remained, for example about the evolution of active lesions and structural changes on M RI over time. Such questions could only be answered using cohorts with a substantial follow-up period, like the ESpAC study, that was the basis for several studies in this thesis.

Next, recent research projects focussing on diagnosing and treating patients with early $\mathrm{SpA}$, presume a timely referral of patients by their GPs. Several referral tools have been developed in order to shorten the diagnostic delay that is so characteristic for these patients, but these tools can only be successful if knowledge and awareness about SpA increases among GPs. Educational programmes with special focus on SpA might improve the recognition of SPA features, and consequently lead to an earlier referral of those suspected of having SpA.

\section{AIMS OF THIS THESIS}

The main research questions underlying this thesis are as follows:

Epidemiology of spondyloarthritis

What is the global prevalence of spondyloarthritis (SpA) and its phenotypes and which study characteristics might explain heterogeneity in prevalence estimates?

The use of MRI in detection of early axial spondyloarthritis

How can the use and interpretation of M RI of the SIJ in patients with early axial SpA be improved? Which determinants predict the presence of active and structural lesions on MRI over time?

Timely identification of spondyloarthritis in primary care

What is the current level of knowledge of GPs about axSpA?

How can the recognition and referral of SpA by GPs in clinical practice be improved?

\section{OUTLNE OF THIS THESIS}

This thesis is divided into three related parts. Part I describes the global prevalence of SpA (Chapter 2). Part // of this thesis focuses on the use of M RI of the SIls for detection of sacroiliitis in 68 patients with recent-onset IBP, included in the ESPAC. Chapter 3 describes how active lesions on MRI of the SIJs in patients included in ESpAC evolve over time, and discusses which determinants are responsible for persisting active lesions on M RI of the SIJs. Chapter 4 describes the association between BM E on M RI of the SIJS and development of structural changes on both MRI and conventional 
radiographs in patients included in the ESpAC. To assess active lesions on M RI of the SIJS, several MRI sequences can be used. In Chapter 5, the potential incremental value of the T1 post-Gd-DTPA MRI sequence of SIJs compared to the combination of the STIR MRI sequence and conventional radiographs is discussed. Chapter 6 describes the natural course of BME on M RI of the SIJs over a 2-year follow-up period.

The optimization of identification and referral of patients suspected of having SpA in primary care is described in part III of this thesis. Chapter 7 describes the level of knowledge and experiences of GPs with regard to axSpA. Chapter 8 describes a study in which the current practice performance with regard to referral and recognition of patients with early SpA was investigated by using standardized patients. In addition, the influence of education on this performance was also studied. The research presented in this thesis is summarized and discussed in Chapter 9 and 10. Chapter 10 also discusses how the research presented in this thesis can be translated to clinical and societal benefit. 


\section{REFERENCES}

1. Mercieca C, Landewé R, Borg AA. Spondyloarthropathies: pathogenesis, clinical features. In JWJ Bijlsma, ed. EULAR textbook on rheumatic diseases. London: BMJ Publishing Group, 2012: 255-275.

2. Rudwaleit M, Khan MA, Sieper J. The challenge of diagnosis and classification in early ankylosing spondylitis: do we need new criteria? Arthritis Rheum 2005;52:1000-8.

3. Poddubnyy $D$, Rudwaleit $M$, Haibel $H$, et al. Rates and predictors of radiographic sacroiliitis progression over 2 years in patients with axial spondyloarthritis. Ann Rheum Dis 2011;70:1369-1374.

4. Sampaio-Barros PD, Bortoluzzo AB, Conde RA, et al. Undifferentiated spondyloarthritis: a longterm followup. J Rheumatol 2010;37:1195-9.

5. Sampaio-Barros PD, Bertolo M B, Kraemer MH, et al. Undifferentiated spondyloarthropathies: a 2-year follow-up study. Clin Rheumatol 2001;20:201-6.

6. Sieper J, Rudwaleit M, Baraliakos X, et al. The Assessment of SpondyloArthritis international Society (ASAS) handbook: a guide to assess spondyloarthritis. Ann Rheum Dis 2009;68:ii1-44.

7. Rudwaleit M, van der Heijde D, Landewé R, et al. The development of Assessment of Spondyloarthritis international society classification criteria for axial spondyloarthritis (part II): validation and final selection. Ann Rheum Dis 2009; 68:777-83.

8. Calin A, Porta J, Fries JF, et al. Clinical history as a screening test for ankylosing spondylitis. JAMA 1977;237:2613-4.

9. Van Tubergen A. The changing clinical picture and epidemiology of spondyloarthritis. Nat Rev Rheumatol. 2015;11:110-118.

10. Van Tubergen A, Weber U. Diagnosis and classification in spondyloarthritis: identifying a chameleon. Nat Rev Rheumatol 2012;8:253-61.

11. Robinson PC, Brown MA. The genetics of ankylosing spondylitis and axial spondyloarthritis. Rheum Dis Clin North Am 2012;38:539-53.

12. Dougados M, Baeten D. Spondyloarthritis. Lancet 2011;377:2127-37.

13. Braun J, Sieper J. Ankylosing spondylitis, other spondyloarthritides, and related conditions. In Warrell DA, Cox TM, ed. Oxford Textbook of M edicine. Oxford: Oxford University Press, 2010: 3603-3616.

14. Stolwijk C, Boonen A, van Tubergen A, et al. Epidemiology of spondyloarthritis. Rheum Dis Clin North Am 2012;38:441-76.

15. Feldtkeller E, Khan MA, van der Heijde D, et al. Age at disease onset and diagnosis delay in HLA-B27 negative vs. positive patients with ankylosing spondylitis. Rheumatol Int 2003;23:61-6.

16. Feldtkeller E, Bruckel J, Khan MA. Scientific contributions of ankylosing spondylitis patient advocacy groups. Curr Opin Rheumatol 2000;12:239-47.

17. Blumberg BS, Bunim JJ, Calkins E, et al. ARA nomenclature and classification of arthritis and rheumatism (tentative). Arthritis Rheum 1964;7:93-7.

18. Zeidler H, Calin A, Amor B. A historical perspective of the spondyloarthritis. Curr Opin Rheumatol 2011;23:327-33.

19. Moll JM, Haslock I, Macrae IF, et al. Associations between ankylosing spondylitis, psoriatic arthritis, Reiter's disease, the intestinal arthropathies, and Behcet's syndrome. Medicine (Baltimore). 1974;53:343-64.

20. Van der Linden S, Valkenburg HA, Cats A. Evaluation of diagnostic criteria for ankylosing spondylitis. A proposal for modification of the New York criteria. Arthritis Rheum 1984;27:361-8.

21. Amor B, Dougados M, Mijiyawa M. Criteria of the classification of spondylarthropathies. Rev Rhum Mal Osteoartic 1990;57:85-9.

22. Dougados $M$, van der Linden $S$, Juhlin $R$, et al. The European Spondylarthropathy Study Group preliminary criteria for the classification of spondylarthropathy. Arthritis Rheum 1991;34:1218-27.

23. Rudwaleit M, van der Heijde $D$, Landewé $R$, et al. The Assessment of SpondyloArthritis International Society classification criteria for peripheral spondyloarthritis and for spondyloarthritis in general. Ann Rheum Dis 2011;70:25-31.

24. Tomero E, Mulero J, de Miguel E, et al. Performance of the Assessment of Spondyloarthritis International Society criteria for the classification of spondyloarthritis in early spondyloarthritis clinics participating in the ESPERANZA programme. Rheumatology (Oxford) 2014;53:353-60. 
25. Van den Berg R, de Hooge M, van Gaalen $F$, et al. Percentage of patients with spondyloarthritis in patients referred because of chronic back pain and performance of classification criteria: experience from the Spondyloarthritis Caught Early (SPACE) cohort. Rheumatology (Oxford) 2013;52:1492-9.

26. Sieper J, van der Heijde D. Review: Nonradiographic axial spondyloarthritis: new definition of an old disease? Arthritis Rheum 2013;65:543-51.

27. Sieper J, van der Heijde $D$, Landewé $R$, et al. New criteria for inflammatory back pain in patients with chronic back pain: a real patient exercise by experts from the Assessment of SpondyloArthritis international Society (ASAS). Ann Rheum Dis 2009;68:784-8.

28. Rudwaleit M, Metter A, Listing J, et al. Inflammatory back pain in ankylosing spondylitis: a reassessment of the clinical history for application as classification and diagnostic criteria. Arthritis Rheum 2006;54:569-78.

29. Maksymowych WP. Controversies in conventional radiography in spondyloarthritis. Best Pract Res Clin Rheumatol 2012;26:839-52.

31. Braun J, Sieper J, Bollow M. Imaging of sacroiliitis. Clin Rheumatol 2000;19:51-7.

32. Van Tubergen A, Heuft-Dorenbosch L, Schulpen G, et al. Radiographic assessment of sacroiliitis by radiologists and rheumatologists: does training improve quality? Ann Rheum Dis 2003;62:519-25.

33. Van den Berg, R, Lenczner, G, Feydy A, et al. Reading Of The Sacroiliac Joints On Plain Radiographs: Agreement Between Clinical Practice and Trained Central Reading Of The DESIR-Cohort. Abstract ACR/ARHP meeting, 2013 (number: 1718).

34. Rudwaleit M, Jurik AG, Hermann KG, et al. Defining active sacroiliitis on magnetic resonance imaging (MRI) for classification of axial spondyloarthritis: a consensual approach by the ASAS/OM ERACT MRI group. Ann Rheum Dis 2009;68:1520-7.

35. Weber U, Zubler V, Pedersen SJ, et al. Development and validation of a magnetic resonance imaging reference criterion for defining a positive sacroiliac joint magnetic resonance imaging finding in spondyloarthritis. Arthritis Care Res (Hoboken) 2013;65:977-85.

36. Maksymowych WP, Inman RD, Salonen D, et al. Spondyloarthritis research Consortium of Canada magnetic resonance imaging index for assessment of sacroiliac joint inflammation in ankylosing spondylitis. Arthritis Rheum 2005;53:703-9.

37. Madsen $\mathrm{KB}$, Jurik AG. Magnetic resonance imaging grading system for active and chronic spondylarthritis changes in the sacroiliac joint. Arthritis Care Res (Hoboken) 2010;62:11-8.

38. Hermann KG, Braun J, Fischer $T$, et al. Magnetic resonance tomography of sacroiliitis: anatomy, histological pathology, M R-morphology, and grading. Radiologe 2004;44:217-28.

39. Rudwaleit $M$, Claudepierre $P$, Wordsworth $P$, et al. Effectiveness, safety, and predictors of good clinical response in 1250 patients treated with adalimumab for active ankylosing spondylitis. J Rheumatol 2009;36:801-8.

40. Keat AC, Gaffney K, Gilbert AK, et al. Influence of biologic therapy on return to work in people with work disability due to ankylosing spondylitis. Rheumatology (Oxford) 2008;47:481-3.

41. Prince DS, M cGuigan LE, M CGirr EE. Working life and physical activity in ankylosing spondylitis pre and post anti-tumor necrosis factor-alpha therapy. Int J Rheum Dis 2014;17:165-72.

42. Van der Heijde D, Han C, DeVlam K, et al. Infliximab improves productivity and reduces workday loss in patients with ankylosing spondylitis: results from a randomized, placebo-controlled trial. Arthritis Rheum 2006;55:569-74.

43. Boonen A, van der Heijde D, Landewé $R$, et al. Direct costs of ankylosing spondylitis and its determinants: an analysis among three European countries. Ann Rheum Dis 2003;62:732-40.

44. Rudwaleit M, Sieper J. Referral strategies for early diagnosis of axial spondyloarthritis. Nat Rev Rheumatol 2012;8:262-846. Jois RN, Macgregor AJ, Gaffney K. Recognition of inflammatory back pain and ankylosing spondylitis in primary care. Rheumatology (Oxford) 2008;47:1364-6.

45. Jois RN, Macgregor AJ, Gaffney K. Recognition of inflammatory back pain and ankylosing spondylitis in primary care. Rheumatology (Oxford) 2008;47:1364-6.

46. Van Hoeven $\mathrm{L}$, Luime J, Han $\mathrm{H}$, et al. Identifying axial spondyloarthritis in dutch primary care patients, ages 20-45 years, with chronic low back pain. Arthritis Care Res (Hoboken) 2014;66:446-53.

47. Rudwaleit $M$, Sieper J. Referral strategies for early diagnosis of axial spondyloarthritis. Nat Rev Rheumatol 2012;8:262-8.

48. Brandt HC, Spiller I, Song $\mathrm{IH}$, et al. Performance of referral recommendations in patients with chronic back pain and suspected axial spondyloarthritis. Ann Rheum Dis 2007; 66:1479-1484. 
49. Poddubnyy D, Vahldiek J, Spiller I, et al. Evaluation of 2 screening strategies for early identification of patients with axial spondyloarthritis in primary care. J Rheumatol 2011;38:2452-60.

50. Hermann J, Giessauf H, Schaffler $G$, et al. Early spondyloarthritis: usefulness of clinical screening. Rheumatology (Oxford) 2009;48:812-6.

51. Sieper J, Srinivasan S, Zamani O, et al. Comparison of two referral strategies for diagnosis of axial spondyloarthritis: the Recognising and Diagnosing Ankylosing Spondylitis Reliably (RADAR) study. Ann Rheum Dis 2013;72:1621-7.

52. Van den Berg R, de Hooge M, van Gaalen F, et al. Percentage of patients with spondyloarthritis in patients referred because of chronic back pain and performance of classification criteria: experience from the Spondyloarthritis Caught Early (SPACE) cohort. Rheumatology (Oxford) 2013;52:1492-9.

53. Braun J, Brandt J, Listing J, et al. Biologic therapies in the spondyloarthritis: new opportunities, new challenges. Curr Opin Rheumatol 2003;15:394-407.

54. Heuft-Dorenbosch L, Landewé R, Weijers R, et al. Performance of various criteria sets in patients with inflammatory back pain of short duration; the Maastricht early spondyloarthritis clinic. Ann Rheum Dis 2007;66:92-8. 


\section{PART I}

Epidemiology of spondyloarthritis 



\section{CHAPTER 2}

The global prevalence of spondyloarthritis: a systematic review and meta-regression analysis

Carmen Stolwijk, Marloes van Onna, Annelies Boonen, Astrid van Tubergen 


\section{ABSTRACT}

\section{Objective}

To summarize the prevalence of spondyloarthritis (SpA) and its subtypes in the general population, and to identify demographical and methodological characteristics that might explain heterogeneity in prevalence estimates.

\section{Methods}

A systematic literature search was performed to identify relevant articles. Risk of bias was assessed and data were extracted. Pooled prevalences were calculated. Potential sources of heterogeneity were explored by subgroup analysis and meta-regression analysis.

\section{Results}

In total, 84 articles were included. The pooled prevalence of SpA, based on a random effects model, was $0.55 \%$ ( $95 \% \mathrm{Cl} 0.37-0.77$ ); for ankylosing spondylitis (AS) $0.18 \%$ (95\% Cl 0.15-0.23); and for psoriatic arthritis (PsA) $0.15 \%$ (95\% Cl 0.12-0.18), but substantial heterogeneity was revealed $\left(I^{2}>99 \%\right)$. The following characteristics were significantly associated with variation in prevalence of SpA, AS and/or PsA: proportion of females, mean age of the sample, geographic area and setting (demographical characteristics); year of data collection, case finding, and case ascertainment (methodological characteristics). For the other SpA subgroups too few studies were available to conduct a meta-analysis, but prevalence estimates of reactive arthritis (range $0.0 \%-0.2 \%$ ), SpA related to inflammatory bowel disease (range $0.0 \%-0.1 \%$ ), and undifferentiated SpA (range 0.0\%-0.7\%) were generally low.

\section{Conclusion}

SpA is a common disease, but with large variation in reported prevalence estimates, which can partly be explained by differences in demographical and methodological characteristics. Particularly, geographic area as well as case finding account for a substantial part of the heterogeneity. 


\section{INTRODUCTION}

Since its establishment in the 1970s, the disease concept spondyloarthritis (SpA) has seen major developments with respect to identification and classification of the disease, measurement and prediction of outcome, and treatment options.[1] While SpA can be considered a condition itself, several subtypes can be distinguished, including ankylosing spondylitis (AS), psoriatic arthritis (PsA), SpA related to inflammatory bowel disease (IBD-SpA), reactive arthritis (ReA) and undifferentiated SpA (USpA).[2] More recently, the Assessment of SpondyloArthritis international Society (ASAS) proposed to distinguish axial from peripheral SpA, depending on the predominant articular manifestations of the disease, and developed new classification criteria.[3,4] The treatment possibilities in patients with SpA have improved substantially in the last decade with the introduction of biologicals. On this line, it is relevant to gain insight into patterns of the prevalence of SpA and its subtypes, as this may contribute to our understanding of both the needs of healthcare systems - in terms of availability of healthcare resources and budgets - and the etiopathogenesis of the disease.

Considerable variation in the reported prevalence of SpA has already been recognized.[5] In particular, a wide range of estimates across geographic regions is found, which has classically been related to the presence of HLA-B27.[6] However, other yet unknown demographical and methodological characteristics of the studies may also play a role in this variation. Demographical characteristics refer to for example the mean age of the sample, the male:female ratio, or the geographic region. Methodological characteristics include for example year of data collection, sampling frame, and case finding.

Systematic approaches to gain insight into the epidemiology of SpA in the general population are limited.[7] No studies have been performed assessing and quantifying the effect of demographical and methodological characteristics on the prevalence of $\mathrm{SpA}$. Therefore, the aims of the present study were 1) to perform a systematic review and meta-analysis of the literature on the prevalence of SpA and its subtypes, and 2) to identify demographical and methodological characteristics that might explain heterogeneity in prevalence. 


\section{METHODS}

This systematic review was performed in accordance with the quality of reporting meta-analyses of observational studies (M OOSE) guidelines.[8]

\section{Search strategy}

MEDLINE (via PubMed) and EMBASE (OVID) were searched between 1975-2014 July 1st for primary studies investigating the prevalence of SpA or one of its subtypes. The search strategy consisted of a combination of text words and controlled vocabulary terms (e.g. MeSH terms) relating to SpA and its subtypes, and to prevalence or epidemiology. The detailed search strategy is outlined in Supplementary File 1. Two reviewers independently reviewed titles and abstracts on eligibility criteria for inclusion, after which full-text was read. In addition, hand search of references was performed. If the full-text of the articles could not be retrieved, authors were contacted via email. In case of any discrepancies between the two reviewers, a third reviewer was consulted for final decision.

\section{Selection criteria}

Only original research studies reporting primary data on the prevalence of SpA or its subtypes in the general population were included. Studies were excluded if: 1) the study was not observational; 2) the study was published in a language other than English, French, German, Dutch, Spanish or Italian; 3) the study was only describing the prevalence of young-onset ( $<16$ years) SpA; 4 ) the article was not published in full-text; or 5) the study had a sample size $<1000$ subjects.

\section{Data extraction}

Data extraction was performed by two reviewers using a standardized form and included: study identification (first author, year of publication), and demographical as well as methodological characteristics. The demographical characteristics were mean age of the sample, proportion of females, geographic area and setting. Geographic area was subdivided into the following categories: Europe, North America, South America, Middle East and North Africa, Sub-Saharan Africa, Central Asia and Russia, South Asia, South-East Asia, East Asia, Oceania, and "Northern Artic indigenous communities". The last category was separated since it is known that the prevalence of HLA-B27 is higher in these populations.[9,10] The setting was subdivided into urban, rural, or a 
combination of both. The methodological characteristics were starting year of data collection (or alternatively publication year if not reported), sampling frame, case finding and case ascertainment. Sampling frame was subdivided into census, household register, convenience sample, general practitioner database, hospital database, register, or a list of specific group of subjects (e.g. employees of a company). Case finding was based on the procedure to identify cases and included self-reported symptoms, self-reported diagnosis, self-reported diagnosis followed by external confirmation (2-step approach diagnosis), self-reported symptoms followed by external confirmation (2-step approach symptoms), diagnosis by an expert, and hospital medical records or International Classification of Disease (ICD) codes. Case ascertainment was based on an external criterion used for case definition and was subdivided into clinical diagnosis (i.e. diagnosis by a physician) and classification criteria used for each SpA subtype, such as the modified New York criteria for AS, the European Spondyloarthropathy Study Group (ESSG) criteria, the CIASsification for Psoriatic Arthritis (CASPAR) criteria, or ASAS SpA criteria.[3,11-13]

Finally, data related to prevalence were extracted (raw data were extracted or the numerator and denominator were calculated). If a study presented age- and/or sexspecific estimates, these data were extracted, instead of the total count.

\section{Risk of bias assessment}

Two reviewers assessed independently the risk of bias for each included study, using a slightly modified version of a standardized tool by Hoy et al...[14] Supplementary File 2 shows the risk of bias tool including instructions on how each item was scored. We excluded the item "was the length of the shortest prevalence period for the parameter of interest appropriate" from the checklist, since this question is not applicable for a chronic disease, such as SpA.

\section{Data synthesis and analysis}

Because prevalence estimates were expected to be below $1 \%$, the values were transformed with the double arcsine transformation for meta-analysis and metaregression.[15] The pooled prevalence was estimated by combining the transformed prevalence estimates using a random-effects model. Studies from Northern Artic indigenous communities were excluded from the meta-analysis, because the risk for SpA in this group is clearly different from the rest of the world, which would bias (i.e. overestimate) the results. The pooled prevalence and 95\% confidence intervals (Cl) 
were back transformed to prevalence estimates for ease of interpretation. The heterogeneity among studies was tested by the Cochran's Q test and the $I^{2}$ statistic, the latter describing the percentage of variation across studies.[16]

Potential sources of heterogeneity were investigated by an exploratory subgroup analysis, using random effects analogous to one-way analysis of variance, in which groups of estimates were arranged according to potentially relevant demographical (mean age of the sample, proportion of females, geographic area, and setting) and methodological characteristics (year of data collection, study size, sampling frame, case finding, and case ascertainment). Studies from Northern Artic indigenous communities were excluded in the subgroup-analysis.

Univariable and multivariable meta-regression analyses were performed to explore associations between demographical and methodological characteristics and the prevalence. Variables with a $p$-value of $\varangle$.20 in the univariable analysis were entered into the multivariable model. A backward procedure was used, removing variables with a $p$-value of $>0.05$ in the multivariable model in order of significance. The following variables were tested: mean age of the sample, proportion of females, geographic area, setting, year of data collection, case finding, case ascertainment, and the dichotomized risk of bias criteria not yet covered by the previous variables. Due to collinearity, sampling frame was not included in the model. If data on age or sex were missing, respectively the mean or $50 \%$ were imputed. For the meta-regression analysis, SPSS macros were used (M etareg.sps and M etaF.sps).[17]

\section{RESULTS}

\section{Search results}

The database search yielded 9,240 studies (Supplementary File 3). After removing duplicates and title/abstract screening, 179 articles remained for full paper review. Two papers could not be retrieved, despite contacting the authors.[18,19] After full-text reading, 80 articles were included. With hand search of references, 4 papers were added, leading to a total of 84 articles.

\section{Characteristics of included studies}

The prevalence of SpA was reported in 30 studies (100 age- and/or sex-specific estimates), of AS in 53 studies (179 estimates), of PsA in 35 studies (89 estimates), of ReA in 17 studies (67 estimates), of IBD-SpA in 4 studies (15 estimates), and of USpA in 
15 studies (88 estimates). A detailed overview of all included studies is provided in Supplementary File 4. A combined meta-analysis and meta-regression analysis could be performed for SpA, AS and PsA. Only a limited number of studies were available for ReA, IBD-SpA and USpA, therefore these results are described and summarized narratively.

Table 2.1 shows a summary of the main characteristics of studies included in the largest groups; SpA, AS and PsA.

\section{Risk of bias}

An overview of the risk of bias assessment is provided in Supplementary File 5. High risk of bias was most common for item 1 (representativeness of sample for the national general population) and item 2 (representativeness of sampling frame).

\section{Prevalence of spondyloarthritis}

The pooled population prevalence of SpA was $0.55 \%$ (95\%Cl $0.37-0.77)$, with high heterogeneity $\left(I^{2}=99.9 \%\right)$. Figure 2.1 shows the prevalence estimates of SpA according to different demographical and methodological characteristics. Mean age of the study population and geographic area contributed significantly to the observed heterogeneity. The prevalence of SpA was higher in studies from North America (1.35\%, 95\% $0.44-2.79, n=1$ study) and Europe $(0.54 \%, 95 \% \mathrm{Cl} 0.36-0.78)$ compared with South Asia $(0.22 \%, 95 \% \mathrm{Cl} 0.01-0.66)$ and South-East Asia $(0.20 \%, 95 \% \mathrm{Cl}$ $0.00-0.66)$. No studies from Sub-Saharan Africa, Central Asia and Oceania were available (Figure 2.2a). With respect to the sampling frame, true population studies reported higher prevalence estimates compared with hospital-based studies. The prevalence of SpA was also higher in more recent studies (year of data collection from 2000 onwards) and in smaller studies ( $<5000$ subjects). Further, prevalence estimates were higher if based on the ESSG criteria compared with clinical diagnosis. Table 2.2 shows the results of the meta-regression analysis. The final model explained $51.8 \%$ of the heterogeneity. In this model, case finding ( $p \varangle 0.01$ ), a lower proportion of females $(p=0.01)$, geographic area $(p \varangle 0.01)$, and more recent year of data collection $(p=0.02)$ were positively associated with the prevalence of SpA. 


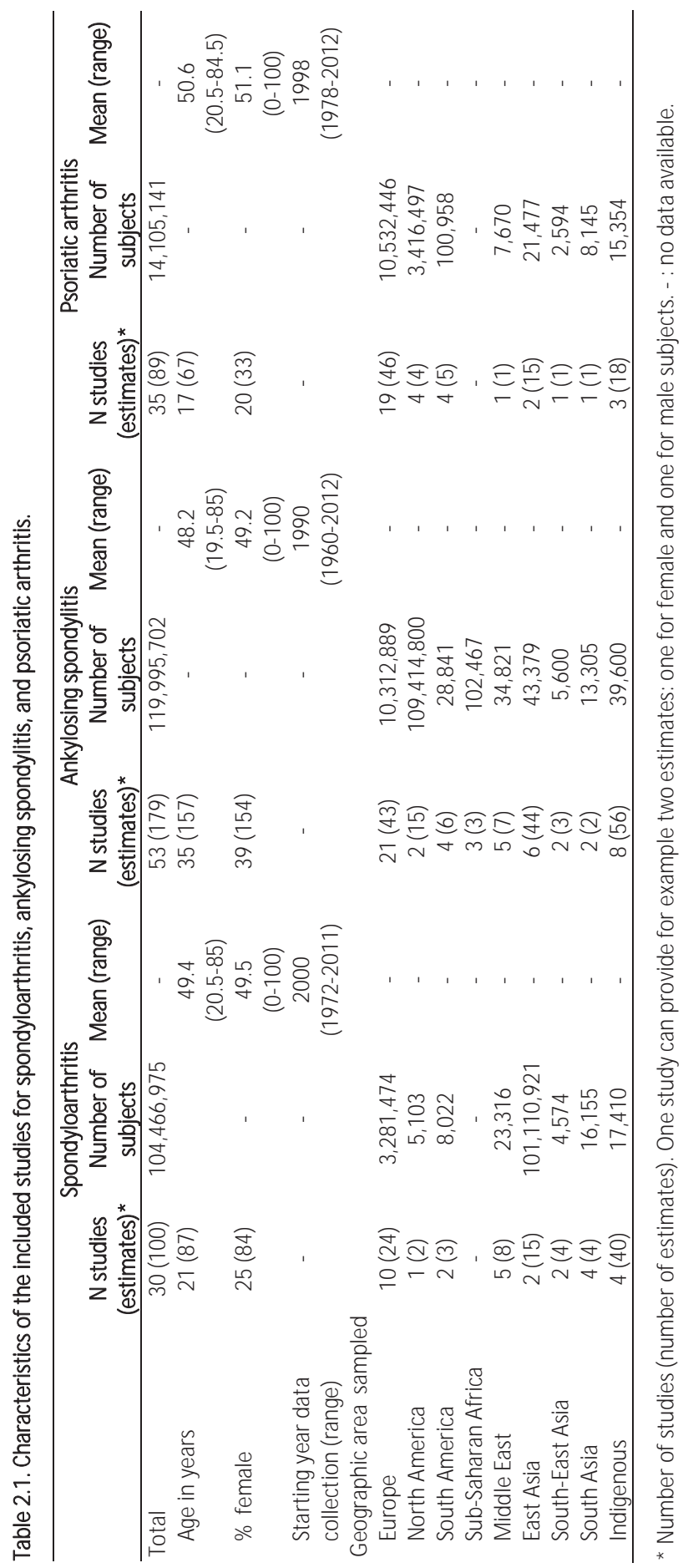




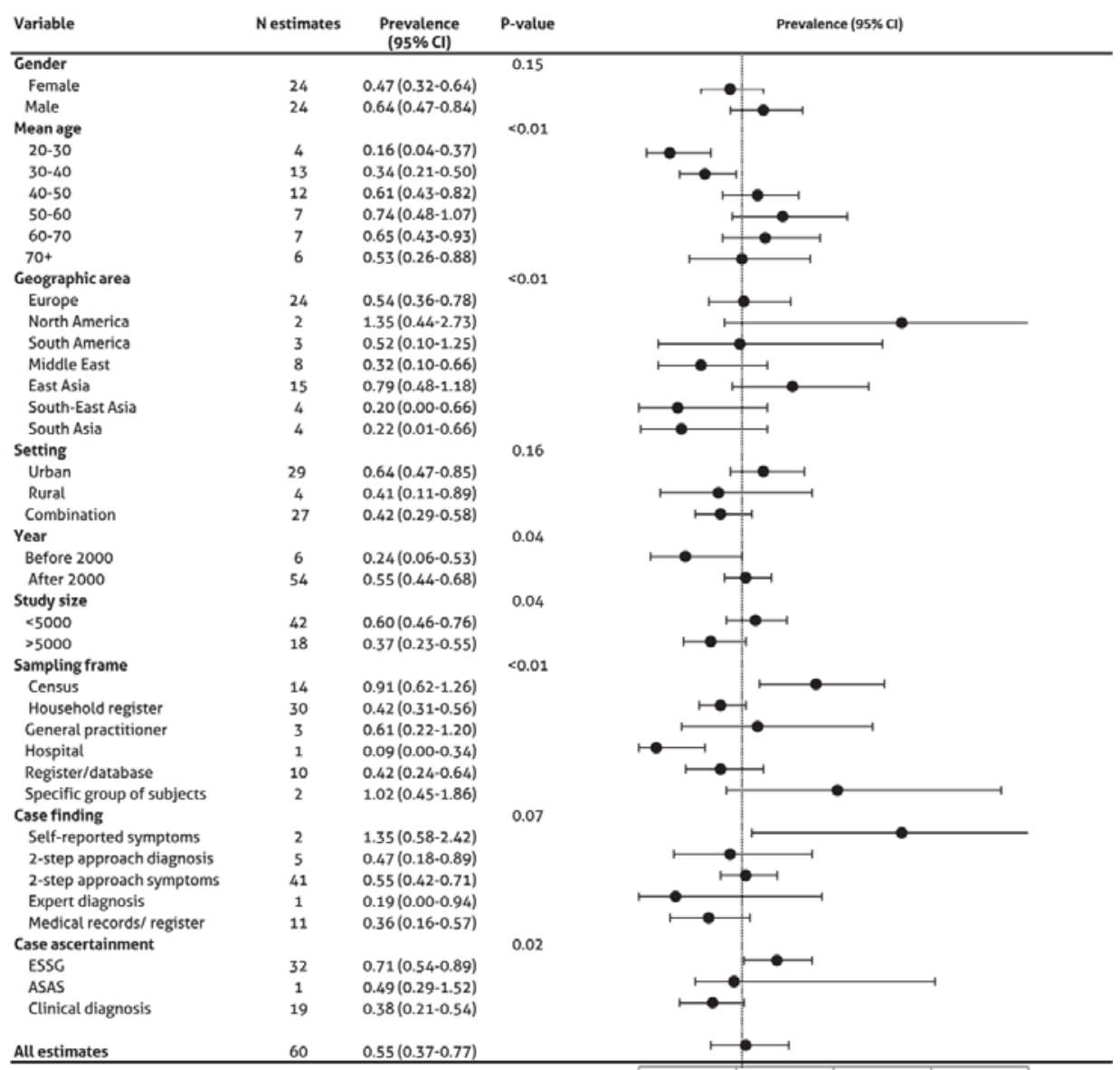

Figure 2.1 Prevalence of spondyloarthritis grouped by demographical and methodological characteristics. Estimates of Northern Artic communities were not included in the subgroup-analysis. ESSG=European Spondyloarthropathy Study Group; ASAS= Assessment of Spondyloarthritis International Society.

\section{Axial and peripheral SpA}

Two studies reported the prevalence of axial and/or peripheral SpA according to the ASAS classification criteria.[20,21] In a large population-based cohort consisting of 20,625 employees of the French national electricity and gas company, a crude prevalence of SpA of $0.48 \%$ was found $(0.36 \%$ for axial SpA and $0.12 \%$ for peripheral $\mathrm{SpA}$ ) (20). In a study from the US, in which a sample of medical records of patients with chronic back pain were reviewed against the ASAS criteria and extrapolated to other US rheumatology practices, the prevalence of axial SpA was estimated at 0.70\%.[21] 
a

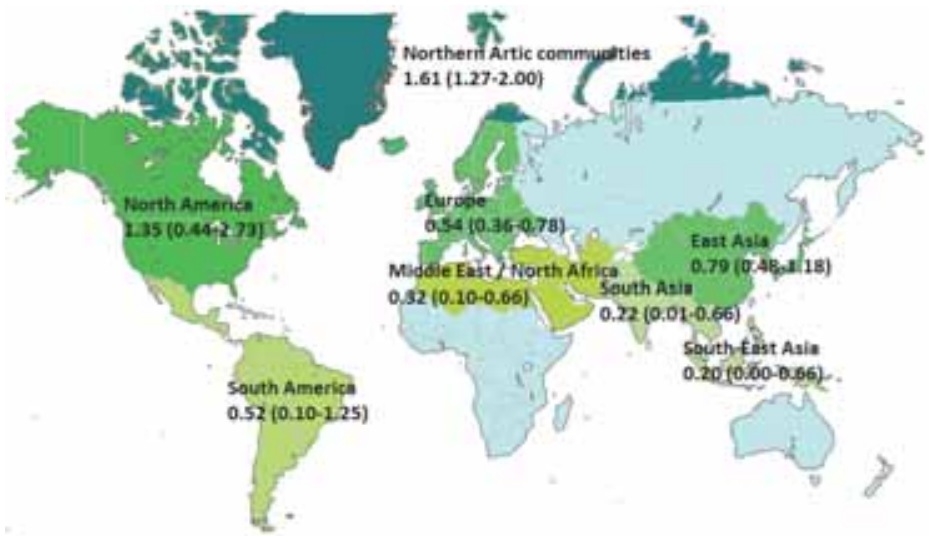

b

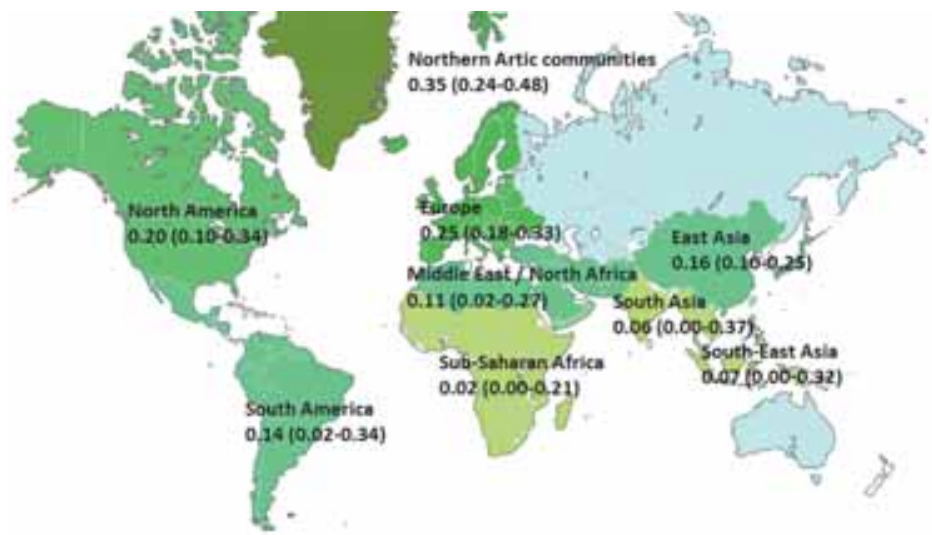

C

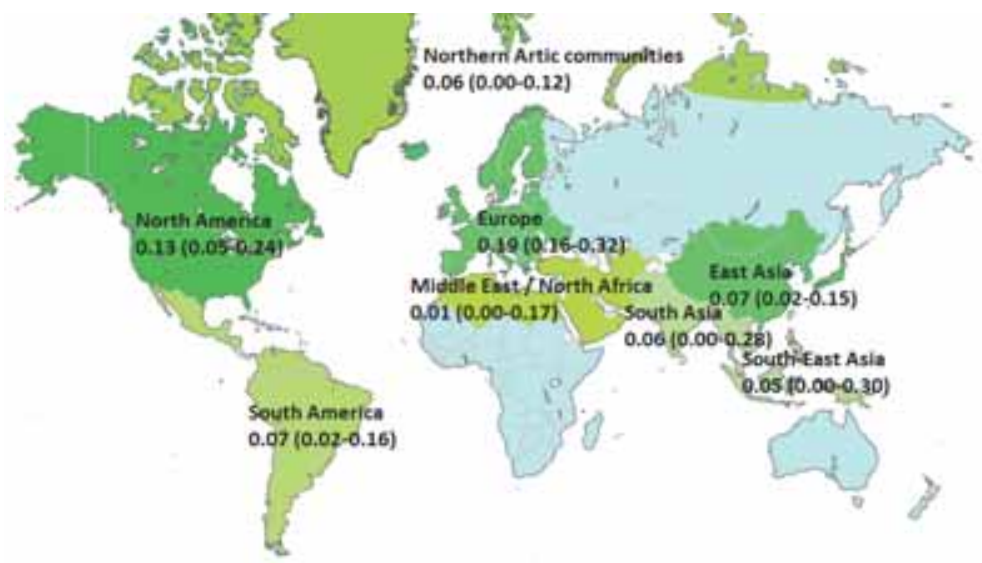

Figure 2.2 Maps showing the global prevalence of spondyloarthritis (a), ankylosing spondylitis (b), and psoriatic arthritis (c) 


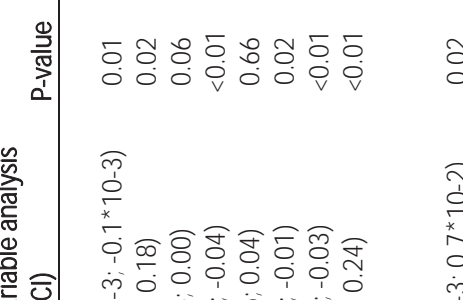

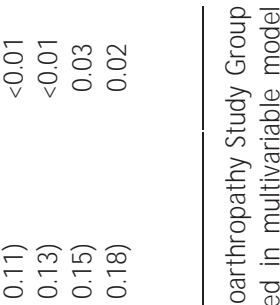

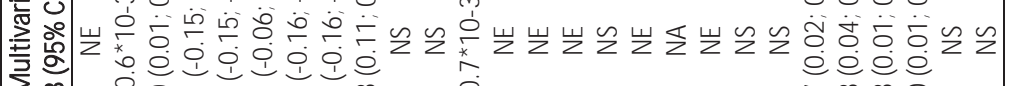

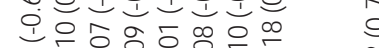

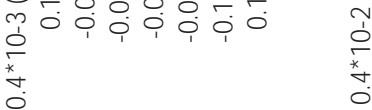

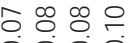
ֻ

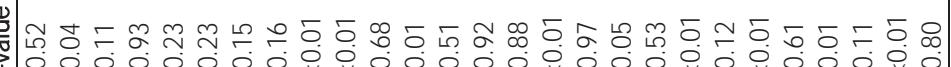
ஸீ $\stackrel{m}{\stackrel{n}{-}}$

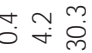
(1)

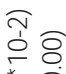

$\widehat{\mathrm{N}}$

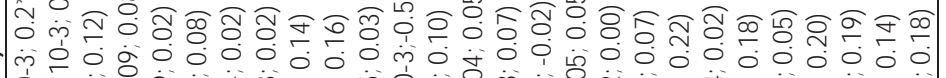
क人

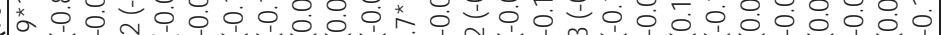
๓

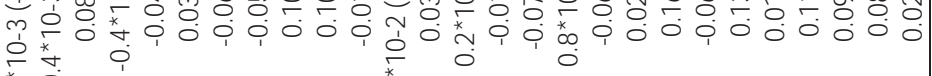
苦

前

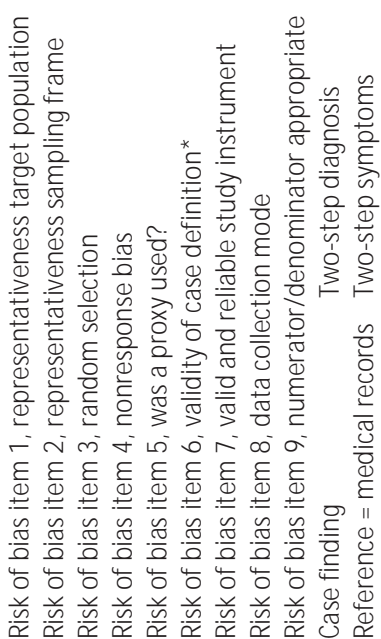
व)

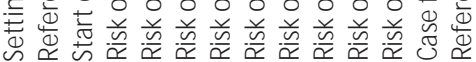




\section{Ankylosing spondylitis}

The pooled population prevalence of AS was $0.18 \%(95 \% \mathrm{Cl} 0.15-0.23)$. Heterogeneity was high $\left(I^{2}=99.0 \%\right)$. Figure 2.3 shows the pooled prevalence of AS stratified by subgroups. The prevalence of AS was higher in males compared with females. The prevalence was higher in rural populations and different across geographic areas, with the highest prevalence rates in studies from Europe and North America (Figure 2.2b). With regard to the methodological characteristics, the prevalence was higher in studies with $\measuredangle 000$ subjects, different among sampling frames, and higher when patients were classified according to the (modified) New York or ASAS criteria compared with clinical diagnosis.

The meta-regression analysis of the prevalence of AS is provided in Supplementary File 6. The final model explained $47.0 \%$ of heterogeneity. The prevalence of AS was higher in samples with a lower percentage of females $(p \varangle 0.01$ ), different across geographic areas (higher prevalence rates in studies from North America, Europe and Northern Artic indigenous communities compared with all other geographic regions), and higher in samples from rural areas compared with urban areas $(p \varangle 0.01)$. The prevalence was lower in samples in which cases were found by medical records compared with twostep symptoms approaches $(p \varangle 0.01)$, but higher in studies with high risk of bias for validity/reliability of the study instrument $(p<0.01)$.

\section{Psoriatic arthritis}

The pooled population prevalence of PsA was $0.15 \%(95 \% \mathrm{Cl} 0.12-0.17)$. Heterogeneity was high $\left(I^{2}=99.2 \%\right)$. The results of the subgroup analysis are shown in Figure 2.4 . The prevalence of PSA was significantly different across age groups and related to geographic area (Figure 2.2c). The highest prevalence was found in Europe $(0.19 \%$, $95 \% \mathrm{Cl} 0.16-0.32)$ and the lowest in the Middle East $(0.01 \%, 95 \% \mathrm{Cl} 0.00-0.17)$. The prevalence of PsA was further significantly related to sampling frame and case finding. The highest prevalence of PSA was found when diagnosis was based on self-report $(0.26 \%, 95 \% \mathrm{Cl} 0.06-0.58)$. 


\begin{tabular}{|c|c|c|c|c|}
\hline Variable & $\begin{array}{c}\mathrm{N} \\
\text { estimates }\end{array}$ & $\begin{array}{c}\text { Prevalence } \\
(95 \% \mathrm{CI})\end{array}$ & P-value & Prevalence $(95 \% \mathrm{Cl})$ \\
\hline Gender & & & $<0.01$ & \\
\hline Female & 48 & $0.12(0.09-0.17)$ & & \\
\hline Male & 51 & $0.31(0.23-0.41)$ & & $\mapsto \bullet$ \\
\hline Mean age & & & 0.44 & \\
\hline $20-30$ & 17 & $0.15(0.04-0.23)$ & & \\
\hline $30-40$ & 23 & $0.18(0.03-0.29)$ & & \\
\hline $40-50$ & 24 & $0.27(0.16-0.41)$ & & \\
\hline $50-60$ & 16 & $0.24(0.12-0.41)$ & & \\
\hline $60-70$ & 13 & $0.16(0.05-0.32)$ & & $\longrightarrow$ \\
\hline $70+$ & 12 & $0.14(0.03-0.33)$ & & \\
\hline Geographic area & & & $<0.01$ & \\
\hline Europe & 43 & $0.25(0.18-0.33)$ & & $\bullet-1$ \\
\hline North America & 15 & $0.20(0.10-0.34)$ & & \\
\hline South America & 6 & $0.14(0.02-0.34)$ & & 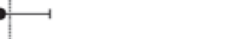 \\
\hline Sub-Saharan Africa & 3 & $0.02(0.00-0.21)$ & & \\
\hline Middle East & 7 & $0.11(0.02-0.27)$ & & $\rightarrow 1$ \\
\hline East Asia & 44 & $0.16(0.10-0.25)$ & & -1 \\
\hline South-East Asia & 3 & $0.07(0.00-0.32)$ & & $\longrightarrow$ \\
\hline South Asia & 2 & $0.06(0.00-0.37)$ & & \\
\hline Setting & & & $<0.01$ & \\
\hline Urban & 45 & $0.20(0.14-0.28)$ & & $b-1$ \\
\hline Rural & 14 & $0.52(0.35-0.72)$ & & $\longmapsto$ \\
\hline Combination & 64 & $0.12(0.08-0.16)$ & & \\
\hline Year & & & 0.75 & \\
\hline Before 2000 & 71 & $0.19(0.14-0.26)$ & & -1 \\
\hline After 2000 & 52 & $0.18(0.12-0.25)$ & & -1 \\
\hline Study size & & & $<0.01$ & \\
\hline$<5000$ & 88 & $0.23(0.18-0.30)$ & & -1 \\
\hline$>5000$ & 32 & $0.11(0.06-0.17)$ & & \\
\hline Sampling frame & & & $<0.01$ & \\
\hline Census & 22 & $0.56(0.41-0.74)$ & & $\longmapsto$ \\
\hline Household register & 59 & $0.13(0.08-0.18)$ & & \\
\hline General practitioner & 2 & $0.36(0.05-0.92)$ & & \\
\hline Hospital & 7 & $0.11(0.02-0.22)$ & & \\
\hline Register/database & 27 & $0.13(0.08-0.21)$ & & H \\
\hline Specific group of subjects & 3 & $0.28(0.08-0.59)$ & & $\bullet$ \\
\hline Case finding & & & 0.22 & \\
\hline 2-step approach diagnosis & 5 & $0.24(0.06-0.54)$ & & $\bullet$ \\
\hline 2-step approach symptoms & 80 & $0.22(0.16-0.28)$ & & $\bullet-1$ \\
\hline Expert diagnosis & 5 & $0.13(0.01-0.26)$ & & $\longrightarrow$ \\
\hline Medical records/ register & 33 & $0.13(0.07-0.20)$ & & \\
\hline Case ascertainment & & & .0 .03 & \\
\hline (mod) NY, Rome & 87 & $0.23(0.08-0.29)$ & & - \\
\hline ASAS & 2 & $0.32(0.00-1.11)$ & & \\
\hline Clinical diagnosis & 19 & $0.10(0.04-0.18)$ & & \\
\hline All estimates & 123 & $0.18(0.15-0.23)$ & & $\bullet$ \\
\hline
\end{tabular}

Figure 2.3 Prevalence of ankylosing spondylitis grouped by demographical and methodological characteristics. 


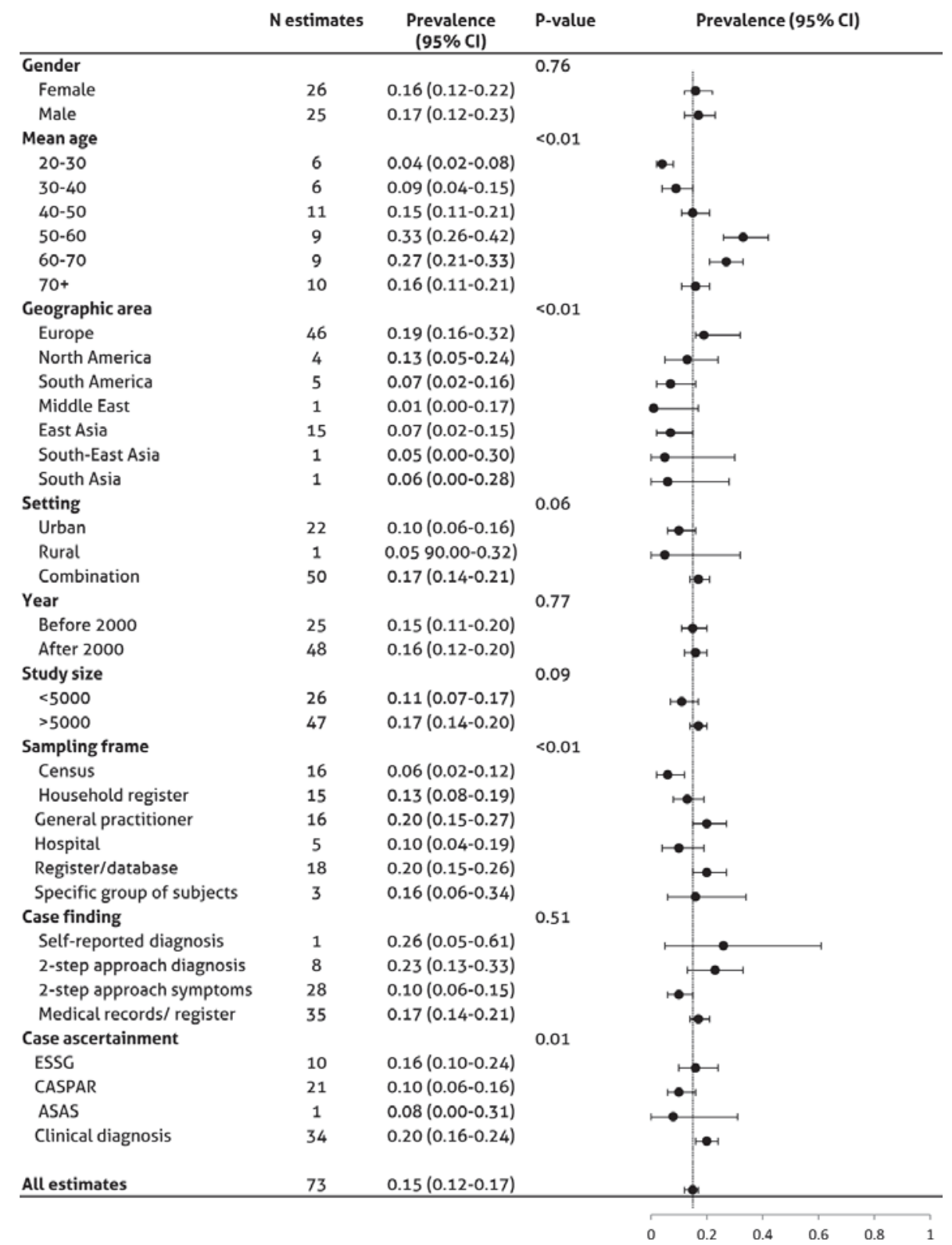

Figure 2.4 Prevalence of psoriatic arthritis grouped by demographical and methodological characteristics. 
Supplementary File 7 shows the meta-regression analysis of the prevalence of PsA. The final model explained $44.7 \%$ of the total heterogeneity. A higher mean age of the sample was positively related to the prevalence of PsA $(p<0.01)$ and prevalence was significantly different across geographic areas. With respect to the methodological characteristics, prevalence was significantly higher when case finding was based on self-report compared with medical records.

\section{Reactive arthritis}

The prevalence of ReA was reported in 17 studies: 6 from Europe, 1 from South-East Asia, 1 from Sub-Saharan Africa, and 9 from Northern Arctic indigenous populations. In Europe, the prevalence of ReA ranged from $0.03 \%$ in Greece to $0.21 \%$ in Lithuania.[22,23] In a study from India, in which 8,145 individuals were interviewed, no cases of ReA were identified (prevalence 0\%).[24] In a hospital-based study from Zimbabwe a prevalence of $0.001 \%$ was found.[25] In Northern Artic indigenous people, the prevalence ranged from $0.25 \%$ to $1.0 \%$. [26,27]

\section{Spondyloarthritis associated with inflammatory bowel disease}

The prevalence of IBD-SpA was reported in only 4 studies, all from Europe. Prevalence ranged from $0.0 \%$ in Greece to $0.09 \%$ in Italy.[22,28] No formal criteria exist to classify IBD-SpA. In these 4 studies, classification was based on the ASAS-criteria, the ESSG criteria in combination with IBD, or ICD codes.[20,22,28,29]

\section{Undifferentiated spondyloarthritis}

The prevalence of USpA was reported in 15 studies. Different criteria were used to classify patients with uSpA. In most European studies, the prevalence ranged from $0.03 \%$ to $0.10 \%[20,22,23,28-30]$ In an urban population from Turkey, a prevalence of $0.56 \%$ was found.[31] In a study in blood donors from Germany a prevalence of $0.67 \%$ was reported.[32] In two Asian studies, the reported prevalence was $0.15 \%$ in a study from India [24] and $0.55 \%$ in a study from China.[33] In Northern Artic indigenous people, prevalences ranged from $0.20 \%$ to $1.3 \%$.[26,27,34-36] 


\section{DISCUSSION}

In this systematic review, pooled population prevalence estimates were calculated for SpA $(0.55 \%, 95 \% \mathrm{Cl} 0.37-0.77)$, AS $(0.18 \%, 95 \% \mathrm{Cl} 0.15-0.23)$ and PSA $(0.15 \%, 95 \% \mathrm{Cl}$ $0.12-0.18)$. Heterogeneity across studies was high, therefore estimates should be interpreted with caution. For ReA, IBD-SpA and USpA too few studies were available to conduct a meta-analysis and, therefore, results were only summarized. Prevalence estimates of ReA (range $0.0 \%-0.2 \%$ ), IBD-SpA (range $0.0 \%-0.1 \%$ ), and uSpA (range $0.0 \%-0.7 \%$ ) were generally low.

This study is the first that pooled prevalences of SpA and its subtypes in the general population, and additionally investigated demographical and methodological characteristics influencing the estimates. Geographic area was in the multivariable meta-regression analysis one of the most important characteristics explaining heterogeneity in prevalence estimates of SpA. This variation might particularly be explained by genetic characteristics, such as HLA-B27. Independent of other characteristics, the highest prevalence estimates of SpA were found in Northern Artic indigenous communities, in which up to $50 \%$ of people have been reported to be HLAB27 positive.[9] Further, higher prevalence estimates were found in studies from North America and Europe compared with Asia, Africa and the Middle East, corresponding with reported HLA-B27 prevalences in these areas.[37] A relatively high pooled prevalence of SpA was found in North America, however, the estimates came from a single study with a high risk of bias.[38] In this study, the prevalence of SpA was estimated according to the ESSG and the Amor criteria, resulting in estimates of 1.4\% and $0.9 \%$ respectively.[38] This finding also illustrates that the choice of different classification criteria in epidemiological studies have a large impact on the reported prevalence. For reasons of comparability, we used estimates from this study based on the ESSG criteria when reporting the pooled prevalence in the present review, because these were also applied in most other studies.[38] Also the prevalence of SpA in East Asia was unexpectedly high $(0.79 \%)$, and seems to be explained by a high prevalence of uSpA in China (0.55\%).[33]

Among the methodological characteristics explored, prevalence estimates of SpA were positively and independently related to the year of data collection with more recent studies reporting higher prevalences. This may either be a true increase in the prevalence of SpA, or, more likely, an increased awareness and recognition of SpA. Further, prevalence estimates were higher in studies where populations were screened for SpA compared with studies in which cases were identified from medical records. 
This finding suggests that there is under-recognition of SpA. In the subgroup analyses this is supported by the fact that sampling form census lists yielded the highest prevalence. With respect to case ascertainment, no significant difference was found between classification based on the ESSG criteria compared with clinical diagnoses. In the present review, too few studies using the new ASAS criteria were available to draw a conclusion. Future studies are needed to gain more insight into the impact of the ASAS criteria on the prevalence of SpA in population studies, although application of these criteria might be less feasible in large epidemiological studies, because of inclusion of HLA-B27 and M RI.[39]

Similarly to SpA, also the prevalence of AS was significantly different among geographic areas in multivariable meta-regression and generally higher in regions of the northern hemisphere. Further, the prevalence of AS was higher in the male population. Traditionally, AS is considered as a disease predominantly occurring in males, although it has been shown that this may in part be an artefact induced by deficits in the diagnosis of AS in females.[40-42] Non-radiographic axial SpA, on the other hand, is as common in female as in male subjects, indicating that females develop structural changes later or less frequently than males.[39,43] In contrast, no difference in the prevalence of PSA in gender distribution was found with the multivariable metaregression. The prevalence of PSA, however, was significantly related to age, and peaked in the age category between 50 and 60 years.

Some limitations of the present study should be addressed. First, we applied a language restriction; therefore language bias cannot be excluded. Second, because the majority of the studies came from Europe, geographical bias could have occurred. This undoubtedly influenced the pooled population prevalence, which should, therefore, be interpreted with caution. Further, even within the defined geographic areas, variation in prevalence might exist, for example between North and South Europe. However, further subdivision would have hampered the meta-regression analysis. Third, direct comparisons between the results of the meta-analyses and meta-regression analyses of SpA, AS, and PsA are hampered, because often populations from different studies were used. Last, meta-regression analysis itself has some limitations.[44] Results from meta-regressions are observational, and therefore, can suffer from bias by confounding. Patients' characteristics are based on group-averages, and the relationship on study level may not be the same as the relationship on patient level. Consistent with these concerns, high risk of bias was found for the items on representativeness of the sample and the sampling frame. Only a few studies were 
truly representative for the general population, which may hamper the generalization of the results.

In conclusion, this systematic review with meta-analysis summarized the prevalence of SpA and its subtypes. A large part of the heterogeneity could be explained by geographic characteristics. However, also other demographical and methodological characteristics, such as the proportion of females, year of data collection and case finding accounted for the observed variation. The results also suggested that there might still be an under-diagnosis of SpA. It is to be expected that better recognition of $\mathrm{SpA}$ will likely further increase the prevalence. High quality studies are needed to estimate the prevalence of axial and peripheral SpA in the general population, and to estimate the prevalence of SpA in developing countries. 


\section{REFERENCES}

1. Moll JM, Haslock I, Macrae IF, et al. Associations between ankylosing spondylitis, psoriatic arthritis, Reiter's disease, the intestinal arthropathies, and Behcet's syndrome. Medicine (Baltimore). 1974/09/01 ed1974. p. 343-64.

2. Dougados M, Baeten D. Spondyloarthritis. Lancet 2011;377:2127-37.

3. Rudwaleit M, van der Heijde D, Landewe R, et al. The Assessment of SpondyloArthritis International Society classification criteria for peripheral spondyloarthritis and for spondyloarthritis in general. Ann Rheum Dis 2011;70:25-31.

4. Rudwaleit M, van der Heijde D, Landewe R, et al. The development of Assessment of SpondyloArthritis international Society classification criteria for axial spondyloarthritis (part II): validation and final selection. Ann Rheum Dis 2009;68:777-83.

5. Stolwijk C, Boonen A, van Tubergen A, et al. Epidemiology of Spondyloarthritis. Rheum Dis Clin N Am 2012;38:441-76.

6. Mathieu A, Paladini F, Vacca A, et al. The interplay between the geographic distribution of HLA-B27 alleles and their role in infectious and autoimmune diseases: A unifying hypothesis. Autoimmun Rev 2009;8:420-5.

7. Dean LE, Jones GT, MacDonald AG, et al. Global prevalence of ankylosing spondylitis. Rheumatology 2014;53:650-7.

8. Stroup DF, Berlin JA, Morton SC, et al. Meta-analysis of observational studies in epidemiology: a proposal for reporting. Meta-analysis Of Observational Studies in Epidemiology (MOOSE) group. JAM A 2000;283:2008-12.

9. Gofton JP, Chalmers A, Price GE, et al. HL-A 27 and ankylosing spondylitis in B.C. Indians. J Rheumatol 1984;11:572-3.

10. Benevolenskaia LI, Erdes $\mathrm{S}$, Krylov M, et al. The epidemiology of spondyloarthropathies among the native inhabitants of Chukotka. 2. The prevalence of HLA-B27 in the population and among spondyloarthropathy patients. Ter Arkh 1994;66:41-4.

11. Van der Linden S, Valkenburg HA, Cats A. Evaluation of diagnostic criteria for ankylosing spondylitis. A proposal for modification of the New York criteria. Arthritis Rheum 1984;27:361-8.

12. Dougados $M$, van der Linden $S$, Juhlin $R$, et al. The European Spondylarthropathy Study Group preliminary criteria for the classification of spondylarthropathy. Arthritis and rheumatism 1991;34:1218-27.

13. Rudwaleit M, van der Heijde D, Landewe R, et al. The development of Assessment of SpondyloArthritis international Society classification criteria for axial spondyloarthritis (part II): validation and final selection. Ann Rheum Dis 2009;68:777-83.

14. Hoy D, Brooks P, Woolf $A$, et al. Assessing risk of bias in prevalence studies: modification of an existing tool and evidence of interrater agreement. J Clin Epidemiol 2012;65:934-9.

15. Barendregt JJ, Doi SA, Lee YY, et al. Meta-analysis of prevalence. J Epidemiol Community Health 2013;67:974-8.

16. Higgins JP, Thompson SG. Quantifying heterogeneity in a meta-analysis. Stat M ed 2002;21:1539-58.

17. Wilson D. METAREG for SPSS/Win 6.1 or higher MACRO. 2001; Available from: http://mason.gmu.edu/ -dwilsonb/ma.html.

18. Chopra A, Patil J, Billempelly V, et al. Prevalence of rheumatic diseases in a rural population in western India: a WHO-ILAR COPCORD Study. J Assoc Physicians India 2001;49:240-6.

19. Mürden KD, Valkenburg HA, Hopper J. The epidemiology of rheumatic diseases in Australia. APLAR J Rheumatol 1992:402-210.

20. Costantino F, Talpin A, Said-Nahal R, et al. Prevalence of spondyloarthritis in reference to HLA-B27 in the French population: results of the GAZEL cohort. Ann Rheum Dis 2013. doi: 10.1136/annrheumdis2013-204436. [Epub ahead of print]

21. Strand V, Rao SA, Shillington AC, et al. Prevalence of axial spondyloarthritis in United States rheumatology practices: Assessment of SpondyloArthritis International Society criteria versus rheumatology expert clinical diagnosis. Arthritis Care Res (Hoboken) 2013;65:1299-306. 
22. Trontzas $\mathrm{P}$, Andrianakos $\mathrm{A}$, Miyakis $\mathrm{S}$, et al. Seronegative spondyloarthropathies in Greece: a population-based study of prevalence, clinical pattern, and management. The ESORDIG study. Clin Rheumatol 2005;24:583-9.

23. Adomaviciute D, Pileckyte $M$, Baranauskaite $A$, et al. Prevalence survey of rheumatoid arthritis and spondyloarthropathy in Lithuania. Scand J Rheumatol 2008;37:113-9.

24. Joshi VL, Chopra A. Is there an urban-rural divide? Population surveys of rheumatic musculoskeletal disorders in the Pune region of India using the COPCORD Bhigwan model. J Rheumatol 2009;36:614-22.

25. Lutalo SK. Chronic inflammatory rheumatic diseases in black Zimbabweans. Ann Rheum Dis 1985;44:121-5.

26. Boyer GS, Lanier AP, Templin DW, et al. Spondyloarthropathy and rheumatoid arthritis in Alaskan Yupik Eskimos. J Rheumatol 1990;17:489-96.

27. Boyer GS, Templin DW, Cornoni-Huntley JC, et al. Prevalence of spondyloarthropathies in Alaskan Eskimos. J Rheumatol 1994;21:2292-7.

28. De Angelis R, Salaffi F, Grassi W. Prevalence of spondyloarthropathies in an Italian population sample: a regional community-based study. Scand J Rheumatol 2007;36:14-21.

29. Haglund $E$, Bremander $A B$, Petersson IF, et al. Prevalence of spondyloarthritis and its subtypes in southern Sweden. Ann Rheum Dis 2011;70:943-8.

30. Saraux A, Guillemin F, Guggenbuhl P, et al. Prevalence of spondyloarthropathies in France: 2001. Ann Rheum Dis 2005;64:1431-5.

31. Onen $F, A$ kar $S$, Birlik $M$, et al. Prevalence of ankylosing spondylitis and related spondyloarthritides in an urban area of Izmir, Turkey. J Rheumatol 2008;35:305-9.

32. Braun J, Bollow M, Remlinger G, et al. Prevalence of spondylarthropathies in HLA-B27 positive and negative blood donors. Arthritis Rheum 1998;41:58-67.

33. Liao ZT, Pan YF, Huang JL, et al. An epidemiological survey of low back pain and axial spondyloarthritis in a Chinese Han population. Scand J Rheumatol 2009;38:455-9.

34. Benevolenskaya LI, Boyer GS, Erdesz S, et al. Spondylarthropathic diseases in indigenous circumpolar populations of Russia and Alaska. Rev Rhum Engl Ed 1996;63:815-22.

35. Boyer GS, Lanier AP, Templin DW. Prevalence rates of spondyloarthropathies, rheumatoid arthritis, and other rheumatic disorders in an Alaskan Inupiat Eskimo population. J Rheumatol 1988;15:678-83.

36. Boyer GS, Templin DW, Lanier AP. Rheumatic diseases in Alaskan Indians of the southeast coast: high prevalence of rheumatoid arthritis and systemic lupus erythematosus. J Rheumatol 1991;18:1477-84.

37. Bakland G, Nossent HC. Epidemiology of spondyloarthritis: a review. Curr Rheumatol Rep 2013;15:351.

38. Reveille JD, Witter JP, Weisman M H. Prevalence of axial spondylarthritis in the United States: estimates from a cross-sectional survey. Arthritis Care Res (Hoboken) 2012;64:905-10.

39. Van Tubergen A. The changing clinical picture and epidemiology of spondyloarthritis. Nat Rev Rheumatol 2014.

40. Gran JT, Husby G, Hordvik M. Prevalence of ankylosing spondylitis in males and females in a young middle-aged population of Tromso, northern Norway. Ann Rheum Dis 1985;44:359-67.

41. Masi AT, Wilkins WR. Does male:female sex ratio in ankylosing spondylitis change with age? J Rheumatol 1996;23:947-8.

42. Feldtkeller E, Bruckel J, Khan MA. Scientific contributions of ankylosing spondylitis patient advocacy groups. Curr Opin Rheumatol 2000;12:239-47.

43. Sieper J, van der Heijde D. Review: Nonradiographic axial spondyloarthritis: new definition of an old disease? Arthritis and rheumatism 2013;65:543-51.

44. Thompson SG, Higgins JP. How should meta-regression analyses be undertaken and interpreted? Stat Med 2002;21:1559-73. 


\section{SUPPLEM ENTARY FILE 1}

\section{Search strategy}

1. Spondylarthropathies/

2. Spondylarthr*

3. Spondyloarthr*

4. Spondyloarthritis.tw

5. (1 OR 2 OR 3 OR 4)

6. Bechtere* .tw.

7. (ankylos* AND spondy/*).tw.

8. (M arie AND struempell*).tw.

9. (6 OR 7 OR 8)

10. Arthritis, Psoriatic/

11. (psoria* AND (arthriti* or arthropath*)).tw.

12. (10 OR 11)

13. Arthritis, Infectious/

14. reactive arthritis.tw.

15. (reiter* AND (disease or syndrome)).tw.

16. ((sexual* or chlamydia or yersinia or postyersinia or postdysenteric or salmonella or Shigella or b27 or postinfectious or post infectious) AND arthrit*).tw.

17. (13 OR 14 OR 15 OR 16)

18. Inflammatory Bowel Diseases/

19. exp Arthritis/

20. (18 AND 19)

21. COPCORD

22. (5 OR 9 OR 12 OR 17 OR 20 OR 21)

23. Prevalence.tw.

24. Prevalence/

25. Incidence.tw.

26. Incidence/

27. Epidemiology/

28. Epidemiolog*.tw.

29. (23 OR 24 OR 25 OR 26 OR 27 OR 28)

30. 12 AND 29 


\section{SUPPLEMENTARY FILE 2}

\section{Risk of bias tool}

This risk of bias tool is based on the risk of bias tool by Hoy et al. [1], adapted to assess the risk of bias in prevalence studies of spondyloarthritis (SpA).

\begin{tabular}{|c|c|c|}
\hline Risk of bias item & Criteria for answers & Additional notes and examples \\
\hline $\begin{array}{l}\text { 1. Was the target } \\
\text { population a close } \\
\text { representation of the } \\
\text { national population in } \\
\text { relation to relevant } \\
\text { variables, e.g. age, sex, } \\
\text { occupation? }\end{array}$ & $\begin{array}{l}\text { - Yes (LOW RISK): The study's } \\
\text { target population was a close } \\
\text { representation of the national } \\
\text { population. } \\
\text { - No (HIGH RISK): The study's } \\
\text { target population was clearly } \\
\text { NOT representative of the } \\
\text { national population }\end{array}$ & $\begin{array}{l}\text { The target population refers to the group of } \\
\text { people or entities to which the results of the } \\
\text { study will be generalised. Examples: } \\
\text {-The study was a national health survey of people } \\
15 \text { years and over and the sample was drawn } \\
\text { from a list that included all individuals } \\
\text { in the population aged } 15 \text { years and over. The } \\
\text { answer is: Yes (LOW RISK). } \\
\text {-The study was conducted in one province only, } \\
\text { and it is not clear if this was representative of the } \\
\text { national population. The answer is: } \\
\text { No (HIGH RISK). } \\
\text {-The study was undertaken in one village only and } \\
\text { it is clear that this was not representative of the } \\
\text { national population. The answer is: } \\
\text { No (HIGH RISK). }\end{array}$ \\
\hline $\begin{array}{l}\text { 2. Was the sampling } \\
\text { frame a true or close } \\
\text { representation of the } \\
\text { target population? }\end{array}$ & $\begin{array}{l}\text {-Yes (LOW RISK): The } \\
\text { sampling frame was a true or } \\
\text { close representation of the } \\
\text { target population. } \\
\text { - No (HIGH RISK): The sampling } \\
\text { frame was NOT a true or close } \\
\text { representation of the target } \\
\text { population. }\end{array}$ & $\begin{array}{l}\text { The sampling frame is a list of the sampling units } \\
\text { in the target population and the study sample is } \\
\text { drawn from this list. Examples: } \\
\text { - The sampling frame was a list of almost every } \\
\text { individual within the target population. The } \\
\text { answer is: Yes (LOW RISK). } \\
\text {-The cluster sampling method was used and the } \\
\text { sample of clusters/villages was drawn from a list } \\
\text { of all villages in the target population. The } \\
\text { answer is: Yes (LOW RISK). } \\
\text {-The sampling frame was a list of just one } \\
\text { particular ethnic group within the overall target } \\
\text { population, which comprised many groups. } \\
\text { The answer is: No (HIGH RISK). }\end{array}$ \\
\hline $\begin{array}{l}\text { 3. Was some form of } \\
\text { random selection used } \\
\text { to select the sample? }\end{array}$ & $\begin{array}{l}\text {-Yes (LOW RISK): A census } \\
\text { was undertaken, OR, some form } \\
\text { of random selection was used to } \\
\text { select the sample (e.g. simple } \\
\text { random sampling, stratified } \\
\text { random sampling, cluster } \\
\text { sampling, systematic sampling). } \\
\text {-No (HIGH RISK): A census was } \\
\text { NOT undertaken, AND some } \\
\text { form of random selection was }\end{array}$ & $\begin{array}{l}\text { A census collects information from every unit in } \\
\text { the sampling frame. In a survey, only part of the } \\
\text { sampling frame is sampled. In these } \\
\text { instances, random selection of the sample helps } \\
\text { minimise study bias. } \\
\text { Examples: } \\
\text {-The sample was selected using simple random } \\
\text { sampling. The answer is: Yes (LOW RISK). } \\
\text { - The target population was the village and every } \\
\text { person in the village was sampled. The answer is: }\end{array}$ \\
\hline
\end{tabular}




\begin{tabular}{|c|c|c|}
\hline & NOT used to select the sample. & $\begin{array}{l}\text { Yes (LOW RISK). } \\
\text { - The nearest villages to the capital city were } \\
\text { selected in order to save on the cost of fuel. The } \\
\text { answer is: No (HIGH RISK). }\end{array}$ \\
\hline $\begin{array}{l}\text { 4. Was the likelihood of } \\
\text { nonresponse bias } \\
\text { minimal? }\end{array}$ & $\begin{array}{l}\text { A census collects information } \\
\text { from every unit in the sampling } \\
\text { frame. In a survey, only part of } \\
\text { the sampling frame is sampled. } \\
\text { In these } \\
\text { instances, random selection of } \\
\text { the sample helps minimising } \\
\text { study bias. Examples: } \\
\text { - The sample was selected using } \\
\text { simple random sampling. The } \\
\text { answer is: Yes (LOW RISK). } \\
\text { - The target population was the } \\
\text { village and every person in the } \\
\text { village was sampled. The answer } \\
\text { is: Yes (LOW RISK). } \\
\text { - The nearest villages to the } \\
\text { capital city were selected in } \\
\text { order to save on the cost of fuel. } \\
\text { The answer is: No (HIGH RISK). }\end{array}$ & $\begin{array}{l}\text { A census collects information from every unit in } \\
\text { the sampling frame. In a survey, only part of the } \\
\text { sampling frame is sampled. In these instances, } \\
\text { random selection of the sample helps minimising } \\
\text { study bias. } \\
\text { Examples: } \\
\text { - The sample was selected using simple random } \\
\text { sampling. The answer is: Yes (LOW RISK). } \\
\text { - The target population was the village and every } \\
\text { person in the village was sampled. The answer is: } \\
\text { Yes (LOW RISK). } \\
\text { - The nearest villages to the capital city were } \\
\text { selected in order to save on the cost of fuel. The } \\
\text { answer is: No (HIGH RISK). }\end{array}$ \\
\hline $\begin{array}{l}\text { 5. Were data collected } \\
\text { directly from the } \\
\text { subjects? }\end{array}$ & $\begin{array}{l}\text {-Yes (LOW RISK): All data were } \\
\text { collected directly from the } \\
\text { subjects. } \\
\text { - No (HIGH RISK): In some } \\
\text { instances, data were collected } \\
\text { from a proxy. }\end{array}$ & $\begin{array}{l}\text { Examples: } \\
\text { - All eligible subjects in the household were } \\
\text { interviewed separately. The answer is: Yes (LOW } \\
\text { RISK). } \\
\text { - A representative of the household was } \\
\text { interviewed and questioned about the presence } \\
\text { of low back pain in each household member. } \\
\text { The answer is: No (HIGH RISK). } \\
\text {-Data were collected from medical records or a } \\
\text { dataset: No (HIGH RISK) }\end{array}$ \\
\hline $\begin{array}{l}\text { 6. Was an acceptable } \\
\text { case definition used }\end{array}$ & $\begin{array}{l}\text { - Yes (LOW RISK): An } \\
\text { acceptable case definition was } \\
\text { used. } \\
\text { - No (HIGH RISK): An } \\
\text { acceptable case definition was } \\
\text { NOT used. }\end{array}$ & $\begin{array}{l}\text { Examples: } \\
\text {-SpA: case definition was based on the ASAS } \\
\text { criteria, ESSG criteria, expert opinion, medical } \\
\text { records, or ICD-codes: Yes (LOW RISK). } \\
\text {-AS: case definition was based on the (modified) } \\
\text { New-York criteria, the Rome criteria, medical } \\
\text { records, or ICD-codes: Yes (LOW RISK). } \\
\text {-PSA: case definition was based on: the CASPAR } \\
\text { criteria, ESSG criteria + psoriasis, ASAS criteria + } \\
\text { psoriasis, medical records, or ICD-codes: Yes } \\
\text { (LOW RISK) } \\
\text {-There was no description of classification criteria } \\
\text { used: No (HIGH RISK) }\end{array}$ \\
\hline $\begin{array}{l}\text { 7. Was the study } \\
\text { instrument reliable and } \\
\text { valid? }\end{array}$ & $\begin{array}{l}\text {-Yes (LOW RISK): The study } \\
\text { instrument is shown to be } \\
\text { reliable and valid (if this was }\end{array}$ & $\begin{array}{l}\text { - The authors used the COPCORD questionnaire, } \\
\text { which had previously been validated. They also } \\
\text { tested the inter-rater reliability of the }\end{array}$ \\
\hline
\end{tabular}




\begin{tabular}{|l|l|l|}
\hline & $\begin{array}{l}\text { necessary), e.g. test-retest, } \\
\text { piloting, validation in a previous } \\
\text { study, etc. } \\
\text {-No (HIGH RISK): the study } \\
\text { instrument is not shown to be } \\
\text { reliable and valid (if this was } \\
\text { necessary) }\end{array}$ & $\begin{array}{l}\text { questionnaire. The answer is: Yes (LOW RISK). } \\
\text {-The authors developed their own questionnaire } \\
\text { and did not test this } \\
\text { for validity or reliability. The answer is: No (HIGH } \\
\text { RISK). }\end{array}$ \\
\hline $\begin{array}{l}\text { 8. Was the same mode } \\
\text { of data collection used } \\
\text { for all subjects?, }\end{array}$ & $\begin{array}{l}\text {-Yes (LOW RISK): The same } \\
\text { mode of data collection was } \\
\text { used for all subjects. } \\
\text { - No (HIGH RISK): The same } \\
\text { mode of data collection was } \\
\text { NOT used for all subjects. }\end{array}$ & $\begin{array}{l}\text { The mode of data collection is the method used } \\
\text { for collecting information from the subjects. The } \\
\text { most common modes are face-to-face interviews, } \\
\text { telephone interviews and self-administered } \\
\text { questionnaires. Examples: } \\
\text {-All eligible subjects had a face-to-face interview. } \\
\text { The answer is: Yes (LOW RISK). } \\
\text {-Some subjects were interviewed over the } \\
\text { telephone and some filled in postal } \\
\text { questionnaires. The answer is: No (HIGH RISK). }\end{array}$ \\
\hline $\begin{array}{l}\text { 9. Were the numerator } \\
\text { and denominator for } \\
\text { the parameter of } \\
\text { interest appropriate? }\end{array}$ & $\begin{array}{l}\text { There may be errors in the calculation and/or } \\
\text { reporting of the numerator and/or denominator. } \\
\text { presented appropriate } \\
\text { numerator(s) AND } \\
\text { denominator(s) for the } \\
\text { parameter of interest (e.g. the } \\
\text { prevalence of SpA). } \\
\text { - No (HIGH RISK): The paper } \\
\text { did present numerator(s) AND } \\
\text { denominator(s) for the } \\
\text { parameter of interest but one or } \\
\text { more of }\end{array}$ & $\begin{array}{l}\text { - There were no errors in the reporting of the } \\
\text { numerator(s) AND denominator(s) for the } \\
\text { prevalence of SpA. The answer is: } \\
\text { Yes (LOW RISK). } \\
\text { - In reporting the overall prevalence of low back } \\
\text { pain (in both men and women), the authors } \\
\text { accidentally used the population of women as the } \\
\text { denominator rather than the combined } \\
\text { population. The answer is: No (HIGH RISK). }\end{array}$ \\
\hline
\end{tabular}

\section{Reference}

1. Hoy D, Brooks P, Woolf A, et al. Assessing risk of bias in prevalence studies: modification of an existing tool and evidence of interrater agreement. J Clin Epidemiol 2012;65:934-9. 


\section{SUPPLEMENTARY FILE 3}

\section{Selection of studies for the systematic review on the prevalence of spondyloarthritis}

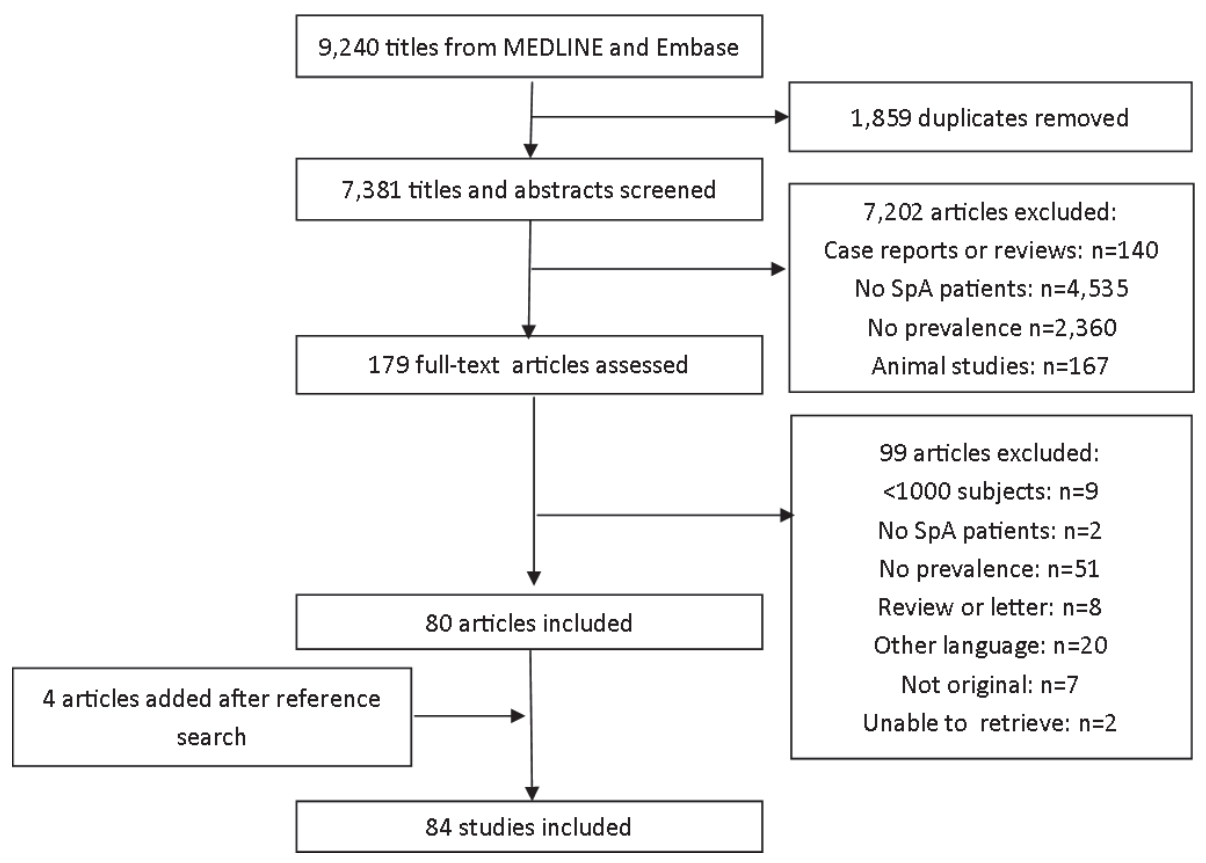


52 Chapter 2

SUPPLEMENTARY FILE 4

Characteristics of included studies 


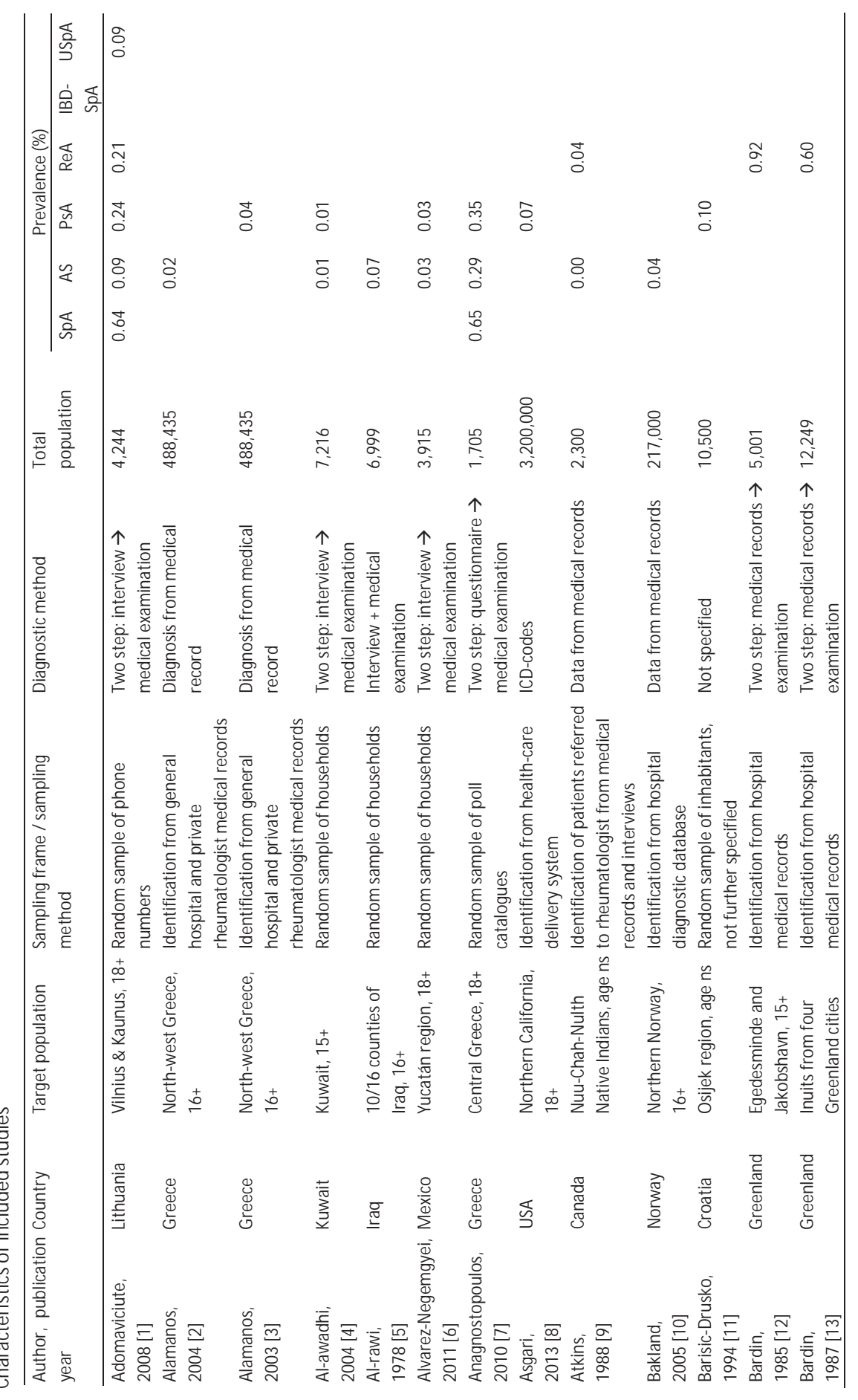




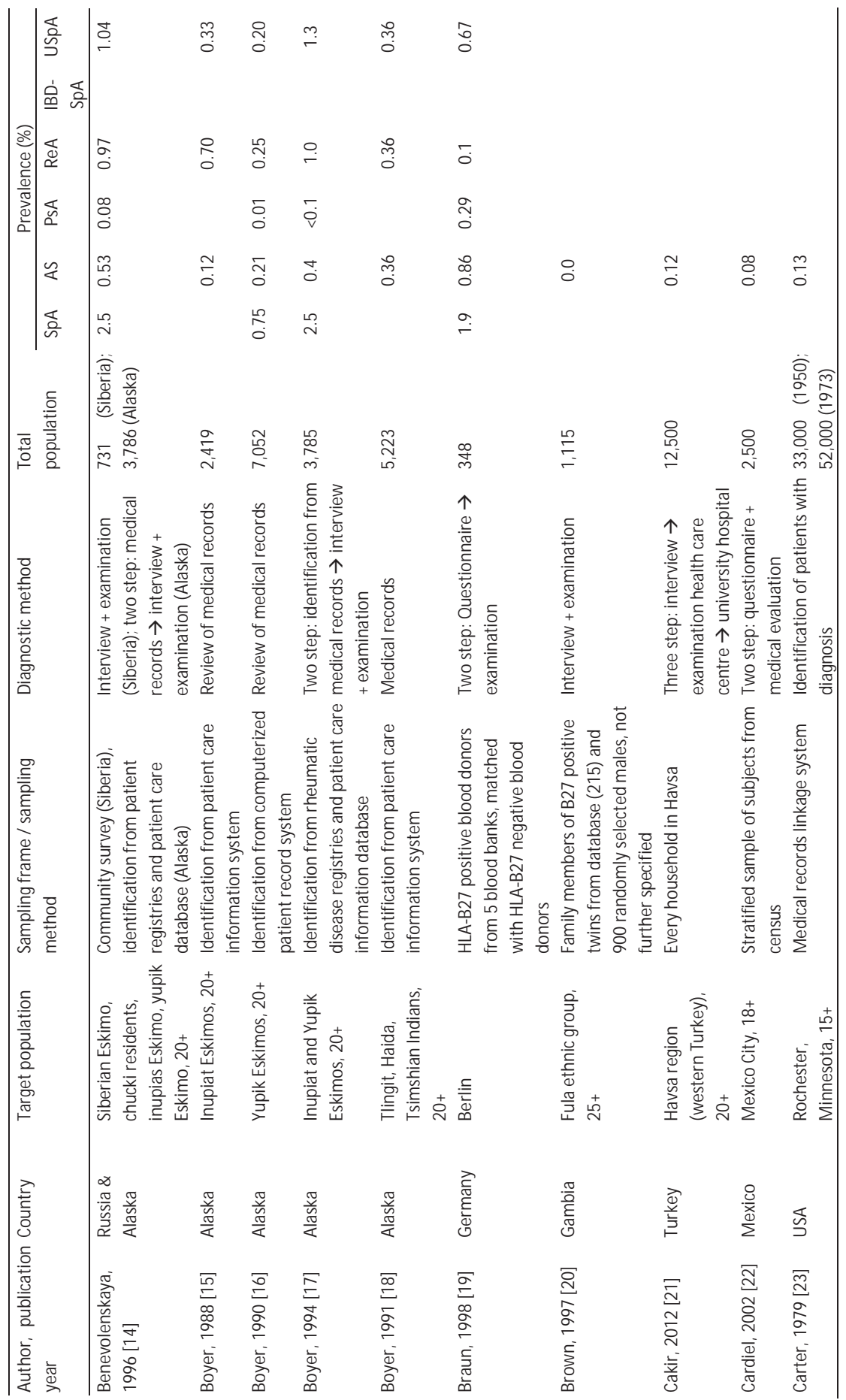




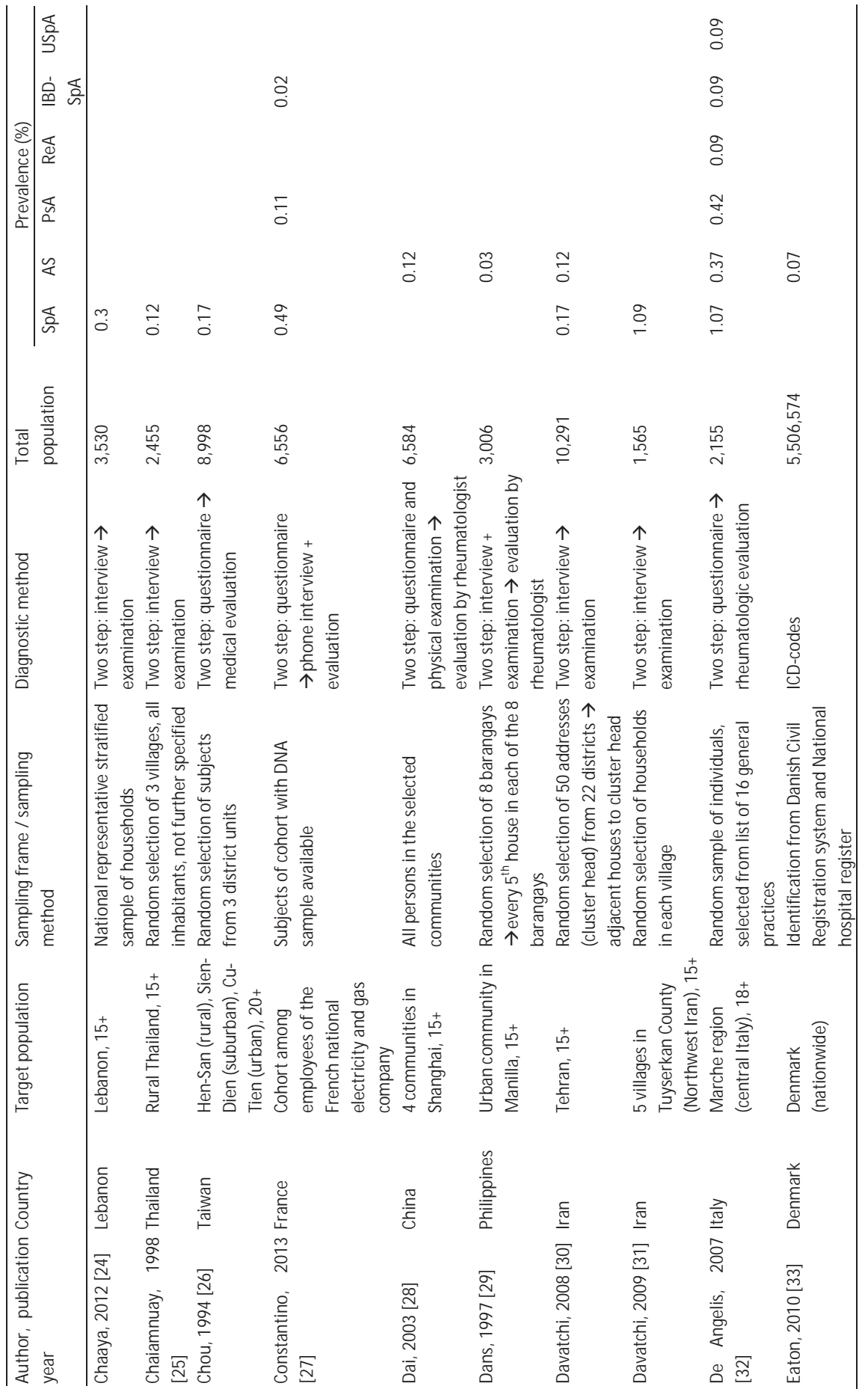




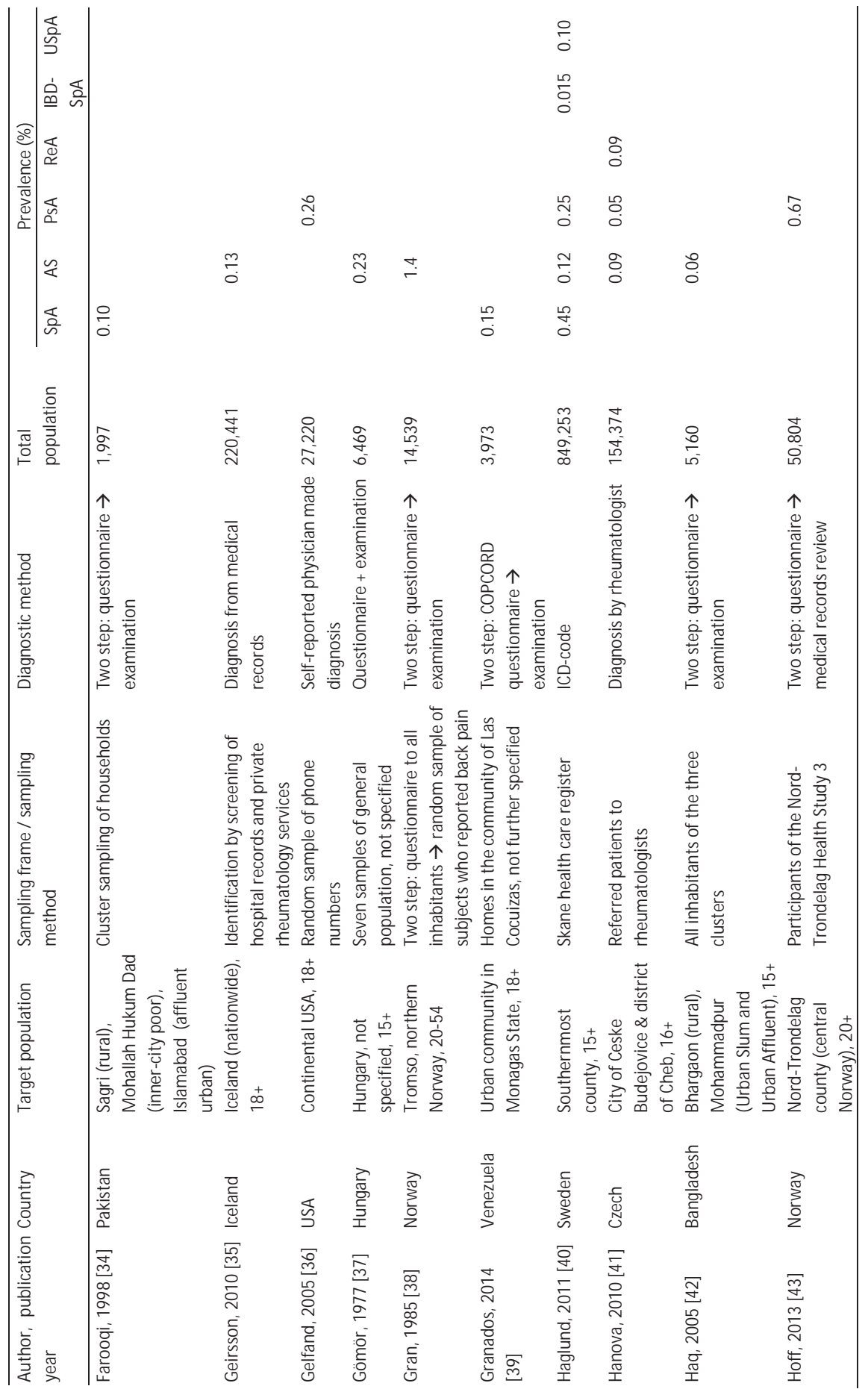




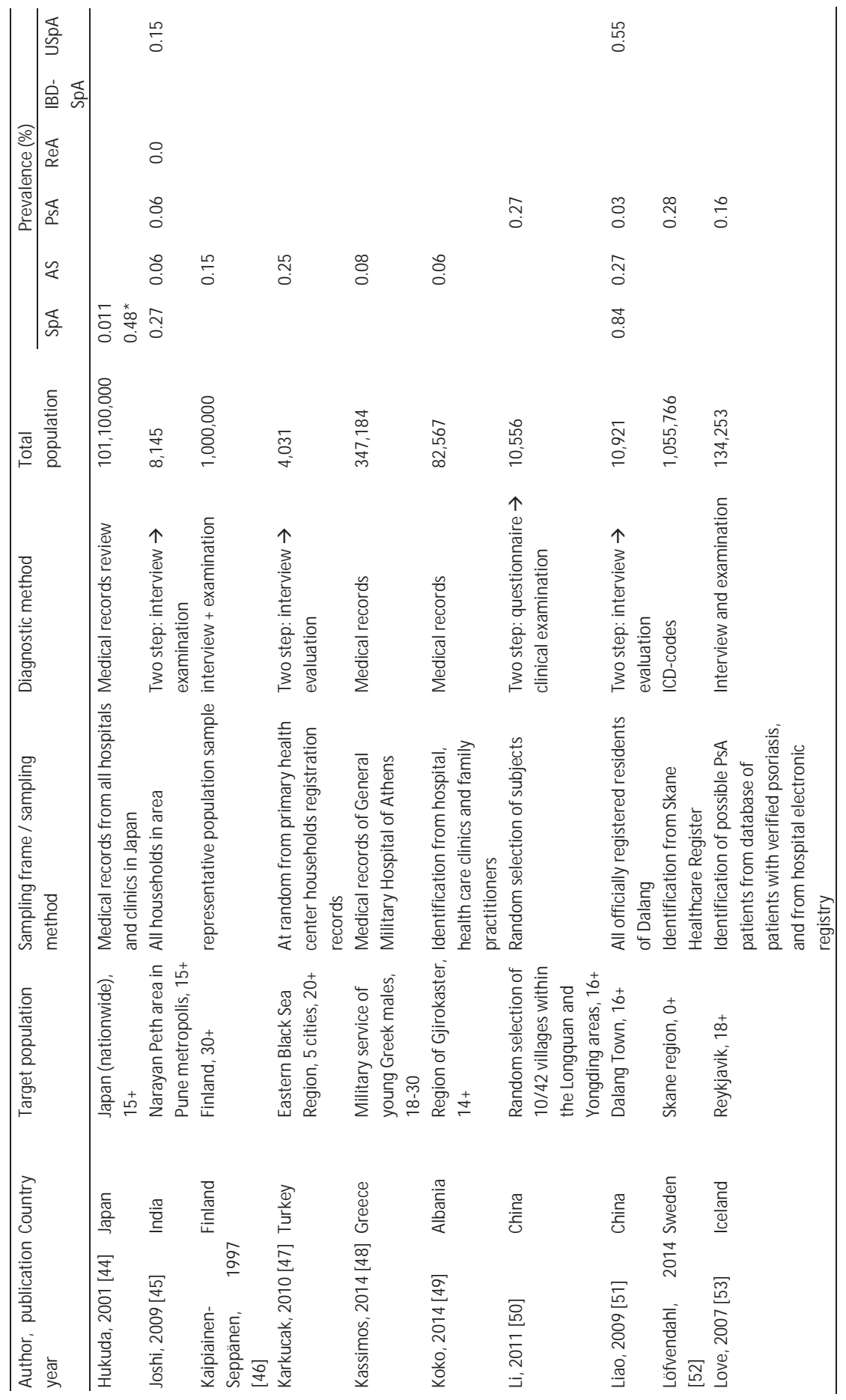




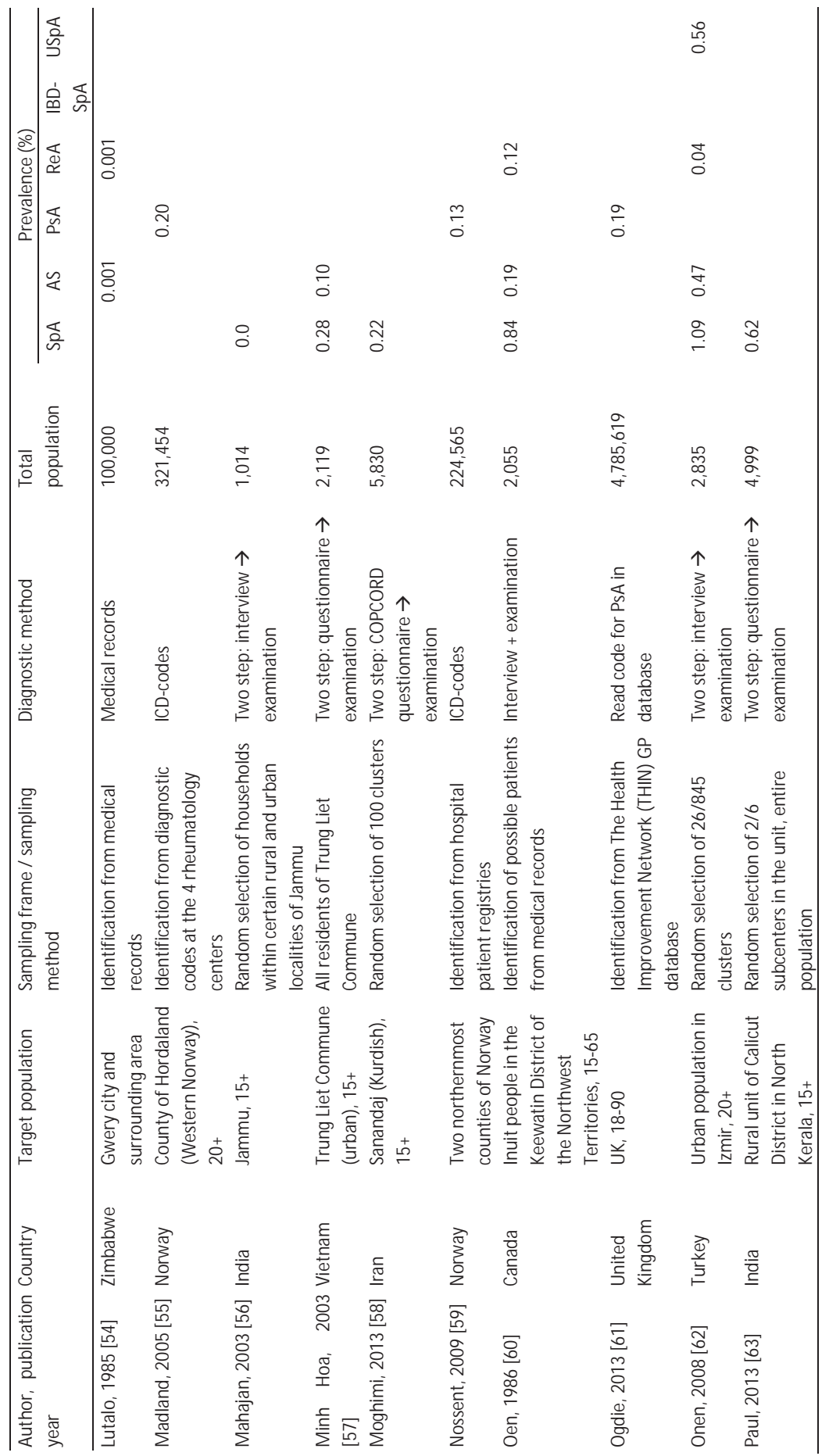




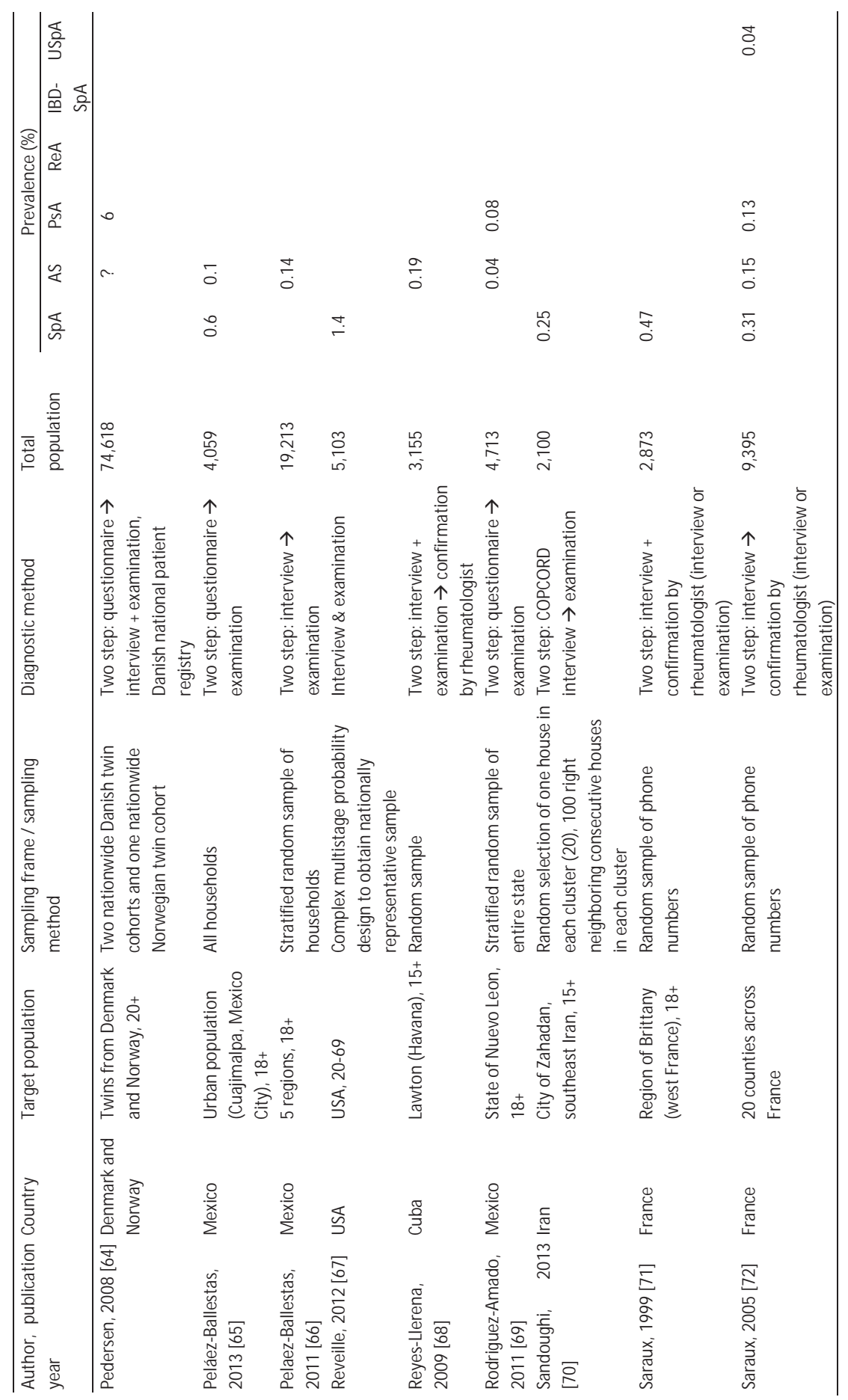




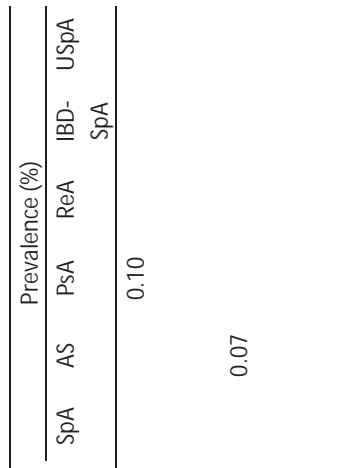

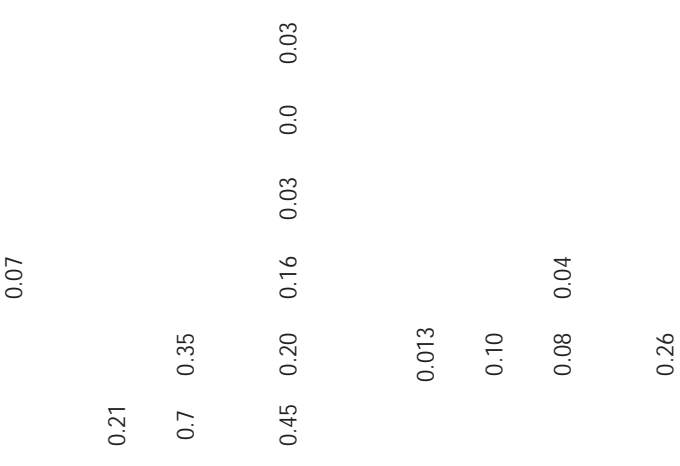

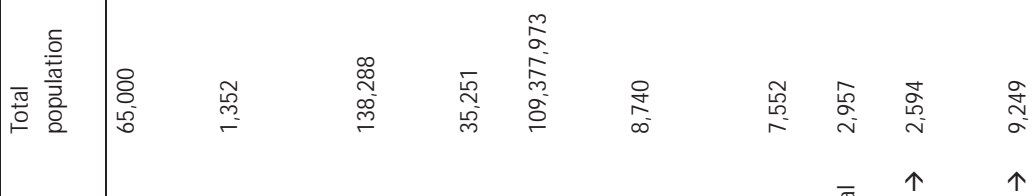

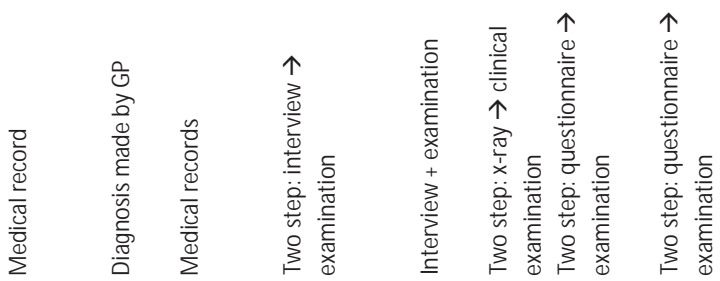

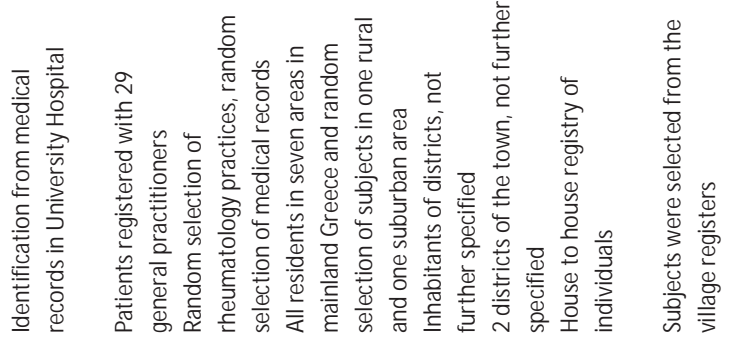

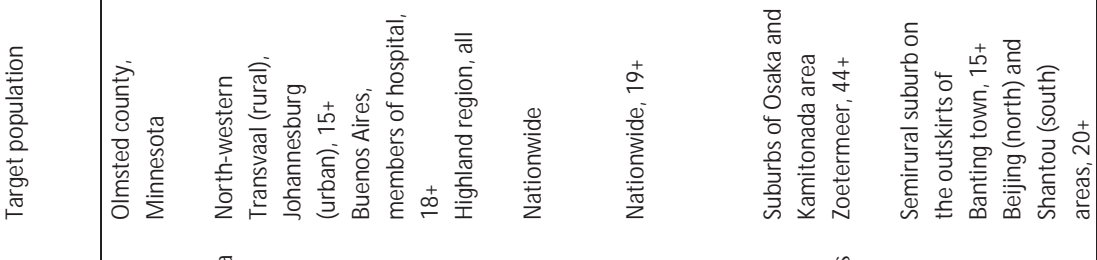

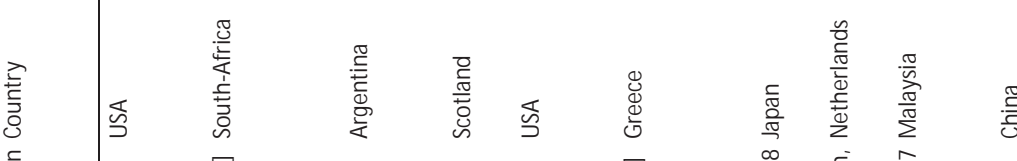

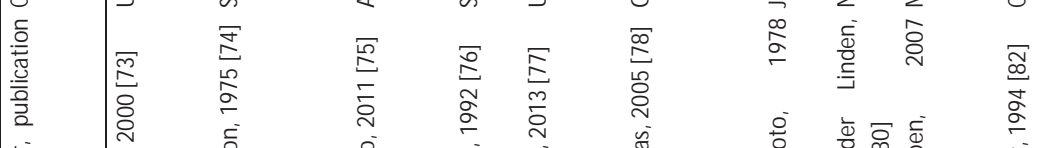

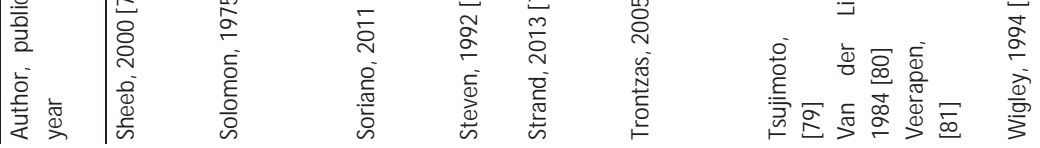


The global prevalence of spondyloarthritis | 61

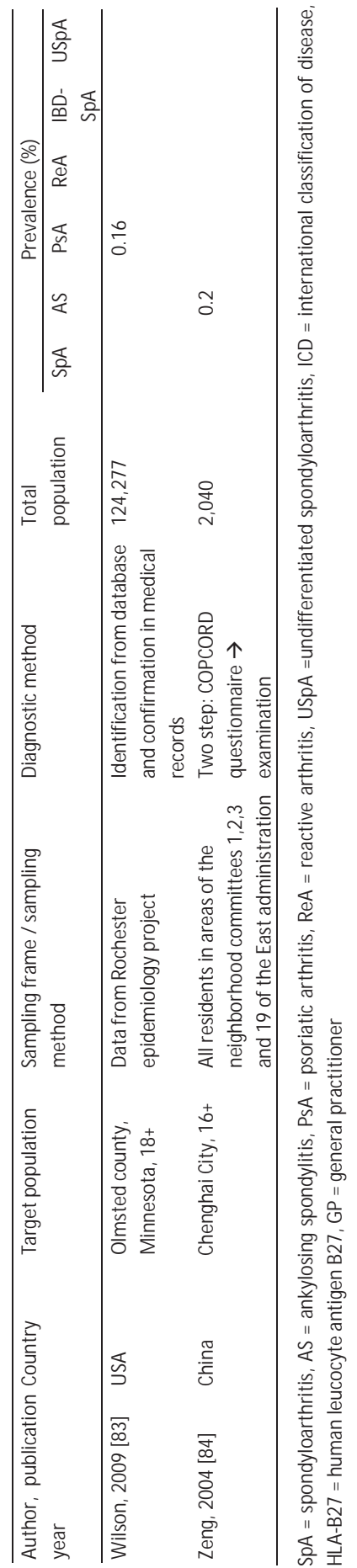




\section{REFERENCES}

1. Adomaviciute D, Pileckyte M, Baranauskaite A, et al. Prevalence survey of rheumatoid arthritis and spondyloarthropathy in Lithuania. Scand J Rheumatol 2008;37:113-9.

2. Alamanos Y, Papadopoulos NG, Voulgari PV, et al. Epidemiology of ankylosing spondylitis in Northwest Greece, 1983-2002. Rheumatology (Oxford) 2004;43:615-8.

3. Alamanos Y, Papadopoulos NG, Voulgari PV, et al. Epidemiology of psoriatic arthritis in northwest Greece, 1982-2001. J Rheumatol 2003;30:2641-4.

4. Al-Awadhi AM, Olusi SO, M oussa M, et al. Musculoskeletal pain, disability and health-seeking behavior in adult Kuwaitis using a validated Arabic version of the WHO-ILAR COPCORD Core Questionnaire. Clin Exp Rheumatol 2004;22:177-83.

5. Al-Rawi ZS, Al-Shakarchi HA, Hasan F, et al. Ankylosing spondylitis and its association with the histocompatibility antigen HL-A B27: an epidemiological and clinical study. Rheumatol Rehabil 1978;17:72-5.

6. Alvarez-Nemegyei J, Pelaez-Ballestas I, Sanin LH, et al. Prevalence of musculoskeletal pain and rheumatic diseases in the southeastern region of Mexico. A COPCORD-based community survey. J Rheumatol Suppl 2011;86:21-5.

7. Anagnostopoulos I, Zinzaras E, Alexiou I, et al. The prevalence of rheumatic diseases in central Greece: a population survey. BM C M usculoskelet Disord 2010;11:98.

8. Asgari MM, Wu JJ, Gelfand JM, et al. Validity of diagnostic codes and prevalence of psoriasis and psoriatic arthritis in a managed care population, 1996-2009. Pharmacoepidemiol Drug Saf 2013;22: 842-9.

9. Atkins C, Reuffel L, Roddy J, et al. Rheumatic disease in the Nuu-Chah-Nulth native Indians of the Pacific Northwest. J Rheumatol 1988;15:684-90.

10. Bakland G, Nossent HC, Gran JT. Incidence and prevalence of ankylosing spondylitis in Northern Norway. Arthritis Rheum 2005;53:850-5.

11. Barisic-Drusko V, Dobric I, Pasic A, et al. Frequency of psoriatic arthritis in general population and among the psoriatics in Department of Dermatology. Acta Derm Venereol Suppl (Stockh) 1994;186:107-8.

12. Bardin T, Enel C, Lathrop M, et al. Reiter's syndrome in Greenland. A clinical and epidermiological study of two communities. Scand J Rheumatol 1985;14:369-74.

13. Bardin T, Enel C, Lathrop MG. [Fiessinger-Leroy-Reiter syndrome in Greenland. Clinical and epidemiological aspects]. Rev Rhum Mal Osteoartic 1987;54:37-43.

14. Benevolenskaya LI, Boyer GS, Erdesz S, et al. Spondylarthropathic diseases in indigenous circumpolar populations of Russia and Alaska. Rev Rhum Engl Ed 1996;63:815-22.

15. Boyer GS, Lanier AP, Templin DW. Prevalence rates of spondyloarthropathies, rheumatoid arthritis, and other rheumatic disorders in an Alaskan Inupiat Eskimo population. J Rheumatol 1988;15:678-83.

16. Boyer GS, Lanier AP, Templin DW, et al. Spondyloarthropathy and rheumatoid arthritis in Alaskan Yupik Eskimos. J Rheumatol 1990;17:489-96.

17. Boyer GS, Templin DW, Cornoni-Huntley JC, et al. Prevalence of spondyloarthropathies in Alaskan Eskimos. J Rheumatol 1994;21:2292-7.

18. Boyer GS, Templin DW, Lanier AP. Rheumatic diseases in Alaskan Indians of the southeast coast: high prevalence of rheumatoid arthritis and systemic lupus erythematosus. J Rheumatol 1991;18:1477-84.

19. Braun J, Bollow M, Remlinger G, et al. Prevalence of spondylarthropathies in HLA-B27 positive and negative blood donors. Arthritis Rheum 1998;41:58-67.

20. Brown MA, Jepson A, Young A, et al. Ankylosing spondylitis in West Africans--evidence for a non-HLAB27 protective effect. Ann Rheum Dis 1997;56:68-70.

21. Cakir N, Pamuk ON, Dervis E, et al. The prevalences of some rheumatic diseases in western Turkey: Havsa study. Rheumatol Int 2012;32:895-908.

22. Cardiel MH, Rojas-Serrano J. Community based study to estimate prevalence, burden of illness and help seeking behavior in rheumatic diseases in Mexico City. A COPCORD study. Clin Exp Rheumatol 2002;20:617-24.

23. Carter ET, McKenna CH, Brian DD, et al. Epidemiology of Ankylosing spondylitis in Rochester, Minnesota, 1935-1973. Arthritis Rheum 1979;22:365-70. 
24. Chaaya M, Slim ZN, Habib RR, et al. High burden of rheumatic diseases in Lebanon: a COPCORD study. Int J Rheum Dis 2012;15:136-43.

25. Chaiamnuay P, Darmawan J, Muirden KD, et al. Epidemiology of rheumatic disease in rural Thailand: a WHO-ILAR COPCORD study. Community Oriented Programme for the Control of Rheumatic Disease. J Rheumatol 1998;25:1382-7.

26. Chou CT, Pei L, Chang DM, et al. Prevalence of rheumatic diseases in Taiwan: a population study of urban, suburban, rural differences. J Rheumatol 1994;21:302-6.

27. Costantino F, Talpin A, Said-Nahal R, et al. Prevalence of spondyloarthritis in reference to HLA-B27 in the French population: results of the GAZEL cohort. Ann Rheum Dis 2013.

28. Dai SM, Han XH, Zhao DB, et al. Prevalence of rheumatic symptoms, rheumatoid arthritis, ankylosing spondylitis, and gout in Shanghai, China: a COPCORD study. J Rheumatol 2003;30:2245-51.

29. Dans LF, Tankeh-Torres S, Amante CM, et al. The prevalence of rheumatic diseases in a Filipino urban population: a WHO-ILAR COPCORD Study. World Health Organization. International League of Associations for Rheumatology. Community Oriented Programme for the Control of the Rheumatic Diseases. J Rheumatol 1997;24:1814-9.

30. Davatchi F, Jamshidi AR, Banihashemi AT, et al. WHO-ILAR COPCORD Study (Stage 1, Urban Study) in Iran. J Rheumatol 2008;35:1384.

31. Davatchi F, Tehrani Banihashemi A, Gholami J, et al. The prevalence of musculoskeletal complaints in a rural area in Iran: a WHO-ILAR COPCORD study (stage 1, rural study) in Iran. Clin Rheumatol 2009;28:1267-74.

32. De Angelis R, Salaffi F, Grassi W. Prevalence of spondyloarthropathies in an Italian population sample: a regional community-based study. Scand J Rheumatol 2007;36:14-21.

33. Eaton WW, Pedersen M G, Atladottir HO, et al. The prevalence of 30 ICD-10 autoimmune diseases in Denmark. Immunologic Research 2010;47:228-31.

34. Faroogi A, Gibson T. Prevalence of the major rheumatic disorders in the adult population of north Pakistan. Br J Rheumatol 1998;37:491-5.

35. Geirsson AJ, Eyjolfsdottir H, Bjornsdottir G, et al. Prevalence and clinical characteristics of ankylosing spondylitis in Iceland - a nationwide study. Clin Exp Rheumatol 2010;28:333-40.

36. Gelfand JM, Gladman DD, M ease PJ, et al. Epidemiology of psoriatic arthritis in the population of the United States. J Am Acad Dermatol 2005;53:573.

37. Gomor B, Gyodi E, Bakos L. Distribution of HLA B27 and ankylosing spondylitis in the Hungarian population. J Rheumatol Suppl 1977;3:33-5.

38. Gran JT, Husby G, Hordvik M. Prevalence of ankylosing spondylitis in males and females in a young middle-aged population of Tromso, northern Norway. Ann Rheum Dis 1985;44:359-67.

39. Granados Y, Cedeno L, Rosillo C, et al. Prevalence of musculoskeletal disorders and rheumatic diseases in an urban community in Monagas State, Venezuela: a COPCORD study. Clin Rheumatol 2014.

40. Haglund $E$, Bremander $A B$, Petersson IF, et al. Prevalence of spondyloarthritis and its subtypes in southern Sweden. Ann Rheum Dis 2011;70:943-8.

41. Hanova P, Pavelka K, Holcatova I, et al. Incidence and prevalence of psoriatic arthritis, ankylosing spondylitis, and reactive arthritis in the first descriptive population-based study in the Czech Republic. Scand J Rheumatol 2010;39:310-7.

42. Haq SA, Darmawan J, Islam MN, et al. Prevalence of rheumatic diseases and associated outcomes in rural and urban communities in Bangladesh: a COPCORD study. J Rheumatol 2005;32:348-53.

43. Hoff M, Gulati AM, Romundstad PR, et al. Prevalence and incidence rates of psoriatic arthritis in central Norway: data from the Nord-Trondelag Health Study (HUNT). Ann Rheum Dis 2013.

44. Hukuda S, M inami M, Saito T, et al. Spondyloarthropathies in Japan: nationwide questionnaire survey performed by the Japan Ankylosing Spondylitis Society. J Rheumatol 2001;28:554-9.

45. Joshi VL, Chopra A. Is there an urban-rural divide? Population surveys of rheumatic musculoskeletal disorders in the Pune region of India using the COPCORD Bhigwan model. J Rheumatol 2009;36:614-22.

46. Kaipiainen-Seppanen 0 , Aho K, Heliovaara M. Incidence and prevalence of ankylosing spondylitis in Finland. J Rheumatol 1997;24:496-9.

47. Karkucak M, Cakirbay H, Capkin E, et al. The prevalence of ankylosing spondylitis in The Eastern Black Sea region of Turkey. [Turkish]Turkiye'de dogu Karadeniz Bolgesinde ankilozan spondilit (as) prevalansi \{dotless\}. European Journal of General M edicine 2011;8:40-5. 
48. Kassimos DG, Vassilakos J, Magiorkinis G, et al. Prevalence and clinical manifestations of ankylosing spondylitis in young Greek males. Clin Rheumatol 2014.

49. Koko V, Ndrepepa A, Skenderaj S, et al. An epidemiological study on ankylosing spondylitis in southern Albania. Mater Sociomed 2014;26:26-9.

50. Li R, Sun J, Ren LM, et al. Epidemiology of eight common rheumatic diseases in China: a large-scale cross-sectional survey in Beijing. Rheumatology (Oxford) 2012;51:721-9.

51. Liao ZT, Pan YF, Huang $J \mathrm{~L}$, et al. An epidemiological survey of low back pain and axial spondyloarthritis in a Chinese Han population. Scand J Rheumatol 2009;38:455-9.

52. Lofvendahl S, Theander E, Svensson A, et al. Validity of diagnostic codes and prevalence of physiciandiagnosed psoriasis and psoriatic arthritis in southern Sweden--a population-based register study. PLoS One 2014;9:e98024.

53. Love TJ, Gudbjornsson B, Gudjonsson JE, et al. Psoriatic arthritis in Reykjavik, Iceland: prevalence, demographics, and disease course. J Rheumatol 2007;34:2082-8.

54. Lutalo SK. Chronic inflammatory rheumatic diseases in black Zimbabweans. Ann Rheum Dis 1985;44:121-5.

55. Madland TM, Apalset EM, Johannessen AE, et al. Prevalence, disease manifestations, and treatment of psoriatic arthritis in Western Norway. J Rheumatol 2005;32:1918-22.

56. Mahajan A, Jasrotia DS. Prevalence of major rheumatic disorders in Jammu. JK Science 2003;5:63-6.

57. Minh Hoa TT, Darmawan J, Chen SL, et al. Prevalence of the rheumatic diseases in urban Vietnam: a WHO-ILAR COPCORD study. J Rheumatol 2003;30:2252-6.

58. Moghimi N, Davatchi F, Rahimi E, et al. WHO-ILAR COPCORD study (stage 1, urban study) in Sanandaj, Iran. Clin Rheumatol 2013.

59. Nossent JC, Gran JT. Epidemiological and clinical characteristics of psoriatic arthritis in northern Norway. Scand J Rheumatol 2009;38:251-5.

60. Oen K, Postl B, Chalmers IM, et al. Rheumatic diseases in an Inuit population. Arthritis Rheum 1986;29:65-74.

61. Ogdie A, Langan S, Love T, et al. Prevalence and treatment patterns of psoriatic arthritis in the UK. Rheumatology (Oxford) 2013;52:568-75.

62. Onen $\mathrm{F}$, Akar $\mathrm{S}$, Birlik $\mathrm{M}$, et al. Prevalence of ankylosing spondylitis and related spondyloarthritides in an urban area of Izmir, Turkey. J Rheumatol 2008;35:305-9.

63. Paul BJ, Rahim AA, Bina T, et al. Prevalence and factors related to rheumatic musculoskeletal disorders in rural south India: WHO-ILAR-COPCORD-BJD India Calicut study. Int J Rheum Dis 2013;16:392-7.

64. Pedersen $\mathrm{OB}$, Svendsen AJ, Ejstrup L, et al. The occurrence of psoriatic arthritis in Denmark. Ann Rheum Dis 2008;67:1422-6.

65. Pelaez-Ballestas I, Navarro-Zarza JE, Julian B, et al. A community-based study on the prevalence of spondyloarthritis and inflammatory back pain in Mexicans. J Clin Rheumatol 2013;19:57-61.

66. Pelaez-Ballestas I, Sanin LH, Moreno-Montoya J, et al. Epidemiology of the rheumatic diseases in Mexico. A study of 5 regions based on the COPCORD methodology. J Rheumatol Suppl 2011;86:3-8.

67. Reveille JD, Witter JP, Weisman M H. Prevalence of axial spondylarthritis in the United States: estimates from a cross-sectional survey. Arthritis Care Res (Hoboken) 2012;64:905-10.

68. Reyes-Llerena GA, Guibert-Toledano M, Penedo-Coello A, et al. Community-based study to estimate prevalence and burden of illness of rheumatic diseases in Cuba: a COPCORD study. J Clin Rheumatol 2009;15:51-5.

69. Rodriguez-Amado J, Pelaez-Ballestas I, Sanin $\mathbf{L H}$, et al. Epidemiology of rheumatic diseases. A community-based study in urban and rural populations in the state of Nuevo Leon, Mexico. J Rheumatol Suppl 2011;86:9-14.

70. Sandoughi M, Zakeri Z, Tehrani Banihashemi A, et al. Prevalence of musculoskeletal disorders in southeastern Iran: a WHO-ILAR COPCORD study (stage 1, urban study). Int J Rheum Dis 2013;16:50917.

71. Saraux A, Guedes C, Allain J, et al. Prevalence of rheumatoid arthritis and spondyloarthropathy in Brittany, France. Societe de Rhumatologie de l'Ouest. J Rheumatol 1999;26:2622-7.

72. Saraux A, Guillemin F, Guggenbuhl P, et al. Prevalence of spondyloarthropathies in France: 2001. Ann Rheum Dis 2005;64:1431-5.

73. Shbeeb M, Uramoto KM, Gibson LE, et al. The epidemiology of psoriatic arthritis in Olmsted County, Minnesota, USA, 1982-1991. J Rheumatol 2000;27:1247-50. 
74. Solomon L, Beighton P, Valkenburg HA, et al. Rheumatic disorders in the South African Negro. Part I. Rheumatoid arthritis and ankylosing spondylitis. S Afr M ed J 1975;49:1292-6.

75. Soriano ER, Rosa J, Velozo E, et al. Incidence and prevalence of psoriatic arthritis in Buenos Aires, Argentina: a 6-year health management organization-based study. Rheumatology (Oxford) 2011;50:729-34.

76. Steven M M. Prevalence of chronic arthritis in four geographical areas of the Scottish Highlands. Ann Rheum Dis 1992;51:186-94.

77. Strand V, Rao SA, Shillington AC, et al. Prevalence of axial spondyloarthritis in United States rheumatology practices: Assessment of SpondyloArthritis International Society criteria versus rheumatology expert clinical diagnosis. Arthritis Care Res (Hoboken) 2013;65:1299-306.

78. Trontzas P, Andrianakos A, Miyakis S, et al. Seronegative spondyloarthropathies in Greece: a population-based study of prevalence, clinical pattern, and management. The ESORDIG study. Clin Rheumatol 2005;24:583-9.

79. Tsujimoto M. Epidemiological research on the prevalence of ankylosing spondylitis. Med J Osaka Univ 1978;28:363-81.

80. Van Der Linden SM, Valkenburg HA, De Jongh BM, et al. The risk of developing ankylosing spondylitis in HLA-B27 positive individuals. A comparison of relatives of spondylitis patients with the general population. Arthritis and Rheumatism 1984;27:241-9.

81. Veerapen K, Wigley RD, Valkenburg H. Musculoskeletal pain in Malaysia: a COPCORD survey. J Rheumatol 2007;34:207-13.

82. Wigley RD, Zhang NZ, Zeng QY, et al. Rheumatic diseases in China: ILAR-China study comparing the prevalence of rheumatic symptoms in northern and southern rural populations. J Rheumatol 1994;21:1484-90.

83. Wilson FC, Icen M, Crowson CS, et al. Time trends in epidemiology and characteristics of psoriatic arthritis over 3 decades: a population-based study. J Rheumatol 2009;36:361-7.

84. Zeng QY, Chen R, Xiao ZY, et al. Low prevalence of knee and back pain in southeast China; the Shantou COPCORD study. J Rheumatol 2004;31:2439-43. 


\section{SUPPLEMENTARY FILE 5}

Results of risk of bias assessment

\begin{tabular}{|c|c|c|c|c|c|c|c|c|c|}
\hline Author, year & ROB-1* & ROB-2* & ROB-3* & ROB-4* & ROB-5* & ROB-6* & ROB-7* & ROB-8* & ROB-9* \\
\hline Adomaviciute, 2008 & High & High & Low & High & Low & Low & Low & Low & Low \\
\hline Alamanos, 2004 & High & High & Low & Low & High & Low & Low & Low & Low \\
\hline Alamanos, 2003 & High & High & Low & Low & High & Low & Low & Low & Low \\
\hline Al-awadhi, 2004 & High & Low & Low & Low & Low & High & Low & Low & Low \\
\hline Al-rawi, 1978 & Low & Low & Low & Low & Low & High & High & Low & Low \\
\hline Alvarez-Nemegyei,2011 & High & High & Low & Low & Low & High & Low & Low & Low \\
\hline Anagnostopoulos, 2010 & High & Low & Low & High & Low & Low & Low & Low & Low \\
\hline Asgari, 2013 & High & High & Low & Low & High & Low & Low & Low & Low \\
\hline Atkins, 1988 & High & High & Low & Low & Low & Low & Low & High & Low \\
\hline Bakland, 2005 & High & High & Low & Low & High & Low & Low & Low & Low \\
\hline Barisic-Drusko, 1994 & High & High & Low & High & Low & High & High & Low & Low \\
\hline Bardin, 1985 & High & High & Low & Low & Low & Low & Low & Low & Low \\
\hline Bardin, 1987 & High & High & Low & Low & Low & Low & Low & Low & Low \\
\hline Benevolenskaya (Russia), 1996 & High & Low & Low & Low & Low & Low & Low & Low & Low \\
\hline Benevolenskaya (Alaska), 1996 & High & High & Low & Low & High & Low & Low & Low & Low \\
\hline Boyer, 1988 & High & High & Low & Low & High & Low & Low & Low & Low \\
\hline Boyer , 1990 & High & High & Low & Low & Low & Low & Low & Low & Low \\
\hline Boyer, 1994 & High & High & Low & Low & Low & Low & Low & High & Low \\
\hline Boyer, 1991 & High & High & Low & Low & High & Low & Low & Low & Low \\
\hline Braun, 1998 & High & High & High & Low & Low & Low & Low & Low & High \\
\hline Brown, 1997 & High & High & High & High & Low & High & Low & High & Low \\
\hline Cakir, 2012 & High & Low & Low & Low & Low & Low & Low & Low & Low \\
\hline Carter, 1979 & High & High & Low & Low & High & Low & Low & Low & High \\
\hline Cardiel, 2002 & High & High & Low & High & Low & High & Low & Low & Low \\
\hline Chaaya, 2012 & Low & Low & Low & Low & Low & High & Low & Low & Low \\
\hline Chaiamnuay, 1998 & High & High & Low & Low & Low & Low & Low & Low & Low \\
\hline Chou, 1994 & High & Low & Low & Low & Low & Low & Low & Low & Low \\
\hline Constantino, 2013 & High & High & High & High & Low & Low & Low & Low & Low \\
\hline Dai, 2003 & High & High & Low & Low & Low & Low & Low & Low & Low \\
\hline Dans, 1997 & High & High & Low & Low & Low & High & Low & Low & Low \\
\hline Davatchi, 2008 & High & Low & Low & High & Low & Low & Low & Low & Low \\
\hline Davatchi, 2009 & High & High & Low & Low & Low & Low & Low & Low & Low \\
\hline De Angelis, 2007 & High & High & Low & High & Low & Low & High & Low & Low \\
\hline Eaton, 2010 & Low & High & Low & Low & High & Low & Low & Low & High \\
\hline Farooqi, 1998 & High & High & Low & Low & Low & Low & Low & Low & Low \\
\hline Geirsson, 2010 & Low & High & Low & Low & High & Low & Low & High & Low \\
\hline Gelfand, 2005 & High & High & Low & High & Low & High & High & Low & Low \\
\hline Gomor, 1977 & High & High & High & High & Low & Low & Low & Low & Low \\
\hline Gran, 1985 & High & Low & Low & Low & Low & Low & High & Low & Low \\
\hline Granados, 2014 & High & High & High & Low & Low & Low & Low & Low & Low \\
\hline Haglund, 2011 & High & High & Low & Low & High & Low & Low & Low & Low \\
\hline Hanova, 2010 & High & High & High & High & High & Low & Low & Low & Low \\
\hline Haq, 2005 & High & Low & Low & Low & Low & High & Low & Low & Low \\
\hline Hoff, 2013 & Low & Low & Low & High & Low & Low & Low & Low & Low \\
\hline
\end{tabular}




\begin{tabular}{|c|c|c|c|c|c|c|c|c|c|}
\hline Author, year & ROB-1* & ROB-2* & ROB-3* & ROB-4* & ROB-5* & ROB-6* & ROB-7* & ROB-8* & ROB-9* \\
\hline Hukuda, 2001 & High & High & Low & High & High & Low & Low & Low & High \\
\hline Joshi, 2009 & High & High & High & High & Low & High & Low & Low & Low \\
\hline Kaipiainen-Seppanen, 1997 & High & High & Low & Low & Low & Low & Low & Low & Low \\
\hline Karkucak, 2010 & High & High & Low & Low & Low & Low & High & Low & Low \\
\hline Kassimos, 2014 & High & High & Low & Low & High & Low & Low & Low & Low \\
\hline Koko, 2014 & High & High & Low & Low & High & Low & Low & Low & Low \\
\hline Li, 2011 & High & High & High & High & Low & Low & Low & Low & Low \\
\hline Liao, 2009 & High & Low & Low & Low & Low & Low & High & Low & Low \\
\hline Löfvendahl , 2014 & High & High & Low & Low & High & Low & Low & Low & Low \\
\hline Love, 2007 & High & High & Low & High & High & Low & Low & Low & Low \\
\hline Lutalo, 1985 & High & High & Low & Low & High & High & Low & Low & High \\
\hline M adland, 2005 & High & High & Low & Low & High & Low & Low & Low & Low \\
\hline Mahajan, 2003 & High & High & Low & High & Low & Low & Low & Low & Low \\
\hline M inh Hoa, 2003 & High & High & Low & High & Low & High & Low & Low & Low \\
\hline Moghimi, 2013 & High & High & Low & High & Low & High & Low & Low & Low \\
\hline Nossent, 2009 & High & High & Low & Low & High & Low & Low & Low & Low \\
\hline Oen, 1986 & High & High & Low & Low & High & Low & Low & Low & Low \\
\hline Ogdie, 2012 & Low & High & Low & Low & High & Low & Low & Low & Low \\
\hline Onen, 2008 & High & High & Low & Low & Low & Low & Low & Low & Low \\
\hline Paul, 2013 & High & High & Low & High & Low & High & Low & Low & High \\
\hline Pedersen, 2008 & High & Low & Low & Low & Low & Low & Low & Low & Low \\
\hline Pelaez-Ballestas, 2013 & High & High & Low & High & Low & Low & Low & Low & Low \\
\hline Pelaez-Ballestas, 2011 & High & High & Low & High & Low & Low & Low & Low & High \\
\hline Reveille, 2012 & Low & High & High & Low & Low & High & High & Low & Low \\
\hline Reyes-Llerena, 2009 & High & High & Low & High & Low & High & Low & Low & Low \\
\hline Rodriguez-Amado, 2011 & High & Low & Low & Low & Low & High & Low & Low & Low \\
\hline Sandoughi, 2013 & High & Low & Low & Low & Low & Low & Low & Low & High \\
\hline Saraux, 1999 & High & High & Low & Low & Low & Low & High & Low & Low \\
\hline Saraux, 2005 & High & High & Low & High & Low & Low & Low & Low & Low \\
\hline Sheeb, 2000 & High & High & Low & Low & High & Low & Low & Low & High \\
\hline Solomon, 1975 & High & High & Low & High & Low & High & High & Low & Low \\
\hline Soriano, 2011 & High & High & Low & Low & High & Low & Low & Low & Low \\
\hline Steven, 1992 & High & High & Low & High & Low & High & High & Low & High \\
\hline Strand, 2013 & High & High & High & High & High & Low & Low & Low & High \\
\hline Trontzas, 2005 & Low & Low & Low & Low & Low & Low & Low & Low & Low \\
\hline Tsujimoto, 1978 & High & Low & Low & Low & Low & High & High & Low & Low \\
\hline Van der Linden, 1984 & High & High & Low & High & Low & Low & Low & Low & Low \\
\hline Veerapen, 2007 & High & Low & Low & High & Low & High & Low & Low & Low \\
\hline Wigley, 1994 & High & High & Low & Low & Low & High & Low & Low & Low \\
\hline Wilson, 2009 & High & High & Low & Low & High & Low & Low & Low & Low \\
\hline Zeng, 2004 & High & High & Low & Low & Low & Low & Low & Low & Low \\
\hline
\end{tabular}

$*$ ROB $=$ Risk of bias.

ROB-1 $=$ Was the target population representative for the general population? ROB-2 $=$ Was the sampling frame a close representation of the target population? ROB- $3=$ Was some form of random selection used to select the sample? ROB-4 $=$ Was the likelihood of nonresponse bias minimal (participation $\geq 75 \%$ or nonresponder analysis) ROB- $5=$ Were data collected directly from the subjects? ROB- $6=$ Was an acceptable case definition used (i.e. validated classification criteria or a diagnosis by a health professional)? ROB-7 $=$ Was the study instrument reliable and valid? ROB- $8=$ Was the same mode of data collection used for all subjects? ROB- $9=$ Were the numerator and denominator for the parameter of interest appropriate? 


\section{SUPPLEMENTARY FILE 6}

Univariable and multivariable meta-regression analysis on the prevalence of ankylosing spondylitis

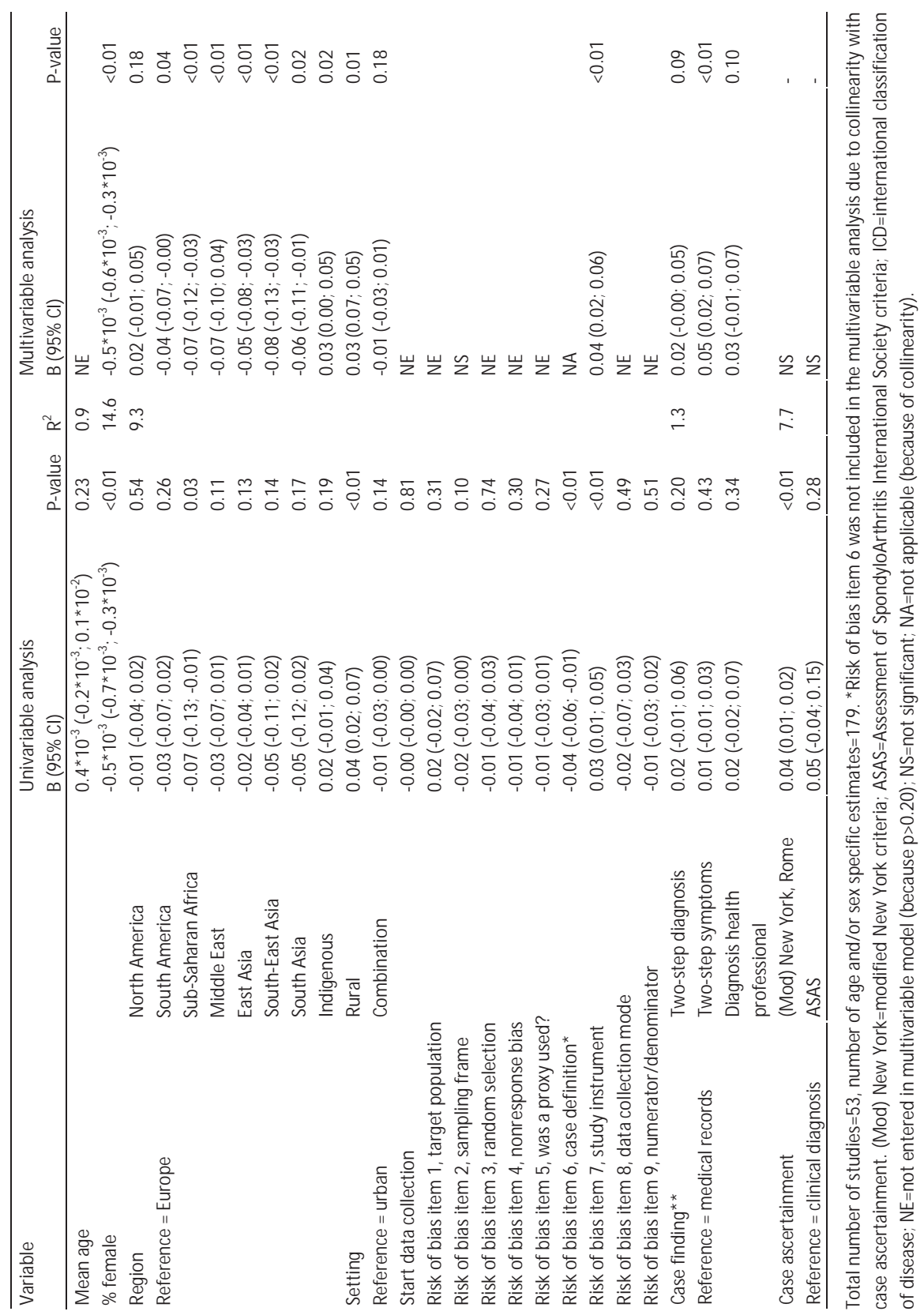




\section{SUPPLEM ENTARY FILE 7}

Univariable and multivariable meta-regression analysis on the prevalence of psoriatic arthritis

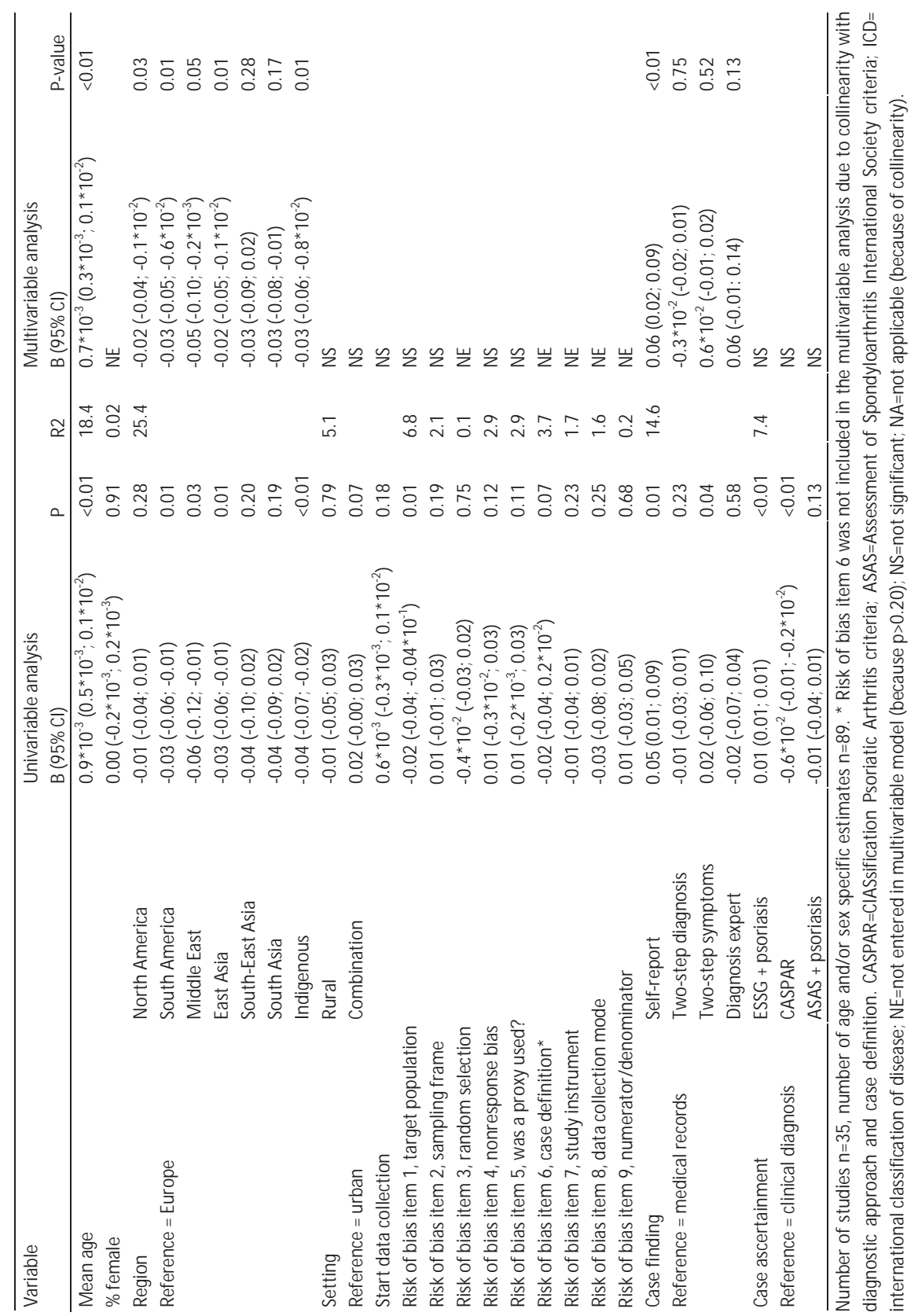





\section{PART II}

The use of MRI in detection of early axial spondyloarthritis 



\section{CHAPTER 3}

HLA-B27 and gender independently determine the likelihood of a positive M RI of the sacroiliac joints in patients with early inflammatory back pain: A twoyear M RI follow-up study

Marloes van Onna, Anne Grethe Jurik, Désirée van der Heijde, Astrid van Tubergen, Liesbeth Heuft-Dorenbosch, Robert Landewé 


\section{ABSTRACT}

\section{Objectives}

To describe how inflammation on MRI of the sacroiliac joints in patients with recentonset inflammatory back pain (IBP) evolves over time, and to study determinants of activity on M RI of the sacroiliac joint.

\section{Methods}

A 2-year follow-up study with annual MRI of the sacroiliac joints was conducted in patients with IBP of less than 2 years' duration. Images were scored for bone marrow edema on short $\tau$ inversion recovery and enhancement after administration of gadolinium on $\mathrm{T1}$.

\section{Results}

Of the 68 patients ( $38 \%$ male; mean age $34.9 \pm 10.3$ years) enrolled, 44 had a negative baseline MRI. Of these 44 patients, 39 patients had at least 1 follow-up M RI of whom 6 patients (15\%) developed activity on MRI during follow-up. Twenty-four patients (35\%) had an abnormal MRI at baseline. In 23 of these 24 patients follow-up MRI was available. The MRI became negative in 7 of these 23 patients (30\%) during follow-up. HLA-B27 positivity and male gender determined independently the likelihood of a positive MRI at any time point. In an HLA-B27 positive patient the likelihood of a positive MRI during follow-up is $88 \%$ if the baseline MRI is positive and $27 \%$ if the baseline MRI is negative. In an HLA-B27 negative patient with a negative MRI at baseline the likelihood of a positive MRI during follow up is less than $5 \%$.

\section{Conclusions}

A positive MRI at baseline predicts a positive M RI during follow-up in HLA-B27 positive patients. A negative MRI at baseline in HLA-B27 negative patients strongly predicts a negative M RI during follow-up. 


\section{INTRODUCTION}

The concept of spondyloarthritis (SPA) covers a family of seronegative rheumatic disorders that share distinct clinical and genetic characteristics. General symptoms include inflammatory back pain (IBP), peripheral arthritis, enthesitis, dactylitis and anterior uveitis. Ankylosing spondylitis (AS) is the prototype of SpA with predominant axial involvement.[1,2] Other subtypes of SpA are characterised by predominant peripheral involvement, such as psoriatic arthritis. To classify patients with SpA, several criteria sets are available. These are the European Spondyloarthropathy Study Group criteria (ESSG) and Amor criteria for SpA and the modified New York criteria specifically for AS.[3-5] Recently, a new criteria set for classifying axial SpA has been developed, mainly because available classification criteria were considered too insensitive, especially in early and mild disease.[6] Although not intended for this purpose, classification criteria are frequently used in daily practice. As a consequence, the diagnosis of AS is often delayed for 10 years, since according to modified New York criteria sacroiliitis should be demonstrated on a conventional radiograph, which is a relatively late feature of the disease.[7]

Magnetic resonance imaging (MRI) can play an important role in the non-radiographic stage of axial SpA. It has been shown that M RI can detect the early inflammatory stages of sacroilitis, months to years before structural damage can be detected on a conventional radiograph.[8]

Although activity (inflammation) detected on MRI is considered an important manifestation in early SpA, there is still uncertainty about how activity on M RI evolves over time. MRI follow-up studies in patients with a short duration of symptoms are limited. Oostveen et al. suggested that chronic changes on radiographs are preceded by inflammatory lesions on MRI.[8] More recently, Bennett et al. showed that both severe sacroiliitis on MRI at baseline as well as HLA-B27 positivity predict the development of abnormalities on radiographs 8 years later.[9] It is, however, unclear whether activity in the sacroiliac (SI) joints as seen on M RI is stable over time, becomes quiescent after an initial period of activity, or fluctuates over time. More knowledge about this is important with regard to the reliability of the new ASAS classification criteria in which activity on M RI is considered one of the entry criteria. Furthermore, it is extremely important for clinical practice to know if one single MRI is sufficient or that it is necessary to repeat the M RI in certain patients during the diagnostic process. 
The aim of the present paper is to describe the evolution of active changes on M RI of the $\mathrm{SI}$ joints in a group of patients presenting with inflammatory back pain (IBP) of short duration that were followed for 2 years with repeated M RIS.

\section{PATIENTS AND METHODS}

\section{Design and study population}

Patients with IBP of less than 2 years' duration were included in the Early SpondyloArthritis Cohort (ESPAC) study. The details of this study have been described previously.[10] In brief, IBP was defined according to the Calin criteria, and was considered present if 4 out of 5 of the following criteria were present: onset of back pain before the age of 40 years with a persistence of at least 3 months, insidious onset, association with morning stiffness and improvement with exercise.[11] Patients that fulfilled only 3 out of 5 of the Calin criteria but reported night pain, were also included in ESpAC. Presence of other common SpA features as defined in the ESSG criteria, such as a positive family history, anterior uveitis or a history of psoriasis or inflammatory bowel disease (IBD), was preferred but not mandatory.

The study was designed as a prospective cohort study that consisted of three identical clinical and radiological examination rounds performed at baseline and after 1 and 2 years. Data obtained at baseline have been published previously.[10,12-13]

The study was approved by the institutional review board and all patients have provided written informed consent.

\section{MRI}

M RI of the SI joints was obtained with a 1.5 Tesla Philips Gyro Scan ACS-NT (Philips, The Netherlands). Patients were examined in a supine position with their knees bent. The following sequences were used in an oblique coronal orientation: T1-weighted spin echo (SE), short $\tau$ inversion recovery (STIR), T2 weighted fast SE with fat saturation and T1-weighted SE with fat suppression (FS) after administration of the intravenous contrast agent gadolinium diethylenetriaminepentate (Gd-DTPA, $0.1 \mathrm{mmol} / \mathrm{kg}$ body weight). The slice thickness was $4 \mathrm{~mm}$ with intervals of $0.4 \mathrm{~mm}$. The matrix was 512 for the T1 FS post Gd-DTPA sequence and 256 for the remaining sequences. The M RIs of each patient were scored as one set with random time sequence, by one experienced radiologist (AGJ), who was blinded to clinical, laboratory and radiographic results. 
The MR images were scored using a combination of the Spondyloarthritis research Consortium of Canada (SPARCC) method and a modified version of the Aarhus MRI scoring method.[14,15] The SI joints were divided into four quadrants: upper iliac, lower iliac, upper sacral and lower sacral. In contrast to the original SPARCC system, there was no maximum to the number of evaluated slices, in order to maximise the detection of abnormal MR findings. The total number of evaluated slices in individual patients remained stable. Inflammation in the cartilagenous part of the joint was scored per slice in a dichotomous manner (present vs. absent). Both subchondral bone marrow edema and enhancement after administration of Gd-DTPA were scored. Bone marrow edema was defined as areas of increased signal intensity on STIR images compared with normal bone marrow. Its presence was estimated in each of the four quadrants. Lesions extending at least $1 \mathrm{~cm}$ from the joint space or demonstrating high signal intensity comparable to that of spinal fluid, were given an additional score on a per joint and per slice basis.

Subchondral enhancement was defined as areas of increased signal intensity compared with normal bone marrow on post Gd-DTPA images. Scoring was comparable to scoring edema, including additional scores for depth and high signal intensity comparable to enhanced vessels, respectively.

An MRI was considered positive for active sacroiliitis according to the ASAS/Outcome Measures in Rheumatoid Arthritis Clinical Trials (OMERACT) MRI working group definition: the presence of at least one active lesion in at least two successive slices or the presence of more than one lesion in only one slice which is highly suggestive of sacroiliitis.[16]

\section{Statistical analysis}

The MRI scores were analyzed and described in three different manners. First, we described the M RI status over time (positive or negative). Second, we have investigated the likelihood of having a positive MRI at any time during follow-up, as well as factors determining MRI-positivity, making use of generalized estimating equation (GEE) analysis for binomial outcome variables, with MRI status as dependent variable, and HLA-B27 status and gender as independent explanatory variables. The contribution of C-reactive protein (CRP) in explaining a positive M RI was tested by adding CRP in the model as a covariate. GEE is an appropriate technique to study time trends in data sets with missing values while adjusting for within-patient correlation. Thirdly, we have investigated the likelihood of finding a positive MRI if the baseline MRI is either negative or positive. 
SPSS software version 15.0 was used for all descriptive statistics and the GEE analysis. All $P$ values were two-tailed and statistical significance was set at the 0.05 level.

\section{RESULTS}

\section{Patient characteristics}

In total, 68 patients with IBP were included in this study. Baseline characteristics are shown in Table 3.1. Details of these patients have been described previously.[10] Ninety-seven percent of all patients fulfilled at least four out of five Calin criteria. Almost half of the patients was HLA-B27 positive. Anterior uveitis and IBD were reported in 10 (15\%) patients each, and 16 (24\%) patients had a history of psoriasis. Twenty-five patients had a positive family history for AS. Table 3.1 also provides information about the 44 patients that completed the 2-year follow-up. These patients did not differ from the complete group at baseline.

Table 3.1 Baseline characteristics of 68 patients included in the ESpAC study.

\begin{tabular}{lcc}
\hline Characteristic & All patients & $\begin{array}{c}\text { Patients with complete } \\
\text { follow-up examinations } \\
(n=44)\end{array}$ \\
\hline Male gender & $(n=68)$ & $15(34)$ \\
Mean age (years) (SD) & $26(38)$ & $36.0(11.7)$ \\
Median symptom duration (months) [IQR] & $34.9(10.3)$ & $18[12-24]$ \\
HLA-B27 positive & $18[12-24]$ & $17(39)$ \\
History of inflammatory bowel disease & $31(46)$ & $7(16)$ \\
History of anterior uveitis & $10(15)$ & $8(18)$ \\
History of psoriasis & $10(15)$ & $12(27)$ \\
History of peripheral arthritis & $16(24)$ & $12(27)$ \\
Positive family history of AS & $19(28)$ & $17(39)$ \\
CRP (in mg/l) (mean (median)) & $25(37)$ & $9(7)$ \\
ESR (in mm) (mean (median)) & $9(7)$ & $13(6)$ \\
Patients with elevated acute phase reactants (in \%) & $13(6)$ & 37 \\
\hline
\end{tabular}

The values are expressed as number (percentage) of patients or as stated otherwise. ESpAC=Early Spondyloarthritis Clinic; $\mathrm{AS}=$ =ankylosing spondylitis; IQR=interquartile range; $\mathrm{SD}=$ standard deviation; $\mathrm{CRP}=$ C-reactive protein; ESR=erythrocyte sedimentation rate.

\section{MRI findings}

$\mathrm{MRI}$ of the SI joints was performed in all patients at baseline. Sixty-two patients had at least one follow-up MRI after 1 or 2 years follow-up and 44 patients completed all 
3 examinations. Table 3.2 shows the MRI status (positive or negative) at baseline according to the ASAS/OMERACT MRI working group definition as well as how these findings develop over time.

In total, 44 patients (65\%) had a negative M RI at baseline, of which 15 patients (34\%) were HLA-B27 positive. Of these 44 patients, 39 (89\%) completed either one or two follow-up MRIs. In six of these 39 patients (15\%), the MRI became positive at 1 or 2 years follow-up. In one HLA-B27 positive patient of these six patients the M RI remained positive at 2 years follow-up, in one HLA-B27 negative patient the MRI became negative again at 2 years follow up, in two HLA-B27 negative patients the MRI became positive at 2 years follow-up, and in 2 HLA-B27 positive patients no M RIs were available at 2 years follow up.

Table 3.2 MRI status over time according to the ASAS/OM ERACT MRI working group definition in 68 patients with early inflammatory low back pain who were included in the Early SpondyloArthritis Cohort (ESpAC).

\begin{tabular}{lcccc}
\hline Number of patients & \multicolumn{3}{c}{ MRI availability } & HLA-B27 + \\
\cline { 2 - 4 } & Baseline & 1 -year & 2-years & \\
\hline 9 & + & + & + & 8 \\
5 & + & + & NA & 4 \\
2 & + & - & + & 2 \\
1 & + & + & - & 0 \\
2 & + & - & - & 0 \\
2 & + & NA & + & 1 \\
2 & + & NA & - & 0 \\
1 & + & NA & NA & 1 \\
26 & - & - & - & 6 \\
2 & - & - & + & 0 \\
7 & - & - & NA & 3 \\
1 & - & + & + & 1 \\
1 & - & + & - & 0 \\
2 & - & + & NA & 2 \\
5 & - & NA & NA & 3 \\
\hline
\end{tabular}

$+=$ positive MRI; -=negative MRI, ASAS=Assessment of SpondyloArthritis international Society; ESpAC=Early Spondyloarthritis Cohort; HLA-B27=human leukocyte antigen B27; NA=not available; OM ERACT=Outcome Measures in Rheumatoid Arthritis Clinical Trials.

Twenty-four patients (35\%) had a positive M RI at baseline, of which 16 (66\%) patients were HLA-B27 positive. In total 23 of these 24 patients completed either one or two follow-up MRIs. The MRI became negative in seven of these 23 patients (30\%) during follow-up at one or at both assessments. Five of these seven patients were HLA-B27 negative and in three of them the MRI was only weakly positive at baseline. In the 
remaining two patients a strongly positive MRI was detected at baseline, but the MRI became negative during follow-up. In two HLA-B27 positive patients with a negative $\mathrm{MRI}$ at 1 year follow up, the M RI was positive again at 2 years follow-up.

\section{Factors determining a positive MRI}

In the GEE analysis, both male gender (odds ratio (OR) 3.0 (95\% confidence interval $(\mathrm{Cl}) ; 1.1-8.2), \mathrm{p}=0.035)$ and HLA-B27 positivity (OR 5.1 (95\% Cl 1.9-13.6), $\mathrm{p} \measuredangle 0.001$ ) independently determined the likelihood of a positive MRI at any time point. CRP did not contribute to explaining variation in the model. The effects of these determinants are visualised in an absolute manner in Figure 3.1, showing that the likelihood of a positive MRI in HLA-B27-negative females with IBP is only about $10 \%$ as compared to HLA-B27 positive males with IBP in whom this likelihood is close to $70 \%$.

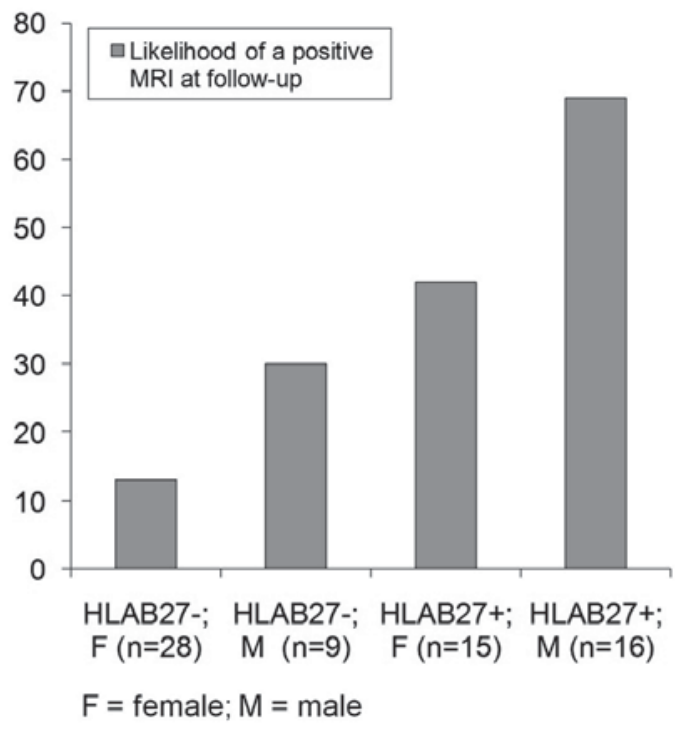

Figure 3.1 Likelihood of a positive MRI at any time point in patients with short-standing inflammatory back pain assessed at baseline, 1-year and 2-years of follow-up in function of HLA-B27 status and gender. HLA-B27, human leukocyte antigen B27.

\section{Likelihood of a positive MRI during follow-up}

The likelihood of finding a positive MRI if the baseline MRI is either negative or positive was also investigated. Both HLA-B27 status (OR 8.1 (95\% Cl 2.3-28.3), $\mathrm{p} \varangle .001$ ) and M RI status at baseline (OR $22.0(95 \% \mathrm{Cl} 6.1-79.6), \mathrm{p} \varangle 0.001)$ appeared to be strongly and independently contributory to a positive MRI of the SI joints over time. Figure 3.2 
shows the likelihood of a positive MRI in relation to HLA-B27 status. The likelihood of a positive M RI is negligible $(\measuredangle 5 \%)$ in case of an HLA-B27 negative patient with a negative MRI at baseline. The likelihood is close to $90 \%$ in case of an HLA-B27 positive patient with a positive MRI at baseline. The likelihood is intermediate in patients with either HLA-B27 positivity but a negative MRI at baseline (27\%) or a positive M RI but negative HLA-B27 status at baseline (49\%).

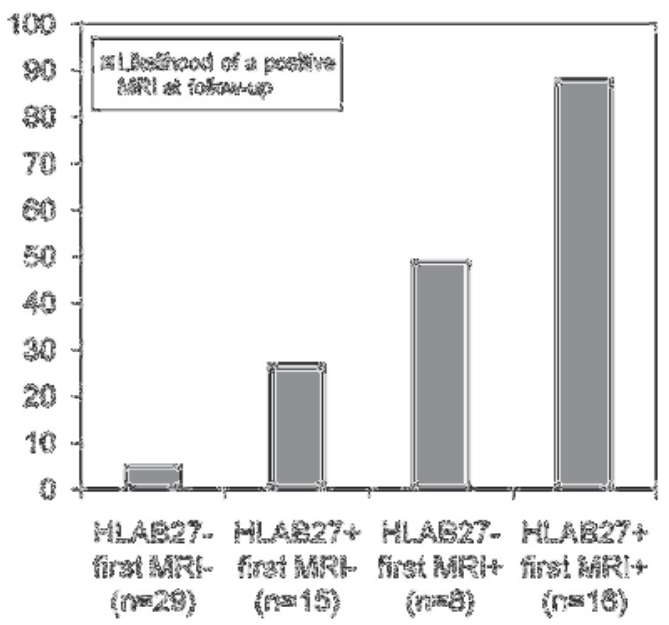

Figure 3.2 Likelihood of a positive MRI at 1- or 2-years of follow-up in patients with short-standing inflammatory back pain assessed at baseline, 1-year and 2-years of follow-up, in function of the result of the baseline MRI (negative or positive) and HLA-B27 status. HLA-B27, human leukocyte antigen B27.

\section{DISCUSSION}

In this cohort of patients with early IBP, almost two-thirds of the patients had a negative MRI at baseline. Interestingly, in only a minority of these patients (15\%), the M RI status changed during follow-up. A negative MRI at baseline in combination with a negative HLA-B27 status had a likelihood of $95 \%$ of finding a negative M RI in the next 2 years. This finding may be of clinical relevance, since it suggests that in HLA-B27 negative patients with a negative MRI sacroiliitis can be excluded with a high level of certainty.

A similar conclusion can be drawn from the group of patients with a positive MRI. One can conclude that if sacroiliitis is detected by MRI, there is a high likelihood that sacroiliitis remains present in HLA-B27 positive patients (88\%). This finding therefore 
adds to the credibility of M RI as a pivotal measure in the axial SpA criteria. It is of note that there was no use of biologicals in this cohort of patients with early IBP during this 2 year period.

In general, both male gender and HLA-B27 positivity independently determined the likelihood of a positive MRI at any time point. This is not surprising, since SpA and in particular AS is strongly associated with HLA-B27 and has an overall male predominance. In this study it was found that HLA-B27 positive male patients with IBP have the highest chance of a positive M RI at any time.

It is now well recognised that $\mathrm{MRI}$ is superior to conventional radiography in diagnosing early SpA. However, insight in the evolution in MRI findings in patients with early SpA and sacroiliitis is limited, since follow-up studies are scarce. To our knowledge, this is the first study in patients with early IBP with three successive MRI examinations spanning 2 years of follow-up. Puhakka et al. performed a 1-year follow-up study to describe changes in MRI findings of the $\mathrm{SI}$ joints in 34 patients with SpA of recent onset.[17] In this study, 30 out of 34 patients already had signs of inflammation on their M RI at baseline, which is a higher proportion than in our cohort. Results from this study showed that the general MRI activity score did not change at 1 year; however, bone marrow edema decreased significantly during follow-up.

The MRI scoring method used in the present study is a combination of the published SPARCC and the Aarhus grading methods.[14, 15] Both systems have proven to be reliable and reproducible. With the SPARCC scoring method, a maximum of six consecutive slices are evaluated. Instead, we chose to score the entire SI joint on all qualitatively optimal slices. This was done to maximise the detection of active lesions. In practice, it implied that in the majority of patients between 5 and 8 slices were evaluated, while taking care that the same (number of) slices were scored per patient over time. The scoring of active lesions was done dichotomously as by the SPARCC method. Due to the unlimited number of slices evaluated, the present scoring method demands M R scans of the same anatomical area of each patient examined at follow-up to secure that scoring starts and ends at the same anatomic level. This may cause some limitation of the method if the technique for obtaining oblique coronal slices is not standardized. With a scoring based on both oblique coronal and axial slices this problem does not exist as the SI joints then can be evaluated three-dimensionally.[18] The present study has several limitations that need to be acknowledged. Although we had M Rls of all patients at baseline, a substantial number of MRls was missing at one or at both follow-up visits. Missing data may have influenced the results, since it is possible that patients with missing MRIs represent a proportion of patients in whom 
the symptoms that made them eligible for inclusion in the ESpAC study have disappeared. Although such a bias cannot be excluded, GEE adjusts to some extent for such spurious effects, by adjusting for within-patient correlation and not excluding patients with missing time points. Another limitation of this study is that the MRI sets were scored by one reader. However, the scoring system used in the present study uses a combination of scoring systems that already have proven to be reliable with respect to inter-reader agreement.[19] A general issue regarding assessment of M RIs of the $\mathrm{SI}$ joints, is that in a previous study in up to $30 \%$ of the $\mathrm{SI}$ joints of individuals with chronic low back pain or healthy controls abnormalities were detected [20] Such lesions may have contributed to some extent to the results we have found, but it is likely that these abnormalities will disappear in non-inflammatory conditions over time in contrast to male patients with IBP that are HLA-B27 positive. At last, the ESpAC cohort in which the analyses were performed is a rather small cohort with characteristics that do not necessarily resemble the average patient presenting with complaints suggestive of SpA. Extrapolation of findings should therefore be done cautiously.

In conclusion, MRI is a very useful imaging technique in establishing inflammation in the $\mathrm{SI}$ joints and may contribute to making a diagnosis of axial SpA in patients with IBP. In this cohort of patients with IBP of recent-onset, it seems that during a 2-year followup period, the proportion of patients with and without signs of MRI activity remains stable to a great extent. This is an important finding, since it suggests that in case of both a negative MRI and a negative HLA-B27 status, a classifying diagnosis of axial SpA can be excluded with great certainty. In this cohort we found that the combination of a positive MRI scan and HLA-B27 positivity is associated with a high likelihood of a persistent positive MRI during follow-up. In HLA-B27 positive patients with a negative $\mathrm{MRI}$ at baseline, in whom a classifying diagnosis of axial SpA cannot be made by the route of HLA-B27 presence plus two additional SpA features, a follow-up MRI can be considered since a reasonable proportion of these patients will develop MRI activity over time, especially in male patients. 


\section{REFERENCES}

1. Song IH, Sieper J, Rudwaleit M. Diagnosing early ankylosing spondylitis. Curr Rheumatol Rep 2007; 9:367-74.

2. Rudwaleit M. New approaches to diagnosis and classification of axial and peripheral spondyloarthritis. Curr Opin Rheumatol 2010;22:375-80.

3. Dougados $M$, van der Linden $S$, Juhlin $R$, et al. The European spondyloarthropathy study group preliminary criteria for the classification of spondyloarthropathy. Arthritis Rheum 1991;34:1218-27.

4. Amor B, Dougados M, Mijiyawa M. Criteria for the classification of spondyloarthropathies (French). Rev Rhum Mal Osteoartic 1990;57:85-9.

5. Van der Linden S, Valkenburg HA, Cats A. Evaluation of diagnostic criteria for ankylosing spondylitis. A proposal for modification of the New York Criteria. Arthritis Rheum 1984;27:361-8.

6. Rudwaleit M, Van der Heijde D, Landewé R, et al. The development of Assessment of Spondyloarthritis international society classification criteria for axial spondyloarthritis (part II): validation and final selection. Ann Rheum Dis 2009;68:777-83.

7. Feldtkeller E, Khan MA, van der Heijde D, et al. Age at onset and diagnosis delay in HLA-B27 negative vs positive patients with ankylosing spondylitis. Rheumatol Int 2003;23:61-6.

8. Oostveen J, Prevo R, Den Boer J, et al. Early detection of sacroiliitis on magnetic resonance imaging and subsequent development of sacroiliitis on plain radiograpghy. A prospective, longitudinal study. J Rheumatol 1999;26:1953-8.

9. Bennett AN, M CGonagle $D, O^{\prime}$ Connor $P$, et al. Severity of baseline magnetic resonance imaging-evident sacroiliitis and HLA-B27 status in early inflammatory back pain predict radiographically evident ankylosing spondylitis at eight years. Arthritis Rheum 2008;58:3413-18.

10. Heuft-Dorenbosch LH, Landewé R, Weijers R, et al. Performance of various criteria sets in patients with inflammatory back pain of short duration; the Maastricht early spondyloarthritis clinic. Ann Rheum Dis 2007;66:92-8.

11. Calin A, Porta J, Fries JF, et al. Clinical history as a screening test for ankylosing spondylitis. JAMA 1977;237:2613-4.

12. Heuft-Dorenbosch $L H$, Landewé $R$, Weijers $R$, et al. Combining information obtained from magnetic resonance imaging and conventional radiographs to detect sacroiliitis in patients with recent onset inflammatory back pain. Ann Rheum Dis 2006;65:804-8.

13. Heuft-Dorenbosch $L$, Weijers $R$, Landewé $R$, et al. Magnetic resonance imaging changes of sacroiliac joints in patients with recent-onset inflammatory back pain. Arthritis Res Ther 2006;8:R11.

14. Maksymowych WP, Inman RD, Salonen D, et al. Spondyloarthritis research consortium of Canada magnetic resonance imaging index for assessment of sacroiliac joint inflammation in ankylosing spondylitis. Arthritis Rheum 2005;53:703-9.

15. Puhakka KB, Jurik AG, Egund N, et al. Imaging of sacroiliitis in early seronegative spondyloarthropathy. Assessment of abnormalities by MR in comparison with radiography and CT. Acta Radiol 2003;44: 218-29.

16. Rudwaleit $M$, Jurik AG, Hermann K-G A, et al. Defining active sacroiliitis on magnetic resonance imaging (MRI) for classification of axial spondyloarthritis: a consensual approach by the ASAS/OM ERACT MRI group. Ann Rheum Dis 2009;68:1520-7.

17. Puhakka KB, Jurik AG, Schiottz-Christensen B, et al. MRI abnormalities of sacroiliac joints in early spondyloarthropathy: a 1-year follow-up study. Scan J Rheumatol 2004;33:332-338.

18. Madsen KB, Jurik AG. Magnetic resonance imaging grading system for active and chronic spondylarthritis changes in the sacroiliac joint. Arthritis Care Res 2010;62:11-8.

19. Landewé RB, Hermann KG, van der Heijde DM. Scoring sacroiliac joints by magnetic resonance imaging. A multiple-reader reliability experiment. J Rheumatol. 2005;32:2050-5.

20. Weber $U$, Lambert RGW, Ostergaard M, et al. The diagnostic utility of MRI in spondyloarthritis: An international multicentre evaluation of one hundred and eighty-seven subjects. Arthritis Rheum 2010;62:3048-3058. 


\section{CHAPTER 4}

Bone marrow edema on M RI of the sacroiliac joints is associated with development of fatty lesions on M RI over a 1-year interval in patients with early inflammatory low back pain: a 2-year follow-up study

Marloes van Onna, Astrid van Tubergen, Désirée van der Heijde, Anne Grethe Jurik,

Robert Landewé 


\section{ABSTRACT}

\section{Objective}

To assess whether bone marrow edema (BM E) detected on M RI of the sacroiliac joints (M RI-SIJ) is associated with development of structural changes on both M RI and pelvic radiographs in patients with early inflammatory back pain (IBP).

\section{Methods}

Patients with IBP $\leq 2$ years were followed for 2 years with annual M RI-SIJ. MRIs were scored for BME and structural changes (erosions and fatty lesions). Pelvic radiographs were graded according to the modified New York (mNY) criteria. With generalized estimated equation analysis, a time trend in the structural change scores was investigated.

\section{Results}

Sixty-eight patients (38\% male; mean (SD) age 34.9 (10.3) years) were included. During the 2-year follow-up, pelvic radiograph grading remained constant. On $\mathrm{MRI}$, the number of erosions per patient increased significantly (mean score 2.5 at baseline and 3.5 at 2 -years follow-up; $p=0.05$ ). A trend was found for an increase in the number of fatty lesions per patient (mean score 5.4 at baseline and 8.5 at 2-years follow-up; $\mathrm{p}=0.06$ ). Overall, BME was associated with the development of fatty lesions (right SIJ: odds-ratio (OR) 3.13, 95\% confidence interval (CI) 1.06-9.20; left SI): OR 22.13, 95\%-CI 1.27-384.50), preferentially in quadrants showing resolution of BME. In contrast, BME (or the resolution thereof) was not associated with the development of erosions.

\section{Conclusion}

BME at baseline, especially when it disappears over time, results in the development of fatty lesions, but an association with erosions could not be demonstrated. 


\section{INTRODUCTION}

MRI of the sacroiliac joints (M RI-SIJ) and pelvic radiographs play an important role in the diagnosis and classification of axial spondyloarthritis (axSpA). Both imaging techniques are included in the "imaging arm" of the Assessment in SpondyloArthritis international Society (ASAS) criteria for axSpA.[1] MRI-SIJ has especially proven to be useful in the early stage of axSpA, because M RI may detect sacroilitis years before it is seen on a pelvic radiograph. Moreover, MRI can detect both active lesions and structural changes, in contrast to pelvic radiographs which only detect structural changes.[2] Patients without radiographic sacroiliitis, but with active lesions on MRI suggestive for sacroiliitis, are labelled non-radiographic axSpA (nr-axSpA).[1]

Active (inflammatory) lesions that can be detected on MRI are bone marrow edema (BME), capsulitis, synovitis and enthesitis. Structural changes on MRI are erosions, fat deposition (fatty lesions), sclerosis and ankylosis.[1,3] To date, only BME is considered mandatory for fulfilment of the ASAS/Outcome Measures in Rheumatoid Arthritis Clinical Trials (OMERACT) working group definition of a positive MRI.[2] However, Weber et al. suggested that also the detection of erosions on M RI-SIJ may be helpful in making a diagnosis in early axSpA.[3] There is, however, limited knowledge about the development of structural changes as detected on MRI-SIJ in patients with early IBP who may possibly have or develop axSpA. Furthermore, data on the association between BME and development of structural changes are scarce. Only one study suggested that fatty lesions on MRI-SIJ may be the first sign of structural damage after previous active inflammation.[4]

The aims of this study were to assess the presence 1) of structural changes on both M RI-SIJ and pelvic radiographs and 2) whether BME detected on M RI-SIJ is associated with the development of structural changes on both M RI-SIJ and pelvic radiographs in patients with recent onset IBP over a 2 year follow-up period.

\section{PATIENTS AND METHODS}

\section{Study population}

Patients with IBP of less than 2 years duration were enrolled in the Early SpondyloArthritis Clinic (ESPAC) study. In this prospective inception cohort study, three identical clinical and radiological examinations were performed at baseline and after 1 and 2 years. A more detailed description of the study population and inclusion can be 
found in previous reports.[5-7] The Calin criteria were used to define the presence of IBP. Patients had to fulfil at least 4 of the criteria: onset before the age of 40 years, duration of back pain more than 3 months, insidious onset, morning stiffness, and improvement with exercise.[8] Patients who fulfilled only 3 out of 5 of Calin criteria, but reported night pain were also included. Presence of other SpA features was preferred but not obligatory. Patients were not treated with biological therapy during the entire study period, the use of non-steroidal anti-inflammatory drugs (NSAIDs) was allowed. The study was approved by the ethics committee from the Maastricht University M edical Center. All patients gave written informed consent.

\section{MRI protocol}

MRI-SIJ was performed using a 1.5 Tesla Philips Gyro scan ACS-NT (Philips, The Netherlands). Patients were placed in supine position in a spine surface coil. The following sequences were used in an oblique coronal plane: T1-weighted spin echo (SE), short tau inversion recovery (STIR) and T2-weighted fast SE with fat saturation. The MRI set of each individual was scored independently and in a random time order by 1 experienced radiologist (AGJ), without knowledge of clinical or laboratory findings. The SIJs were scored using a combination of the Spondyloarthritis Research Consortium of Canada (SPARCC) method and a modified version of the Aarhus M RI scoring system. $[9,10]$ In contrast to the original SPARCC system, there was no maximum to the number of evaluated slices, but the number of slices within a patient was kept the same for all time points. First, each SIJ was divided into 4 quadrants (upper/lower sacral and upper/lower iliac quadrant) and both BME and structural changes were scored separately per slice in a dichotomous manner (absent vs. present). Second, a total count of both BME and structural changes per SIJ was performed. The method for scoring BME has been published.[11] The structural changes scores included scoring of both erosions and fatty deposition of the bone marrow (fatty lesions). Erosions, defined as cortical defects of the SIJ lining, are detected as hypointense signal on the T1 sequence. Subcortical fatty lesions, defined as replacement of normal bone marrow by fatty tissue, are detected as an increased signal on the T1 sequence. According to the ASAS/OM ERACT working group definition for active lesions on MRI-SIJ, an MRI-SIJ is considered positive for active sacroilitis when at least 1 active lesion is present in at least 2 successive slices or when $\geq 2$ lesions are detected in 1 slice.[2] Analogous to the ASAS/OM ERACT working group definition for active lesions on MRI-SIJ, we defined an MRI-SIJ as positive for structural changes 
when at least 1 erosion or fatty lesion is present in at least 2 successive slices or when $\geq 2$ erosions or fatty lesions are detected in 1 slice.

\section{Pelvic radiographs}

Antero-posterior pelvic radiographs of the SIJ were obtained and independently scored in a random time order by 2 readers (AT and RL) who were blinded to clinical and laboratory findings and were not involved in the M RI reading. In case of disagreement, the judgment of a third reader (DH) was decisive. The pelvic radiographs were scored according to the modified New York (mNY) criteria for sacroiliitis, in which sacroiliitis of at least grade 2 bilaterally or grade 3-4 unilaterally must be present for fulfillment of the mNY criteria.[12]

\section{Statistical analysis}

Descriptive statistics were used to describe the presence or absence of structural changes on M RI-SIJ and pelvic radiographs during the 2-year follow-up period.

The presence of BME at baseline and during follow-up in relation to the development of fatty lesions and/or erosions at the site of BME was investigated per quadrant of SIJ (8 quadrants per patient) using descriptive analysis. Generalized estimated equation (GEE) analysis was performed to investigate a time trend in the MRI and pelvic radiograph structural changes scores. GEE is a model that allows studying time trends while taking the within-subject correlation into account in a dataset with missing values. Furthermore, this technique was used to test whether BME on MRI is associated with erosions and fatty lesions on MRI and structural changes on a pelvic radiograph 1 year later. This was done using a GEE autoregressive time-lag model that correlates the presence of BME on M RI to each structural change score on either M RI or pelvic radiograph 1 year later. On a per SIJ level, BME was used as independent variable and the continuous (sum of) M RI or the pelvic radiograph $\mathrm{mNY}$ grading in the same location were used as dependent variables. SPSS software version 18.0 was used for all statistical analyses. All p-values were two-tailed and statistical significance was set at 0.05 . 


\section{RESULTS}

\section{Patient characteristics}

Baseline characteristics of the 68 patients included in ESpAC are shown in Table 4.1. MRI-SIJ and pelvic radiographs were obtained in all patients at baseline. Sixty-two (91\%) patients had at least 1 follow-up MRI and 44 (65\%) patients completed both follow-up M Rls. Sixty-five (96\%) patients had at least 1 follow-up pelvic radiograph and 48 (71\%) patients completed both follow-up pelvic radiographs. In 10 (15\%) of 68 patients adjudication of pelvic radiographs was considered necessary because of disagreement between the first 2 readers.

Table 1. Baseline characteristics of 68 patients included in the ESpAC.

\begin{tabular}{lcc}
\hline Characteristic & All patients & $\begin{array}{c}\text { Patients with complete M RI follow- } \\
\text { up data } \\
(\mathrm{n}=44)\end{array}$ \\
\hline Male sex & $26(38)$ & $15(34)$ \\
M ean age (SD) [years] & $34.9(10.3)$ & $36.0(11.7)$ \\
M edian symptom duration (IQR) [months] & $18(12-24)$ & $18(12-24)$ \\
HLA-B27 positive & $31(46)$ & $17(39)$ \\
History of inflammatory bowel disease & $10(15)$ & $7(16)$ \\
History of anterior uveitis & $10(15)$ & $8(18)$ \\
History of psoriasis & $16(24)$ & $12(27)$ \\
History of peripheral arthritis & $19(28)$ & $12(27)$ \\
Family history of SpA & $37(54)$ & $26(59)$ \\
M ean CRP (SD) [mg/l] & $9(11)$ & $9(12)$ \\
Elevated CRP & $16(24)$ & $10(22)$ \\
M ean ESR (SD) [mm] & $13(15)$ & $13(16)$ \\
Elevated ESR & $13(30)$ \\
Presence of BM E on M RI-SIJ & $24(36)$ & $14(32)$ \\
Fulfillment ESSG criteria & $24(35)$ & $39(89)$ \\
Fulfillment Amor criteria & $58(85)$ & $31(70)$ \\
Fulfillment ASAS axSpA criteria & $48(71)$ & $22(50)$ \\
Fulfillment mNY criteria & $40(59)$ & $9(20)$ \\
\hline
\end{tabular}

The values are expressed as number (percentage) of patients unless stated otherwise. ESpAC=Early Spondyloarthritis Clinic; SpA=spondyloarthritis; IQR=interquartile range; $S D=$ standard deviation; $C R P=C$ -

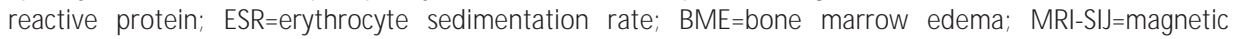
resonance imaging of the sacroiliac joints; ESSG=European Spondyloarthropathy Study Group; ASAS= Assessment in SpondyloArthritis international Society; axSpA=axial spondyloarthritis; $\mathrm{mNY}$ criteria=modified New York criteria. ${ }^{a}$ In 66 of 68 patients baseline CRP and ESR measurements were available. ESR normal range: $\leq 7 \mathrm{~mm}$ for males; $\leq 12 \mathrm{~mm}$ for females. CRP cut-off value, normal range: $<10 \mathrm{mg} / \mathrm{l}$.

At baseline, 64 (94\%) out of 68 patients fulfilled the European Spondyloarthropathy Study Group (ESSG) and/or Amor and/or ASAS axSpA classification criteria. Sixty-six $(97 \%)$ patients fulfilled 4 of the 5 Calin criteria. The remaining $2(3 \%)$ patients fulfilled 3 
of the 5 Calin criteria and reported 'night pain' as well. Forty (59\%) patients fulfilled the ASAS axSpA criteria at baseline, of which 22 fulfilled the imaging and clinical arm of the ASAS axSpA criteria, 9 patients fulfilled only the imaging arm, and 9 other patients fulfilled only the clinical arm. Fifteen (22\%) patients fulfilled the mNY criteria at baseline.

\section{Structural changes on M RI-SIJ}

Scores for BME on MRI-SIJ have been presented in a previous report.[11] Table 4.2 and 4.3 show the baseline and follow-up MRI findings for erosions and fatty lesions, respectively and the relation with fulfillment of the mNY criteria and ASAS axSpA criteria at baseline, and HLA-B27 status.

Table 4.2 Erosions on M RI-SIJ at baseline and during follow-up.

\begin{tabular}{|c|c|c|c|c|c|c|}
\hline \multirow{2}{*}{$\begin{array}{l}\text { Number of } \\
\text { patients }\end{array}$} & \multicolumn{3}{|c|}{ MRI-SIJ } & \multirow[t]{2}{*}{$\mathrm{mNY}$ criteria $t^{\mathrm{a}}$} & \multirow{2}{*}{$\begin{array}{l}\text { ASAS axSpA } \\
{\text { criteria }{ }^{\mathrm{b}}}^{{ }^{2}}\end{array}$} & \multirow[t]{2}{*}{$\mathrm{HLA}-\mathrm{B} 27+^{\mathrm{c}}$} \\
\hline & Baseline & 1-Year & 2-Years & & & \\
\hline 5 & + & + & + & 3 & 4 & 4 \\
\hline 2 & + & + & NA & 1 & 2 & 2 \\
\hline 3 & + & NA & + & 2 & 3 & 1 \\
\hline 1 & + & + & - & 1 & 1 & 1 \\
\hline 1 & + & NA & NA & 1 & 1 & 1 \\
\hline 35 & - & - & - & 3 & 14 & 11 \\
\hline 11 & - & - & NA & 1 & 7 & 6 \\
\hline 1 & - & - & + & 1 & 1 & 1 \\
\hline 2 & - & + & + & 1 & 2 & 0 \\
\hline 1 & - & + & NA & 1 & 1 & 1 \\
\hline 1 & - & NA & - & 0 & 1 & 0 \\
\hline 5 & - & NA & NA & 0 & 3 & 3 \\
\hline
\end{tabular}

The number of patients with present or absent signs of erosions on M RI-SIJ at baseline and during follow-up is shown. ${ }^{a}$ Number of patients that fulfil the mNY criteria at baseline. ${ }^{b}$ Number of patients that fulfil the ASAS axSpA criteria at baseline. ${ }^{c}$ Number of patients that are HLA-B27 positive. $+=$ structural changes present; - =structural changes absent, NA=MRI not available, MRI-SIJ=magnetic resonance imaging of the sacroiliac joints; HLA-B27=human leukocyte antigen B27, mNY criteria=modified New York criteria, ASAS axSpA criteria=Assessment in SpondyloArthritis international Society axial spondyloarthritis criteria.

At baseline, erosions and/or fatty lesions on M RI were detected in 17 (25\%) patients, of which $71 \%$ were HLA-B27 positive and $9(53 \%)$ fulfilled the mNY criteria. Erosions were detected in $12(18 \%)$ out of 68 patients of which $8(66 \%)$ patients also fulfilled the mNY criteria (Table 4.2). Fatty lesions were detected in 13 (19\%) out of 68 patients of which 7 (54\%) patients also fulfilled the mNY criteria (Table 4.3). Coexistence of both erosions and fatty lesions on M RI occurred in $8(9 \%)$ out of 68 patients of which $6(75 \%)$ patients also fulfilled the mNY criteria. 
Table 4.3 Fatty lesions on M RI-SIJ at baseline and during follow-up.

\begin{tabular}{|c|c|c|c|c|c|c|}
\hline \multirow{2}{*}{$\begin{array}{l}\text { Number } \\
\text { patients }\end{array}$} & \multicolumn{3}{|c|}{ M RI-SIJ } & \multirow[t]{2}{*}{ mNY criteria $t^{a}$} & \multirow{2}{*}{$\begin{array}{l}\text { ASAS axSpA } \\
{\text { criteria }+{ }^{\mathrm{b}}}^{2}\end{array}$} & \multirow[t]{2}{*}{ HLA-B27+ } \\
\hline & Baseline & 1-Year & 2-Years & & & \\
\hline 6 & + & + & + & 3 & 5 & 5 \\
\hline 2 & + & + & NA & 1 & 2 & 2 \\
\hline 1 & + & NA & + & 1 & 1 & 0 \\
\hline 1 & + & NA & - & 0 & 1 & 0 \\
\hline 2 & + & - & + & 1 & 2 & 1 \\
\hline 1 & + & NA & NA & 1 & 1 & 1 \\
\hline 35 & - & - & - & 4 & 14 & 11 \\
\hline 9 & - & - & NA & 1 & 5 & 4 \\
\hline 1 & - & NA & - & 0 & 1 & 0 \\
\hline 1 & - & + & + & 1 & 1 & 0 \\
\hline 3 & - & + & NA & 1 & 3 & 3 \\
\hline 1 & - & NA & + & 1 & 1 & 1 \\
\hline 5 & - & NA & NA & 0 & 3 & 3 \\
\hline
\end{tabular}

The number of patients with present or absent signs of fatty lesions on M RI-SIJ at baseline and during followup is shown. ${ }^{a}$ Number of patients that fulfil the mNY criteria at baseline. ${ }^{b}$ Number of patients that fulfil the ASAS axSpA criteria at baseline. ${ }^{c}$ Number of patients that are HLA-B27 positive. $+=$ structural changes present; - =structural changes absent, NA=MRI not available, MRI-SIJ=magnetic resonance imaging of the sacroiliac joints; HLA-B27=human leukocyte antigen B27, mNY criteria=modified New York criteria, ASAS axSpA criteria=Assessment in SpondyloArthritis international Society axial spondyloarthritis criteria.

During follow-up, 4 (8\%) out of 51 patients with no signs of erosions at baseline, and at least 1 follow-up MRI present, have developed erosions, of which 2 patients were HLAB27 positive and 3 patients already fulfilled the $\mathrm{mNY}$ criteria at baseline (Table 4.2). In 2 of these 4 patients, the erosions were accompanied by simultaneous appearance of fatty lesions on M RI. Five (10\%) out of 50 patients without fatty lesions at baseline and at least 1 follow-up MRI developed fatty lesions during follow-up, four of them were HLA-B27 positive and 3 patients fulfilled the mNY criteria at baseline (Table 4.3).

In $1(8 \%)$ out of 12 patients with erosions on MRI at baseline, the erosions were not detected anymore at the 2-year time point (Table 4.2). In 3 (23\%) out of 13 patients with fatty lesions on $\mathrm{MRI}$ at baseline, the fatty lesions were not detected during followup (Table 4.3).

\section{Structural changes on pelvic radiographs}

At baseline, 15 (22\%) patients fulfilled the $\mathrm{mNY}$ criteria for radiographic sacroiliitis of which $80 \%$ were HLA-B27 positive. Eight (53\%) of these 15 patients also had BME at baseline and in $9(60 \%)$ patients erosions and/or fatty lesions were detected on M RI. During follow-up no changes in mNY grading were found in these 15 patients. Four patients who fulfilled the $\mathrm{mNY}$ criteria at baseline developed new erosions and/or fatty 
lesions on MRI (Table 4.2 and 4.3). No patients were newly classified with radiographic sacroiliitis according to the $\mathrm{mNY}$ criteria at follow-up.

\section{Association between BME and structural changes on MRI-SIJ}

The first analysis was a GEE analysis (scores of 58 patients with at least 2 successive time points available included) showing that the number of erosions per patient increased significantly during follow-up (estimated marginal (EM) mean score of 2.5 at baseline, 3.3 at 1-year follow-up and 3.5 at 2-year follow-up; $p=0.05$ ). There was also a trend for an increase in the number of fatty lesions (EM mean score of 5.4 at baseline, 7.7 at 1-year follow-up and 8.5 at 2-year follow-up; $p=0.06$ ).

The second analysis was a GEE analysis per SIJ (2 per patient) showing an association between BME and the development of fatty lesions on MRI (Table 4.4). An association between BME and subsequent development of erosions on M RI could not be proven (Table 4.4).

Table 4.4 GEE analysis (continuous MRI-SIJ score) showing association between bone marrow edema on M RI-SIJ and the development of structural changes on M RI-SIJ during follow-up.

\begin{tabular}{llccc}
\hline Per joint analysis, structural changes M RI-SIJ & & Odds ratio (95\% Cl) & p-value \\
\hline M RI development of & Fatty degeneration (per unit) & Right SIJ & $3.13(1.06-9.20)$ & 0.04 \\
structural changes & & Left SIJ & $22.13(1.27-384.50)$ & 0.03 \\
(per unit change) & Erosions (per unit) & Right SIJ & $0.24(0.07-8.24)$ & 0.43 \\
& & Left SIJ & $1.24(0.09-18.03)$ & 0.88 \\
\hline
\end{tabular}

$\mathrm{N}=58$. GEE=generalized estimated equation, $\mathrm{MRI}$ SIJ = magnetic resonance imaging of the sacroiliac joints. $95 \% \mathrm{Cl}=95 \%$ confidence interval

The third analysis was a detailed descriptive analysis at the level of quadrants of SIJ, in order to investigate the association between the presence of BME and the development of erosions and/or fatty lesions at the same site. This analysis was done to investigate how an inflammatory lesion at a particular site associates with the development of a structural lesion at the same site. Every patient had 8 quadrants (4 left and 4 right) available for comparison.

The starting point of this analysis was the presence of BME. Continuous presence of BME over time vs. resolution of BME was taken into consideration. The results of this analysis which are presented in Table 4.5 show that an increase of fatty lesions preferentially occurs in quadrants in which BME has resolved over time $(55 \%)$ in comparison with quadrants in which BME has persisted over time (26\%). With regard to the development of erosions such a disparity could not be confirmed ( $26 \%$ vs. $30 \%$ ). 
Table 4.5 Presence of bone marrow edema on MRI at baseline and follow-up in relation to the subsequent development of fatty lesions and erosions at the same sacroiliac joint quadrant.

\begin{tabular}{|c|c|c|c|c|c|}
\hline & Baseline & & Last follow & Ip MRI* & \\
\hline & BME (present) & BME (present) & BME (present) & BME (absent) & BME absent \\
\hline & & & AND increase of & & AND increase of \\
\hline & & & FL at the same & & FL at the same \\
\hline & & & quadrant & & quadrant \\
\hline All quadrants & 89 & 47 & $12(26)$ & 42 & $23(55)$ \\
\hline & BME (present) & BME (present) & BME (present) & BME (absent) & BME absent \\
\hline & & & $\begin{array}{l}\text { AND increase of } \\
\text { erosions at the } \\
\text { same quadrant }\end{array}$ & & $\begin{array}{l}\text { AND increase of } \\
\text { erosions at the } \\
\text { same quadrant }\end{array}$ \\
\hline All quadrants & 89 & 47 & $14(30)$ & 42 & $11(26)$ \\
\hline
\end{tabular}

$\mathrm{n}=62$ patients.* Follow-up at 1 or 2 years, depending on last MRI. SIJ =sacroiliac joint; BM E=bone marrow edema, $\mathrm{FL}=$ fatty lesion, $\mathrm{MRI}=$ magnetic resonance imaging.

\section{DISCUSSION}

The present study has demonstrated that BME on MRI-SIJ is associated with the development of fatty lesions in a cohort of patients with early IBP. Such an association could not be demonstrated for erosions, despite a significant overall numerical increase of erosions over time. Furthermore, approximately $10 \%$ of the patients without erosions and fatty lesions at baseline developed new structural changes on MRI during the 2-year follow-up period.

An increase in the number of structural changes on MRI over time has been demonstrated in a previous study evaluating MRI-SIJ abnormalities in patients with early axSpA.[13] In this study by Madsen et al. 80 out of 94 (85\%) patients with axSpA had erosions and fatty lesions present on MRI at baseline. After a mean follow-up period of 51 months, both the number of erosions and fatty lesions had significantly increased.[13] We have also found a significant increase in the number of erosions, as well as a strong trend for an increase in the number of fatty lesions. In the study by Madsen et al., the proportion of patients with structural changes was higher at baseline compared with our cohort ( $85 \%$ versus $25 \%$ ), and also their follow-up duration was longer, which might explain the difference in time trends found for fatty lesions. The presence of fatty lesions might also be underestimated in our study due to the fact that the presence of intense BME may prevent the detection of fatty lesions due to counteracting MR signals on the TIMRI sequence (BME low signal intensity; fatty lesions high signal intensity).[4] 
In the present study, we have statistically demonstrated an association between the presence of BME and the subsequent development of fatty lesions on MRI. Even more important is the indication that these fatty lesions seem to have preferentially occurred at the sites (quadrants) in which existing BME has resolved over time. This is entirely in line with existing theories about the role of fatty lesions as a repair reaction in response to inflammatory triggers. A study by Song et al. has described an association between disappearance of BME on MRI in both the SIJ and spine and the subsequent appearance of fatty lesions on MRI in patients with early axial SpA treated with either etanercept or sulfasalazine over a 1 year follow-up period. In patients in whom BME resolved, fatty lesions occurred in $10.5 \%$ of the SIJ quadrants 1 year later, but in those in whom BME persisted, fatty lesions occurred in only $2.4 \%$ of the SIJ quadrants 1 year later.[4] In a study by Maksymowych et al., 76 patients with axSpA were followed for 1 year with repeated MRIs of the spine.[14] The chance of developing new fatty lesions was significantly higher at vertebral corners with BME at baseline as compared to vertebral corners without BME at baseline (18\% vs. 3\%).[14] A correlation between BME and the subsequent development of fatty lesions on MRI-SIJ could not be demonstrated in the SPondyloArthritis Caught Early (SPACE)-cohort over a 3-month follow-up period.[15] This last finding suggests that a longer follow-up period is necessary before fatty lesions can be detected in response to subsiding BME.

Whilst we have found an increase in the number of erosions in this study, we have failed to demonstrate a significant association between the presence of BME and the development of erosions. A possible explanation is that the erosions occur independently of inflammation. Larger cohorts are necessary to provide sufficient statistical power to clarify the relation between BME and development of both fatty lesions and erosions.

The rate of development from non-radiographic to radiographic axSpA in patients with a clinical diagnosis of axSpA without signs of radiographic sacroiliitis is estimated to be approximately $10 \%$ per 2 years.[16] In patients with BME on M RI-SIJ, this percentage increases to around $20 \%$ per 2 years.[17] Our study has failed to demonstrate an association between BME and development of structural changes detected on pelvic radiographs, nor could we demonstrate a change in the level of sacroiliitis according to the mNY criteria during the 2-year follow-up. The short follow-up period and the relatively small sample size may have hampered to detect these changes.

There are several concerns when assessing structural changes of the SIJ on either an $\mathrm{MRI}$ or pelvic radiograph and it is debatable which imaging modality is approaching the truth or whether they are complementary. Both imaging modalities are subject to 
observer errors and especially the evaluation of pelvic radiographs may be hampered by projection artifacts and poor visibility.[18,19] Erosions on MRI may not be reliably detected if the slice thickness is not small enough or movement artifacts may limit an accurate image interpretation. The natural irregular shape of the cortical lining of the SIJ may also limit detection of erosions. In the present study, of the 15 patients with sacroiliitis on pelvic radiographs according to independent readers, erosions and/or fatty lesions on MRI were detected in only $9(60 \%)$ patients at baseline. The majority of the patients, who developed new erosions and/or fatty lesions on MRI during followup, already fulfilled the mNY criteria at baseline.

Some limitations of the present study need to be addressed. First, the MRIs were scored by one reader only, which may in theory influence the reliability of the data. However, the reader was very experienced and the MRI scores showed a high consistency over time despite scoring each MRI set independently and blinding of the reader for time order. Furthermore, and in contrast to scoring pelvic radiographs, a number of studies have shown a rather high inter-observer agreement when scoring MRI-SIJs.[9,20] Second, in the present study, the T1 and STIR sequence were simultaneously scored for active lesions and structural changes. This scoring method could have resulted in reader bias, since the presence of BME on the STIR sequence may possibly have triggered the reader to screen more carefully for structural changes on the $\mathrm{T} 1$ sequence or vice versa. This may influence the sensitivity for scoring structural changes on MRI-SIJ. In 16 of the 17 patients with erosions and/or fatty lesions at baseline, concomitant BME was also found. However, one could also postulate that concomitant BME decreases the specificity of scoring structural changes on $\mathrm{MRl}$, since a reader is more likely to score an indeterminate lesion as a structural change. Scoring the $\mathrm{T} 1$ and STIR sequence independently could possibly lower the risk of reader bias when evaluating the presence of active lesions and structural changes on MRI-SIJ. Third, in the MRI scoring system used in the present study, we applied an unlimited number of evaluated slices. Serial image acquisition of the same anatomical region offers advantages to monitor changes over time. However, this scoring method may be limited by the possibility of misalignment between 2 successive MRI examinations, which may cause measurement error. Last, ESpAC is a relatively small cohort with selected patients. Patients were referred by (related) medical specialties (i.e. dermatology, gastroenterology) and through family members of the local ankylosing spondylitis society. This referral strategy may explain the relative high proportion of patients with extra-axial manifestations and/or positive family history for $\mathrm{SpA}$. As a consequence, a high proportion of patients fulfilled at least one of the 
classification criteria for SpA. Furthermore, the proportion of female patients in ESpAC is relatively high (62\%) and the proportion of patients with a positive HLA-B27 status is relatively low (46\%). However, these percentages are in accordance with other cohorts that included patients with early IBP. $[21,22]$ Nevertheless, extrapolation of the study findings should be done with caution.

In conclusion, in this cohort of patients presenting with IBP of recent onset and suspected for axSpA, the number of patients with erosions and fatty lesions detected on MRI-SIJ remained relatively stable during the 2 years of follow-up, but the overall number of $\mathrm{MRl}$ erosions in patients who already had erosions at baseline has increased. Signs of BME on MRI, and especially the resolution of it, were significantly correlated with the development of fatty lesions on MRI, but not with the development of structural changes visible on pelvic radiographs. 


\section{REFERENCES}

1. Rudwaleit M, van der Heijde D, Landewé R, et al. The development of Assessment of Spondyloarthritis international society classification criteria for axial spondyloarthritis (part II): validation and final selection. Ann Rheum Dis 2009;68:777-83.

2. Rudwaleit $M$, Jurik $A G$, Hermann $K G$, et al. Defining active sacroiliitis on magnetic resonance imaging (M RI) for classification of axial spondyloarthritis: a consensual approach by the ASAS/OMERACT MRI group. Ann Rheum Dis 2009;68:1520-7.

3. Weber U, Zubler V, Pedersen SJ, et al. Development and validation of an M RI reference criterion for defining a positive SIJ M RI in spondyloarthritis. Arthritis Care Res (Hoboken) 2013;65:977-85.

4. Song $\mathrm{IH}$, Hermann KG, Haibel $\mathrm{H}$, et al. Relationship between active inflammatory lesions in the spine and sacroiliac joints and new development of chronic lesions on whole-body MRI in early axial spondyloarthritis: results of the ESTHER trial at week 48. Ann Rheum Dis 2011;70:1257-63.

5. Heuft-Dorenbosch L, Landewé R, Weijers R, et al. Performance of various criteria sets in patients with inflammatory back pain of short duration; the Maastricht early spondyloarthritis clinic. Ann Rheum Dis 2007;66:92-8.

6. Heuft-Dorenbosch L, Landewé R, Weijers R, Wanders A, Houben H, van der Linden S, et al. Combining information obtained from magnetic resonance imaging and conventional radiographs to detect sacroiliitis in patients with recent onset inflammatory back pain. Ann Rheum Dis 2006;65:804-8.

7. Heuft-Dorenbosch L, Weijers R, Landewé R, van der Linden S, van der Heijde D. Magnetic resonance imaging changes of sacroiliac joints in patients with recent-onset inflammatory back pain. Arthritis Res Ther 2006;8:R11.

8. Calin A, Porta J, Fries JF, Schurman DJ. Clinical history as a screening test for ankylosing spondylitis. JAM A 1977;237:2613-4.

9. Maksymowych WP, Inman RD, Salonen D, Dhillon SS, Williams M, Stone M, et al. Spondyloarthritis research consortium of Canada magnetic resonance imaging index for assessment of sacroiliac joint inflammation in ankylosing spondylitis. Arthritis Rheum 2005;53:703-9.

10. Puhakka KB, Jurik AG, Egund N, Schiottz-Christensen B, Stengaard-Pedersen K, van Overeem Hansen G, et al. Imaging of sacroilitis in early seronegative spondyloarthropathy. Assessment of abnormalities by M R in comparison with radiography and CT. Acta Radiol 2003;44:218-29.

11. Van Onna M, Jurik AG, van der Heijde D, van Tubergen A, Heuft-Dorenbosch L, Landewé R. HLA-B27 and gender independently determine the likelihood of a positive M RI of the sacroiliac joints in patients with early inflammatory back pain: A two-year M RI follow-up study. Ann Rheum Dis 2011;70:1981-5.

12. Van der Linden S, Valkenburg HA, Cats A. Evaluation of diagnostic criteria for ankylosing spondylitis. A proposal for modification of the New York Criteria. Arthritis Rheum 1984;27:361-8.

13. Madsen KB, Schiøttz-Christensen B, Jurik AG. Prognostic significance of magnetic resonance imaging changes of the sacroiliac joints in spondyloarthritis-a follow-up study. J Rheumatol 2010;37:1718-27.

14. Maksymowych WP, Morency N, Conner-Spady B, Lambert RG. Suppression of inflammation and effects on new bone formation in ankylosing spondylitis: evidence for a window of opportunity in disease modification. Ann Rheum Dis 2013;72:23-8.

15. De Hooge M, Van den Berg R, Navarro Compán MV, Reijnierse M, Van Gaalen F, Fagerli KM, et al. Do bone marrow edema (BME) lesions in the sacroiliac joint (SIJ) change into fatty lesions over a 3-month period in patients with axial spondyloathritis (axSpA) [abstract]? Ann Rheum Dis 2013;72:656.

16. Poddubnyy D, Rudwaleit M, Haibel H, Listing J, Märker-Hermann E, Zeidler $H$, et al. Rates and predictors of radiographic sacroilitis progression over 2 years in patients with axial spondyloarthritis. Ann Rheum Dis 2011;70:1369-74.

17. Sieper J, van der Heijde D. Review: Nonradiographic axial spondyloarthritis: new definition of an old disease? Arthritis Rheum 2013;65:543-51.

18. Braun J, Sieper J, Bollow M. Imaging of sacroiliitis. Clin Rheumatol 2000;19:51-7.

19. Van Tubergen A, Heuft-Dorenbosch L, Schulpen G, Landewé R, Wijers R, van der Heijde D, et al. Radiographic assessment of sacroiliitis by radiologists and rheumatologists: does training improve quality? Ann Rheum Dis 2003;62:519-25. 
20. Weber U, Maksymowych WP, Jurik AG, et al. Validation of whole-body against conventional magnetic resonance imaging for scoring acute inflammatory lesions in the sacroiliac joints of patients with spondylarthritis. Arthritis Rheum 2009;61:893-9.

21. van den Berg R, de Hooge M, Rudwaleit M, Sieper J, van Gaalen F, Reijnierse M, et al. ASAS modification of the Berlin algorithm for diagnosing axial spondyloarthritis: results from the SPondyloArthritis Caught Early (SPACE)-cohort and from the Assessment of SpondyloArthritis international Society (ASAS)-cohort. Ann Rheum Dis 2013;72:1646-53.

22. Dougados M, d'Agostino MA, Benessiano J, Berenbaum F, Breban M, Claudepierre P, et al. The DESIR cohort: a 10-year follow-up of early inflammatory back pain in France: study design and baseline characteristics of the 708 recruited patients. Joint Bone Spine 2011;78:598-603. 



\section{CHAPTER 5}

Gadolinium contrast-enhanced M RI sequence does not have an incremental value in the assessment of sacroiliitis in patients with early inflammatory back pain by using $\mathrm{MRI}$ in combination with pelvic radiographs: A 2 year follow up study

Marloes van Onna, Astrid van Tubergen, Désirée van der Heijde, Anne Grethe Jurik, Robert Landewé 


\section{ABSTRACT}

\section{Objective}

To evaluate the potential incremental value in detecting sacroiliitis of the T1 postgadolinium diethylenetriaminepentaacetic acid (Gd-DTPA) MRI sequence of the sacroiliac joints (SIJ) compared with the combination of short tau inversion recovery (STIR) MRI sequence and pelvic radiographs in patients with inflammatory back pain (IBP) suspected for axial spondyloarthritis.

\section{Methods}

A 2-year follow-up study was conducted in patients with IBP of less than 2 years duration. Annual MRI of the SIJ (MRI-SIJ) was performed and scored for bone marrow edema (BME). Pelvic radiographs were scored according to the modified New York ( $\mathrm{mNY}$ ) criteria. Agreement on the presence of BME detected by the STIR and post-GdDTPA sequence and the incremental value of post-Gd-DTPA sequence over STIR plus radiographs was analysed by descriptive methods and kappa statistics.

\section{Results}

At baseline, 20 (29\%) out of 68 patients (38\% male; mean (SD) age 34.9 (10.3) years) enrolled had BME both on the STIR and post-Gd-DTPA sequences; 4 patients (6\%) on the STIR sequence only; none on the post-Gd-DTPA sequence only (kappa value: 0.87 ). Fifteen (22\%) patients fulfilled the $\mathrm{mNY}$ criteria at baseline.

Sixty-two (91\%) patients had at least 1 follow-up MRI-SIJ. At 2-year follow-up, 2 patients had BME on the post-Gd-DTPA sequence without BME on the STIR sequence. These 2 patients already fulfilled the $\mathrm{mNY}$ criteria at baseline.

\section{Conclusion}

In this cohort of patients with early IBP, the post-Gd-DTPA sequence of the MRI-SIJ did not have an incremental value in the detection of sacroiliitis compared with the STIR sequence plus pelvic radiographs. 


\section{INTRODUCTION}

Pelvic radiographs and magnetic resonance imaging (MRI) are important imaging techniques to detect sacroiliitis in patients with a suspicion of axial spondyloarthritis (axSpA). In the Assessment in SpondyloArthritis international Society (ASAS) axSpA classification criteria, sacroiliitis on either MRI or pelvic radiograph is used as the entry criterion for fulfillment of the 'imaging arm'.[1]. With MRI, both active lesions and structural changes can be detected, in contrast to pelvic radiographs that only visualize structural changes. Typical 'active lesions' in the sacroiliac joints (SIJ) detected by M RI are subchondral bone marrow edema (BME), as well as synovitis, enthesitis and capsulitis.[2] Different MRI techniques can be used to detect active lesions; these are short tau inversion recovery (STIR) that suppresses the signal intensity of fat, and T1 with or without fat suppression after administration of the contrast agent gadolinium diethylenetriaminepentaacetic acid (Gd-DTPA). Only BME on the STIR or post-Gd-DTPA sequence is considered for the definition of active sacroilitis according to the ASAS/Outcome Measures in Rheumatoid Arthritis Clinical Trials (OMERACT) consensus.[2] The ASAS/OMERACT MRI working group further states that the STIR sequence alone is usually sufficient to detect sacroiliitis. This statement is supported by several studies that found no additional value of the post-Gd-DTPA sequence compared with the STIR sequence in detecting sacroiliitis in patients with early or established axSpA.[3,4] However, these studies were cross-sectional[3] or had a 3-month follow-up period only.[4] Furthermore, these studies did not include pelvic radiographs. Besides that in the ASAS classification criteria both pelvic radiographs and MRI-SIJ are considered for fulfilment of the imaging arm, also in daily practice, usually the first step for making a diagnosis is to perform a pelvic radiograph. When negative of equivocal, the next step is to make an M RI-SIJ. Although on the short term, the postGd-DTPA M RI sequence does not seem to be of additional value, it is unknown what its value is over a longer follow-up period, especially in patients with early disease, and taking the pelvic radiograph into account. Fluctuating or subsiding BME on either the STIR or post-Gd-DTPA sequence may affect the sensitivity and specificity of MRI in detecting sacroiliitis and hamper the diagnostic process.[5] Combining the information on pelvic radiographs with the information on M RI-SIJ may yield an higher probability of detecting sacroiliitis.[6]

The aim of this study was to evaluate the potential incremental value of the post-GdDTPA sequence for detecting sacroiliitis compared with the combination of STIR MRI sequence and pelvic radiographs in patients presenting with IBP of short duration 
suspected for axSpA. These patients were followed for 2 years with repeated radiological examinations.

\section{MATERIALS AND METHODS}

\section{Study population}

Patients with IBP of less than 2 years duration were enrolled in the Early SpondyloArthritis Clinic (ESpAC) study. In this prospective cohort study, systematic clinical and radiological examinations were performed at baseline and after 1 and 2 years. A more detailed description of the study population has been reported previously.[7] For IBP to be present, patients had to fulfil 4 of the following 5 Calin criteria: onset of symptoms before the age of 40 years, duration of back pain more than 3 months, insidious onset, morning stiffness and improvement with exercise.[8] Patients who fulfilled only 3 out of 5 of the Calin criteria but reported night pain, were also eligible. Presence of extra-axial manifestations of SpA was preferred but not obligatory. Patients were not treated with biological therapy during the entire study period. The use of non-steroidal anti-inflammatory drugs (NSAIDs) was allowed. The study has been approved by the ethics committee of the Maastricht University Medical Center. All patients have given written informed consent.

\section{MRI protocol}

M RI of the SI joints was obtained with a 1.5 Tesla Philips Gyro Scan ACS-NT (Philips, The Netherlands). Patients were examined while lying in a supine position. By using an oblique coronal slice orientation, the following sequences were obtained:

- T1-weighted spin echo (SE), $256 \times 256$ matrix

- $\quad$ STIR, $256 \times 256$ matrix

- T1-weighted SE with fat suppression after administration of the intravenous contrast agent Gd-DTPA ( $0.1 \mathrm{mmol} / \mathrm{kg}$ body weight), $512 \times 256$ matrix

The slice thickness was $4 \mathrm{~mm}$ with $0.4 \mathrm{~mm}$ intervals. Each MRI set was scored with unknown time sequence by one experienced radiologist (AGJ), without knowledge of clinical or laboratory findings. 


\section{RI and pelvic radiograph scoring}

The MR images were scored using a combination of the Spondyloarthritis Research Consortium of Canada (SPARCC) method and a modified version of the Aarhus MRI scoring method. $[9,10]$ In contrast to the original SPARCC system, there was no maximum to the number of evaluated slices, in order to maximise the detection of abnormal M RI findings. The number of evaluated slices within a individual patient was kept the same for all time points. Each SIJ was divided into 4 quadrants: upper iliac, lower iliac, upper sacral and lower sacral. All images (STIR and post-Gd-DTPA) were scored for the presence of subchondral BME with the corresponding T1 sequence without contrast simultaneously. BME present in the cartilaginous part of the joint was scored per slice in a dichotomous manner (present vs. absent). BME was defined as areas of increased signal intensity on both the STIR and post-Gd-DTPA images compared with normal bone marrow, and its presence was estimated in each of the 4 quadrants. Since synovitis, capsulitis and enthesitis are not considered sufficient for the definition of a positive MRI according to the ASAS/OMERACT definition, only the M RI scores of BME were taken into account.[2]

An MRI was considered positive when at least one BME lesion was present in at least two consecutive slices, or when two or more BME lesions were detected in one slice, following the ASAS/OM ERACT working group definition for BME lesions on M RI-SIJ.[2]

Anteroposterior pelvic radiographs of the SIJ were obtained from all patients at baseline and during one- and 2-year follow up. Two readers (AT and RL), who were blinded to the clinical and laboratory findings and were not involved in the MRI reading, independently scored all radiographs with unknown time sequence according to the modified New York (mNY) criteria.[11] In case of disagreement, judgment of a third reader (DH) was conclusive.

\section{Statistical analysis}

Descriptive statistics were used to analyse the presence of BME on MRI-SIJ and structural changes on pelvic radiographs at baseline and during the 2-year follow-up period. Agreement on the presence of BME suggestive for sacroiliitis detected by STIR and post-Gd-DTPA sequences was analyzed on a per patient basis by kappa statistics. A kappa value of 0-0.20 indicated poor agreement, $0.21-0.40$ indicated fair agreement, 0.40-0.60 indicated moderate agreement, $0.60-0.80$ indicated substantial agreement and 0.80-1.0 indicated (almost) perfect agreement.[12] Descriptive statistics were used 
to compare the presence of sacroiliitis detected on either pelvic radiographs or STIR M RI with findings on the post-Gd-DTPA M RI sequences. SPSS software version 18.0 was used for all statistical analyses.

\section{RESULTS}

\section{Patient characteristics}

Baseline M RI-SIJ and pelvic radiographs were available in all 68 patients included in the ESpAC. Baseline characteristics are shown in Table 5.1.

Sixty-two (91\%) patients had at least 1 follow-up M RI and 44 (65\%) patients completed both follow-up M RIs. Sixty-five (96\%) patients had at least 1 follow-up pelvic radiograph and 48 (71\%) patients completed both follow-up pelvic radiographs.

At baseline, 64 (94\%) out of 68 patients fulfilled the European Spondyloarthropathy Study Group (ESSG) and/or Amor and/or ASAS axSpA classification criteria. Fifteen (22\%) patients fulfilled the mNY criteria at baseline and in 24 (35\%) patients BME was detected on MRI-SIJ. Eight (53\%) of 15 patients who fulfilled the mNY criteria at baseline had signs of BME on both the STIR and post-Gd-DTPA sequence at baseline.

\section{Agreement between the STIR- and post-Gd-DTPA M RI sequences}

At baseline, a good agreement between the STIR and post-Gd-DTPA sequence on a per patient basis was found (kappa $=0.87$ ). Twenty (29\%) patients showed BME on M RI-SIJ suggestive for sacroiliitis on both STIR and post-Gd-DTPA sequences. In 4 (6\%) patients, BME was detected on the STIR sequence only, but this was minimal in 3 of these 4 patients. None of the patients had signs of BM E on the post-Gd-DTPA sequence only. Twenty-three (96\%) of 24 patients with BME on MRI at baseline had at least one follow-up MRI. A moderate to good agreement between the STIR and post-Gd-DTPA sequence on a per patient basis was also found at 1-year (kappa $=0.83$ ) and 2-year (kappa=0.75) follow-up. 
Table 5.1 Baseline characteristics of 68 patients included in the ESpAC.

\begin{tabular}{lcc}
\hline Characteristic & All patients & $\begin{array}{c}\text { Patients with complete M RI follow- } \\
\text { up data } \\
(n=44)\end{array}$ \\
\hline Male sex & $(n=68)$ & $15(34)$ \\
M ean age (SD) [years] & $26(38)$ & $36.0(11.7)$ \\
Median symptom duration (IQR) [months] & $18(10.3)$ & $18(12-24)$ \\
HLA-B27 positive & $31(46)$ & $17(39)$ \\
History of inflammatory bowel disease & $10(15)$ & $7(16)$ \\
History of anterior uveitis & $10(15)$ & $8(18)$ \\
History of psoriasis & $16(24)$ & $12(27)$ \\
History of peripheral arthritis & $19(28)$ & $12(27)$ \\
Family history of SpA & $37(54)$ & $26(59)$ \\
M ean CRP (SD) [mg/l] & $9(11)$ & $9(12)$ \\
Elevated CRP & $16(24)$ & $10(22)$ \\
M ean ESR (SD) [mm] & $13(15)$ & $13(16)$ \\
Elevated ESR & $13(30)$ \\
Presence of BM E on M RI & $24(36)$ & $14(32)$ \\
Fulfillment ESSG criteria & $24(35)$ & $39(89)$ \\
Fulfillment Amor criteria & $58(85)$ & $31(70)$ \\
Fulfillment ASAS axSpA criteria & $48(71)$ & $22(50)$ \\
Fulfillment mNY criteria & $40(59)$ & $9(20)$ \\
\hline
\end{tabular}

The values are expressed as number (percentage) of patients unless stated otherwise. ESpAC=Early Spondyloarthritis Clinic; SpA=spondyloarthritis; IQR=interquartile range; $S D=s t a n d a r d$ deviation; $C R P=$ $\mathrm{C}$-reactive protein; $\mathrm{ESR}=$ erythrocyte sedimentation rate; $\mathrm{BME}=$ bone marrow edema; $\mathrm{MRI}=$ magnetic resonance imaging; ESSG=European Spondyloarthropathy Study Group; ASAS=Assessment in SpondyloArthritis international Society; axSpA=axial spondyloarthritis; $\mathrm{mNY}$ criteria = modified New York criteria. ${ }^{a}$ In 66 of 68 patients baseline CRP and ESR measurements were available. ESR normal range: $\leq 7 \mathrm{~mm}$ for males; $\leq 12 \mathrm{~mm}$ for females. CRP cut-off value, normal range: $<10 \mathrm{mg} / \mathrm{l}$

\section{Detection of BME on the STIR and post-Gd-DTPA sequence at follow-up}

Table 5.2 shows that in $5(26 \%)$ of 19 patients with BME on both STIR and postGd-DTPA sequences at baseline, BME could no longer be detected on STIR sequence at 2-years follow-up. In 2 of these 5 patients, however, BME was still visible on the postGd-DTPA sequence. In the remaining 3 patients BME has disappeared on both the STIR and post-Gd-DTPA sequence at 2-years follow-up. These 3 patients were all HLA-B27negative. In 2 of 4 patients with BME on the STIR sequence only at baseline, BME was no longer present at 2-years follow-up. Both patients were HLA-B27-negative.

Five $(13 \%)$ of 39 patients without signs of BME on both the STIR and post-Gd-DTPA sequences at baseline, developed BME at follow-up. None of these 5 patients developed BME on the post-Gd-DTPA sequence only. 
Table 5.2 Detection of BME on the STIR and post-Gd-DTPA sequences per patient at baseline and followup.

\begin{tabular}{|c|c|c|c|c|c|}
\hline & \multicolumn{4}{|c|}{ Follow-up ${ }^{*}$} \\
\hline & & $\begin{array}{l}\text { BM E on both STIR } \\
\text { and post- Gd-DTPA }\end{array}$ & $\begin{array}{l}\text { BME on STIR } \\
\text { only }\end{array}$ & $\begin{array}{l}\text { BME on post-Gd- } \\
\text { GTPA only }\end{array}$ & No BME \\
\hline \multirow{3}{*}{ Baseline } & $\begin{array}{l}\text { BME on both STIR } \\
\text { and post- Gd-DTPA } \\
(n=19)\end{array}$ & 13 & 1 & 2 & 3 \\
\hline & $\begin{array}{l}\text { BME on STIR only } \\
(n=4)\end{array}$ & 1 & 1 & 0 & 2 \\
\hline & $\begin{array}{l}\text { No BME } \\
(n=39)\end{array}$ & 3 & 2 & 0 & 34 \\
\hline
\end{tabular}

Bone marrow edema (BME) on the Short $\tau$ Inversion Recovery (STIR) and post-gadolinium diethylenetriaminepentaacetic acid (post-Gd-DTPA) sequence in 62 patients with at least 1 follow-up M RI. * Follow-up M RI at 1 or 2 years, depending on last available M RI

\section{Incremental value of the post-Gd-DTPA sequence compared with the combination of STIR sequence and pelvic radiograph}

At baseline, 31 (46\%) patients had BME on M RI-SIJ and/or fulfilled the $\mathrm{mNY}$ criteria for radiographic sacroiliitis. None of these 31 patients had signs of BME on the post-GdDTPA sequence only at baseline. Thirty (97\%) of 31 patients had both at least one follow-up MRI-SIJ and at least one follow up pelvic radiograph. At follow-up, no new patients fulfilled the mNY criteria for radiographic sacroiliitis. BME on the post-GdDTPA sequence only was found in 2 (7\%) of these 30 patients at follow up. However, both patients already fulfilled the $\mathrm{mNY}$ criteria.

\section{DISCUSSION}

The present study showed that the post-Gd-DTPA MRI sequence does not have an incremental value in the detection of sacroiliitis in a cohort of patients with early IBP who were followed for 2 years compared to the combination of STIR M RI sequence and pelvic radiographs.

Both MRI sequences can be used to detect sacroilitis with similar efficiency, as is reflected in the high kappa values found in our study. Earlier studies also compared the concordance between STIR and post-Gd-DTPA sequences in detecting BME on MRI-SI].[3,4] De Hooge et al. found a 100\% agreement between the STIR and postGd-DTPA MRI sequence in detecting BME on MRI-SIJ in a prospective cohort study of 127 patients with chronic back pain of less than 2 years duration with onset below 
45 years. [4]. In 8 (6\%) of the 127 patients, synovitis and/or capsulitis and/or enthesitis was detected on the post-Gd-DTPA sequence, but without corresponding BME. However, these findings are not solely considered in the ASAS/OMERACT definition of active sacroiliitis. Also in this study, it was concluded that the post-Gd-DTPA sequence does not have an additional value in the assessment of active sacroiliitis over the STIR sequence.[4] Madsen et al. found in 40 patients with established axSpA, who were assessed by an oblique transaxial MRI of the SIJ, that the STIR sequence can replace the post-Gd-DTPA sequence.[3] There was agreement between both imaging sequences in $60(75 \%)$ of the $80 \mathrm{SIJs}$. With the STIR sequence more BME, mainly in the periphery of structural changes, was detected. However, the authors suggested that the postGd-DTPA sequence might be superior to the STIR sequence with respect to detecting small subcortical lesions.[3] In contrast to these two studies, our longitudinal study also compared the MRI findings to the findings of pelvic radiographs over a 2-year follow-up period. In a small subset of patients, BME could be detected on the post-Gd-DTPA sequence only during follow-up. However, these patients already fulfilled the mNY criteria. This suggests that post-Gd-DTPA sequence does not provide additional diagnostic information in the detection of sacroiliitis in this cohort of patients with early IBP when information from the STIR sequence and pelvic radiographs are combined.

The present study shows that in case of discordance between the STIR and postGd-DTPA sequences, BME was mainly detected on the STIR sequence. In a previous study in the same cohort we have demonstrated that the combination of a positive M RI scan for BM E and a positive HLA-B27 status is associated with a high likelihood of persistent signs of BME on MRI during follow-up.[13] Five patients in our cohort showed subsiding BME on the STIR sequence without BME on the post-Gd-DTPA sequence during follow-up, and all of them were HLA-B27 negative. Three of these 5 patients did not fulfil the mNY criteria. Whether the MRI in these 5 patients gave false-positive results or whether these patients showed fluctuating disease activity remains unclear because in ESpAC patients were not given a clinical diagnosis of axSpA that could serve as an external standard.

The MRI scoring method used in the present study is a combination of the SPARCC and Aarhus grading method.[9,10] Both scoring systems have proved to be reliable with respect to inter-reader agreement.[14] In contrast to the SPARCC method, we applied an unlimited number of slices to be evaluated, and the same (number of) slices were scored per MRI examination per patient over time. The advantage of this method is that all qualitatively optimal slices are scored, thereby maximising the chance of 
detecting active lesions. A general concern when scoring MRIs of the SIJs is the possibility of misalignment between two successive MRI examinations, which may cause measurement error. We ensured that scoring started and ended at the same anatomical level to minimize the chance of misalignment between two successive M RI examinations.

Some limitations of the present study need to be addressed. First, the MRI sets were scored by one reader. However, the reader was experienced and the MRI scores showed high consistency over time despite independent scoring of each M RI set and blinding of the reader for time order. Second, the STIR sequence was not scored independently of the post-Gd-DTPA sequence. This might have contributed to the high per patient kappa values at baseline and follow-up. Third, a number of M RIs and pelvic radiographs was missing at follow-up. Baseline MRls and pelvic radiographs were nevertheless complete and the baseline results already led to the conclusion that the post-Gd-DTPA sequence can be omitted, a conclusion that did not change when assessing the follow-up MRIs combined with the information from pelvic radiographs. Fourth, discordances between the STIR sequence and the post-Gd-DTPA sequence can be due to MRI coil artefacts, which may have contributed to an overestimation of the presence of BME on the STIR sequence.[15] Fifth, in ESpAC, the use of NSAIDs was allowed. The actual use of NSAIDs per patient was not recorded. It is possible that continuous or on-demand treatment with NSAIDs may have led to subsiding BME.[16] However, a number of BME lesions may also have subsided due to the natural fluctuating course of the disease.[17] Last, patients included in ESpAC were recruited via local rheumatologists, (related) medical specialties (i.e. dermatology, gastroenterology) and through family members of the local ankylosing spondylitis society. This selective recruitment may explain the relative high proportion of patients that fulfilled a least one of the classification criteria for axSpA. Furthermore, the proportion of female patients in ESpAC is relatively high (62\%) whereas the proportion of patients with a positive HLA-B27 status is relatively low (46\%). However, these percentages are in accordance with other cohorts that included patients with early IBP. $[18,19]$ Nevertheless, extrapolation of the study findings should be done cautiously. In conclusion, combined use of pelvic radiographs and the STIR MRI sequence is sufficient for detecting sacroilitis in this early IBP cohort suspected for axSpA. The post-Gd-DTPA MRI sequence does not have an incremental value in detecting sacroiliitis, neither at baseline nor during 2 years of follow-up. 


\section{REFERENCES}

1. Rudwaleit M, Van de Heijde D, Landewé, et al. The development of Assessment of Spondyloarthritis international society classification criteria for axial spondyloarthritis (part II): validation and final selection. Ann Rheum Dis 2009;68:777-83.

2. Rudwaleit $M$, Jurik $A G$, Hermann $K G$, et al. Defining active sacroiliitis on magnetic resonance imaging (MRI) for classification of axial spondyloarthritis: a consensual approach by the ASAS/OM ERACT MRI group. Ann Rheum Dis 2009;68:1520-7.

3. Madsen KB, Egund N, Jurik AG. Grading of inflammatory disease activity in the sacroiliac joints with magnetic resonance imaging: comparison between short-tau inversion recovery and gadolinium contrast-enhanced sequences. J Rheumatol 2010;37:393-400.

4. De Hooge M, Van den Berg R, Navarro-Compán V, et al. Magnetic resonance imaging (MRI) of the sacroiliac joints in the early detection of spondyloarthritis (SpA): No added value of gadolinium compared to short tau inversion recovery (STIR) sequence. Rheumatology (Oxford), in press.

5. oussou E, Jurik AG. Difficulties for the detection of positive signs of sacroiliitis in spondyloarthritides by magnetic resonance imaging (M RI) in everyday clinical practice. Results from an audit circle (audit and re-audit). Clin Exp Rheumatol 2011;29:594-5.

6. Salvadorini G, Bandinelli F, Delle Sedie A, et al. Ankylosing spondylitis: how diagnostic and therapeutic delay have changed over the last six decades. Clin Exp Rheumatol 2012;30:561-5.

7. Heuft-Dorenbosch L, Landewé R, Weijers $R$ et al. Performance of various criteria sets in patients with inflammatory back pain of short duration; the Maastricht early spondyloarthritis clinic. Ann Rheum Dis 2007;66:92-8.

8. Calin A, Porta J, Fries JF, et al. Clinical history as a screening test for ankylosing spondylitis. JAMA 1977;237:2613-4.

9. Maksymowich WP, Inman RD, Salonen D, et al. Spondyloarthritis research consortium of Canada magnetic resonance imaging index for assessment of sacroiliac joint inflammation in ankylosing spondylitis. Arthritis Rheum 2005;53:703-9.

10. Puhakka KB, Jurik AG, Egund N, et al. Imaging of sacroilitis in early seronegative spondyloarthropathy. Assessment of abnormalities by MR in comparison with radiography and CT. Acta Radiol 2003;44: 218-9.

11. Van der Linden S, Valkenburg HA, Cats A. Evaluation of diagnostic criteria for ankylosing spondylitis. A proposal for modification of the New York Criteria. Arthritis Rheum 1984;27:361-8.

12. Landis JR, Koch GG. The measurement of observer agreement for categorical data. Biometrics 1977;33:159-74.

13. Van Onna M, Jurik AG, Van der Heijde D, et al. HLA-B27 and gender independently determine the likelihood of a positive MRI of the sacroiliac joints in patients with early inflammatory back pain: A twoyear M RI follow-up study. Ann Rheum Dis 2011;70:1981-5.

14. Landewé RB, Hermann KG, Van der Heijde DM et al. Scoring sacroiliac joints by magnetic resonance imaging. A multiple-reader reliability experiment. J Rheumatol 2005;32:2050-5.

15. Althoff $C E$, Feist $E$, Burova $E$, et al. Magnetic resonance imaging of active sacroiliitis: do we really need gadolinium? Eur J Radiol 2009;71:232-6.

16. Jarett SJ, Sivera F, Cawkwell LS, et al. MRI and clinical findings in patients with ankylosing spondylitis eligible for anti-tumour necrosis factor therapy after a short course of etoricoxib. Ann Rheum Dis 2009;68:1466-9.

17. Barkham N, Keen HI, Coates LC, et al. Clinical and imaging efficacy of infliximab in HLA-B27-Positive patients with magnetic resonance imaging-determined early sacroiliitis. Arthritis Rheum 2009;60: 946-54.

18. Van den Berg R, De Hooge M, Rudwaleit M, et al. ASAS modification of the Berlin algorithm for diagnosing axial spondyloarthritis: results from the SPondyloArthritis Caught Early (SPACE)-cohort and from the Assessment of SpondyloArthritis international Society (ASAS)-cohort. Ann Rheum Dis doi:10.1136/annrheumdis-2012-201884.

19. Dougados M, D'Agostino MA, Benessiano J, et al. The DESIR cohort: a 10-year follow-up of early inflammatory back pain in France: study design and baseline characteristics of the 708 recruited patients. Joint Bone Spine 2011;78:598-603. 



\section{CHAPTER 6}

Natural course of bone marrow edema on magnetic resonance imaging of the sacroiliac joints in patients with early inflammatory back pain: a 2-year follow-up study

Marloes van Onna, Astrid van Tubergen, Désirée van der Heijde, Anne Grethe Jurik,

Robert Landewé 


\section{ABSTRACT}

\section{Objective}

To describe the distribution and evolution over time of bone marrow edema (BM E) on MRI of the sacroiliac joints (MRI-SIJ) in patients with recent-onset inflammatory back pain (IBP) suspected for axial spondyloarthritis (axSpA).

\section{Methods}

A 2-year follow-up study with annual MRI-SIJ was conducted in patients with IBP of duration $\leq 2$ years. Each SIJ was divided into 4 quadrants and M RI scores were analyzed on a per patient and per SIJ-quadrant basis. The presence of BME in each SIJ-quadrant was recorded. Fulfilment of the Assessment of SpondyloArthritis International Society (ASAS) axSpA criteria was assessed at baseline and follow-up.

\section{Results}

At baseline, 68 patients ( $38 \%$ male; mean age $34.9 \pm 10.3$ years) were included. BME was visible at baseline in $24(35 \%)$ patients, all fulfilling the ASAS axSpA criteria. Twenty-three of these 24 patients had a follow-up MRI. Not taking into account the baseline MRI, $3(13 \%)$ of these 23 patients would no longer fulfill the ASAS criteria during follow-up because of subsiding BME. Forty-four (65\%) patients had a negative baseline MRI, of whom 39 have a follow-up MRI available. New BME at follow-up meant that $3(8 \%)$ of these 39 patients now fulfilled the ASAS criteria. At follow-up, baseline BME lesions subsided completely in mean $47 \%$ of SII-quadrants (range $33 \%$ $71 \%$ ), new BME lesions were detected in mean $8 \%$ of SIJ-quadrants (range $2 \%-11 \%$ ).

\section{Conclusion}

BME shows a fluctuating course in patients with early IBP suspected for axSpA. This may have an impact on diagnosis making and the overall performance of the ASAS axSpA criteria. 


\section{INTRODUCTION}

Inflammation of the sacroiliac joints (SI) detected on magnetic resonance imaging (MRI) is a common finding in axial spondyloarthritis (axSpA).[1] In daily practice, MRI is frequently used as a diagnostic tool in those patients suspected for axSpA but with normal pelvic radiographs. In addition to pelvic radiographs, $M$ RI is incorporated in the imaging arm of the Assessment in SpondyloArthritis international Society (ASAS) classification criteria for axSpA.[2] Active inflammatory lesions that can be detected on M RI are bone marrow edema (BME), synovitis, capsulitis and enthesitis. Of these, only BME is considered mandatory for fulfilment of the ASAS/Outcome Measures in Rheumatoid Arthritis Clinical Trials (OM ERACT) working group definition of a positive M RI.[1] To date, there is limited knowledge about the exact distribution, frequency of occurrence, and evolution over time of BME detected on MRI of the SIJ (MRI-SIJ), especially in patients with short duration of disease. Knowledge about the natural course of BME is important both for research and daily practice. M RI is frequently used as an "objective" measure of outcome to examine the efficacy of (biological) therapy in clinical trials. However, as an example, subsiding lesions may give the impression of efficacy of treatment, whereas this may in fact be the natural course. Also, fluctuating or subsiding BME may affect the sensitivity and specificity of MRI in detecting sacroiliitis, which may hamper the diagnostic process.

The aims of this study were first to describe the distribution and frequency of occurrence of BME, and second to assess the evolution over time of BME on MRI-SIJ in patients with early inflammatory back pain (IBP) followed for 2 years with annual M RI.

\section{METHODS}

Patients with IBP of less than 2 years duration were enrolled in the Early SpondyloArthritis Clinic (ESpAC) study. In this prospective cohort study, systematic clinical and radiological examinations were performed at baseline and after 1 and 2 years. A more detailed description of the study population has been reported previously.[3] For IBP to be present, patients had to fulfil at least 4 of the following 5 Calin criteria: onset of symptoms before the age of 40 years, duration of back pain more than 3 months, insidious onset, morning stiffness and improvement with exercise.[4] Patients who fulfilled only 3 out of 5 of the Calin criteria but reported night pain, were also included. Presence of extra-axial manifestations of SpA was preferred but not obligatory. Patients were not treated with biological therapy during the entire 
study period. The use of non-steroidal anti-inflammatory drugs (NSAIDs) was allowed. Fulfilment of the ASAS axSpA criteria [2], modified New York (mNY) criteria [5], European Spondyloarthropathy Study Group (ESSG) criteria [6], and Amor criteria [7] was assessed. The study was approved by the ethics committee from the Maastricht University Medical Center. The study was conducted according to the principles of the Declaration of Helsinki. All patients gave written informed consent.

The MR images were scored using a combination of the Spondyloarthritis Research Consortium of Canada (SPARCC) method and a modified version of the Aarhus MRI scoring method.[8,9] In contrast to the original SPARCC scoring method, there was no maximum to the number of evaluated slices, but the number of slices within a patient was kept the same for all time points. MRIs were scored as series per patient with unknown time sequence by an experienced reader for the presence of bone marrow edema (BME) on the Short Tau Inversion Recovery (STIR) sequence. Each SIJ was divided into 4 quadrants and the presence of BME was recorded for each SIJ-quadrant. The ASAS/OMERACT definition was followed for fulfilment of a positive MRI for sacroiliitis.[1] An MRI-SI] is considered positive for active sacroiliitis when at least 1 active lesion that is characteristic of sacroiliitis is present in at least 2 successive slices or when $\geq 2$ of such lesions are detected in 1 slice.[1]

Anteroposterior pelvic radiographs of the SIJ were obtained and independently scored according to the mNY criteria in a random time order by 2 readers who were not involved in the MRI reading.[5] In case of disagreement, judgment of a third reader was conclusive.

Descriptive statistics were used to analyse the presence of BME detected on M RI on a per patient and per SIJ-quadrant basis, and the consequences of fluctuations in BM E on MRI-SIJ for fulfilment of the ASAS axSpA criteria at baseline and at follow-up.[2] Generalized estimated equation (GEE) analysis was used to investigate if there was a time trend for the MRI BME lesion scores in individual patients. SPSS software version 18.0 was used for all statistical analyses.

\section{RESULTS}

\section{Patient characteristics}

Baseline M RI-SIJ and pelvic radiographs were available in all 68 patients included in the ESpAC study. Table 6.1 shows the baseline demographics and clinical characteristics of 
all included patients. Sixty-two (91\%) patients had at least 1 follow-up MRI and 44 (65\%) patients completed both follow-up M RIs. Sixty-five (96\%) patients had at least 1 follow-up pelvic radiograph and 48 (71\%) patients completed both follow-up pelvic radiographs. Adjudication of pelvic radiographs was considered necessary in 10 (15\%) of 68 patients because of disagreement between the first 2 readers.

Table 6.1 Baseline characteristics.

\begin{tabular}{|c|c|c|}
\hline Characteristic & $\begin{array}{l}\text { All patients } \\
\qquad(n=68)\end{array}$ & $\begin{array}{l}\text { Patients with complete M RI follow- } \\
\qquad \begin{array}{l}\text { up data } \\
(n=44)\end{array}\end{array}$ \\
\hline Male sex & $26(38)$ & $15(34)$ \\
\hline M ean age (SD) [years] & $34.9(10.3)$ & $36.0(11.7)$ \\
\hline M edian symptom duration (IQR) [months] & $18(12-24)$ & $18(12-24)$ \\
\hline HLA-B27 positive & $31(46)$ & $17(39)$ \\
\hline History of inflammatory bowel disease & $10(15)$ & 7 (16) \\
\hline History of anterior uveitis & $10(15)$ & $8(18)$ \\
\hline History of psoriasis & $16(24)$ & $12(27)$ \\
\hline History of peripheral arthritis & $19(28)$ & $12(27)$ \\
\hline Family history of SpA & $37(54)$ & $26(59)$ \\
\hline M ean CRP (SD) [mg/l] & $9(11)$ & $9(12)$ \\
\hline Elevated CRP ${ }^{\mathrm{a}}$ & $16(24)$ & $10(22)$ \\
\hline M ean ESR (SD) [mm] & $13(15)$ & $13(16)$ \\
\hline Elevated ESR ${ }^{\mathrm{a}}$ & $24(36)$ & $13(30)$ \\
\hline Presence of BME on M RI & $24(35)$ & $14(32)$ \\
\hline Fulfillment ASAS axSpA criteria & $40(59)$ & $22(50)$ \\
\hline Fulfillment mNY criteria & $15(22)$ & $9(20)$ \\
\hline Fulfillment ESSG criteria & $58(85)$ & $39(89)$ \\
\hline Fulfillment Amor criteria & $48(71)$ & $31(70)$ \\
\hline
\end{tabular}

The values are expressed as number (percentage) of patients unless stated otherwise. ESpAC=Early Spondyloarthritis Clinic; SpA=spondyloarthritis; IQR=interquartile range; $S D=s t a n d a r d$ deviation; $C R P=C$ -

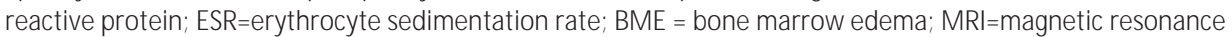
imaging; ESSG=European Spondyloarthropathy Study Group; ASAS=Assessment in SpondyloArthritis international Society; axSpA=axial spondyloarthritis; $\mathrm{mNY}$ criteria=modified New York criteria. ${ }^{a}$ In 66 of 68 patients baseline CRP and ESR measurements were available. ESR normal range: $\leq 7 \mathrm{~mm}$ for males; $\leq 12 \mathrm{~mm}$ for females. CRP cut-off value, normal range: $<10 \mathrm{mg} / \mathrm{l}$.

Sixty-six (97\%) patients fulfilled the Calin criteria at baseline. The remaining 2 (3\%) patients fulfilled 3 of the 5 Calin criteria and reported 'night pain'. At baseline, 40 (59\%) out of 68 patients fulfilled the ASAS axSpA criteria. Twenty-two patients fulfilled both the imaging and clinical arm of the ASAS axSpA criteria; 9 patients only fulfilled the imaging arm and 9 patients only fulfilled the clinical arm. At baseline, 58 (85\%) patients fulfilled the ESSG criteria, 48 (71\%) patients the Amor criteria, and 15 (22\%) patients the mNY criteria. None of the patients met the mNY criteria for the first time at followup visits. 
The estimated marginal (EM) mean score for BME lesions on MRI was 6.8 at baseline; 4.6 at 1 -year follow-up; 5.0 at 2 -years follow-up ( $p=0.21$ ).

\section{Baseline distribution and frequency of occurrence of BME}

Per patient. In total, 24 (35\%) patients had signs of BME on M RI-SIJ at baseline. Per SIJ-quadrant. Table 2 shows that in all four quadrants of the SIJ, BME could be detected on MRI. The right caudal iliac quadrant of the SIJ was slightly more affected than other SIJ-quadrants. BME was detected in the right caudal iliac quadrant in 16 (24\%) out of 68 patients at baseline. In the remaining SIJ-quadrants, BM E was detected in 8 to 13 (12\%-19\%) out of 68 patients at baseline.

\section{Evolution of BME in the SIJs at follow-up}

Per patient. Figure 6.1 shows the fulfilment of the ASAS axSpA criteria at baseline and at the last follow-up in 62 patients with at least one follow-up MRI and pelvic radiograph available. In 23 of 24 patients with BME at baseline, follow-up MRI was available. BME subsided completely in 7 (30\%) of these 23 patients at the last available follow-up M RI. Four of these 7 patients fulfilled the MNY criteria at baseline and followup, and would therefore remain in the imaging arm of the ASAS axSpA criteria at the last available follow-up examination. The other 3 patients did not fulfil the mNY criteria, were HLA-B27 negative, and because BME on MRI also completely subsided, these patients would - without prior knowledge of the baseline MRI - not longer fulfil the ASAS axSpA criteria at the last available follow-up examination. All these 3 patients, however, still fulfilled the ESSG and Amor classification criteria because of various combinations of other SpA features such as psoriasis, anterior uveitis, peripheral arthritis and/or a positive family history for SpA, besides the presence of IBP.

At least one follow-up MRI was available in 39 of the 44 patients without BME on MRI at baseline. In 6 (15\%) of these patients, BME was detected on at least 1 follow-up M RI. Three of these patients already fulfilled the imaging and clinical arm of the ASAS axSpA criteria, because of radiographic sacroiliitis at baseline and a positive HLA-B27 status. The other 3 patients newly fulfilled the ASAS axSpA criteria at follow-up (Figure 6.1). However, 2 of these 3 patients already fulfilled the ESSG and Amor criteria at baseline. 


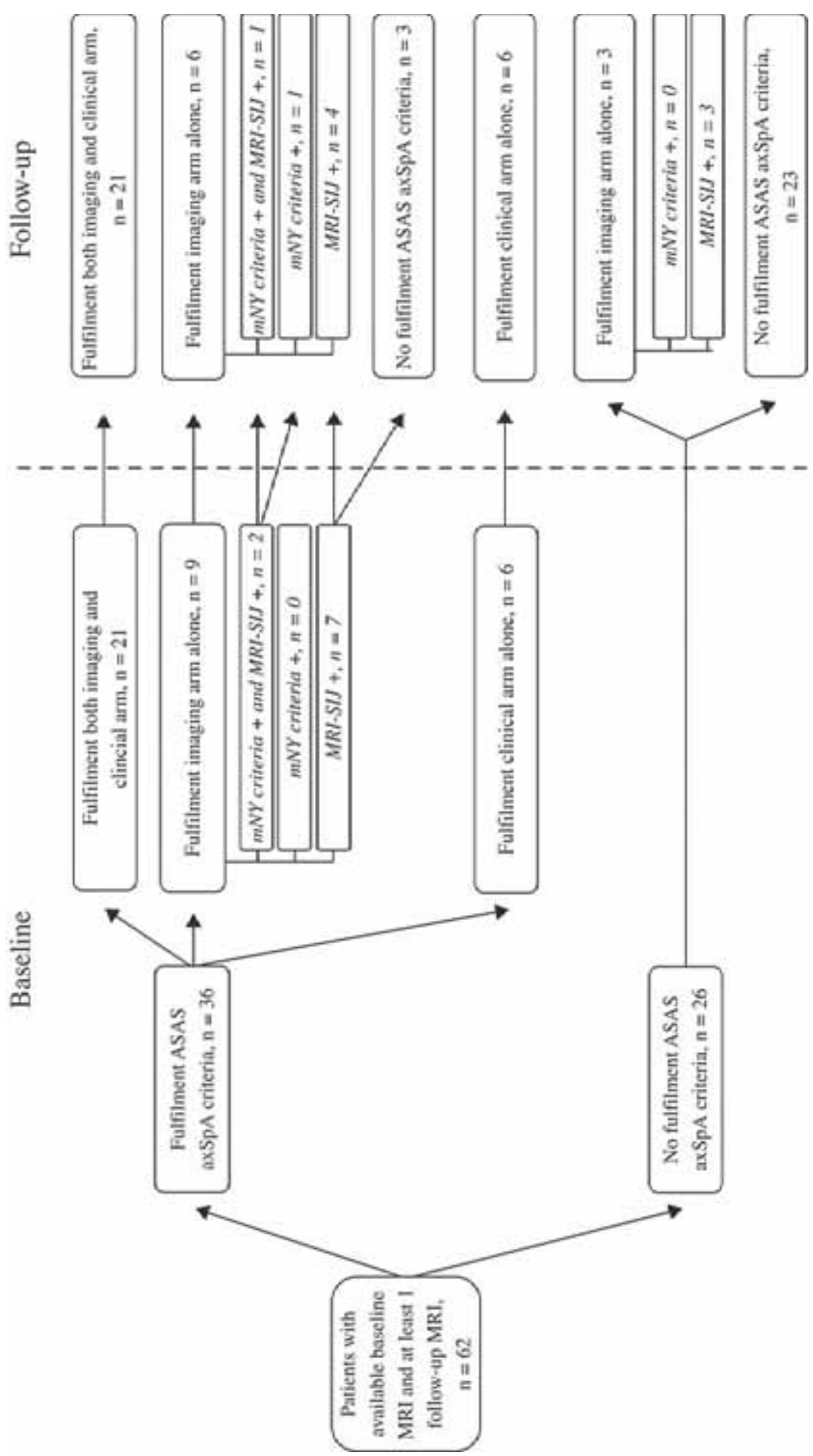

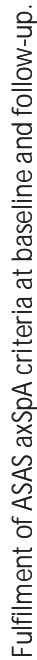

문
0
$\frac{0}{3}$
인 
Per SIJ-quadrant. Table 6.2 shows that BME remained present in $53 \%$ of the SIJquadrants (range $29 \%$ to $69 \%$ ) at follow-up and was persistent most frequently in the right and left caudal iliac quadrants (table 2). BME subsided in $47 \%$ of the SI-quadrants (range $33 \%$ to $71 \%$ ) and was newly detected at the last follow-up moment in approximately $8 \%$ of the SI-quadrants (range $2 \%$ to $11 \%$ ). Most of these lesions were detected in the right and left caudal sacral quadrants (Table 6.2).

Table 6.2 Presence of BME on M RI per SIJ quadrant at baseline and follow-up.

\begin{tabular}{|c|c|c|c|}
\hline \multirow[t]{2}{*}{ SIJ quadrant } & \multirow{2}{*}{$\begin{array}{c}\text { Baseline } \\
\begin{array}{c}\text { Presence of BM E } \\
\text { (yes vs no) }\end{array}\end{array}$} & \multicolumn{2}{|c|}{ Last follow-up M RI* } \\
\hline & & Presence of BME & Absence BME \\
\hline \multirow[t]{2}{*}{ Right proximal iliac quadrant } & Yes $(n=10)$ & $3(30)$ & $7(70)$ \\
\hline & No $(n=52)$ & $1(2)$ & $51(98)$ \\
\hline \multirow[t]{2}{*}{ Right proximal sacral quadrant } & Yes $(n=8)$ & $5(62)$ & $3(38)$ \\
\hline & No $(n=54)$ & $3(6)$ & $51(94)$ \\
\hline \multirow[t]{2}{*}{ Right caudal iliac quadrant } & Yes $(n=16)$ & $9(56)$ & $7(44)$ \\
\hline & No $(n=46)$ & $5(11)$ & $41(89)$ \\
\hline \multirow[t]{2}{*}{ Right caudal sacral quadrant } & Yes $(n=8)$ & $5(62)$ & $3(38)$ \\
\hline & No $(n=54)$ & $6(11)$ & $48(89)$ \\
\hline \multirow[t]{2}{*}{ Left proximal iliac quadrant } & Yes $(n=11)$ & $6(55)$ & $5(45)$ \\
\hline & No $(n=51)$ & $3(6)$ & $48(94)$ \\
\hline \multirow[t]{2}{*}{ Left proximal sacral quadrant } & Yes $(n=14)$ & $4(29)$ & $10(71)$ \\
\hline & No $(n=48)$ & $3(6)$ & $45(94)$ \\
\hline \multirow[t]{2}{*}{ Left caudal iliac quadrant } & Yes $(n=13)$ & $9(69)$ & $4(31)$ \\
\hline & No $(n=49)$ & $4(8)$ & $45(92)$ \\
\hline \multirow[t]{2}{*}{ Left caudal sacral quadrant } & Yes $(n=9)$ & $6(67)$ & $3(33)$ \\
\hline & No $(n=53)$ & $6(11)$ & $47(89)$ \\
\hline
\end{tabular}

$\mathrm{n}=62$ patients.* Follow-up at 1 or 2 years, depending on last MRI. The values are expressed as number (percentage) of patients unless stated otherwise. SIJ =sacroiliac joint; BME=bone marrow edema, $\mathrm{MRI}=$ magnetic resonance imaging.

\section{DISCUSSION}

The present study, in a cohort of patients with early IBP suspected for axSpA, demonstrated that BME subsided completely in approximately half of the SI-quadrants during follow-up and in $30 \%$ of the patients with a positive MRI-SIJ at baseline. On average, in less than $10 \%$ of the SI-quadrants, BME was newly detected at some point in time during follow-up. Not taking into account the baseline MRI, $13 \%$ of the patients would not fulfil the ASAS axSpA criteria at a follow-up moment, as a consequence of fluctuations of BME on MRI. Another $8 \%$ of patients newly fulfilled the ASAS axSpA criteria at follow-up. 
In daily practice, MRI-SIJ is ordered when a diagnosis of non-radiographic (nr)-axSpA is suspected on clinical grounds and conventional pelvic radiographs are normal or inconclusive. In this context, subsiding or fluctuating BME may affect the sensitivity of MRI in detecting sacroiliitis and subsequently could cause a delay in the diagnosis of axSpA. In addition, for clinical trials it is important to be aware of the fluctuating course of BME on MRI, which may in fact be the natural course instead of any treatment effect. This is illustrated by a study of Barkham et al. that evaluated the efficacy of infliximab on inflammation detected on MRI in HLA-B27 positive patients with recentonset IBP.[10] In the treatment group, $62.7 \%$ of the BME lesions detected on M RI-SIJ at baseline had completely subsided at week 16 . Remarkably, in the placebo group, $29.4 \%$ of BME lesions detected at baseline had also completely subsided at week 16.[10] In a study by Marzo-Ortega et al., the frequency of BME lesions on M RI-SIJ was evaluated over a 1-year follow-up period in patients with early IBP.[11] Of the 34 patients with a baseline and follow-up MRI, the majority (73.5\%) of the patients still had BME on MRISIJ at 1-year follow-up, but the overall disease activity score, defined by the extent of BME, had decreased.[11] These findings are consistent with the results of our present study. However, in contrast to the study of Barkham and Marzo-Ortega et al., our study not only evaluated the presence of BME per SII-quadrant over a 2-year follow-up period, but also incorporated its exact localisation. In a previous study with data from the ESpAC study, we have demonstrated that both HLA-B27 status (odds ratio (OR) 8.1, $95 \%$ confidence interval $(\mathrm{Cl}) 2.3-28.3, p<0.001$ ) and M RI status at baseline (OR 22.0, $95 \% \mathrm{Cl} 6.1$ - 79.6, $\mathrm{p}<0.001$ ) were strongly and independently associated with a positive M RI-SIJ over time.[12]

Some MRI studies reported that the caudal parts of the SIJ are more frequently affected than the proximal parts in patients with nr-axSpA and ankylosing spondylitis.[13,14] These findings contribute to the notion that inflammation is merely present in the lower synovial dorsocaudal part of the SIJ. This assumption is supported by histologic studies. $[15,16]$ In our study we found that the percentage of affected SIquadrants is rather equally distributed, although there is a slight preference for the caudal iliac Sl-quadrants, observed both at baseline and at follow-up. This corresponds with a study by Althoff et al., in which no difference in the amount of BME between SIquadrants was detected in patients with axSpA with a symptom duration of $\leq 5$ years.[17]

It is known that approximately one third of the patients with axSpA according to experts do not fulfil the imaging arm of the ASAS axSpA criteria.[2,18] Several factors might contribute to this restricted sensitivity of the imaging arm. First, MRI of the spine 
is not included in the imaging arm of the ASAS axSpA criteria. However, up to $70 \%$ of the patients with axSpA may have spinal inflammation, even in the absence of active lesions on M RI of the SIJs.[18] Second, structural changes (i.e. erosions) on M RI are not considered for the definition of a positive MRI-SII.[2] Recent data, however, suggest that assessment of erosions on MRI-SIJ may enhance the diagnostic utility of MRI in early axSpA.[19] Finally, although MRI might be the most sensitive imaging modality for detection of SIJ inflammation, not all inflammation is captured by MRI. A study has shown that in biopsies taken from the SIJ clear inflammation on histology was found, whereas this was not visible on the concurrently performed MRI.[20]

There are several limitations of this study that need to be addressed. First, the MR images were scored by one reader only for reasons of experienced reader availability, which may in theory influence the reliability of the data. However, this reader (a musculoskeletal radiologist, and member of the ASAS/OMERACT MRI working group) was highly experienced, the MRIs were scored with unknown time sequence, and blinding was preserved for clinical and laboratory findings.[1] The intra-observer agreement of our reader was very good in another study that evaluated BME on MRISIJs in patients with early axial spondyloarthritis, using the Danish (Aarhus) scoring method (weighted kappa value 0.96 (95\%-confidence interval: 0.92-0.98)).[21] Further, a high inter-observer agreement among experienced readers for scoring of MRI-SIJS has been reported in previous studies.[8,22] These arguments reasonably justify an unbiased acquisition of M RI-scores.

Second, the interval between 2 M RI examinations was 1 year. Serial M RI examinations at for instance 3- or 6 months follow-up could provide more information about short term fluctuations of BME on MRI-SIJ. Third, the MRI scoring method used in the present study is a combination of the SPARCC and Aarhus grading method which is not as such formally validated. $[8,9]$ The disadvantage of the SPARCC grading method is that a maximum of 6 slices are scored. With our modification an unlimited number of slices could be evaluated, while ensuring that the same (number of) slices were scored per patient over time. The advantage of this method is that all qualitatively optimal slices are scored, thereby maximising the chance of detecting active lesions. Furthermore, a general concern when scoring M RI-SIJ is the possibility of misalignment between two successive MRI examinations, which may eventually result in measurement error. We have ensured that the scoring starts and ends at the same anatomical level, so that the risk of misalignment is minimized.

Fourth, in ESPAC, the use of NSAIDs was allowed. Detailed information about the use of NSAIDs per patient is not available, so that the effects of NSAIDs on MRI-scores could 
not be studied. It is therefore unclear whether continuous or on-demand treatment with NSAIDs may ultimately have led to subsiding inflammation detected on MRI. Results from the second part of the Infliximab as First Line Therapy in Patients with Early Active Spondyloarthritis Trial (INFAST) suggest that it may not be different. In this study, patients who continued naproxen were compared with patients who discontinued therapy. At the end of the follow-up period, complete absence of lesions on M RI-SIJ was found in similar numbers of patients in the naproxen and no-treatment groups (7.5\% vs. 10.0\%).[23] Fifth, ESpAC patients were not given a clinical diagnosis of axSpA. However, 40 (59\%) patients fulfilled the ASAS axSpA criteria at baseline. The overall sensitivity and specificity of the ASAS axSpA criteria is $82.9 \%$ and $84.4 \%$, respectively. The diagnostic performance of the ASAS axSpA criteria is good, with an overall post-test probability of $89 \%$.[2] Considering the characteristics of the ASAS axSpA criteria and the caveats related to the diagnostic utility of MRI in axSpA, most patients included in the ESpAC that fulfil the ASAS axSpA criteria, will probably also have or develop a clinical diagnosis of axSpA. Unfortunately, patients were not actively followed after the study was terminated. Finally, ESpAC is a relatively small cohort including patients referred by (related) medical specialties (i.e. dermatology, gastroenterology) and relatives of members of the local ankylosing spondylitis society. This recruitment strategy may therefore explain the high proportion of patients fulfilling at least one of the classification criteria for SpA. Furthermore, the proportion of male patients in ESpAC is relatively low (38\%) and the proportion of patients with a negative HLA-B27 status is relatively high (54\%). However, these percentages are in accordance with other cohorts that included patients with early IBP suspected for axSpA $(24,25)$. In the SPondyloArthritis Caught Early (SPACE)-cohort, for example, the proportion of male patients among axSpA patients is $48 \%$, and the proportion of patients with a negative HLA-B7 status is 20\%.[24] In the Devenir des Spondylarthropathies Indifférenciées Récentes (DESIR)-cohort these proportions are $46 \%$ and $43 \%$, respectively.[25]

In conclusion, in this cohort of 68 patients presenting with recent-onset IBP, BME on MRI was equally distributed throughout the SIJs, with a slight preference for the caudal iliac quadrants. Nearly half of the BME lesions subsided during follow-up. These changes in MRI status are important and should be taken into account in clinical practice when evaluating patients with IBP suspected for axSpA and may have an impact on the overall performance of the ASAS axSpA criteria. 


\section{REFERENCES}

1. Rudwaleit M, Jurik AG, Hermann KG, et al. Defining active sacroiliitis on magnetic resonance imaging (MRI) for classification of axial spondyloarthritis: a consensual approach by the ASAS/OM ERACT MRI group. Ann Rheum Dis 2009;68:1520-7.

2. Rudwaleit $M$, van der Heijde D, Landewé R, et al. The development of Assessment of Spondyloarthritis international society classification criteria for axial spondyloarthritis (part II): validation and final selection. Ann Rheum Dis 2009;68:777-83.

3. Heuft-Dorenbosch L, Landewé R, Weijers R, et al. Performance of various criteria sets in patients with inflammatory back pain of short duration; the Maastricht early spondyloarthritis clinic. Ann Rheum Dis 2007;66:92-8.

4. Calin A, Porta J, Fries JF, et al. Clinical history as a screening test for ankylosing spondylitis. JAM A 1977;237:2613-4.

5. Van der Linden S, Valkenburg HA, Cats A. Evaluation of diagnostic criteria for ankylosing spondylitis. A proposal for modification of the New York Criteria. Arthritis Rheum 1984;27:361-8.

6. Dougados $M$, van der Linden $S$, Juhlin $R$, et al. The European Spondylarthropathy Study Group preliminary criteria for the classification of spondylarthropathy. Arthritis Rheum 1991;34:1218-27.

7. Amor B, Dougados M, Listrat V, et al. Are classification criteria for spondylarthropathy useful as diagnostic criteria? Rev Rhum Engl Ed 1995;62:10-5.

8. Maksymowych WP, Inman RD, Salonen D, et al. Spondyloarthritis research consortium of Canada magnetic resonance imaging index for assessment of sacroiliac joint inflammation in ankylosing spondylitis. Arthritis Rheum 2005;53:703-9.

9. Puhakka KB, Jurik AG, Egund N, et al. Imaging of sacroiliitis in early seronegative spondyloarthropathy. Assessment of abnormalities by MR in comparison with radiography and CT. Acta Radiol 2003;44: 218-29.

10. Barkham N, Keen HI, Coates LC, et al. Clinical and imaging efficacy of infliximab in HLA-B27-Positive patients with magnetic resonance imaging-determined early sacroiliitis. Arthritis Rheum 2009;60:94654.

11. Marzo-Ortega $\mathrm{H}, \mathrm{M}$ cGonagle $\mathrm{D}, \mathrm{O}^{\prime}$ Connor $\mathrm{P}$, et al. Baseline and 1-year magnetic resonance imaging of the sacroiliac joint and lumbar spine in very early inflammatory back pain. Relationship between symptoms, HLA-B27 and disease extent and persistence. Ann Rheum Dis 2009;68:1721-7.

12. Van Onna M, Jurik AG, van der Heijde D, et al. HLA-B27 and gender independently determine the likelihood of a positive M RI of the sacroiliac joints in patients with early inflammatory back pain: A twoyear M RI follow-up study. Ann Rheum Dis 2011;70:1981-5.

13. Muche $B$, Bollow $M$, François RJ, et al. Anatomic structures involved in early- and late-stage sacroilitis in spondylarthritis: a detailed analysis by contrast-enhanced magnetic resonance imaging. Arthritis Rheum 2003;48:1374-84.

14. Weber U, Pfirrmann CW, Kissling RO, et al. Whole body MR imaging in ankylosing spondylitis: a descriptive pilot study in patients with suspected early and active confirmed ankylosing spondylitis. BM C M usculoskelet Disord 2007;8:20.

15. François RJ, Gardner DL, Degrave EJ, et al. Histopathologic evidence that sacroiliitis in ankylosing spondylitis is not merely enthesitis. Arthritis Rheum 2000;43:2011-24.

16. Puhakka $K B$, M elsen $F$, Jurik $A G$, et al. MR imaging of the normal sacroiliac joint with correlation to histology. Skeletal Radiol 2004;33:15-28.

17. Althoff $\mathrm{CE}$, Sieper J, Song $\mathrm{IH}$, et al. Active inflammation and structural change in early active axial spondyloarthritis as detected by whole-body M RI. Ann Rheum Dis 2013;72:967-73.

18. Sieper J, van der Heijde D. Review: Nonradiographic axial spondyloarthritis: new definition of an old disease? Arthritis Rheum 2013;65:543-51.

19. Weber U, Zubler V, Pedersen SJ, et al. Development and validation of an MRI reference criterion for defining a positive SIJ M RI in spondyloarthritis. Arthritis Care Res (Hoboken) 2013;65:977-85.

20. Gong $Y$, Zheng N, Chen SB, et al. Ten years' experience with needle biopsy in the early diagnosis of sacroiliitis. Arthritis Rheum 2012;64:1399-406.

21. Arnbak B, Jensen TS, Manniche $C$, et al. Spondyloarthritis-related and degenerative M RI changes in the axial skeleton--an inter- and intra-observer agreement study. BM C M usculoskelet Disord 2013;14:274. 
22. eber U, Maksymowych WP, Jurik AG, et al. Validation of whole-body against conventional magnetic resonance imaging for scoring acute inflammatory lesions in the sacroiliac joints of patients with spondylarthritis. Arthritis Rheum 2009;61:893-9.

23. Sieper J, Lenaerts J, Wollenhaupt J, et al. A randomised, open- label study to explore whether partial remission van be maintained with naproxen or no treatment in patients with early, active axial spondyloarthritis: preliminary results results of INFAST Part II. Ann Rheum Dis 2012;71 Suppl:248.

24. van den Berg R, de Hooge $M$, Rudwaleit $M$, et al. ASAS modification of the Berlin algorithm for diagnosing axial spondyloarthritis: results from the SPondyloArthritis Caught Early (SPACE)-cohort and from the Assessment of SpondyloArthritis international Society (ASAS)-cohort. Ann Rheum Dis 2013;72:1646-53.

25. Dougados M, d'Agostino MA, Benessiano J, et al. The DESIR cohort: a 10-year follow-up of early inflammatory back pain in France: study design and baseline characteristics of the 708 recruited patients. Joint Bone Spine 2011;78:598-603. 



\section{PART III}

Timely identification of spondyloarthritis in primary care 



\section{CHAPTER 7}

General practitioners' perceptions of their ability to identify and refer patients with suspected axial spondyloarthritis: a qualitative study 


\section{ABSTRACT}

\section{Objectives}

To explore the knowledge, beliefs and experiences of general practitioners (GPs) about inflammatory back pain (IBP) and axial spondyloarthritis (axSpA) and potential barriers for referral of patients suspected for axSpA.

\section{Methods}

A qualitative study involving semi-structured interviews with GPs was conducted. Transcripts of the interviews were independently read and annotated by 2 readers. Illustrative themes were identified and a coding system to categorize the data was developed.

\section{Results}

Ten GPs (all men; mean age 49 years) were interviewed. All could adequately describe "classic" ankylosing spondylitis (AS) and mentioned chronic back pain and/or stiffness as key features. All GPs thought that AS is almost exclusively diagnosed in men. Six GPS knew that there is a difference between mechanical back pain (M BP) and IBP, but could recall only a limited number of parameters indicative of IBP, such as: awakening night pain (4 GPs), insidious onset of back pain (1 GP), improvement with movement (1 GP) and (morning) stiffness (2 GPs). Two GPs mentioned peripheral arthritis as other SpA features, none mentioned dactylitis or enthesitis. GPs' awareness of associated extraarticular manifestations was low. Most GPs expressed that (practical) referral parameters would be useful.

\section{Conclusion}

GPs are aware of "classic", but long-term features of axSpA. Knowledge about the disease spectrum and early detection is, however, limited. Addressing these issues in training programmes may improve better recognition of axSpA in primary care. This may ultimately contribute to earlier referral, diagnosis, and initiation of effective treatment in patients with axSpA. 


\section{INTRODUCTION}

Spondyloarthritis (SpA) comprises a group of interrelated inflammatory disorders with overlapping clinical features and shared genetic markers. The estimated prevalence of SpA in Caucasian populations is approximately $1 \%$, similarly to that of rheumatoid arthritis.[1] Symptom patterns and physical signs of SpA can be divided into predominantly axial involvement, with inflammatory back pain (IBP) as the most important clinical feature and predominantly peripheral involvement including peripheral arthritis, dactylitis and enthesitis.[2] Extra-articular manifestations related to axial and peripheral SpA include psoriasis, anterior uveitis and inflammatory bowel disease.

Axial SpA (axSpA) comprises a disease continuum, including both non-radiographic axSpA and ankylosing spondylitis (AS).[3] Patients with non-radiographic axSpA have similar clinical characteristics, disease activity and response to treatment as patients with established AS, emphasizing the need for early and correct diagnosis.[4] However, the diagnosis of axSpA is often delayed due to the insidious onset, the heterogeneous clinical picture, and a limited knowledge about the manifestations belonging to axSpA by general practitioners (GPs) or other referring physicians.[5] Offering tools for referral may be helpful in improving early diagnosis. Several initiatives have been performed to study the effect of referral strategies in primary care. The objectives of these referral programs were to identify patients with possible axSpA early, make a correct diagnosis, and to provide the best possible care as early as possible.[6] However, limited knowledge of manifestations belonging to axSpA might prevent successful implementation of these referral strategies in the primary care setting. The aim of the present qualitative study is to explore by using semi-structured interviews the knowledge, beliefs and experiences of GPs about IBP and axSpA, and the potential barriers for referral of patients suspected for axSpA.

\section{MATERIALS AND METHODS}

\section{Study design and participants}

For this qualitative study, GPs, acquainted with the interviewers, without known specific interest or knowledge of musculoskeletal diseases and with various years of experience, were invited for a semi-structured interview. A semi-structured interview is a technique to collect qualitative data about the topic of interest by combining open 
questions with the option to further explore particular answers.[7] The duration of one interview was about one hour. The interviews took place in 2012 and all invited GPs were working in the region of Limburg, The Netherlands. The study was approved by the ethics committee from the Maastricht University Medical Center. All participants provided written informed consent and thereby agreed to present the collected data and quotes in anonymized form.

\section{Data collection}

An interview guide that consisted of both open- and closed-ended questions was developed to secure uniform data quality and comparability. A pilot interview was conducted to ensure that the questions were clear and addressed all important topics. Each interview was audio-taped and afterwards fully transcribed. Each transcript was offered to the matching GP to review for validation.

The topics addressed in the interview included:

- General questions: age, working experience in years as a GP, specific medical interests.

- Approach to patients presenting with chronic back pain, knowledge about symptoms indicative of mechanical back pain (M BP) or IBP, management of back pain, motivating factors to refer a patient to a rheumatologist.

- Perceptions and knowledge about axSpA, including non-radiographic axSpA and AS. Awareness about diagnostic delay, knowledge of extra-articular manifestations of axSpA.

- Approach to patients already diagnosed with axSpA, disease management.

- Awareness about treatment options and opinion of GPs about the current standards of care for patients with axSpA.

\section{Data analysis}

The transcripts were independently analyzed by 2 readers. All transcripts were repeatedly read and annotated. A coding system based on the grounded theory approach was developed by defining categories and developing a taxonomy of the data.[7] The readers met regularly to discuss coding and interpretation of data. In case of disagreement, consensus was reached between the two readers after re-reading the specific passage of the transcript. While analyzing the data, illustrative quotes made by GPs were collected. 


\section{RESULTS}

\section{Participant characteristics}

Ten of 16 invited GPs agreed to participate and were interviewed. All included GPs were men and the mean age was 49 years (range 37-58 years; standard deviation (SD) 6.4 years). The mean number of years of experience as a GP was 20 years (range 10-29 years; SD 6.0 years). Three GPs had a specific interest in musculoskeletal disorders. When GPs were asked to estimate the mean number of patients with AS registered in their practice, the range of answers was between 0 and "more than 10" patients (without further specification).

When analyzing the data, a number of themes and patterns were identified across the interviews. These themes and patterns are described below and exemplified in quotes (Table 7.1).

\section{Ability to differentiate MBP from IBP}

Four GPs were not familiar with the terms M BP and IBP (quote 1). Six GPs knew that there is a difference between MBP and IBP, but these GPs could recall only a limited number of typical parameters to differentiate MBP from IBP. Four of these 6 GPS mentioned awakening night pain as a typical feature of IBP and considered it a relevant symptom that needed attention (quote 2). Two GPs also mentioned insidious onset of back pain and improvement of back pain with movement as typical features of IBP. Morning stiffness was mentioned by 2 GPs. Seven GPs mentioned stiffness of the back as typical for AS but did not elaborate on the course of stiffness during the day.

\section{Knowledge about the terms "classic" AS and axSpA and awareness about diagnostic delay}

All GPs were familiar with the term AS and mentioned back pain and/or stiffness of the back as prominent features of AS. Three GPs also considered (severe) kyphosis as an important feature of AS. None of the GPs could give an adequate description of the term axSpA.

When asked about the age at onset of first symptoms, all GPs answered that symptoms first appear in early adulthood. All GPs thought that AS is almost exclusively diagnosed in men. Two GPs thought that the delay in diagnosis was less than one year. The remainder of GPs answered that the delay in diagnosis was up to several years, without 
further specification. A few GPs commented that this is probably due to a patients' and doctors' delay (quote 3).

Table 7.1 Illustrative quotes made by general practitioners.

\begin{tabular}{|c|c|}
\hline Quote* & \\
\hline 1 & $\begin{array}{l}\text { "I really do not know the difference between mechanical and inflammatory back pain. I do not see a } \\
\text { lot of patients with a history of inflammatory back pain. (...)When a patient has back pain for a long } \\
\text { period of time, I usually refer them to a rheumatologist. But it certainly would not surprise me if } \\
\text { there are several undiagnosed patients with AS in my practice." }\end{array}$ \\
\hline 2 & $\begin{array}{l}\text { "If a patient presents with a history of back pain, I ask if he or she can still perform household } \\
\text { chores and work-related duties. I ask if the pain is continuous or not and if there is night pain or } \\
\text { pain when waking-up. (...) When there are signs of awakening night pain, I tend to look more } \\
\text { seriously at the symptoms. During the physical examination I check the range of motion and the } \\
\text { stiffness of the back." }\end{array}$ \\
\hline 3 & $\begin{array}{l}\text { "I think that the time between first complaints and diagnosis of AS varies. There is a patient delay, } \\
\text { but also a doctor delay. When there are family members with AS, you tend to look more seriously } \\
\text { and will probably refer this patient to a rheumatologist at an early stage. But if this is not the case... } \\
\text { How long it will take before a GP will refer a patient with chronic back pain? I do not know, months } \\
\text { to years maybe?" }\end{array}$ \\
\hline 4 & $\begin{array}{l}\text { "Whether I can mention other symptoms associated with AS? Eye complaints probably, but I do not } \\
\text { think it is very typical. Conjunctivitis maybe? Psoriasis also, but that is not really inflammation, but it } \\
\text { belongs to another group of auto-immune disorders. It is not really clear to me." }\end{array}$ \\
\hline 5 & $\begin{array}{l}\text { "If the HLA-B27 test is positive or negative, it will not solve the diagnostic problem. When the test is } \\
\text { positive, you think, "OK, maybe...", but what to do when the test is negative? In case of a negative } \\
\text { test result, that does not mean that the patient does not have AS. I still have to refer the patient to } \\
\text { the rheumatologist." }\end{array}$ \\
\hline 6 & $\begin{array}{l}\text { "When a patient presents with a history of low back pain and there are no abnormalities on the X- } \\
\text { ray, I will refer this patient to the neurologist. It is very unlikely that I refer this patient to the } \\
\text { rheumatologist. Provided that low back pain is the only symptom." }\end{array}$ \\
\hline 7 & $\begin{array}{l}\text { "I want to know more about how to recognize AS. Are there specific tools or diagnostic tests you } \\
\text { can use as a GP to make a diagnosis of AS more or less likely? If so, I will perform those tests and } \\
\text { consult a rheumatologist or I will refer the patient. I also want to know more about how you treat } \\
\text { patients with AS. What are the results?" }\end{array}$ \\
\hline 8 & $\begin{array}{l}\text { "I think that I miss the diagnosis frequently. Yes, too many times. The reason for this? Probably due } \\
\text { to lack of knowledge." }\end{array}$ \\
\hline
\end{tabular}

* Quotes were translated from Dutch.

\section{Knowledge about associated clinical manifestations of axSpA}

Most GPs could describe only a limited number of clinical features belonging to axSpA. Two GPs considered peripheral arthritis as belonging to the spectrum of axSpA; dactylitis and enthesitis were not mentioned at all. When asked about extra-articular manifestations of patients with axSpA, 5 GPs mentioned anterior uveitis and 1 GP 
mentioned "eye complaints" (quote 4). Inflammatory bowel disease was mentioned by 2 GPs and psoriasis by 3 GPs.

\section{Use of diagnostic tests in the primary care setting}

None of the GPs would order a Human Leukocyte Antigen (HLA)-B27 test when a patient presents with chronic back pain. A few GPs commented that this test should only be ordered by the rheumatologist (quote 5). Most GPs specifically commented that they would only order a conventional radiograph in case of chronic back pain. One GP mentioned that a normal pelvic radiograph in a patient presenting with back pain, would be a motivating factor to refer this patient to a neurologist and not a rheumatologist (quote 6).

\section{Perceptions about management of axSpA}

A decrease in pain and stiffness of the back and maintaining function were judged as the most important treatment goals by the majority of the GPs. The use of nonsteroidal-anti-inflammatory drugs (NSAIDs) were considered an adequate treatment option by all GPs. M ost GPs also mentioned physical therapy or that the patient should do home-based exercises. Five GPs indicated that anti-TNF-alpha therapy can be prescribed to patients with axSpA. Four GPs were aware of the fact that an increased risk of (serious) infections is an important side effect of anti-TNF-alpha therapy.

\section{Preferences for educational programmes about axSpA}

Most GPs expressed that (practical) referral parameters to decrease the delay in diagnosis would be useful in clinical practice (quote 7). Most GPs also wanted to know more about the treatment options, including anti-TNF-alpha therapy. One GP revealed that he recently visited an educational training that focused on axSpA. At the end of this training he realized that there were probably several undiagnosed patients in his practice (quote 8).

\section{DISCUSSION}

The present study demonstrated that there are several inconsistencies in the perceptions of GPs about diagnosis and management of axSpA, including AS. M ost GPS could provide an adequate description about "classic" AS and were aware of the fact 
that there is a substantial delay in diagnosis. GPs also knew that there is a difference between M BP and IBP, but were unable to explain how to differentiate MBP from IBP. Knowledge about the disease spectrum of axSpA and associated extra-articular manifestations was limited. All GPs were aware of the benefits of physiotherapy and NSAIDs, and half of the GPs knew that anti-TNF-alpha therapy can be prescribed in patients with axSpA.

Chronic back pain is a common symptom in the general population and it is estimated that in $5 \%$ of these cases axSpA is the underlying disease.[8] In approximately $75 \%$ of the patients with axSpA, the chronic back pain has an inflammatory character. Several criteria sets to define IBP have been proposed, consisting of several parameters in order to differentiate IBP from M BP. Single parameters were insufficiently predictive in defining IBP, because they are also frequently present in patients without an inflammatory cause of their back pain.[9] Overall, the IBP criteria sets have a comparable sensitivity and specificity of about 75-80\%.[9-11] IBP has been tested as a single referral parameter and as part of a composite referral strategy in several studies. [5,12-14] When patients were referred by GPs because of IBP alone, axSpA was diagnosed in $16-33 \%$ of the referred patients.[5,12-13] However, when patients were referred because of IBP in combination with other parameters such as HLA-B27 or sacroiliitis on imaging, axSpA was diagnosed in $35-56 \%$ of the referred patients.[5,12,14]

Knowledge of important features associated with axSpA is essential before a referral strategy can successfully be implemented in the primary care setting. Six GPs in our study could recall only a few items indicative of IBP and 4 GPs were not familiar with the terms M BP and IBP. This was also observed in a study by Jois et al.[15] Only $5 \%$ of GPs in their study could identify all parameters indicative of IBP when a list of prespecified response choices was presented to them. Furthermore, recent studies have shown that the degree of agreement between referring physicians (including GPs) and rheumatologists when evaluating IBP in patients with suspected axSpA is poor (kappa values between $0.04-0.20)$.[5,16] Educating GPs about the full range of parameters indicative of IBP therefore seems the first step before IBP can successfully be used in a referral tool. The term "axial spondyloarthritis" will also increasingly be used in correspondence from rheumatologists to GPs. It is therefore important to make GPs also familiar with this new terminology.

In the present study, GPs could recall only a limited number of extra-articular manifestations associated with axSpA. In a some cases, GPs mentioned "eye complaints" or "skin problems". Dactylitis and enthesitis were not at all mentioned by 
the GPs in our study. Jois et al. also investigated the recognition of extra-articular manifestations of SpA by GPs.[15] Psoriasis, inflammatory bowel disease and uveitis were recognized as an extra-articular manifestation by respectively $96 \%, 68 \%$ and $60 \%$ of GPs, which is a higher proportion than in our small-sized study.[15] However, in our study open-ended questions were used, which probably resulted in lower response rates than the survey used in the study of Jois et al. All GPs in the present study also indicated that AS is almost exclusively diagnosed in men. Several recent studies that included patients with undifferentiated and non-radiographic axSpA, however, demonstrated that the gender ratio is more equally distributed.[17-19] Male gender has however been found to be a risk factor for developing radiographic sacroiliitis. $[20,21]$ Furthermore, patients with radiographic sacroilitis have in general higher inflammatory markers than patients with non-radiographic axSpA.[4,22] Increasing awareness among GPs that axSpA is equally present in females and males, and making them aware of the "SpA concept", which includes axial, but also peripheral and extra-articular manifestations, will likely facilitate referral and timely diagnosis.

Half of GPs in the present study were aware that the therapeutic armamentarium in patients with axSpA is broadened with the introduction of anti-TNF-alpha therapy. When GPs were asked about the side-effects of anti-TNF-alpha therapy, 6 GPs were not aware of the higher risk of (serious) infections. Collaboration and co-management together with the rheumatologist is essential in managing patients with axSpA. Education about (the side-effects of) anti-TNF therapy is therefore an important step to maintain and improve the general health status of a patient with axSpA.

In general, the level of knowledge about axSpA was low. None of the GPs could provide a specific reason for this lack of knowledge. Possible explanations are relatively low attention to this topic in medical school or at continuous medical education, and the large emphasis on a non-specific cause of chronic back pain.[23]

There are limitations in this present study that need to be addressed. The design of the study is qualitative and the number of GPs included is small. Furthermore, only male and experienced GPs were included in this study. Several female GPs were asked, but they unfortunately declined to participate. Logistically, it was extremely difficult to include recently qualified GPs, because in the Netherlands almost none of them have own practices. We cannot rule out that selection bias or knowledge bias has occurred. This may limit reproducibility of results and the ability to generalize them to a wider population. However, the main goal of this study was not to extrapolate the current findings to all GPs, but to explore the level of knowledge and awareness that probably 
need attention in future educational programmes. Furthermore, theoretical saturation was reached with this number of GPs.

In conclusion, most GPs were familiar with "classic" but long-term features of axSpA. Knowledge about parameters indicative of IBP and awareness about the full range of SpA features, including the associated extra-articular manifestations, was limited. The disease spectrum and management of axSpA have substantially changed over the last few years. Educating GPs about the leading presenting symptoms of axSpA and providing information about extra-articular disease manifestations and management of axSpA, will play a pivotal role in the successful referral of patients with suspected axSpA by GPs. This may ultimately contribute to earlier initiation of effective treatment and the improvement of quality of life. 


\section{REFERENCES}

1. Stolwijk C, Boonen A, van Tubergen A, et al. Epidemiology of spondyloarthritis. Rheum Dis Clin North Am 2012;38:441-76.

2. Rudwaleit M, Khan MA, Sieper J. The challenge of diagnosis and classification in early ankylosing spondylitis: do we need new criteria? Arthritis Rheum 2005;52:1000-8.

3. Rudwaleit $M$, van der Heijde D, Landewé R, et al. The development of Assessment of Spondyloarthritis international society classification criteria for axial spondyloarthritis (part II): validation and final selection. Ann Rheum Dis 2009; 68:777-83.

4. Rudwaleit $M$, Haibel $H$, Baraliakos $X$, et al. The early disease stage in axial spondylarthritis: results from the German Spondyloarthritis Inception Cohort. Arthritis Rheum 2009;60:717-27.

5. Poddubnyy D, Vahldiek J, Spiller I, et al. Evaluation of 2 screening strategies for early identification of patients with axial spondyloarthritis in primary care. J Rheumatol 2011;38:2452-60.

6. Rudwaleit M, Sieper J. Referral strategies for early diagnosis of axial spondyloarthritis. Nat Rev Rheumatol 2012;8:262-8.

7. Pope C, Mays N. Qualitative research in health care. Blackwell Publishing, 2006.

8. Underwood M R, Dawes P. Inflammatory back pain in primary care. Br J Rheumatol 1995;34:1074-7.

9. Sieper J, van der Heijde D, Landewé R, et al. New criteria for inflammatory back pain in patients with chronic back pain: a real patient exercise by experts from the Assessment of SpondyloArthritis international Society (ASAS). Ann Rheum Dis 2009;68:784-8.

10. Rudwaleit M, Metter A, Listing J, et al. Inflammatory back pain in ankylosing spondylitis: a reassessment of the clinical history for application as classification and diagnostic criteria. Arthritis Rheum 2006;54:569-78.

11. Calin A, Porta J, Fries JF, et al. Clinical history as a screening test for ankylosing spondylitis. JAMA 1977;237:2613-4.

12. Brandt HC, Spiller I, Song IH, et al. Performance of referral recommendations in patients with chronic back pain and suspected axial spondyloarthritis. Ann Rheum Dis 2007;66:1479-84.

13. Hermann J, Giessauf H, Schaffler G, et al. Early spondyloarthritis: usefulness of clinical screening. Rheumatology (Oxford) 2009;48:812-6.

14. Sieper J, Srinivasan S, Zamani O, et al. Comparison of two referral strategies for diagnosis of axial spondyloarthritis: the Recognising and Diagnosing Ankylosing Spondylitis Reliably (RADAR) study. Ann Rheum Dis 2013;72:1621-7.

15. Jois RN, Macgregor AJ, Gaffney K. Recognition of inflammatory back pain and ankylosing spondylitis in primary care. Rheumatology (Oxford) 2008;47:1364-6.

16. López-González R, Hernández-Sanz A, Almodóvar-González R, et al. Are spondyloarthropathies adequately referred from primary care to specialized care? Reumatol Clin 2013;9:90-3.

17. Heuft-Dorenbosch $L H$, Landewé $R$, Weijers $R$, et al. Performance of various criteria sets in patients with inflammatory back pain of short duration; the Maastricht early spondyloarthritis clinic. Ann Rheum Dis 2007;66:92-8.

18. van den Berg $R$, de Hooge $M$, Rudwaleit $M$, et al. ASAS modification of the Berlin algorithm for diagnosing axial spondyloarthritis: results from the SPondyloArthritis Caught Early (SPACE)-cohort and from the Assessment of SpondyloArthritis international Society (ASAS)-cohort. Ann Rheum Dis 2013;72:1646-53.

19. Dougados M, d'Agostino MA, Benessiano J, et al. The DESIR cohort: a 10-year follow-up of early inflammatory back pain in France: study design and baseline characteristics of the 708 recruited patients. Joint Bone Spine 2011;78:598-603.

20. Van Tubergen A, Weber U. Diagnosis and classification in spondyloarthritis: identifying a chameleon. Nat Rev Rheumatol 2012;8:253-61.

21. Feldtkeller E, Bruckel J, Khan MA. Scientific contributions of ankylosing spondylitis patient advocacy groups. Curr Opin Rheumatol 2000;12:239-47.

22. Kiltz $\mathrm{U}$, Baraliakos $\mathrm{X}$, Karakostas $\mathrm{P}$, et al. Do patients with non-radiographic axial spondylarthritis differ from patients with ankylosing spondylitis? Arthritis Care Res (Hoboken) 2012;64:1415-22.

23. Balagué F, Mannion AF, Pellisé F, et al. Non-specific low back pain. Lancet 2012;379:482-91. 



\section{CHAPTER 8}

Education improves referral of patients suspected of having spondyloarthritis by general practitioners. A study with unannounced standardized patients in daily practice

Marloes van Onna, Simone Gorter, Bas M aiburg, Gerrie Waagenaar,

Astrid van Tubergen 


\section{ABSTRACT}

\section{Objectives}

To evaluate the practice performance of general practitioners (GPs) and GP residents in recognising and referring patients suspected for having axial or peripheral spondyloarthritis $(\mathrm{SpA})$, and to investigate the influence of education on this performance.

\section{Methods}

GP (residents) were visited in 2 rounds by standardised patients (SPs) simulating axial $\mathrm{SpA}$, peripheral SpA or carpal tunnel syndrome (CTS) with in between an educational intervention on SpA for part of the participants. Participants were unaware of the nature of the medical problem and study purpose. CTS was included as diversionary tactic. The primary outcome was $\geq 40 \%$ improvement in (considering) referral of the SPS with SpA to the rheumatologist after education. Secondary outcomes included ordering additional diagnostic tests, correct recognition of SpA and identification of variables contributing to this.

\section{Results}

Sixty-eight participants (30 GPs and 38 GP residents) were included, of which 19 received education. The primary outcome was met. A significantly higher proportion of GP (residents) from the intervention group referred patients to the rheumatologist compared with the control group after education (change scores, axial SpA $+71 \%$ vs. $+15 \%(p \varangle 0.01)$; peripheral SpA $+48 \%$ vs. $0 \%(p \varangle 0.001))$. Participants who received education, more frequently correctly recognised SpA compared with controls (change scores, axial SpA $+50 \%$ vs. $-5 \%(p \varangle 0.001)$; peripheral SpA $+21 \%$ vs. $0 \%(p=0.01)$.

\section{Conclusions}

Recognition and referral of patients suspected for having SpA by GP (residents) is low, but targeted education markedly improved this. This supports the development of educational initiatives to improve recognition of SpA and hence referral to a rheumatologist. 


\section{INTRODUCTION}

Musculoskeletal complaints account for $20 \%$ of all consultations in primary care.[1-3] The challenge for general practitioners (GPs) is to filter patients with a high suspicion of an inflammatory rheumatic disorder.[4] Insufficient knowledge might result in a diagnostic delay, which subsequently may have a negative impact on physical functioning, social participation and quality of life in an individual patient.[5,6] Among all rheumatic diseases, spondyloarthritis (SpA) has the longest diagnostic delay, which may be up to 10 years or even longer.[7,8]

Many SpA patients are not adequately recognised, as illustrated by a study in primary care where $24 \%$ of the patients with chronic low back pain that started before the age of 45 years, were classified as having axial SpA after careful evaluation.[9] It is important to obtain an early diagnosis in order to tailor treatment to the individual needs of a patient and to prevent a debilitating disease course.[10] A short disease duration before initiation of treatment is also a good predictor of achieving a major clinical response on treatment.[11-13]

In order to improve timely diagnosis, several referral tools, which include characteristic features of SpA, have been proposed for axial SpA.[14-18] Application of a referral tool increases the probability of a disease in referred patients from $5 \%$ to $33-45 \%$.[18] However, for successful implementation of such a tool, knowledge about SpA in primary care is essential.[19,20] A qualitative study involving GPs showed that GPs were aware of "classic", but long-term features of axial SpA, i.e. hyperkyphosis and a bamboo spine. Knowledge about the entire disease spectrum, including early disease, extra-articular manifestations and other characteristic SpA features, was limited.[21] We hypothesised that education with special focus on SpA might improve the recognition of SpA features and early referral of patients suspected for having SpA. The objectives of this study were to evaluate (1) the current practice performance of GPS and GP residents in recognizing and (considering) referral of patients suspected for having axial or peripheral SpA, and (2) to assess the influence of education on this performance, by using unannounced standardised patients (SPs) who visit GP (residents) in their own practices. 


\section{METHODS}

\section{Study design and participants}

This study is a prospective controlled multicenter educational intervention study in primary care. GP residents and their supervising GPs were recruited through the department of General Practice from the Maastricht University Medical Centre (MUMC). Every trimester, 1-2 group(s) of 10-12 GP residents enter the final year of their residency. Once a week, they meet at the MUMC for training. We used this structure for providing an educational programme, 'the intervention', to half of the groups. Each group was alternately assigned to either the intervention group or the control group. This allocation strategy was only applied to the GP residents. The groups did not have direct contact hours with each other. A similar training structure was not available for GPs. It was logistically not possible to organize an extra training conference for GPs without revealing the topic of interest in advance. Therefore, despite GPs may be supervising a resident who received intervention, we decided to assign all GPs to the control group.

The ethics committee of the academic hospital Maastricht considered this study as "evaluation and improvement of daily clinical practice". No further approval was required. The GP (residents) were informed about SPs visiting their practice for "evaluation of using SPs in daily practice and education", and were asked to sign informed consent. No further specification was provided on the purpose of the study and the nature of the medical problems, nor were they informed that the education was related to the study with unannounced SPs.

The SP encounters took place 3 months before and 3 months after the intervention. The study started in September 2012, and was ended prematurely in May 2014.

\section{Standardised patients}

SPs, recruited from a pool of SPs working at the Maastricht University medical school and among clerkships, had to meet the following criteria: stable health, ability to play the role and to fill out the case-specific checklists, no confounding physical symptoms and sufficient time available for the visits.[22]

All SPs were trained to simulate one case. Two 2-hour training sessions were organised and guided by several GPs and rheumatologists, during which the SPs were trained in playing their role, and how to behave during the physical examination, in a valid and reliable way. GPs and a rheumatologist not involved in the development of the cases 
judged whether the SP simulated realistically. Close attention was paid on completion of the checklist to secure uniform data quality and comparability. Discrepancies in checklist rating scores were discussed.[22] Based on good reproducibility demonstrated in previous studies, and after this thorough training, we assumed good representation of the cases by the SPs.[23-25]

All participants faced two cases of axial SpA, two cases of peripheral SpA, and one case of carpal tunnel syndrome (CTS). Figure 8.1 shows an example of a predefined schedule for two participants. The CTS case was included as a diversionary tactic, preventing premature identification of the objectives of the study, but was also considered as 'common knowledge'. Recognition of CTS by the far majority of participants was expected and therefore only simulated during round 1. Each SpA case was simulated by a male and a female SP, in random order, according to a predefined schedule (Figure 8.1 shows an example). A short description of the included cases is provided in Box 8.1. The SPs were unaware which participants received education. The SPs received a small allowance for every visit.

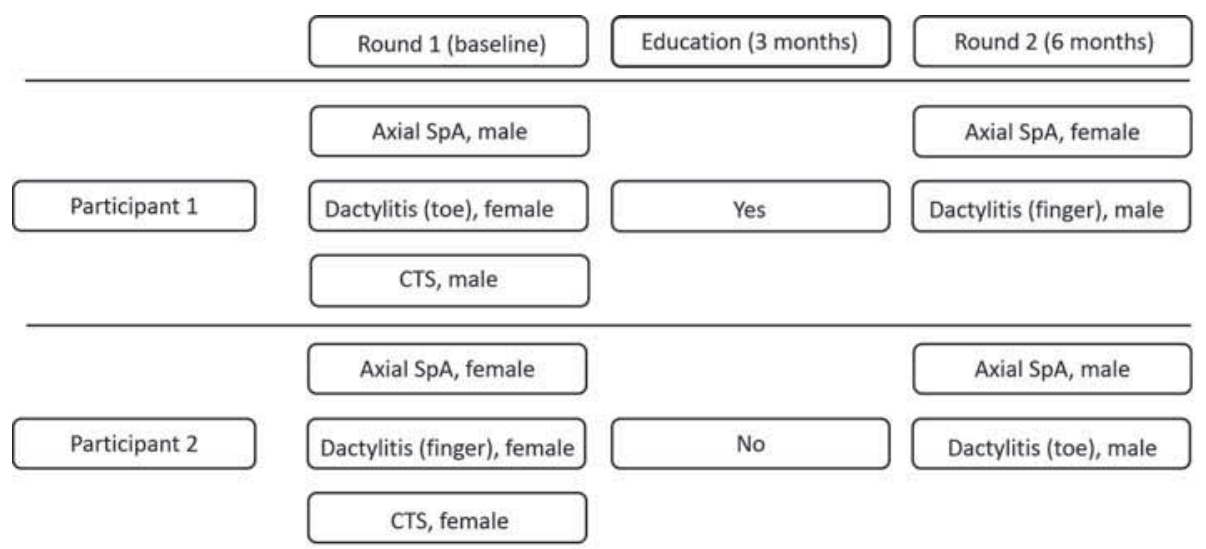

Figure 8.1 Example of a predefined schedule for 2 participants. $\mathrm{SpA}=$ spondyloarthritis.

\section{Practice visits and checklist}

At the practice visit, the SPs identified themselves as an SP, without providing further information. The duration of one consultation was 10-15 minutes, corresponding to the standard consultation time by a GP (resident).

After the visit, the SP immediately completed the case-specific checklist reporting the activities of participants during the visit, which consisted of: 
- Disease related items (e.g. onset of symptoms, presence of low back pain, family medical history);

- Items on physical examination (e.g. of the joints and/or back).

The GP (residents) indicated for this specific case which additional diagnostic investigations they would have ordered, which medication they would have prescribed (if any), and whether referral to another health care professional (and which) would be advised. Participants also ranked their differential diagnosis, from 1 (most likely) to 3 (less likely). The SPs were responsible for collecting and returning all forms to the study coordinator.

Box 8.1 Summary of included cases, simulated by standardized patients.

Early axial SpA:

- Case 1a: a 27-year-old male / female, suffering from chronic back pain with an inflammatory character since one year. He/she has a history of Achilles tendinitis. Physical therapy has a limited effect in back pain relief. The patient visits the GP (resident) because the back pain is now also present in the thoracic spine. An aunt has Crohn's disease.

- Case 1b: a 26-year-old male / female with chronic back pain with an inflammatory character since 1.5 years. There are also symptoms of anterior chest wall pain. Physical therapy has a limited effect on back pain relief. The patient visits the GP (resident) because of progressive work disability. A brother has psoriasis.

Early peripheral SpA:

- Case 2a: a 27-year-old male / female, who presents with a painful and swollen middle finger of the right hand with morning stiffness since a few weeks. The SP hands over a photograph to the GP (resident), showing dactylitis of the affected finger. He/she has a history of knee arthritis three years ago that resolved with non-steroidal anti-inflammatory drugs (NSAIDs). The mother has psoriasis.

- Case 2b: a 26-year-old male / female, who presents with and a painful and swollen second toe of the right foot with morning stiffness since a few weeks. The SP hands over a photograph to the GP (resident), showing dactylitis of the affected toe. The patient experienced similar complaints of a finger about one year ago. The brother has psoriasis.

CTS:

- Case 3: a 50-year-old male / female, with a tingling and burning sensation of the index, middle and ring finger since three months. The symptoms are worst at night. Flicking the wrist gives symptom relief.

\section{Educational intervention}

The interactive 3-hour case-based educational programme took place at the department of General Practice of the MUMC. Three topics, were presented and discussed by two rheumatologists:

- Diagnosis and management of gout (duration 45 minutes); 
- Axial and peripheral SpA (duration 90 minutes), i.e. concept and epidemiology of SpA, history taking and physical examination of patients suspected for having SpA, and criteria for referral of these patients to the rheumatologist.

- Safety considerations for biologic therapy (i.e. anti-Tumor Necrosis Factor (TNF)alpha therapy; duration 45 minutes).

Printed materials, including SpA features, were supplied to the participants supporting self-directed learning after the training.

\section{Study outcomes}

Our primary outcome was referral or considering referral of the SP to a rheumatologist by the GP (resident). We decided to combine both referral and considering referral, because GPs may spread diagnostic interventions over several consultations or only refer to secondary care when complaints fail to resolve within a few weeks after the first consultation. Secondary outcomes included (1) correct recognition of axial SPA, peripheral SpA and CTS respectively by the GP (resident), (2) ordering of additional diagnostic tests, (3) identification of variables contributing to correct recognition of SpA or CTS (GP versus GP resident, and gender of the SPs).

\section{Statistical analysis}

The sample size calculation was based on the primary outcome, (considering) referral of the SP to the rheumatologist. We estimated that $20 \%$ of the SPs would be referred without education and aimed at increasing this by $40 \%$. In order to detect a $40 \%$ difference in the change scores between the intervention group and control group in the proportion of SPs referred to the rheumatologist, 23 complete pre- and posteducation SP encounters were needed per group ( $80 \%$ power, alpha of 0.05 ).

Descriptive analyses were used for the demographic data. Chi square tests and fisher's exact tests, as appropriate, were used to analyse the primary and secondary endpoints. The difference in change scores between the intervention group and control group with regard to (considering) referral of the SP and correct recognition of SpA was compared with the Mann-Whitney $U$ test. Within-group changes in referral and recognition of SpA before and after education were analysed with M cNemar tests. Only participants that completed both rounds of SP encounters were included in these analyses. Descriptive analysis was used for investigating which diagnoses were mentioned by GP (residents) and the frequency of ordering additional diagnostic tests by GP (residents). SPSS software 20.0 was used for all analyses. 


\section{RESULTS}

\section{Participant characteristics}

In total, 117 GPs residents and their supervising GPs were invited, of which 68 (38 GP residents and $30 \mathrm{GPs}$ ) participated in the study. Reasons for non-participation were not collected. The study was ended prematurely, because many GP (residents) declined participation, and the chance that newly enrolled GP residents came into direct contact with GP (residents) that already participated was considered high. The a priori sample size was therefore not pursued.

Baseline characteristics of the participants are shown in Table 8.1. Three (4\%) participants mentioned an interest in musculoskeletal disorders.

In total, 256 SP encounters took place, excluding the CTS cases. Both rounds were completed by 61 (90\%) and 59 (87\%) participants for the axial SpA and peripheral SpA case, respectively. Reasons for incomplete SP visits were: illness $(n=6)$, unable to schedule an appointment within the given time frame $(n=4)$, late arrival by SP due to traffic problems ( $n=3)$, GP left for a medical emergency $(n=2)$, and maternity leave $(n=1)$.

Table 8.1 Characteristics of the participating general practitioners and residents.

\begin{tabular}{lccc}
\hline & $\begin{array}{c}\text { GP residents } \\
(\mathrm{n}=38)\end{array}$ & $\begin{array}{c}\text { GPs } \\
(\mathrm{n}=30)\end{array}$ & $\begin{array}{c}\text { All participants } \\
(\mathrm{n}=68)\end{array}$ \\
\hline Age [years] & $28(1.6)$ & $52(5.9)$ & $39(12.9)$ \\
Male & $12(32 \%)$ & $24(80 \%)$ & $36(53 \%)$ \\
Working experience, including training [years] & $2(0.4)$ & $22(7.2)$ & $11(10.9)$ \\
Weekly consultations [number] & $62(15.6)$ & $107(26.5)$ & $82(30.6)$ \\
Specific interest in musculoskeletal disorders & $2(7 \%)$ & $1(3 \%)$ & $3(4 \%)$ \\
\hline
\end{tabular}

The values are expressed as mean (standard deviation) or as number (\%). GP = general practitioner.

\section{Axial spondyloarthritis}

\section{Primary endpoint}

Referral of SPs simulating axial SpA. In the first round of SP encounters, $6 \%$ of the participants in the intervention group $(n=18)$ and $10 \%$ of participants in the control group $(n=43)$ referred or considered referral of the SP to the rheumatologist (Figure 8.2). Participants who received the educational programme clearly more often referred 
or considered referral in the second round of SP encounters than controls (changes scores: $+71 \%$ vs. $+15 \%(p \varangle 0.001)$; Figure 8.2$)$.
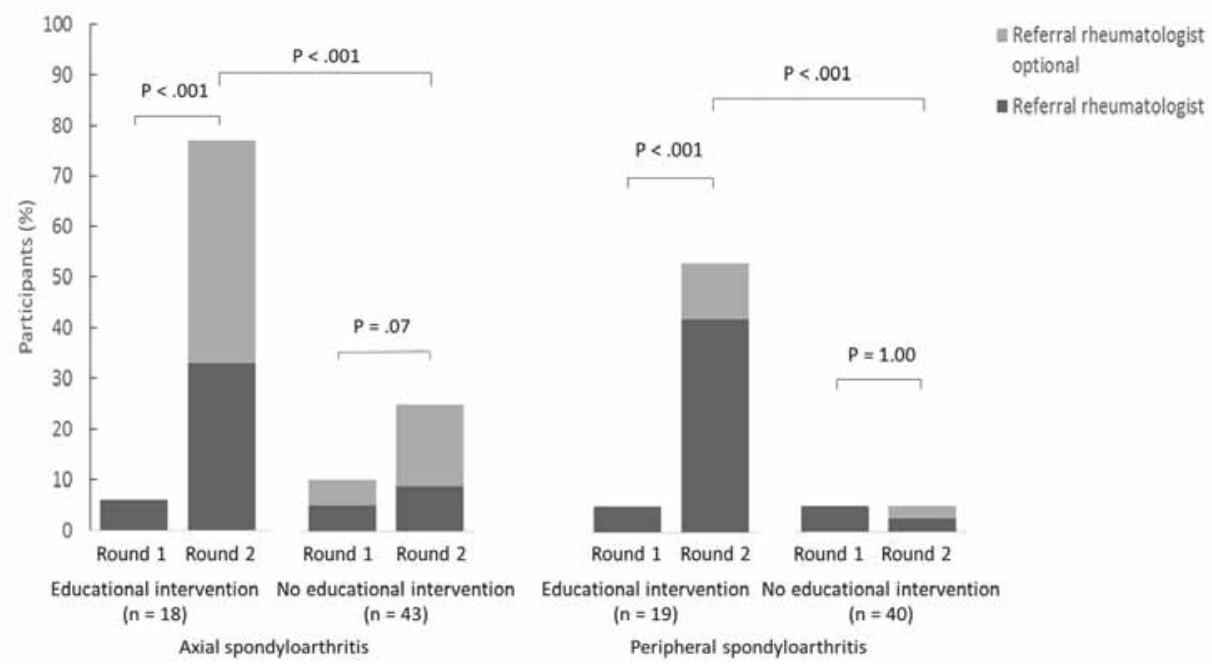

Figure 8.2 Referral of standardized patients simulating axial and peripheral spondyloarthritis to a rheumatologist.

\section{Secondary endpoints}

Recognition of axial SpA. In the first round of SP encounters, 4 (22\%) out of 18 participants in the intervention group and 8 (19\%) out of 43 participants in the control group ranked axial SpA as their no. 1 diagnosis. Non-specific back pain was most frequently ranked as no. 1 diagnosis by 10 (56\%) out of 18 participants in the intervention group and 31 (72\%) out of 43 participants in the control group (Table 82). In total, 34 (56\%) out of 68 participants ranked axial SpA as no. 1, 2 or 3 in their differential diagnosis before education.

In the second round, the intervention group more frequently ranked axial SpA as their no. 1 diagnosis (round 1: $22 \%$ vs. round 2: $72 \%(p=0.01$ ); Table 8.2 ), which was statistically significantly different from the control group (changes scores: $+50 \%$ intervention group vs. $-5 \%$ control group, $(p \varangle 0.001)$; Table 8.2). In the second round, non-specific back pain remained the no. 1 diagnosis in $74 \%$ of the participants from the control group (Table 8.2).

Additional diagnostic tests. In the intervention group less HLA-B27 tests were ordered in the second round, whereas in the control group the opposite was seen (changes scores: $-22 \%$ intervention group vs. $+12 \%$ control group, $(p=0.01)$; Table 8.2$)$. 


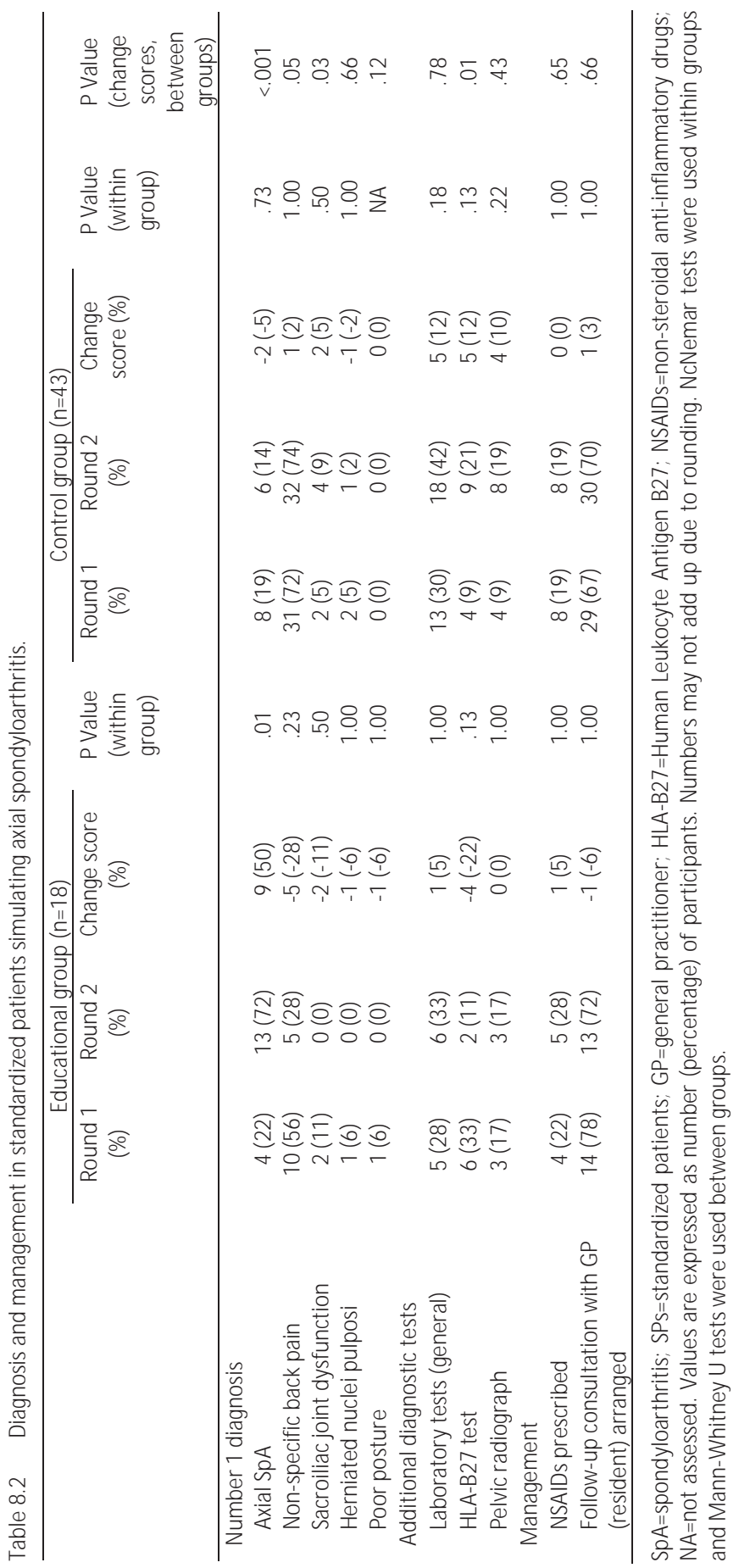


Variables contributing to recognition of axial SpA. No difference between the GPS and GP resident characteristics with regard to correct recognition of axial SpA was found (data not shown). In addition, male and female SPs were equally considered to have axial SpA (data not shown).

\section{Peripheral spondyloarthritis}

\section{Primary endpoint}

Referral of SPS simulating peripheral SPA. In the first round, participants in both the intervention $(n=19)$ and control group $(n=40)$ referred the SPs to the rheumatologist in $5 \%$ of cases (Figure 8.2). The intervention group referred or considered referral more frequently compared to the control group in the second round (change scores: $+48 \%$ vs. $0 \%(p \varangle 0.01)$; Figure 8.2$)$.

\section{Secondary endpoints}

Recognition of peripheral SPA. In the first round of SP encounters, 2 (11\%) out of 19 participants in the intervention group and $4(10 \%)$ out of 40 participants in the control group ranked peripheral SpA as their no. 1 diagnosis (Table 8.3). All specified this as "reactive arthritis". Two participants ranked psoriatic arthritis in their differential diagnosis as no. 2 or 3. "Arthritis not otherwise specified" was ranked by most participants as no. 1 diagnosis (5 (26\%) participants in the intervention group and 15 (38\%) participants in the control group; Table 8.3).

Four $(21 \%)$ of the 19 participants from the intervention group correctly recognized "spondyloarthritis" or "psoriatic arthritis" after education, compared with none of the participants in the control group (change scores: $+21 \%$ vs. $0 \%(p=0.01)$; Table 8.3).

Additional diagnostic tests. No differences between the intervention and control group regarding ordering laboratory and diagnostic imaging tests were found in both rounds of SP encounters (Table 8.3).

Variables contributing to recognition of peripheral SpA. No difference between the GPS and GP residents with regard to correct recognition of peripheral SpA was found in the first round of SP encounters. However, in general, GPs ordered more additional diagnostic tests in both rounds of SP encounters (Table 8.4).

In the first round of SP encounters, gout was more often ranked as no. 1 diagnosis in male than in female SPs (male SPs: 8 (26\%) out of 31 diagnoses; female SPs: 1 (4\%) out of 28 diagnoses $(p=0.03)$ ). 


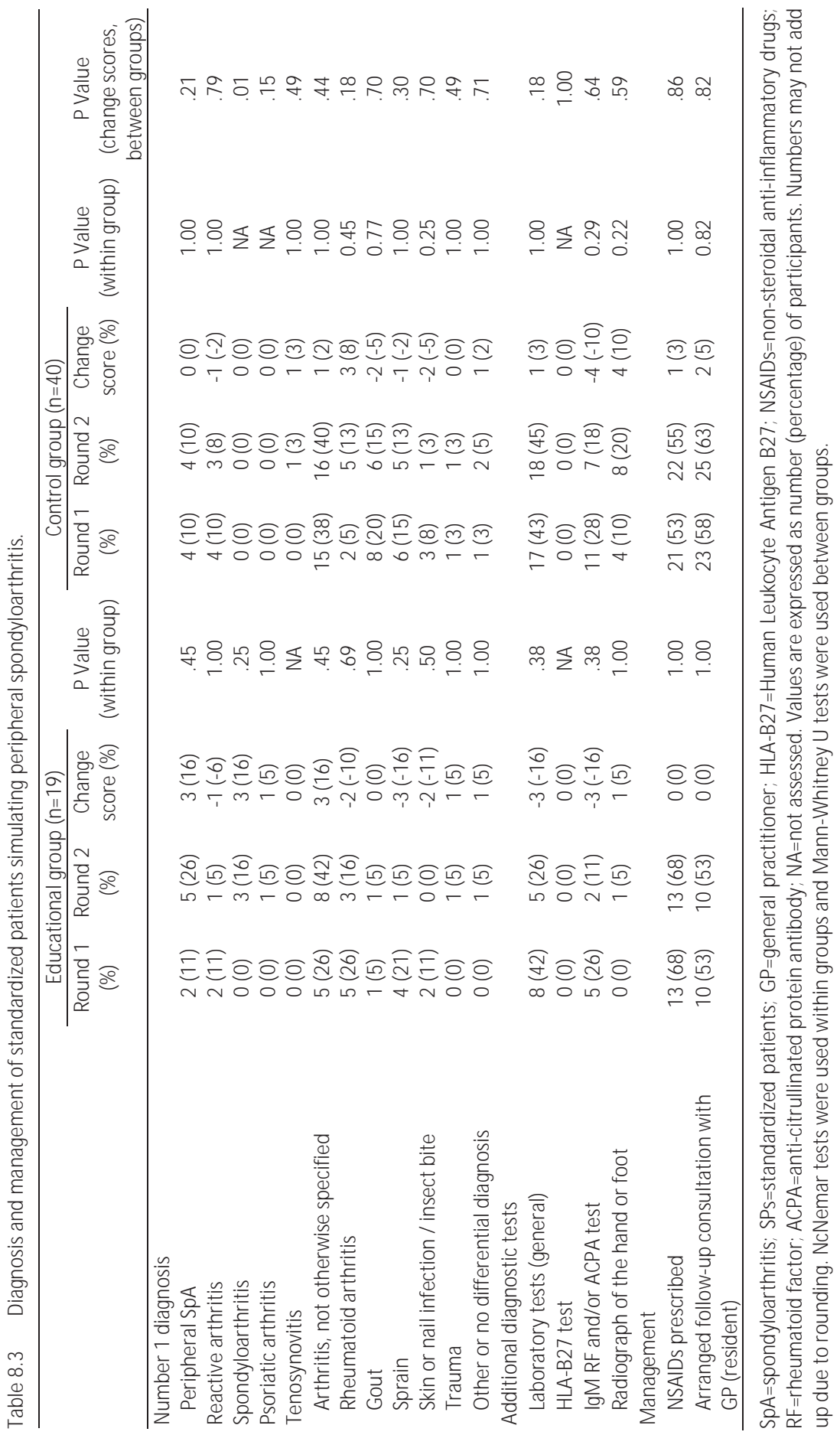


Table 8.4 List of diagnoses and management in patients suspected for carpal tunnel syndrome.

\begin{tabular}{|c|c|c|c|c|}
\hline & $\begin{array}{l}\text { GP resident } \\
(n=37)\end{array}$ & $\begin{array}{c}\mathrm{GP} \\
(\mathrm{n}=28)\end{array}$ & P Value & $\begin{array}{l}\text { All participants } \\
(n=65)\end{array}$ \\
\hline \multicolumn{5}{|l|}{ Number 1 diagnosis } \\
\hline CTS & $30(81 \%)$ & $24(86 \%)$ & .75 & $54(83 \%)$ \\
\hline Osteoarthritis & $1(3 \%)$ & $0(0 \%)$ & 1.00 & $1(2 \%)$ \\
\hline Sprain & $6(16 \%)$ & $4(14 \%)$ & 1.00 & $6(16 \%)$ \\
\hline \multicolumn{5}{|l|}{ Additional diagnostic tests } \\
\hline Radiography of the hand & $0(0 \%)$ & $2(5 \%)$ & .50 & $2(3 \%)$ \\
\hline EM G & $3(11 \%)$ & $3(8 \%)$ & 1.00 & $6(9 \%)$ \\
\hline \multicolumn{5}{|l|}{ Management } \\
\hline NSAIDs prescribed & $3(8 \%)$ & $3(11 \%)$ & .52 & $6(9 \%)$ \\
\hline Local injection with corticosteroids & $2(7 \%)$ & $8(22 \%)$ & .17 & $10(15 \%)$ \\
\hline Splint & $7(25 \%)$ & $15(41 \%)$ & .29 & $22(34 \%)$ \\
\hline $\begin{array}{l}\text { Follow-up consultation with GP } \\
\text { (resident) arranged }\end{array}$ & $10(35 \%)$ & $21(57 \%)$ & .13 & $31(47 \%)$ \\
\hline Referral to neurologist & $1(4 \%)$ & $2(5 \%)$ & .57 & $3(5 \%)$ \\
\hline
\end{tabular}

CTS=carpal tunnel syndrome; EMG=electromyography; NSAIDs=non-steroidal anti-inflammatory drugs; $\mathrm{GP}=$ general practitioner.

\section{Recognition and management of carpal tunnel syndrome}

As expected, CTS was ranked as the no. 1 diagnosis by 54 (83\%) out of 65 participants, and by 61 (90\%) in their top 3 (Table 8.5). No differences between the GP and GP resident or gender of the SP regarding ranking CTS as no. 1 diagnosis were found. Also the management and follow-up of the CTS case were similar for the GP and GP resident.

Table 8.5 List of diagnoses and management in patients suspected for carpal tunnel syndrome.

\begin{tabular}{lcccc}
\hline & $\begin{array}{c}\text { GP resident } \\
(\mathrm{n}=37)\end{array}$ & $\begin{array}{c}\text { GP } \\
(\mathrm{n}=28)\end{array}$ & $\mathrm{p} \mathrm{Value}$ & $\begin{array}{c}\text { All participants } \\
(\mathrm{n}=65)\end{array}$ \\
\hline Number 1 diagnosis & $30(81 \%)$ & $24(86 \%)$ & 0.75 & $54(83 \%)$ \\
CTS & $1(3 \%)$ & $0(0 \%)$ & 1.00 & $1(2 \%)$ \\
$\quad$ Osteoarthritis & $6(16 \%)$ & $4(14 \%)$ & 1.00 & $6(16 \%)$ \\
$\quad$ Sprain & $0(0 \%)$ & $2(5 \%)$ & 0.50 & $2(3 \%)$ \\
$\begin{array}{l}\text { Additional diagnostic tests } \\
\text { Radiography of the hand }\end{array}$ & $3(11 \%)$ & $3(8 \%)$ & 1.00 & $6(9 \%)$ \\
$\quad$ EM G & $3(8 \%)$ & $3(11 \%)$ & 0.52 & $6(9 \%)$ \\
Management & $2(7 \%)$ & $8(22 \%)$ & 0.17 & $10(15 \%)$ \\
$\quad$ NSAIDs prescribed & $7(25 \%)$ & $15(41 \%)$ & 0.29 & $22(34 \%)$ \\
Local injection with corticosteroids & $10(35 \%)$ & $21(57 \%)$ & 0.13 & $31(47 \%)$ \\
Splint & $1(4 \%)$ & $2(5 \%)$ & 0.57 & $3(5 \%)$ \\
$\quad$ Follow-up consultation with & & & \\
$\quad$ GP (resident) arranged & & & \\
Referral to neurologist &
\end{tabular}

CTS = carpal tunnel syndrome, EM G = electromyography, NSAIDs = non-steroidal anti-inflammatory drugs, GP = general practitioner. 


\section{DISCUSSION}

In this study we showed that education is an important means to change clinicians' practice behaviour regarding recognition and referral of patients with SpA. While medical history and symptoms simulated by SPs would have acknowledged a referral to a rheumatologist, such a policy was executed by only $10 \%$ of the GPs. Specific SpAaimed education improved this policy dramatically. The primary outcome, more than $40 \%$ improvement in (considering) referral for both axial and peripheral SpA after education, was met.

Approximately $20 \%$ of the adult population consult their GP because of musculoskeletal complaints, among which chronic low back pain is the most prevalent.[1-3,26] Although it is impossible for GPs to have considerable expertise in all areas, the high exposure to musculoskeletal disorders (MSD) warrants development of high-quality training programs aiming at gaining and maintaining sufficient expertise on MSD. Several studies, however, suggest that graduated medical students and residents lack knowledge and confidence in this respect.[27-30] Multi-faceted education interventions, including mixed interactive and didactic learning activities focussing on pertinent outcomes have shown to sustainably change physicians' behaviour.[31,32] In the present study, we also applied multi-faceted educational tools including interactive power-point presentations, case vignettes and printed materials, which may have added to a better recognition of SpA three months after the intervention. Future studies may shed light on the sustainability of education in this context.

Strengths of our study are that we have used a prospective, multicenter design and that we have included a control group for an evaluation of the effect of education. In addition, our study was conducted in primary care which is the source of most referrals of SpA to the rheumatologist. Furthermore, the SP-model has proven reliability for the assessment of physicians' knowledge and -skills in a 'genuine' clinical setting.[23$25,33,34]$

Several limitations of this study require discussion. First, SPs did not truly have signs of their disease detectable at physical examination, which may have jeopardised recognition. SPs performing a role of peripheral SpA, for example, showed a photograph with dactylitis to the GP. Dactylitis is a relatively uncommon (albeit specific) manifestation of peripheral SpA. Nevertheless, one in two GPs (residents) ranked an inflammatory rheumatic disease as the diagnosis of highest likelihood in both SP encounters. This observation suggests that a knowledge deficit about peripheral SpA prevented an adequate diagnosis but not the recognition of a rheumatic 
disease. While referral to a medical specialist would have been the best option here, only a minority of the patients was indeed referred.

Second, information to GPs about an SP visiting their practice may have raised arousal leading to different diagnostic behaviour. However, GP (residents) were neither aware of the specific case presentation or the purpose of the study nor were they informed about education being part of this study. In addition, participants were visited in their own practices by SPs during regular working hours. Since a previous study has failed to demonstrate a difference in performance by residents evaluating real patients and SPS [35], we believe the precautions we have taken have assured a most truthful performance of GP (residents) in daily practice.

Third, one may argue that the GP (residents) suspected the SP was simulating SpA, but that they were unaware of the fact that referral would have been indicated in this case. Making a correct diagnosis was a secondary outcome in our study. Before education, only a minority of GPs correctly diagnosed axial SpA (20\%) and peripheral SpA (10\%). In contrast, CTS was recognised by the large majority of participants (83\%), indicating that GPs have sufficient knowledge of common disorders. However, they fall short regarding SpA, which is more unfamiliar than CTS.

Fourth, we were unable to include the projected number of participants. Nevertheless, the primary outcome was met. A small sample size, however, may limit generalizability of results to a larger population.

In conclusion, recognition and referral of patients suspected for having SpA by GP (residents) is in general low, but targeted education can markedly improve this. Increased awareness of a potential underlying inflammatory condition in patients presenting with musculoskeletal complaints and timely referral may prevent a debilitating disease course in patients with SpA. Therefore, we recommend the combination of a referral tool targeted at SpA and educational activities that maximize practitioner engagement and support for practice change. 


\section{REFERENCES}

1. Jordan KP, Kadam UT, Hayward R, et al. Annual consultation prevalence of regional musculoskeletal problems in primary care: an observational study. BM C M usculoskelet Disord 2010;11:144.

2. Jordan K, Clarke AM, Symmons DP, et al. Measuring disease prevalence: a comparison of musculoskeletal disease using four general practice consultation databases. Br J Gen Pract 2007;57: 7-14.

3. Hoy D, March L, Brooks P, et al. The global burden of low back pain: estimates from the Global Burden of Disease 2010 study. Ann Rheum Dis 2014;73:968-74.

4. Villeneuve E, Nam JL, Bell MJ, et al. A systematic literature review of strategies promoting early referral and reducing delays in the diagnosis and management of inflammatory arthritis. Ann Rheum Dis 2013;72:13-22.

5. Sieper J, Rudwaleit M. Early referral recommendations for ankylosing spondylitis (including preradiographic and radiographic forms) in primary care. Ann Rheum Dis 2005;64:659-63.

6. Boonen A. A review of work-participation, cost-of-illness and cost-effectiveness studies in ankylosing spondylitis. Nat Clin Pract Rheumatol 2006;2:546-53.

7. Feldtkeller $E$, Khan MA, van der Heijde D, van der Linden S, Braun J. Age at disease onset and diagnosis delay in HLA-B27 negative vs. positive patients with ankylosing spondylitis. Rheumatol Int 2003;23:61-6.

8. Feldtkeller E, Bruckel J, Khan MA. Scientific contributions of ankylosing spondylitis patient advocacy groups. Curr Opin Rheumatol 2000;12:239-47.

9. Van Hoeven L, Luime J, Han $\mathrm{H}$, et al. Identifying axial spondyloarthritis in dutch primary care patients, ages 20-45 years, with chronic low back pain. Arthritis Care Res (Hoboken) 2014;66:446-53.

10. Van Tubergen A. The changing clinical picture and epidemiology of spondyloarthritis. Nat Rev Rheumatol 2015;11:110-8.

11. Van den Berg R, Baraliakos X, Braun J, et al. First update of the current evidence for the management of ankylosing spondylitis with non-pharmacological treatment and non-biologic drugs: a systematic literature review for the ASAS/EULAR management recommendations in ankylosing spondylitis. Rheumatology (Oxford) 2012;51:1388-96.

12. Rudwaleit M, Claudepierre $P$, Wordsworth $P$, et al. Effectiveness, safety, and predictors of good clinical response in 1250 patients treated with adalimumab for active ankylosing spondylitis. J Rheumatol 2009;36:801-8.

13. Rudwaleit M, Listing J, Brandt J, et al. Prediction of a major clinical response (BASDAl 50) to tumour necrosis factor alpha blockers in ankylosing spondylitis. Ann Rheum Dis 2004;63:665-70.

14. Poddubnyy D, Vahldiek J, Spiller I, et al. Evaluation of 2 screening strategies for early identification of patients with axial spondyloarthritis in primary care. J Rheumatol 2011;38:2452-60.

15. Brandt HC, Spiller I, Song $\mathrm{IH}$, et al. Performance of referral recommendations in patients with chronic back pain and suspected axial spondyloarthritis. Ann Rheum Dis 2007;66:1479-84.

16. Hermann J, Giessauf H, Schaffler G, et al. Early spondyloarthritis: usefulness of clinical screening. Rheumatology (Oxford) 2009;48:812-6.

17. Sieper J, Srinivasan S, Zamani O, et al. Comparison of two referral strategies for diagnosis of axial spondyloarthritis: the Recognising and Diagnosing Ankylosing Spondylitis Reliably (RADAR) study. Ann Rheum Dis 2013;72:1621-7.

18. Rudwaleit M, Sieper J. Referral strategies for early diagnosis of axial spondyloarthritis. Nat Rev Rheumatol 2012;8:262-8.

19. Van Tubergen A, Weber U. Diagnosis and classification in spondyloarthritis: identifying a chameleon. Nat Rev Rheumatol 2012;8:253-61.

20. Jois RN, Macgregor AJ, Gaffney K. Recognition of inflammatory back pain and ankylosing spondylitis in primary care. Rheumatology (Oxford) 2008;47;1364-6.

21. Van Onna M, Gorter S, van M eerendonk A, et al. General practitioners' perceptions of their ability to identify and refer patients with suspected axial spondyloarthritis: a qualitative study. J Rheumatol 2014;41:897-901.

22. Gorter S, Rethans JJ, Scherpbier A, et al. How to introduce incognito standardized patients into outpatient clinics of specialists in rheumatology. Medical teacher 2001;23:138-44.

23. Underwood M R, Dawes P. Inflammatory back pain in primary care. Br J Rheumatol 1995;34:1074-7. 
24. Freedman KB, Bernstein J. Educational deficiencies in musculoskeletal medicine. J Bone Joint Surg Am 2002;84:604-8.

25. Skelley NW, Tanaka MJ, Skelley LM, et al. M edical student musculoskeletal education: an institutional survey. J Bone Joint Surg Am 2012;94:1-7.

26. Truntzer J, Lynch A, Kruse D, et al. M usculoskeletal education: an assessment of the clinical confidence of medical students. Perspect Med Educ 2014;3:238-44.

27. Hosie GA. Teaching rheumatology in primary care. Ann Rheum Dis 2000;59:500-3.

28. Cantillon $\mathrm{P}$, Jones $\mathrm{R}$. Does continuing medical education in general practice make a difference? BM J 1999;318:1276-9.

29. Grol R, Grimshaw J. From best evidence to best practice: effective implementation of change in patients' care. Lancet 2003;362:1225-30.

30. Siminoff LA, Rogers $\mathrm{HL}$, Waller AC, et al. The advantages and challenges of unannounced standardized patient methodology to assess healthcare communication. Patient Educ Couns 2011;82:318-24.

31. Shirazi M, Labaf A, M onjazebi F, et al. Assessing medical students' communication skills by the use of standardized patients: emphasizing standardized patients' quality assurance. Acad Psychiatry 2014;38: 354-60.

32. Beullens J, Rethans JJ, Goedhuys J, et al. The use of standardized patients in research in general practice. Fam Pract 1997;14:58-62.

33. Woodward CA, McConvey GA, Neufeld V, et al. Measurement of physician performance by standardized patients. Refining techniques for undetected entry in physicians' offices. Med Care 1985; 23:1019-27.

34. Erby LA, Roter DL, Biesecker BB. Examination of standardized patient performance: accuracy and consistency of six standardized patients over time. Patient Educ Couns 2011;85:194-200.

35. Norman GR, Tugwell P, Feightner JW. A comparison of residence performance on real and simulated patients. J Med Educ 1982;57:708-15. 



\section{CHAPTER 9}

Summary and general discussion 



\section{SUM M ARY AND DISCUSSION OF MAIN FINDINGS}

This thesis describes several studies that focus on the early identification of patients with spondyloarthritis (SpA).

As described in Chapter 1, major advances have been made over the last years to facilitate early diagnosis of SpA. One of the important key changes was the proposal of the Assessment of SpondyloArthritis international Society (ASAS) to revise disease nomenclature. Consistent with this proposal, SpA is now categorised into predominantly axial SpA (axSpA) and predominantly peripheral SpA.[1-4] In addition, axSpA has further been differentiated as "radiographic axial SpA" which is synonymous to ankylosing spondylitis (AS) and "non-radiographic (nr)-axSpA", in which pelvic radiographs are normal or equivocal.[1] By recognizing non-radiographic axSpA and incorporating this concept in the ASAS classification criteria for axSpA, the focus has shifted towards an earlier detection of axSpA.[1,3]

However, to achieve timely and accurate diagnosis of SpA, further research in several areas is required.

One of the challenges was aggregating the available epidemiological data in a reliable manner so that it could be used to better understand disease patterns. This information may also help to provide insight about which health care resources are needed to detect and manage SpA at an early stage.

Chapter 2 presents therefore a systematic literature review and meta-analysis on the prevalence of SpA and its subtypes. Several demographical (including geographical) and methodological variables were studied to explain variation in the prevalence of (subtypes of) SpA in the 84 studies that were included. The pooled prevalence of SpA was $0.55 \%$ (95\% confidence interval $(\mathrm{Cl}): 0.37-0.77)$ and the pooled prevalence of AS was $0.18 \%$ (95\% Cl: $0.15-0.23)$. There was however a high level of heterogeneity across studies. Substantial variation between geographic areas was found, which can partly be explained by the prevalence of HLA-B27; in populations known to have a high prevalence of HLA-B27, a higher prevalence of SpA was reported. The highest prevalence of SpA (including AS) in our review was reported in decreasing order in Northern Artic indigenous communities, North America, East Asia and Europe. Interestingly, prevalence estimates of SpA were positively related to the year of data collection. This finding might be the result of increased awareness and recognition of $\mathrm{SpA}$ as a separate disease entity. In addition, our study showed that the reported prevalence of SpA was highly dependent on the type of case definition that was used. 
This is illustrated by a population-based study in the US.[5] The prevalence of SpA was $1.4 \%$ according to the ESSG criteria, but $0.9 \%$ according to the Amor criteria. This finding makes clear that the type of classification criteria may have an impact on the reported prevalence of (subtypes of) SpA. Consequently, the prevalence of SpA using the new classification criteria for axial and peripheral SpA may be different.

In axSpA, the development of new classification criteria was preceded by the introduction of magnetic resonance imaging (M RI) of the SIJ, with the aim to facilitate an early diagnosis of axSpA.[6] The Early SpondyloArthritis Clinic (ESpAC) was established by our group in order to better understand the role of $\mathrm{MRI}$ in patients suspected for axSpA. The follow-up study included three full clinical and imaging examinations performed with one year time intervals. MRIs of the sacroiliac joints (M RI-SIJ) were an integral part of this study. Chapter 3 describes the evolution of active lesions on MRI-SIJ, suggestive for sacroiliitis, over a 2-year follow-up period. Twentyfour (35\%) out of 68 patients had a positive MRI-SIJ at baseline. We found that both a positive HLA-B27 status and positive M RI-SIJ at baseline were independently associated with a persistently positive MRI-SIJ over time. A combination of a negative HLA-B27 status and a negative MRI-SIJ at baseline essentially ruled out a positive MRI over time. Especially in male HLA-B27 positive patients with a negative baseline M RI-SIJ, a followup M RI seems rational since a considerable proportion of these patients may develop a positive MRI over time. Our findings not only contribute to efficiently diagnose patients with axSpA but also give credit to the prominent place of M RI-SIJ in the ASAS axial SpA classification criteria.[1,7,8]

To date, active lesions (bone marrow edema (BME)) highly suggestive for sacroilitis are required for a positive MRI-SIJ.[9] There is increasing debate, though, if structural lesions (erosions or fatty lesions) may also have an independent diagnostic value.[10] In Chapter 4 we investigated the presence and evolution of structural changes on M RI-SIJ in patients included in the ESPAC. Subsequently, we analysed whether structural changes on either MRI or pelvic radiographs were preceded by BME on MRI at the same anatomic location. The number of erosions on MRI increased significantly during follow-up, but these new erosions were not associated with preceding BME. While the number of fatty lesions only showed a slight increase, the few new fatty lesions were associated with preceding BME. Interestingly, they occurred preferably in locations that showed resolution of BME. The relation between inflammation and structural damage on MRI in patients with axSpA had been extensively discussed over the last years.[11-18] The debate is mainly confined to the question whether inflammation and 
structural damage are "coupled" or "uncoupled" processes. Earlier reports have shown conflicting results.[14-17] Our current findings support the view that fatty lesions should be seen as a repair reaction in response to inflammatory triggers.[19] Other data have suggested that fatty lesions on M RI are linked to subsequent development of syndesmophytes in the spine.[20] We did not find an association between active lesions and erosions on $\mathrm{MRI}$ and subsequent progression of sacroiliitis on conventional radiographs. Larger studies than ours with sequential M RI examinations over a longer follow-up period will be needed in order to be conclusive.

Different MRI techniques can be used to detect active lesions on M Rl; these are short tau inversion recovery (STIR) sequence, and fat-saturated T1-weighted spin-echo sequence after administration of the contrast agent gadolinium diethylenetriaminepentaacetic acid (Gd-DTPA).[9] In Chapter 5 we showed that the post-Gd-DTPA sequence did not have a surplus value compared with the STIR sequence in combination with pelvic radiographs. Our results were comparable to the results of the SPondyloArthritis Caught Early (SPACE)-cohort that found a 100\% agreement between the STIR and post-Gd-DTPA M RI sequence both at baseline and 3-month follow-up.[21] All together, it seems as if the post-Gd-DTPA can safely be omitted. This finding increases feasibility of $M R I$ and reduces costs regarding the use of MRI during the diagnostic work-up of patients suspected for axSpA.

At the start of this project, essential information about the use of M RI was lacking in order to recommend it in all patients with a suspicion of axSpA and a normal or equivocal pelvic radiograph. One of those questions pertained to how stable a lesion found on MRI is over time. Chapter 6 describes the exact distribution, frequency of occurrence, and evolution over time of BME detected on M RI-SIJ in patients included in the ESPAC. Almost half of the BME lesions detected at baseline, had resolved during follow-up. Vice versa, some negative baseline MRIs had become positive over time. Both had consequences for the fulfilment of the ASAS axSpA criteria at any follow-up moment. This finding reflects a general concern inherent to diagnostic imaging in rheumatic conditions, being that imaging findings (which are inherently unreliable due to measurement error and judgement variation) become dominant over clinical findings in the process of diagnostic pattern recognition. Myopically focusing on M RI reports, for instance, could lead to a delay in the diagnosis of axSpA, if signs suggestive for sacroilitis on MRI are absent in an otherwise clinical undisputable SpA patient. On the other hand, a focus on MRI findings could lead to a false diagnosis of SpA if too subtle and not highly suggestive lesions on MRI (the 'innocent white spots') are interpreted without the context of the clinical symptoms of a patient that actually do 
not raise suspicion of SpA. The entire pattern of axSpA, including manifestations such as psoriasis, enthesitis or uveitis should therefore be taken into account. This has actually been done in the 'diagnostic algorithm' in which a thorough medical history and physical examination are prominent steps in the work-up of patients suspected for axSpA, in which imaging also plays a role.[8] MRI should only be ordered in those patients with a reasonable suspicion for SpA.

Optimizing the management of patients with SpA always starts with 'case finding'. In the Dutch healthcare setting, this usually starts in primary care. The level of knowledge and the perceptions of general practitioners (GPs) about inflammatory back pain (IBP) and axSpA, and potential barriers for referral of patients suspected for axSpA were studied in Chapter 7. We found that axSpA is often unrecognized in primary care, and even when recognized, it is often sub-optimally managed. In general, the level of knowledge about IBP, axSpA and the associated extra-articular manifestations is limited. GPs are aware of 'classic', but late features of axSpA, such as hyperkyphosis as seen in AS. Only half of the GPs knew, for example, that Tumor Necrosis Factor (TNF)alpha inhibiting biologicals are a treatment option in axSpA. Improving the knowledge of GPs about the leading presenting symptoms and current treatment options of axSpA, will likely facilitate the referral of patients suspected of having axSpA.

The primary care setting itself does not facilitate the identification of patients with SpA: GPs have to deal with a broad variety of physical and psychological conditions. Chronic back pain is a common symptom in the general population and it is estimated that in only $5 \%$ of cases, axSpA is the underlying condition.[22] GPs may think that adequate recognition of axSpA is of secondary concern. However, fine-tuning the procedure in order to select those patients that may need further evaluation in secondary care is still an important step to make. A recent study has shown that $24 \%$ of primary care patients with chronic low back pain starting before the age of 45 years could be classified as having axial SpA.[23] GPs can provide 'longitudinal continuity' of care to the patient that is consistent with the patient's other needs. This means that GPs are in a unique position to recognize the pattern of symptoms suggestive for SpA (including the occurrence of SpA features over time) when a patient first seeks medical attention. In Chapter 8 we describe the current practice performance of GPs and GP residents with regard to recognizing early axial or peripheral SpA. We used standardized patients (SPs) to demonstrate 'what is really going on' in daily clinical practice. In addition, the influence of education on this performance was investigated. In this study, 68 GP residents and their supervising GPs were included and visited by trained SPs who 
simulated a case of early axial of peripheral SpA. We concluded that recognition and referral of patients suspected for SpA to the rheumatologist by GP (residents) is generally low. Providing education however markedly improved both recognition and referral of patients suspected for SpA to the rheumatologist. Education may therefore be an interesting starting point to increase awareness about SpA, paving the way to successful implementation of a referral strategy.

\section{METHODOLOGICAL CONSIDERATIONS}

The most important limitations of the studies that were described in Chapter 2 to 8 of this thesis have already been described in the respective chapters. Two methodological considerations are highlighted and described in this section: generalizability of results (Chapter 3 to 6 ) and the use of standardized patients in outcome research (Chapter 8).

\section{GENERALIZABILTY OF RESULTS}

Since the main goal of research is to increase our understanding of the world around us, research results should rather be relevant when applied to other patients with a similar clinical profile. Although ESpAC is a relatively small cohort, it clearly represents a study population of high actual interest. Patients in ESpAC had IBP 2 years at most and this cohort is therefore able to provide more insight in the early stages of axSpA. Patients included in the ESPAC were recruited from the regular rheumatology outpatient clinic $(60 \%)$ or by (related) medical specialties (i.e. dermatology, ophthalmology) and relatives of members of the local AS society (40\%). This recruitment strategy may explain the high proportion of patients fulfilling at least one of the classification criteria for SpA (94\%). In the ESpAC study, 31 (46\%) out of 68 patients fulfilled the imaging arm of the ASAS criteria. Although rheumatologists often see patients referred by other medical specialists, selecting patients in this way may hamper generalizability of our results to a wider population to some extent. Our results may be restricted to patients with a clearer clinical presentation (such as "psoriasis and IBP") or those with more active disease. This means that generalization to another population, for example patients with back pain referred by GPs, should be done with caution. It is however important to note that our main research question was how BME and structural changes on MRI-SIJ, suggestive for axSpA, evolve over time. To answer this question, subject restriction by selecting patients with a high 
chance of abnormalities on MRI-SIJ may have improved efficiency and internal validity. Notwithstanding, the lessons learned from ESpAC may help rheumatologists how to assess M RI-SIJ in clinical practice.

\section{STANDARDIZID PATIENTS, EDUCATION AND OUTCOME MEASURES}

In 1968, Barrows was the first to introduce SPs in order to assess the clinical performance of medical residents.[24] Since then, SPs are most commonly used for teaching communication and clinical skills.[25] The study with SPs described in this thesis, however, focused on changes in recognition of SpA and the decision to refer patients to a rheumatologist before and after education. SPs recorded several outcomes of the consultation before as well as after the educational intervention. When evaluating outcome in a study that includes an educational programme, several outcome levels can be distinguished [26]:

- Level 1: reaction. To what extent did the participants like the learning event? Likert scales can be used to measure the participants' level of satisfaction.

- Level 2: learning. To what degree did participants acquire the intended knowledge, skills and attitudes based on their participation in the leaning event? Computer tests or Objective Structured Clinical Examinations (OSCE) can be used to measure changes in for instance knowledge.

- Level 3: behaviour. To what degree apply participants what they learned during the training when they are back on the job? SPs that visit the GP before and after education can record changes in for instance history taking.

- Level 4: To what degree do organizational changes and improvement in health and well-being of a patient occur as a result of the learning event? Surveys and annual reports can be used to measure these changes.

The majority of studies that report on educational program innovations focus on changes in knowledge, skills and attitudes (level 2).[26] Our study also assessed the changes in practice behaviour (level 3). The advantage of collecting data on practice behaviour is that it offers information about what actually happens in clinical practice. The SP method is valid, but thorough selection and training of the SP is a prerequisite. In addition, SP visits have proven to be accurate and reliable in collecting information.[27-30] In a review of Rethans et al. it was concluded that both intra-SP reliability and inter-SP reliability are 0.85 or more, which indicates an excellent agreement.[27] An important limitation regarding the use of SPs in our study is the fact 
that the SP visit was restricted to one (first) consultation. Especially in the case of rare or chronic conditions, GPs may unfold diagnostic and therapeutic interventions in several consultations. To overcome this limitation, we included in the medical history of the SP that complaints were present for more than one year, multiple visits with other GPs had taken place and physiotherapy or swimming were unsuccessful. Overall, the use of SPs seems an excellent method to assess the effect of education on practice performance. When taking the right precautions, it seems that SPs can also be used for less straightforward medical problems, such as we did in the case of SpA.

\section{IM PLICATIONS FOR CLINICAL PRACTICE}

Improving evidence-based care of patients suffering from $\mathrm{SpA}$ is the ultimate goal of research in the SpA-field.

New insights about the epidemiology of SpA, as described in this thesis, suggest that spondyloarthritis is as prevalent as rheumatoid arthritis.[31] The actual prevalence of $\mathrm{SpA}$ is important for implementing standards of care for patients with SpA (including efforts to diagnose the disease earlier), and for decision makers when allocating resources to research and healthcare. Knowledge about (variation in) prevalence contributes to plan optimal quality of care within the limits of available health care resources.

The introduction of MRI to diagnose sacroiliitis at an early stage has already shown to be highly useful to both rheumatologists and patients. For rheumatologists, the introduction of MRI helps to improve the diagnostic approach of a highly prevalent clinical problem. When rheumatologists have a real suspicion of an inflammatory back problem in a patient after careful evaluation, conventional pelvic radiographs often fail to show radiographic sacroiliitis. The findings described in this thesis may guide rheumatologists to correctly assess the value of MRI in these day-to-day clinical cases. For instance, in an HLA-B27 positive male patient with a negative M RI-SIJ, a second M RI can be considered in case of persisting complaints since a reasonable percentage of these patients will develop active lesions on M RI over time.

For patients, early diagnosis is important since the pain and physical limitations associated with axSpA may have important socio-economic consequences, such as decreased work participation.[32] Substantial diagnostic delay can have an adverse impact on several outcomes, including physical functioning and quality of life.[33] Last but not least, patients with $\mathrm{nr}$-axSpA who have objective measures of inflammation (elevated C-reactive protein and active lesions on MRI) have a similar response to 
treatment as compared to patients with established AS, emphasizing the need for early and correct diagnosis.[34,35] Early diagnosis might facilitate early initiation of effective treatment, thereby diminishing the burden of disease for patients and possibly avoid long term costs of work disability for society.[36]

Optimization of the diagnostic and management process by the rheumatologist is important, but decreasing the diagnostic delay in primary care is equally essential. The greater part of the diagnostic delay pertains to primary care. $[37,38]$ It is therefore important to communicate new disease concepts, in particular those with implications for primary care, to the GP. Our data have shown that educating GP residents about $\mathrm{SpA}$ increases the number of referrals to the rheumatologist. Postgraduate training of GPs in rheumatology seems a feasible approach to improve the care for patients with SpA and deserves greater priority.

\section{FUTURE PERSPECTIVES}

A definite diagnosis of axSpA remains a challenge in daily practice due to the heterogeneous clinical picture of the disease. Although M RI has undoubtedly facilitated an early diagnosis of axSpA, several research questions remain unsolved. First, although MRI is widely accepted as imaging technique to detect sacroiliitis at an early stage, the specificity and predictive value of these active MRI lesions on the long-term needs to be further validated in prospective studies.[39] Second, further clarification of the potential contribution of structural changes on MRI in relation to classification and diagnosis of axSpA is needed. Several studies suggest that structural damage on MRI, especially erosions, may be helpful in establishing an early diagnosis of axSpA.[40,41] Detection of erosions on MRI-SIJ is more challenging than detection of $B M E$, since the spectrum of appearance of erosions is more heterogeneous.[42,43] Further defining the characteristics of erosions and their role in further improving the diagnostic utility of M RI is needed. Third, the link between active and structural lesions on M RI and bone formation on conventional radiographs, needs to be further elucidated. Inflammation might be the first step in the domino-effect leading to bone formation.[44] However, inflammation and bone formation might also be (partly) uncoupled processes. New therapeutic options should then also need to target pathways of bone-formation.[11] Prospective (longitudinal) cohorts are necessary to provide more insight into the predictive potential of MRI and may ultimately guide the rheumatologist in clinical decision-making. 
With regard to improving referral of patients suspected for axial and peripheral SpA to specialist services, it is important that GPs are both informed and motivated to incorporate the latest insights about SpA into their daily work practices.[43] Much attention has been given to referral strategies, but lack of knowledge about SpA and absence of incentives for change may prevent successful implementation of any referral strategy. Therefore, a targeted educational activity should not only include increase knowledge about SpA, but also create commitment among GPs to change the quality of care for this relatively young patient group.[45-47] More research is necessary in order to develop and test educational activities that can ultimately be used to successfully implement referral strategies in primary care.

\section{OVERALL CONCLUSIONS}

This thesis shows that the predictive potential of MRI-SIJ in patients with early IBP is high with regard to the presence or absence of active lesions, especially in combination with other parameters such as HLA-B27 and gender. Signs of BME on MRI seem a trigger for reparative processes such as fatty lesions, which strengthen ideas about the need for early anti-inflammatory treatment. Early initiation of treatment can only start after timely referral of patients suspected of SpA by GPs. To achieve timely referral, it is important that GPs and rheumatologists learn from each other. Both have complementary skills that are necessary to ensure high-quality care for patients throughout their disease trajectory. Knowing is half the battle. 


\section{REFERENCES}

1. Rudwaleit M, van der Heijde D, Landewé R, et al. The development of Assessment of Spondyloarthritis international society classification criteria for axial spondyloarthritis (part II): validation and final selection. Ann Rheum Dis 2009; 68:777-83.

2. Rudwaleit M, van der Heijde $D$, Landewé R, et al. The Assessment of SpondyloArthritis International Society classification criteria for peripheral spondyloarthritis and for spondyloarthritis in general. Ann Rheum Dis 2011;70:25-31.

3. Rudwaleit M. New approaches to diagnosis and classification of axial and peripheral spondyloarthritis. Curr Opin Rheumatol 2010;22:375-80.

4. Rudwaleit M, Khan MA, Sieper J. The challenge of diagnosis and classification in early ankylosing spondylitis: do we need new criteria? Arthritis Rheum 2005;52:1000-8.

5. Reveille JD, Witter JP, Weisman MH. Prevalence of axial spondyloarthritis in the United States: estimates from a cross-sectional survey. Arthritis Care Res (Hoboken) 2012;64:905-10.

6. Braun J, Sieper J, Bollow M. Imaging of sacroiliitis. Clin Rheumatol 2000;19:51-7.

7. Van den Berg R, de Hooge M, Rudwaleit $M$, et al. ASAS modification of the Berlin algorithm for diagnosing axial spondyloarthritis: results from the SPondyloArthritis Caught Early (SPACE)-cohort and from the Assessment of SpondyloArthritis international Society (ASAS)-cohort. Ann Rheum Dis 2013; 72:1646-53.

8. Yu D, Van Tubergen A. Clinical manifestations of ankylosing spondylitis in adults. In: DS Basow (Ed.), UpToDate. Waltham MA, 2014.

9. Rudwaleit $M$, Jurik $A G$, Hermann $K G$, et al. Defining active sacroiliitis on magnetic resonance imaging (MRI) for classification of axial spondyloarthritis: a consensual approach by the ASAS/OM ERACT MRI group. Ann Rheum Dis 2009;68:1520-7.

10. Weber U, Ostergaard M, Lambert RG, et al. Candidate lesion-based criteria for defining a positive sacroiliac joint MRI in two cohorts of patients with axial spondyloarthritis. Ann Rheum Dis 2014: doi: 10.1136/annrheumdis-2014-205408.

11. Maksymowych WP, Elewaut D, Schett G. Motion for debate: the development of ankylosis in ankylosing spondylitis is largely dependent on inflammation. Arthritis Rheum 2012;64:1713-9.

12. Maksymowych WP, Chiowchanwisawakit $P$, Clare $T$, et al. Inflammatory lesions of the spine on magnetic resonance imaging predict the development of new syndesmophytes in ankylosing spondylitis: evidence of a relationship between inflammation and new bone formation. Arthritis Rheum 2009;60:93-102.

13. Wanders $A$, van der Heijde $D$, Landewe $R$, et al. Nonsteroidal antiinflammatory drugs reduce radiographic progression in patients with ankylosing spondylitis: a randomized clinical trial. Arthritis Rheum 2005;52:1756-65.

14. Van der Heijde D, Landewe R, Einstein S, et al. Radiographic progression of ankylosing spondylitis after up to two years of treatment with etanercept. Arthritis Rheum 2008;58:1324-31.

15. Van der Heijde D, Landewe R, Baraliakos X, et al, and the Ankylosing Spondylitis Study for the Evaluation of Recombinant Infliximab Therapy Study Group. Radiographic findings following two years of infliximab therapy in patients with ankylosing spondylitis. Arthritis Rheum 2008;58:3063-70.

16. Van der Heijde D, Salonen D, Weissman BN, et al. Assessment of radiographic progression in the spines of patients with ankylosing spondylitis treated with adalimumab for up to 2 years. Arthritis Res Ther 2009;11:R127.

17. Van der Heijde D, Machado P, Braun J, et al. MRI inflammation at the vertebral unit only marginally predicts new syndesmophyte formation: a multilevel analysis in patients with ankylosing spondylitis. Ann Rheum Dis 2012;71:369-73.

18. Lories RJ, Derese I, De Bari C, et al. Evidence for uncoupling of inflammation and joint remodeling in a mouse model of spondylarthritis. Arthritis Rheum 2007;56:489-97.

19. Song $\mathrm{IH}$, Hermann $\mathrm{KG}$, Haibel $\mathrm{H}$, et al. Relationship between active inflammatory lesions in the spine and sacroiliac joints and new development of chronic lesions on whole-body MRI in early axial spondyloarthritis: results of the ESTHER trial at week 48. Ann Rheum Dis 2011;70:1257-63. 
20. Chiowchanwisawakit P, Lambert RG, Conner-Spady B, et al. Focal fat lesions at vertebral corners on magnetic resonance imaging predict the development of new syndesmophytes in ankylosing spondylitis. Arthritis Rheum 2011;63:2215-25.

21. De Hooge M, van den Berg R, Navarro-Compán V, et al. Magnetic resonance imaging of the sacroiliac joints in the early detection of spondyloarthritis: no added value of gadolinium compared with short tau inversion recovery sequence. Rheumatology (Oxford) 2013;52:1220-4.

22. Underwood M R, Dawes P. Inflammatory back pain in primary care. Br J Rheumatol 1995;34:1074-7.

23. Van Hoeven L, Luime J, Han $\mathrm{H}$, et al. Identifying axial spondyloarthritis in dutch primary care patients, ages 20-45 years, with chronic low back pain. Arthritis Care Res (Hoboken) 2014;66:446-53.

24. Barrows HS. Simulated patients in medical teaching. Can M ed Assoc J 1968;98:674-6.

25. May W, Park JH, Lee JP. A ten-year review of the literature on the use of standardized patients in teaching and learning: 1996-2005. Med Teach 2009;31:487-92.

26. Kirkpatrick DL. Evaluating training programs: the four levels. San Francisco: Berett-Koehler Publishers; 1994.

27. Beullens J, Rethans JJ, Goedhuys J, et al. The use of standardized patients in research in general practice. Fam Pract 1997;14:58-62.

28. Tamblyn RM, Abrahamowicz M, Berkson L, et al. First-visit bias in the measurement of clinical competence with standardized patients. Acad M ed 1992;67:S22-4.

29. Carney PA, Dietrich AJ, Freeman DH Jr, et al. The periodic health examination provided to asymptomatic older women: an assessment using standardized patients. Ann Intern M ed 1993;119:129-35.

30. Rethans JJ, Gorter S, Bokken L, Morrison L. Unannounced standardised patients in real practice: a systematic literature review. Med Educ 2007;41:537-49.

31. Bijlsma JWJ. EULAR textbook on rheumatic diseases. BMJ Publishing Group; 2012.

32. Boonen A. A review of work-participation, cost-of-illness and cost-effectiveness studies in ankylosing spondylitis. Nat Clin Pract Rheumatol 2006;2:546-53.

33. Sieper J, Rudwaleit M. Early referral recommendations for ankylosing spondylitis (including preradiographic and radiographic forms) in primary care. Ann Rheum Dis 2005;64:659-63.

34. Sieper J, Landewé R, Rudwaleit M, et al. Effect of Certolizumab Pegol over 96 Weeks in Patients with Axial Spondyloarthritis: Results from a Phase 3 Randomized Trial. Arthritis Rheumatol 2014: doi: 10.1002/art.38973.

35. Sieper J, van der Heijde D, Dougados $M$, et al. Efficacy and safety of adalimumab in patients with nonradiographic axial spondyloarthritis: results of a randomised placebo-controlled trial (ABILITY-1). Ann Rheum Dis 2013;72:815-22.

36. Rudwaleit M, Claudepierre P, Wordsworth P, et al. Effectiveness, safety, and predictors of good clinical response in 1250 patients treated with adalimumab for active ankylosing spondylitis. J Rheumatol 2009;36:801-8.

37. Feldtkeller E, Khan MA, van der Heijde D, et al. Age at disease onset and diagnosis delay in HLA-B27 negative vs. positive patients with ankylosing spondylitis. Rheumatol Int 2003;23:61-6.

38. Feldtkeller E, Bruckel J, Khan MA. Scientific contributions of ankylosing spondylitis patient advocacy groups. Curr Opin Rheumatol 2000;12:239-47.

39. De Rycke L, M aas M, Tak PP, et al. 'M RI-tis' in the early diagnosis of axial SpA: issues and limitations. Nat Rev Rheumatol 2010;6:666-9.

40. Weber $\mathrm{U}$, Zubler V, Pedersen $\mathrm{S}$, et al. Development and validation of an MRI reference criterion for defining a positive SIJ M RI in spondyloarthritis. Arthritis Care Res (Hoboken) 2013;65:977-85.

41. Weber U, Ostergaard M, Lambert RG, et al. Candidate lesion-based criteria for defining a positive sacroiliac joint MRI in two cohorts of patients with axial spondyloarthritis. Ann Rheum Dis 2014; doi: 10.1136/annrheumdis-2014-205408.

42. Weber U, Maksymowych WP. Advances and challenges in spondyloarthritis imaging for diagnosis and assessment of disease. Curr Rheumatol Rep 2013;15:345.

43. Weber U, Pedersen SJ, Østergaard M, et al. Can erosions on MRI of the sacroiliac joints be reliably detected in patients with ankylosing spondylitis? - A cross-sectional study. Arthritis Res Ther $2012 \mathrm{May}$ 24;14:R124.

44. Ramiro $S$, van der Heijde $D$, van Tubergen $A$, et al. Higher disease activity leads to more structural damage in the spine in ankylosing spondylitis: 12-year longitudinal data from the OASIS cohort. Ann Rheum Dis 2014;73:1455-61. 
172 | Chapter 9

45. Davis DA, Taylor-Vaisey A. Translating guidelines into practice. A systematic review of theoretic concepts, practical experience and research evidence in the adoption of clinical practice guidelines. CM AJ 1997; 157:408-16.

46. Coomarasamy A, Khan KS. What is the evidence that postgraduate teaching in evidence based medicine changes anything? A systematic review. BMJ 2004;329:1017.

47. Hosie GA. Teaching rheumatology in primary care. Ann Rheum Dis 2000;59:500-3. 


\section{Samenvatting in het Nederlands}





\section{INLEIDING}

Spondyloartritis $(\mathrm{SpA})$ is een verzamelnaam voor een aantal inflammatoire reumatische aandoeningen van het bewegingsapparaat met verwante klinische kenmerken, genetische aanleg en familiair optreden. Tot de groep van SpA behoren onder andere ankyloserende spondylitis (AS), arthritis psoriatica, reactieve artritis en enteropathische artritis.[1] Typisch voor SpA is dat ook extra-articulaire manifestaties (aandoeningen in andere organen dan het skelet) deel kunnen uitmaken van het ziektebeeld.[2]

Tegenwoordig wordt de groep van SpA ook wel ingedeeld in axiale SpA en perifere SpA. Bij axiale SpA staan symptomen van het axiale skelet op de voorgrond, met als overheersende symptoom inflammatoire rugpijn veroorzaakt door sacro-iliitis (ontsteking van het heiligbeen) en/of spondylitis (ontsteking van de wervellichamen). De bekendste vorm van axiale SpA is de aandoening AS, oftewel de ziekte van Bechterew.[2] Bij perifere SpA staan artritis, enthesitis (inflammatie op de plaats waar pees aan bot vastzit) en dactylitis (worstvormig gezwollen teen of vinger) op de voorgrond.[2] In totaal krijgt 40-50\% van de patiënten met SpA tijdens het beloop van de ziekte een extra-articulaire manifestatie, zoals acute uveitis anterior (regenboogvliesontsteking), inflammatoire darmziekten en psoriasis.[3] SpA begint meestal op jongvolwassen leeftijd. Aanvang van de eerste klachten na het 45e levensjaar is zeldzaam.[4]

Bij axiale SpA en in het bijzonder type AS kan uiteindelijk een klassiek radiologisch beeld met ankylosering van de sacro-liacale gewrichten op een bekkenfoto zichtbaar worden.[1] In de wervelkolom kunnen syndesmofyten ontstaan door verbening van intervertebrale ligamenten.[1] Dit leidt uiteindelijk in het meest gevorderde stadium tot volledige ankylose van de wervelkolom, een zogeheten bamboo spine. Wanneer er geen of slechts dubieuze afwijkingen zichtbaar zijn op een conventionele bekkenfoto, kan men besluiten een Magnetic Resonance Imaging (MRI) van de sacro-liacale gewrichten te maken. Op de MRI kunnen voor sacro-iliitis kenmerkende afwijkingen worden gezien, bijvoorbeeld subchondraal beenmergoedeem. Indien de patiënt een afwijkende MRI heeft in combinatie met een ander SpA kenmerk, dan wordt dit 'nietröntgenologische axiale SpA' genoemd.[5,6] Bij een aantal patiënten met nietröntgenologische axiale SpA is sacro-iliitis op een MRI (nog) niet aantoonbaar. Deze patiënten worden op basis van genetische aanleg (humaan leukocytenantigeen B27 (HLA-B27)) en minimaal twee andere kenmerkende SpA-manifestaties ook gerekend tot de groep van niet-röntgenologische axiale SpA. 
Bij patiënten met axiale SpA duurt het gemiddeld negen jaar na het ontstaan van de eerste rugklachten voordat de diagnose wordt gesteld.[4] Een belangrijke reden hiervoor is dat afwijkingen op een conventionele bekkenfoto, wat voorheen als een vereiste gold voor het stellen van de diagnose ankyloserende spondylitis, slechts laat in het ziekteproces zichtbaar worden. De M RI kan hier uitkomst bieden, omdat op de M RI vaak wel afwijkingen typisch voor sacro-iliitis worden gezien.[6] Daarnaast heeft men lang gedacht dat axiale SpA een typische mannenziekte was. In de literatuur zijn manvrouwverhoudingen beschreven van 8:1 à 10:1. Er blijkt echter sprake te zijn geweest van onderdiagnose bij vrouwen. Bij vrouwen ziet men minder structurele schade op een conventionele bekkenfoto.[7] Tegenwoordig wordt verondersteld dat de prevalentie van axiale SpA in mannen en vrouwen gelijk is.

Eerder onderzoek heeft laten zien dat een goede en tijdige behandeling van SpA uiteindelijk leidt tot een verbetering van verschillende uitkomstmaten, waaronder de mate van ziekteactiviteit, arbeidsproductiviteit en kwaliteit van leven.[8-10] De huisarts is een sleutelfiguur wanneer het gaat om de herkenning en vroege verwijzing van patiënten met klachten die zouden kunnen wijzen op SpA. De afgelopen jaren zijn verschillende strategieën ontwikkeld die een snelle verwijzing van patiënten met SpA mogelijk zouden moeten maken.[11-15] Huisartsen hebben echter moeite met het herkennen van het ziektebeeld.[16] Slechte herkenning kan er toe leiden dat de verwijsstrategieën niet goed worden toegepast in de huisartsenpraktijk. Educatie specifiek gericht op SpA zou de kennis, herkenning en daardoor verwijzing van patiënten naar de reumatoloog mogelijk kunnen verbeteren.

De onderzoeken zoals beschreven in dit proefschrift richten zich op de vroege herkenning van SpA.

\section{DEEL I: DE EPIDEM IOLOGIE VAN SPONDYLOARTRITIS}

In hoofdstuk 1 wordt beschreven dat er de afgelopen jaren veel is verbeterd ten aanzien van de mogelijkheden om SpA eerder te diagnosticeren. Een belangrijke verandering is de ontwikkeling van nieuwe naamgeving door de Assessment in SpondyloArthritis international Society (ASAS).[17-20] Momenteel wordt onderscheid gemaakt tussen axiale SpA en perifere SpA. Axiale SpA wordt verder onderverdeeld in 'röntgenologische axiale SpA' ofwel AS en 'niet-röntgenologische axiale SpA', een aandoening waarbij geen of onvoldoende afwijkingen op een röntgenfoto aanwezig 
zijn.[17] Door niet-röntgenologische axiale SpA als zodanig te erkennen en op te nemen in de ASAS axiale SpA classificatiecriteria, heeft de focus zich de afgelopen jaren verlegd richting vroege herkenning van axiale SpA.[17,19]

Ondanks (of door) deze ontwikkelingen, bleef verder onderzoek op het gebied van SpA nodig. Zo is het belangrijk om betrouwbare epidemiologische gegevens te verzamelen over het wereldwijd voorkomen van (de verschillende subtypes van) SpA. Deze gegevens kunnen worden gebruikt om meer inzicht te krijgen in welke maatregelen en middelen nodig zijn om patiënten met SpA tijdig op te kunnen sporen en te behandelen. In hoofdstuk 2 wordt een systematisch literatuuronderzoek en metaanalyse naar de prevalentie van (subtypes van) SpA gepresenteerd. In totaal werden 84 studies geïdentificeerd. Verschillende demografische (waaronder ook geografische) en methodologische variabelen werden bestudeerd om te achterhalen of zij een deel van de variatie in prevalentie tussen de verschillende studies konden verklaren. De gepoolde populatieprevalentie van SpA was $0.55 \%$ ( $95 \%$ betrouwbaarheidsinterval (BI) 0.37-0.77); de gepoolde populatieprevalentie van AS was $0.18 \%$ (95\% BI 0.15-0.23). Tussen de geïncludeerde studies werd echter een hoge heterogeniteit gevonden. De variatie in prevalentie tussen de verschillende wereldregio's kon deels worden verklaard door de bekende variatie in de prevalentie van HLA-B27 tussen deze regio's. In populaties waar de prevalentie van HLA-B27 hoog is, werd een hoge prevalentie van SpA gevonden. De hoogste prevalenties van SpA (inclusief AS) werden in afnemende volgorde gevonden bij inheemse bevolkingsgroepen die leven in het Arctisch gebied, Noord-Amerika, Oost-Azië en Europa. Een andere interessante bevinding was dat de prevalentie van SpA hoger was in studies van meer recente datum. Wellicht is deze stijging in prevalentie door de jaren heen te verklaren door het feit dat SpA inmiddels beter wordt herkend. Daarnaast was prevalentie afhankelijk van de manier waarop SpA werd gedefinieerd. Dit wordt mooi geillustreerd in een populatiestudie uit de Verenigde Staten.[21] De prevalentie van SpA was 1.4\% wanneer de ESSG criteria werden gehanteerd en $0.9 \%$ wanneer de Amor criteria werden gehanteerd. Dit verschil in prevalentie maakt duidelijk dat het type classificatiecriteria uiteindelijk invloed kan hebben op de gerapporteerde prevalentie van (subtypes van) SpA. Het is daarom te verwachten dat door het toepassen van de nieuwe ASAS axiale en perifere SpA classificatiecriteria, de prevalentie van SpA wederom beïnvloed kan worden en/of andere patiënten geïdentificeerd zullen worden. 


\section{DEEL II: HET GEBRUIK VAN M RI BIJ HET OPSPOREN VAN VROEGE SPONDYLOARTRITIS}

Bij axiale SpA werd de ontwikkeling van nieuwe classificatiecriteria voorafgegaan aan de introductie van de MRI van de sacro-iliacale gewrichten. Door de MRI te gebruiken, wordt het mogelijk de diagnose axiale SpA eerder te stellen.[22] Op een MRI kunnen immers, in tegenstelling met conventionele röntgenfoto's, ook kenmerken van ontstekingsactiviteit worden gezien, zoals beenmergoedeem. Verder kunnen ook structurele veranderingen worden gezien zoals erosies, vervetting van het beenmerg en ankylose.[6] Een M RI van de sacro-iliacale gewrichten wordt positief bevonden voor sacro-liitis wanneer minstens één inflammatoire laesie (beenmergoedeem) aanwezig is op twee opeenvolgende MRI-sneden, of wanneer twee laesies aanwezig zijn op één MRI-snede.[6] De Early SpondyloArthritis Clinic (ESpAC) werd door onze onderzoeksgroep opgezet om meer inzicht te krijgen in de rol van MRI bij patiënten met symptomen suggestief voor axiale SpA. De twee jaar durende follow-up studie bestond uit drie evaluaties met tussenpozen van telkens één jaar. Elke evaluatie bestond onder meer uit een uitgebreid klinisch onderzoek en beeldvorming. M RI-scans van de sacro-iliacale gewrichten maakten een belangrijk onderdeel uit van deze studie. Hoofdstuk 3 beschrijt de ontwikkeling van ontstekingsactiviteit op de MRI van de sacro-iliacale gewrichten, suggestief voor sacro-ilitis, gedurende een twee jaar durende follow-up periode. Op baseline hadden 24 (35\%) van de 68 geïncludeerde patiënten een positieve MRI van de sacro-iliacale gewrichten. Zowel de aanwezigheid van HLA-B27 als een positieve MRI op baseline, waren onafhankelijk geassocieerd met een positieve MRI tijdens de follow-up periode. Bij afwezigheid van HLA-B27 en een negatieve MRI op baseline, was de ontwikkeling een positieve MRI tijdens follow-up zeer onwaarschijnlijk. Enkel bij HLA-B27 positieve mannen met een negatieve MRI kan het zinvol zijn de MRI te herhalen. Een aanzienlijk deel van deze patiënten ontwikkelde namelijk alsnog een positieve MRI tijdens de follow-up periode. Onze resultaten laten zien hoe patiënten met klachten verdacht voor axiale SpA op efficiënte wijze het diagnostisch traject kunnen doorlopen. Daarnaast ondersteunen onze bevindingen het feit dat de MRI inmiddels een prominente plaats heeft gekregen in de ASAS axiale SpA classificatiecriteria.[17,23,24]

Op dit moment wordt alleen ontstekingsactiviteit (beenmergoedeem) meegenomen bij de beoordeling of een MRI van de sacro-iliacale gewrichten al dan niet positief is. Er is momenteel echter een discussie gaande of structurele afwijkingen (erosies of beenmergvervetting) ook niet een onafhankelijke diagnostische waarde hebben.[25] In hoofdstuk 4 onderzochten we de aanwezigheid en ontwikkeling van structurele 
afwijkingen op een MRI van de sacro-iliacale gewrichten bij patiënten die zijn geïncludeerd in de ESpAC. Daarnaast werd gekeken of structurele afwijkingen op zowel de $\mathrm{MRI}$ als conventionele bekkenfoto vooraf werden gegaan door beenmergoedeem op de MRI op dezelfde locatie. Hoewel het aantal erosies op MRI tijdens follow-up toenam, werd er geen associatie met beenmergoedeem op dezelfde locatie een jaar daarvoor gevonden. Ondanks dat er slechts een lichte toename werd gevonden in de gebieden met beenmergvervetting, werd er wel een associatie met beenmergoedeem op dezelfde locatie in het voorafgaande jaar gevonden. Een interessante bevinding was dat beenmergvervetting met name werd gezien op locaties waar beenmergoedeem was verdwenen. De relatie tussen ontstekingsactiviteit en structurele schade op M RI bij patiënten met axiale SpA is de laatste jaren volop bediscussieerd.[26-33] De discussie richt zich met name op de vraag of ontstekingsactiviteit en structurele schade 'in relatie tot elkaar staan' of 'los van elkaar staan'. Eerder onderzoek laat tegenstrijdige resultaten zien.[29-32] Onze bevindingen ondersteunen de theorie dat beenmergvervetting mogelijk een herstelreactie is op eerder aanwezige ontsteking.[34] Ander onderzoek heeft aangetoond dat beenmergvervetting is geassocieerd met ontwikkeling van syndesmofieten (benige vergroeiing) in de wervelkolom.[35] Wij vonden geen associatie tussen ontstekingsactiviteit op M RI enerzijds en ontwikkeling van erosies op MRI of ankylose op de bekkenfoto anderzijds. Grotere studies dan ESpAC met meerdere M RI's en röntgenfoto's over een langere follow-up periode kunnen hierover uitsluitsel geven.

Om ontstekingsactiviteit op de M RI te kunnen vaststellen, kunnen verschillende M RIsequenties worden gebruikt. Dit zijn de short tau inversion recovery (STIR) sequentie en de T1-gewogen spin-echo sequentie met onderdrukking van het vetsignaal na toediening van het contrastmiddel gadolinium diethylenetriaminepentaacetic acid (GdDTPA).[6] In hoofdstuk 5 lieten we zien dat de post-Gd-DTPA-sequentie geen toegevoegde waarde heeft boven de STIR-sequentie in combinatie met de conventionele bekkenfoto. Onze resultaten komen overeen met die van het SPondyloArthritis Caught Early (SPACE)-cohort, waar zowel op baseline als na drie maanden een volledige overeenkomst werd gezien tussen de STIR- en post-Gd-DTPA-sequentie.[36] Het lijkt er dus op dat de post-Gd-DTPA-sequentie kan worden overgeslagen terwijl de diagnostische waarde van de MRI behouden blijft. Deze bevinding leidt tot een kostenbesparing en vergroot daarmee de toepasbaarheid van de MRI wanneer patiënten verdacht voor axiale SpA tijdens het diagnostisch traject een MRI moeten ondergaan. 
Bij aanvang van dit promotieonderzoek was er nog veel onduidelijkheid omtrent de toepasbaarheid van M RI. De aanbeveling dat alle patiënten met klachten verdacht voor axiale SpA en een negatieve bekkenfoto een MRI zouden moeten ondergaan, kon nog niet hard worden gemaakt. Een belangrijke vraag was of beenmergoedeem op MRI stabiel aanwezig blijft over de tijd. In hoofdstuk 6 onderzochten we daarom de verdeling, frequentie van voorkomen en de ontwikkeling over de tijd van beenmergoedeem op een M RI van de sacro-iliacale gewrichten bij patiënten geïncludeerd in de ESpAC. Bijna de helft van de lokalisaties met beenmergoedeem dat op baseline werd vastgesteld, verdween tijdens follow-up. Omgekeerd werden er nieuwe lokalisaties met beenmergoedeem op een aantal MRI's tijdens follow-up vastgesteld, terwijl de voorafgaande MRI op baseline negatief was. In beide gevallen had dit gevolgen voor het al dan niet voldoen aan de ASAS axiale SpA classificatiecriteria. Dit laat zien dat het toepassen van beeldvormende technieken om een reumatische aandoening te diagnosticeren ook beperkingen met zich meebrengt. Bevindingen bij beeldvorming zijn immers altijd onderhevig aan meetfouten van beoordelaars en variatie tussen beoordelaars; beeldvorming moet daarom geen belangrijkere rol toebedeeld krijgen dan de bevindingen tijdens anamnese en klinisch onderzoek. 'Blindstaren' op een M RIuitslag kan bijvoorbeeld leiden tot een vertraging in het stellen van de diagnose van axiale SpA, wanneer cruciale bevindingen op MRI tijdelijk afwezig zijn bij een patiënt die wel past in het klinisch profiel. Omgekeerd, een M RI-uitslag kan ook leiden tot een fout-positieve diagnose van SpA, wanneer aan subtiele en weinig suggestieve laesies op MRI ('onschuldige witte plekjes') veel waarde wordt gehecht terwijl de klinische symptomen van de patiënt hier eigenlijk geen aanleiding toe geven. Alle manifestaties die worden gezien bij axiale SpA moeten daarom in overweging worden genomen bij de beoordeling van een patiënt, waaronder bijvoorbeeld psoriasis, enthesitis of uveitis. Dit gegeven komt eveneens terug in een recent ontwikkeld 'diagnostisch algoritme' waarin een gedegen anamnese en lichamelijk onderzoek onmisbare stappen zijn bij de beoordeling van een patiënt met verdenking op axiale SpA.[24] Alleen wanneer er voldoende verdenking is op axiale SpA, kan aanvullende beeldvorming worden aangevraagd.

\section{DEEL III: HERKENNING VAN SPONDYLOARTRITIS IN DE HUISARTSENPRAKTIJK}

De reumatoloog is mede dankzij de MRI in staat gesteld de diagnose SpA in een eerder stadium te stellen. Patiënten met een verdenking op SpA moeten hiervoor wel eerst 
tijdig naar de reumatoloog verwezen worden. Het optimaliseren van de zorg rondom patiënten met SpA begint dus altijd met zogenaamde 'case finding'. Dit proces start meestal in de eerste lijn. In hoofdstuk 7 werden zowel het kennisniveau als de percepties van huisartsen over inflammatoire rugpijn en axiale SpA bestudeerd. Daarnaast werd gekeken welke potentiële barrières een tijdige verwijzing van patiënten met mogelijk axiale SpA verhinderen. We toonden aan dat axiale SpA vaak niet goed in de eerste lijn wordt herkend. Zelfs wanneer het wel wordt herkend, dan is de zorg rondom deze patiënten vaak suboptimaal. In het algemeen was de kennis omtrent inflammatoire rugpijn, axiale SpA en extra-articulaire manifestaties beperkt. Huisartsen herkenden veelal slechts de 'klassieke', maar langetermijngevolgen van axiale SpA, zoals bijvoorbeeld een kyfose die wordt gezien bij AS. Slechts de helft van de geïnterviewde huisartsen wist dat Tumor Necrosis Factor (TNF)-alpha blokkerende biologicals, een erkende en effectieve behandeling bij een specifieke groep van patiënten met bij axiale SpA, een behandeloptie zijn bij deze patiëntengroep. Vergroten van kennis bij huisartsen aangaande de symptomen en behandeling van axiale SpA, zal waarschijnlijk de verwijzing van patiënten met klachten verdacht voor axiale SpA bevorderen.

In de dagelijkse praktijk moet de huisarts adequaat kunnen anticiperen op velerlei lichamelijke en psychische klachten waar patiënten zich mee presenteren. Herkenning van patiënten met SpA in de huisartsenpraktijk kan lastig zijn. Chronische rugpijn is immers een veelvoorkomend symptoom in de algemene populatie en is voor patiënten ook vaak een reden om de huisarts te bezoeken. Slechts in $5 \%$ van de gevallen is axiale SpA de onderliggende oorzaak.[37] Het finetunen van de procedure om de patiënten te selecteren die wel dienen te worden verwezen naar de tweedelijn, is echter een belangrijke nog te maken stap. Een recente studie heeft laten zien dat bijna een kwart van de patiënten met chronische rugpijn die ontstond voor de leeftijd van 45 jaar geclassificeerd kon worden met axiale SpA nadat de huisarts deze patiënten had verwezen naar de reumatoloog.[38]

De huisarts is onmisbaar bij het herkennen van patiënten met SpA. Huisartsen verkeren in een unieke positie: ze kunnen 'longitudinale continue zorg' leveren in overeenstemming met overige behoeften van een patiënt. Dit betekent dat ze in staat zijn om het patroon kenmerkend voor axiale SpA, bijvoorbeeld achtereenvolgens optreden van psoriasis en rugpijn, als eerste te herkennen wanneer een patiënt de praktijk bezoekt. In hoofdstuk 8 onderzochten we in hoeverre huisartsen en huisartsen in opleiding (HAIO) vroege axiale en perifere SpA herkennen en verwijzen. We maakten gebruik van simulatiepatiënten om te onderzoeken 'hoe het er in de praktijk echt aan toe gaat'. 
Daarbij keken we ook naar de invloed van educatie op de mate van herkenning en uiteindelijk verwijzing. In totaal werden 68 huisartsen en HAIO's bezocht door simulatiepatiënten die waren getraind om een casus van vroege axiale dan wel perifere SpA te simuleren. We bevestigden dat zowel de herkenning als verwijzing van patiënten met klachten suggestief voor SpA slechts beperkt was. Educatie verbeterde duidelijk de herkenning en verwijzing van patiënten naar de reumatoloog. Het geven van onderwijs lijkt daarmee een belangrijke kans om de kennis wat betreft SpA te verbeteren, waardoor een succesvolle implementatie van een verwijsstrategie dichterbij komt.

\section{PERSPECTIEF}

In hoofdstuk 9 werden bevindingen uit dit proefschrift samengevat en enkele methodologische aspecten verder bediscussieerd. Ten eerste werd stilgestaan bij de generaliseerbaarheid van de resultaten die zijn verkregen uit het ESpAC-onderzoek. Patiënten die werden geïncludeerd in de ESpAC waren reeds verdacht op het hebben van SpA en waren verwezen door de reumatoloog of door medisch specialisten die extra-articulaire manifestaties van SpA behandelen (waaronder dermatologen, oogartsen). Veel patiënten in ESpAC presenteerden zich dus met duidelijke klachten, zoals bijvoorbeeld 'inflammatoire rugpijn in combinatie met psoriasis of uveitis'. Door patiënten langs deze route te includeren is het waarschijnlijk dat sommige bevindingen niet meteen te generaliseren zijn naar patiënten met een minder duidelijk klinisch beeld, bijvoorbeeld patiënten met uitsluitend inflammatoire rugpijn in de huisartsenpraktijk. Daarentegen, onze primaire onderzoeksvraag was hoe afwijkingen op de MRI verdacht voor sacro-iliitis zich over de tijd ontwikkelen. Het includeren van patiënten met een hoge 'pakkans' vergroot dan de efficiëntie en interne validiteit.

Ten tweede werden de voor- en nadelen van het gebruik van simulatiepatiënten in onderzoek besproken. Door simulatiepatiënten in te zetten waren wij in staat te kijken of educatie uiteindelijk ook een gedragsverandering in gang zet. Dit gaat dus verder dan het afnemen van een toets na een educatiemoment. Onze resultaten laten zien dat simulatiepatiënten ook ingezet kunnen worden bij meer ingewikkelde medische problemen zoals bijvoorbeeld SpA. Er zijn dan wel meer voorbereidingsmaatregelen nodig. Specifiek in ons onderzoek was het bijvoorbeeld belangrijk om een goede voorgeschiedenis op te stellen en een nauwkeurige beschrijving te geven van de reeds ondernomen stappen, zoals het effect van eerder ontvangen fysiotherapie op de klachten. 
Ten slotte werden er aanbevelingen gedaan voor de klinische praktijk en verder onderzoek. Met de introductie van de MRI van de sacro-liacale gewrichten is de reumatoloog in staat gesteld om patiënten met SpA eerder een diagnose te kunnen geven en hierdoor, indien nodig, tijdig te starten met een behandeling. Het onderzoek beschreven in dit proefschrift kan reumatologen helpen hoe ze de MRI in de dagelijkse praktijk kunnen inzetten. Meer onderzoek is echter nodig om onder andere de diagnostische waarde van structurele veranderingen op een M RI vast te stellen.

Snel instellen van een behandeling leidt mogelijk tot minder werkverzuim en arbeidsongeschiktheid. Om het gunstige effect van een vroege diagnose op de verschillende uitkomstmaten optimaal te benutten, is het wel belangrijk dat patiënten ook snel worden verwezen. Wij hebben laten zien dat educatie aan huisartsen hierbij kan helpen. Meer onderzoek is nodig om te kijken welke onderwijsactiviteiten bijdragen aan een succesvolle verwijsstrategie is. Bij het bewerkstelligen van dit doel is het belangrijk te realiseren dat reumatologen en huisartsen hierbij van elkaar kunnen leren. Beide medische disciplines vullen elkaar mooi aan wanneer het gaat om het leveren van kwalitatief goede zorg voor patiënten met SpA. 


\section{LITERATUUR}

1. Bijlsma JWJ, van Laar JM. Reumatologie en klinische immunologie. Houten: Bohn Stafleu van Loghum, 2013.

2. Rudwaleit M. New approaches to diagnosis and classification of axial and peripheral spondyloarthritis. Curr Opin Rheumatol 2010;22:375-80.

3. Stolwijk C, van Tubergen A, Castillo-Ortiz JD, et al. Prevalence of extra-articular manifestations in patients with ankylosing spondylitis: a systematic review and meta-analysis. Ann Rheum Dis 2013. doi: 10.1136/annrheumdis-2013-203582.

4. Feldtkeller E, Khan MA, Heijde D van der, et al. Age at onset and diagnosis delay in HLA-B27 negative vs positive patients with ankylosing spondylitis. Rheumatol Int 2003;23:61-6.

5. Rudwaleit M, Khan MA, Sieper J. The challenge of diagnosis and classification in early ankylosing spondylitis: do we need new criteria? Arthritis Rheum 2005;52:1000-8.

6. Rudwaleit $M$, Jurik $A G$, Hermann $K G$, et al. Defining active sacroilitis on magnetic resonance imaging (MRI) for classification of axial spondyloarthritis: a consensual approach by the ASAS/OM ERACT MRI group. Ann Rheum Dis 2009;68:1520-7.

7. Feldtkeller E, Bruckel J, Khan MA. Scientific contributions of ankylosing spondylitis patient advocacy groups. Curr Opin Rheumatol 2000;12:239-47.

8. Keat AC, Gaffney K, Gilbert AK, et al. Influence of biologic therapy on return to work in people with work disability due to ankylosing spondylitis. Rheumatology (Oxford) 2008;47:481-3.

9. Prince DS, M CGuigan LE, M CGirr EE. Working life and physical activity in ankylosing spondylitis pre and post anti-tumor necrosis factor-alpha therapy. Int J Rheum Dis 2014;17:165-72.

10. Van der Heijde D, Han C, DeVlam K, et al. Infliximab improves productivity and reduces workday loss in patients with ankylosing spondylitis: results from a randomized, placebo-controlled trial. Arthritis Rheum 2006;55:569-74.

11. Rudwaleit M, Sieper J. Referral strategies for early diagnosis of axial spondyloarthritis. Nat Rev Rheumatol 2012;8:262-8.

12. Brandt $\mathrm{HC}$, Spiller I, Song $\mathrm{IH}$, et al. Performance of referral recommendations in patients with chronic back pain and suspected axial spondyloarthritis. Ann Rheum Dis 2007; 66:1479-1484.

13. Poddubnyy D, Vahldiek J, Spiller I, et al. Evaluation of 2 screening strategies for early identification of patients with axial spondyloarthritis in primary care. J Rheumatol 2011;38:2452-60.

14. Hermann J, Giessauf H, Schaffler G, et al. Early spondyloarthritis: usefulness of clinical screening. Rheumatology (Oxford) 2009;48:812-6.

15. Sieper J, Srinivasan S, Zamani O, et al. Comparison of two referral strategies for diagnosis of axial spondyloarthritis: the Recognising and Diagnosing Ankylosing Spondylitis Reliably (RADAR) study. Ann Rheum Dis 2013;72:1621-7.

16. Jois RN, Macgregor AJ, Gaffney K. Recognition of inflammatory back pain and ankylosing spondylitis in primary care. Rheumatology (Oxford) 2008;47:1364-6.

17. Rudwaleit $M$, van der Heijde $D$, Landewé $R$, et al. The development of Assessment of Spondyloarthritis international society classification criteria for axial spondyloarthritis (part II): validation and final selection. Ann Rheum Dis 2009; 68:777-83.

18. Rudwaleit M, van der Heijde D, Landewé R, et al. The Assessment of SpondyloArthritis International Society classification criteria for peripheral spondyloarthritis and for spondyloarthritis in general. Ann Rheum Dis 2011;70:25-31.

19. Rudwaleit M. New approaches to diagnosis and classification of axial and peripheral spondyloarthritis. Curr Opin Rheumatol 2010;22:375-80.

20. Rudwaleit M, Khan MA, Sieper J. The challenge of diagnosis and classification in early ankylosing spondylitis: do we need new criteria? Arthritis Rheum 2005;52:1000-8.

21. Reveille JD, Witter JP, Weisman MH. Prevalence of axial spondyloarthritis in the United States: estimates from a cross-sectional survey. Arthritis Care Res (Hoboken) 2012;64:905-10.

22. Braun J, Sieper J, Bollow M. Imaging of sacroiliitis. Clin Rheumatol 2000;19:51-7. 
23. Van den Berg $R$, de Hooge $M$, Rudwaleit $M$, et al. ASAS modification of the Berlin algorithm for diagnosing axial spondyloarthritis: results from the SPondyloArthritis Caught Early (SPACE)-cohort and from the Assessment of SpondyloArthritis international Society (ASAS)-cohort. Ann Rheum Dis 2013;72:1646-53.

24. Yu D, Van Tubergen A. Clinical manifestations of ankylosing spondylitis in adults. In: DS Basow (Ed.), UpToDate. Waltham MA, 2014.

25. Weber U, Ostergaard M, Lambert RG, et al. Candidate lesion-based criteria for defining a positive sacroiliac joint MRI in two cohorts of patients with axial spondyloarthritis. Ann Rheum Dis 2014: doi: 10.1136/annrheumdis-2014-205408.

26. Maksymowych WP, Elewaut D, Schett G. M otion for debate: the development of ankylosis in ankylosing spondylitis is largely dependent on inflammation. Arthritis Rheum 2012;64:1713-9.

27. Maksymowych WP, Chiowchanwisawakit $P$, Clare $T$, et al. Inflammatory lesions of the spine on magnetic resonance imaging predict the development of new syndesmophytes in ankylosing spondylitis: evidence of a relationship between inflammation and new bone formation. Arthritis Rheum 2009;60:93-102.

28. Wanders A, van der Heijde $D$, Landewe $R$, et al. Nonsteroidal antiinflammatory drugs reduce radiographic progression in patients with ankylosing spondylitis: a randomized clinical trial. Arthritis Rheum 2005;52:1756-65.

29. Van der Heijde $D$, Landewe $R$, Einstein $S$, et al. Radiographic progression of ankylosing spondylitis after up to two years of treatment with etanercept. Arthritis Rheum 2008;58:1324-31.

30. Van der Heijde D, Landewe R, Baraliakos X, et al, and the Ankylosing Spondylitis Study for the Evaluation of Recombinant Infliximab Therapy Study Group. Radiographic findings following two years of infliximab therapy in patients with ankylosing spondylitis. Arthritis Rheum 2008;58:3063-70.

31. Van der Heijde D, Salonen D, Weissman BN, et al. Assessment of radiographic progression in the spines of patients with ankylosing spondylitis treated with adalimumab for up to 2 years. Arthritis Res Ther 2009;11:R127.

32. Van der Heijde $D, M$ achado $P$, Braun J, et al. MRI inflammation at the vertebral unit only marginally predicts new syndesmophyte formation: a multilevel analysis in patients with ankylosing spondylitis. Ann Rheum Dis 2012;71:369-73.

33. Lories RJ, Derese I, De Bari C, et al. Evidence for uncoupling of inflammation and joint remodeling in a mouse model of spondylarthritis. Arthritis Rheum 2007;56:489-97.

34. Song IH, Hermann KG, Haibel $H$, et al. Relationship between active inflammatory lesions in the spine and sacroiliac joints and new development of chronic lesions on whole-body MRI in early axial spondyloarthritis: results of the ESTHER trial at week 48. Ann Rheum Dis 2011;70:1257-63.

35. Chiowchanwisawakit $P$, Lambert RG, Conner-Spady B, et al. Focal fat lesions at vertebral corners on magnetic resonance imaging predict the development of new syndesmophytes in ankylosing spondylitis. Arthritis Rheum 2011;63:2215-25.

36. De Hooge M, van den Berg R, Navarro-Compán V, et al. Magnetic resonance imaging of the sacroiliac joints in the early detection of spondyloarthritis: no added value of gadolinium compared with short tau inversion recovery sequence. Rheumatology (Oxford) 2013;52:1220-4.

37. Underwood M R, Dawes P. Inflammatory back pain in primary care. Br J Rheumatol 1995;34:1074-7.

38. Van Hoeven L, Luime J, Han $\mathrm{H}$, et al. Identifying axial spondyloarthritis in dutch primary care patients, ages 20-45 years, with chronic low back pain. Arthritis Care Res (Hoboken) 2014;66:446-53. 

Valorisation addendum 



\section{VALORISATION ADDENDUM}

Valorisation refers to the process of how academic research can be utilized and translated to clinical and societal benefit. The relevance of the research presented in this thesis is described in the section below.

\section{Part I: epidemiology of spondyloarthritis}

Quantification of the burden of rheumatic conditions is important for raising awareness among health care professionals, setting research priorities and initiating a policy debate.[1] Rheumatic conditions have major impact on the individual patient, but also on society. Also in the case of spondyloarthritis (SpA), important decreases in almost all aspects of health related quality of life are reported. The onset at a relatively young age, before the fourth decade, adds to the years lived in disability for an individual.[2] As a consequence of decreased functioning, SpA has an adverse impact on the patient and family by reduced participation in social roles.[3,4] The indirect costs related to SpA are four times as high as the direct costs, reflecting the important impact of the disease on work participation in terms of sick leave, disability pensions and early retirement.[5] To extrapolate how this individual burden would affect society, appropriate data on the epidemiology are warranted. In this thesis, we found that the global prevalence of SpA was 0.55\% (95\% Confidence Interval (Cl): 0.37-0.77). This prevalence is comparable to that of rheumatoid arthritis. Substantial variation across geographic regions was however found. For instance, the prevalence of SpA in East Asia was $0.79 \%(\mathrm{Cl}: 0.48-1.18)$. The study described in this thesis adds to the available evidence on epidemiology of rheumatic diseases that can contribute to prioritize research, but also to inform health care systems at the country level, when allocating budgets to improve diagnosis, treatment and prevention of work disability.[1,6-8]

\section{Part II: the use of MRI in early detection of axial spondyloarthritis}

The introduction of $\mathrm{MRI}$ for detecting active sacroiliitis has revolutionized the diagnosis of axial SpA (axSpA), making an early diagnosis possible. This thesis showed that a positive $M R I$ is a reliable finding: a positive $M R I$ at baseline was strongly associated with a positive MRI of the sacroiliac joints (MRI-SIJ) over time, particularly in HLA-B27 positive patients. This is important for clinicians, because it suggests that a diagnosis of axSpA incorporating a positive MRI is robust and credible. Furthermore, the postgadolinium diethylenetriaminepentaacetic acid (Gd-DTPA) M RI sequence can be safely omitted, which increases the feasibility of $\mathrm{MRI}$, since it saves time and reduces costs. 
Further, in axSpA it is a challenge to identify the appropriate target for treatment: should it be disease activity, prevention or delay in progression of structural damage, or both? In this thesis, we focused on the relation between inflammation and development of structural damage (erosions and fatty lesions) on M RI. We have shown that fatty lesions on MRI-SIJ preferably develop after bone marrow edema (BME) has subsided. Other studies have suggested that fatty lesions at vertebral edges predict the development of new syndesmophytes.[9] BME may therefore be the first domino that sets off the chain that leads to development of fatty lesions and eventually new bone formation (syndesmophytes).[10,11] The true relation between BME and new bone formation still needs to be disentangled in further research. This thesis has contributed in one of the many steps to unravel the relation between inflammation and structural damage on MRI in order to enable identification of different treatment targets.

\section{Part III: early identification of spondyloarthritis in primary care}

Musculoskeletal disorders (MSD) are among the most common reasons for consulting a GP and have a major impact on healthcare resources.[12] The Global Burden of Disease 2010 study found that MSD, including rheumatic disorders, were the second main contributor to the number of years lived with disability.[1] Part of this burden is avoidable. The importance of MSD as major cause of (avoidable) disability, however, seems insufficiently acknowledged by GPs.[13,14] Training in rheumatology is rarely mandatory in general practice training programs, despite the large number of patients that present themselves in primary care with rheumatic disorders.[15] Nonetheless, it seems that musculoskeletal conditions are not a priority in primary care.[16,17]

Making a diagnosis of axSpA is often delayed up to 10 years or longer, suggesting that opportunities for early recognition and referral have been missed in primary care. $[18,19]$ Several referral strategies that promote early referral of axSpA have been developed, but successful implementation may be hampered by ineffective referral patterns due to lack of knowledge about axSpA.[20-23] From this thesis, we learned that there is room for improvement with regard to the level of knowledge of GPs about their ability to identify and refer patients with suspected axSpA. Changing clinical practice behavior and assessing such change is a real challenge. The evidence that educational interventions may actually change anything is limited.[24] Lack of time and resources often contribute to failure of the education intervention.[24] This thesis shows that the use of standardized patients (SPS), is a feasible and informative approach to assess the impact of an educational intervention. More importantly, a multi-faceted educational program can play a key role in improving disease recognition 
and referral of patients suspected for SpA. This important finding may further improve timely diagnosis and initiation of treatment of patients with SpA. 


\section{REFERENCES}

1. Vos T, Flaxman AD, Naghavi M, et al. Years lived with disability (YLDs) for 1160 sequelae of 289 diseases and injuries 1990-2010: a systematic analysis for the Global Burden of Disease Study 2010. Lancet 2012;380:2163-96.

2. Feldtkeller $E$, Khan MA, van der Heijde $D$, et al. Age at disease onset and diagnosis delay in HLA-B27 negative vs. positive patients with ankylosing spondylitis. Rheumatol Int 2003;23:61-6.

3. Boonen A, van der Linden SM. The burden of ankylosing spondylitis. J Rheumatol 2006;78:4-11.

4. Boonen A. A review of work-participation, cost-of-illness and cost-effectiveness studies in ankylosing spondylitis. Nat Clin Pract Rheumatol 2006;2:546-53.

5. Akesson K, Dreinhöfer KE, Woolf AD. Improved education in musculoskeletal conditions is necessary for all doctors. Bull World Health Organ 2003;81:677-83.

6. Badley EM, Rasooly I, Webster GK. Relative importance of musculoskeletal disorders as a cause of chronic health problems, disability, and health care utilization: findings from the 1990 Ontario Health Survey. J Rheumatol 1994;21:505-14.

7. March L, Smith EU, Hoy DG, et al. Burden of disability due to musculoskeletal (MSK) disorders. Best Pract Res Clin Rheumatol 2014;28:353-366.

8. Hoy D, March L, Brooks P, et al. The global burden of low back pain: estimates from the Global Burden of Disease 2010 study. Ann Rheum Dis 2014;73:968-74.

9. Chiowchanwisawakit P, Lambert RG, Conner-Spady B, et al. Focal fat lesions at vertebral corners on magnetic resonance imaging predict the development of new syndesmophytes in ankylosing spondylitis. Arthritis Rheum 2011;63:2215-25.

10. Maksymowych WP, Chiowchanwisawakit $P$, Clare $T$, et al. Inflammatory lesions of the spine on magnetic resonance imaging predict the development of new syndesmophytes in ankylosing spondylitis: evidence of a relationship between inflammation and new bone formation. Arthritis Rheum 2009;60:93-102.

11. Song IH, Hermann KG, Haibel $\mathrm{H}$, et al. Relationship between active inflammatory lesions in the spine and sacroiliac joints and new development of chronic lesions on whole-body MRI in early axial spondyloarthritis: results of the ESTHER trial at week 48. Ann Rheum Dis 2011;70:1257-63.

12. Jordan KP, Kadam UT, Hayward R, et al. Annual consultation prevalence of regional musculoskeletal problems in primary care: an observational study. BM C M usculoskelet Disord 2010;11:144.

13. Woolf $A D$, Akesson $\mathrm{K}$. Understanding the burden of musculoskeletal conditions. The burden is huge and not reflected in national health priorities. BMJ 2001;322:1079-80.

14. Woolf AD, Akesson K. Can we reduce the burden of musculoskeletal conditions? The European action towards better musculoskeletal health. Best Pract Res Clin Rheumatol 2007;21:1-3.

15. Rasker JJ. Rheumatology in general practice. Br J Rheumatol 1995;34:494-7.

16. Hosie GA. Teaching rheumatology in primary care. Ann Rheum Dis 2000;59:500-3.

17. Lanyon $\mathrm{P}$, Pope $\mathrm{D}$, Croft $\mathrm{P}$. Rheumatology education and management skills in general practice: a national study of trainees. Ann Rheum Dis 1995;54:735-9.

18. Jois RN, Macgregor AJ, Gaffney K. Recognition of inflammatory back pain and ankylosing spondylitis in primary care. Rheumatology (Oxford) 2008;47;1364-6.

19. Feldtkeller E, Khan MA, van der Heijde D, et al. Age at disease onset and diagnosis delay in HLA-B27 negative vs. positive patients with ankylosing spondylitis. Rheumatol Int 2003;23:61-6.

20. Poddubnyy D, Vahldiek J, Spiller I, et al. Evaluation of 2 screening strategies for early identification of patients with axial spondyloarthritis in primary care. J Rheumatol 2011;38:2452-60.

21. Brandt HC, Spiller I, Song IH, et al. Performance of referral recommendations in patients with chronic back pain and suspected axial spondyloarthritis. Ann Rheum Dis 2007;66:1479-84.

22. Hermann J, Giessauf H, Schaffler G, et al. Early spondyloarthritis: usefulness of clinical screening. Rheumatology (Oxford) 2009;48:812-6.

23. Sieper J, Srinivasan S, Zamani 0 , et al. Comparison of two referral strategies for diagnosis of axial spondyloarthritis: the Recognising and Diagnosing Ankylosing Spondylitis Reliably (RADAR) study. Ann Rheum Dis 2013;72:1621-7.

24. Grol R, Wensing M. What drives change? Barriers to and incentives for achieving evidence-based practice. Med J Aust 2004;180:\$57-60. 


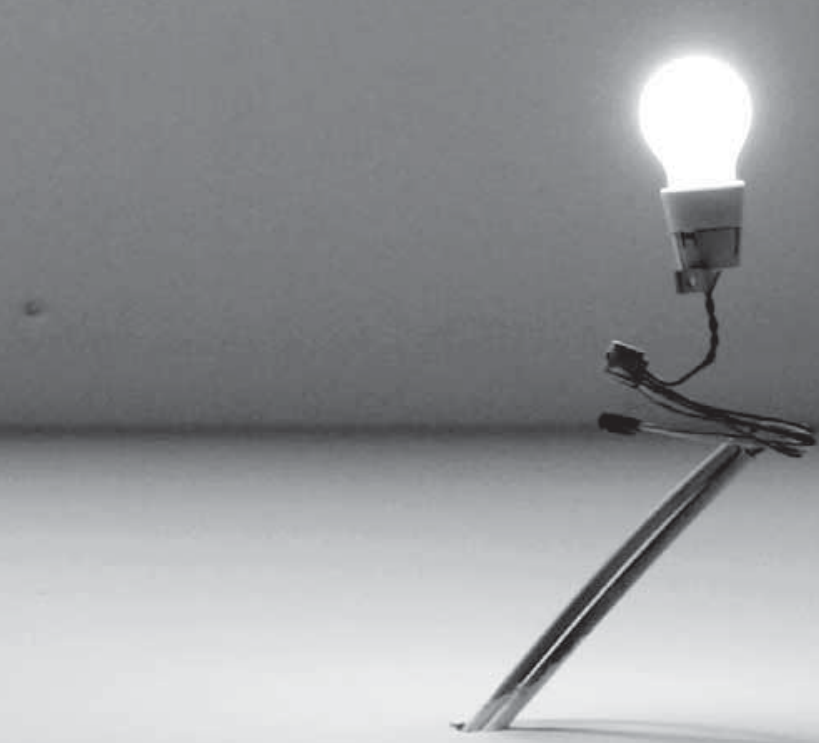

Dankwoord 



\section{DANKWOORD}

Het is af. Zonder een officieel promotietraject is dit proefschrift er dan toch gekomen. In combinatie met mijn opleiding tot reumatoloog was dit niet altijd gemakkelijk, maar met hulp van veel mensen is het uiteindelijk toch gelukt. Dank aan iedereen die mij met zijn/haar bijdrage heeft geholpen. Ik wil deze pagina's gebruiken om een aantal mensen in het bijzonder te bedanken.

Ten eerste wil ik alle patiënten van het ESpAC cohort bedanken voor hun medewerking, zonder jullie zou er voor mij niet veel te onderzoeken zijn geweest. Daarnaast wil ik alle simulatiepatiënten, huisartsen en huisartsen-in-opleiding bedanken. Dankzij jullie enthousiasme en inzet ben ik in staat gesteld om veel belangrijke gegevens voor mijn proefschrift te verzamelen.

Prof. dr. Landewé, beste Robert, tijdens mijn WESP-stage op de afdeling reumatologie heb je me kennis laten maken met het doen van onderzoek. Daarnaast heb je er voor gezorgd dat ik het onderzoek kon voortzetten tijdens mijn opleiding. Ik heb hier geen moment spijt van gehad. Ik hoop dat jij dat ook niet hebt gehad... Zeker omdat het allemaal iets meer tijd heeft gekost dan normaal. Ik heb veel van je geleerd en wil je bedanken voor je vertrouwen, geduld, kritische blik en humor.

Prof. dr. Boonen, beste Annelies, wat ben ik blij dat ik nu steeds meer met je kan samenwerken! Ondanks je eigen drukke programma ben je altijd bereid om mee te denken en help je me weer op weg. Je bent een grote inspiratiebron voor mij. Ik ben heel erg blij en trots dat ik de kans heb gekregen om me in M aastricht verder te mogen ontwikkelen als reumatoloog en onderzoeker.

Dr. van Tubergen, beste Astrid, je bent de afgelopen periode echt een steun en toeverlaat voor me geweest. Ik heb veel bewondering voor je kennis, scherpe analyses en je vermogen om dit alles duidelijk uit te leggen. Inmiddels deel ik een kamer met je. Nu ik weer meer tijd heb, ben ik zeker van plan om die wand met boeken / formulieren / stof eens op te ruimen en de kamer opnieuw in te richten. De plant mag blijven staan, $(-)$.

Prof. dr. van der Heijde, beste Désirée, eigenlijk heb jij het fundament voor dit proefschrift gelegd, onder andere als initiator van het ESpAC cohort. Ik bewonder je 
drive en inzet als wetenschapper en wil je bedanken voor je geduld om mijn artikelen te lezen en deze met me te bespreken.

Ik wil graag de leden van de beoordelingscommissie, Prof. dr. J.E. Wildberger, Prof. dr. R.A. de Bie, Prof. dr. F. van den Bosch, Prof. dr. J.A. Knottnerus, Dr. A.E.A.M. Weel bedanken voor het inhoudelijk commentaar, adviezen en de goedkeuring.

Veel mensen hebben essentiële bijdrage geleverd aan de totstandkoming van verschillende artikelen. Dr. Jurik, dear Anne Grethe, I would like to thank you for helping me to score all those MRIs, in only four days. We finished scoring just ten minutes before I had to leave to catch my flight back home! I enjoyed working together with you. Dr. Heuft, Liesbeth, dankzij jouw investering in het ESpAC cohort ben ik in staat gesteld om verder aan de slag te gaan met de follow-up gegevens. Dank daarvoor! Dr. Gorter, Dr. Maiburg, Drs. Waagenaar, beste Simone, Bas en Gerrie, bedankt voor de prettige samenwerking en jullie enthousiasme bij het opzetten en uitvoeren van het simulatiepatiëntenproject. Aniek en Carmen, het was erg leuk en gezellig om met jullie onderzoek te mogen doen.

Een proefschrift kan natuurlijk alleen maar worden geschreven als je daarvoor de ruimte en mogelijkheden krijgt. Debby, Thea, Caroline, Sandrine, bedankt voor jullie concrete hulp of steuntje in de rug op het juiste moment. Debby, ik wil jou in het bijzonder ook bedanken voor de kans die je mij hebt geboden om me in Maastricht verder te mogen ontwikkelen. Je moet nu toch eens gaan winkelen voor een mooie tas, je hebt hem inmiddels wel verdiend. Caroline en Sandrine, eerst collega-AIOS, nu collega-reumatologen en mijn paranimfen. Ik ben erg blij dat jullie 'achter me staan' op de dag zelf. Onze maandelijkse etentjes moeten we nu echt vol zien te houden. Thea, ik wil je bedanken voor al je hulp op het gebied van patiëntenzorg, ik heb daar altijd veel steun aan gehad. Els, Janine, M ehmet, Andy en Yvonne, dank voor jullie ondersteuning bij het combineren van onderzoek en patiëntenzorg.

Prof. dr. van der Linden, beste Sjef, ik wil u bedanken voor uw nuchtere adviezen en vertrouwen in mij. Dankzij u kon ik starten met de opleiding tot reumatoloog, een prachtig cadeau!

Mijn opleiding heb ik mogen voltooien in Heerlen. Wat heb ik daar een leuke tijd gehad! Ik wil graag alle reumatologen, AIOS reumatologie, reumaconsulenten en polimedewerkers bedanken. Mede dankzij jullie inzet heb ik dat jaar echt tempo 
kunnen maken en veel werk kunnen verzetten. Een bijzonder woord van dank aan Mirian en Ralph, dankzij jullie uitstekende begeleiding kunnen AIOS in Heerlen het beste uit zichzelf halen. Jullie hebben me in de eindfase van mijn opleiding klaargestoomd voor het vak! Femke, dank voor je hulp bij het verwerken en invoeren van data.

Tijdens mijn opleiding heb ik mogen samenwerken met een club van super-AIOS. We hebben heel veel lol gehad. Een aantal heb ik hierboven al genoemd. Kristof, we hebben hetzelfde gevoel voor humor en ik mis nu nog wel eens jouw eigen visie op de wereld die je altijd bereid bent met anderen te delen. Merdan, we moesten voor het eerst samenwerken toen we allebei derdejaars geneeskunde student waren. Wie had gedacht dat we tien jaar later allebei reumatoloog zouden zijn? Ward, bedankt voor je opbeurende woorden als iets weer niet helemaal ging zoals ik van te voren had bedacht. Inmiddels zijn we allemaal klaar met de opleiding en werken we in verschillende ziekenhuizen, maar ik weet zeker dat we contact blijven houden.

Daarnaast ook dank aan alle AIOS en promovendi van de afdeling reumatologie, voor de prettige samenwerking en jullie enthousiasme!

Peggy, Marian en Yvonne, jullie staan garant voor een soepel lopend secretariaat. Wat kan ik me nog meer wensen? Jullie helpen me altijd perfect met de administratie. Dankzij jullie heb ik geleerd dat het soms echt beter is wanneer je de zaken uit handen geeft. Edith, Maddy en Marjos, jullie zijn voor mij het gezicht van de polikliniek reumatologie en zorgen ervoor dat mijn spreekuur soepel loopt. Er verandert nu veel op de polikliniek, maar ik weet zeker dat we er iets moois van gaan maken. Tiny, bedankt voor je hulp bij de lay-out van het proefschrift.

De eerste jaren van mijn opleiding heb ik doorgebracht op de afdeling interne geneeskunde van het MUMC. Ik wil Prof. dr. C. Stehouwer en Prof. dr. R. Koopmans bedanken voor het verzorgen van een gedegen vooropleiding en de vrijheid om daarnaast ook onderzoek te kunnen blijven doen. Een speciaal woord van dank aan Evelien, Wubbo, Ronald en Patricia. Overleg met jullie heb ik altijd als zeer nuttig en waardevol ervaren.

Vrienden, (inmiddels) ver weg maar toch ook dichtbij. Jullie hebben me altijd de nodige gezelligheid en afleiding geboden. Floor, ik ken je al vanaf de eerste klas van de middelbare school. We hebben samen zowat heel Europa gezien. Ik ben blij dat we 
ondanks de reisafstand elkaar regelmatig blijven zien om gezellig bij te kletsen. Cécile, volgens mij hebben we in totaal maar twee weken samengewerkt op B5, maar we zijn altijd contact blijven houden. Ik wil je bedanken voor je vriendschap. Ik kijk uit naar de nog komende thee-en-koffie-momentjes. Sofia, je toont altijd interesse voor mijn bezigheden en bent immer bereid te helpen. Bedankt daarvoor!

En dan....familie. Tantes, ooms, neven en nichten, bedankt voor jullie betrokkenheid. Berdien en Corrie, nogmaals dank voor jullie hulp bij het opknappen van mijn huis. Dankzij jullie heb ik mijn proefschrift kunnen schrijven met een door jullie geverfde muur (schoon en wit) als prettig uitzicht.

Rogier en Roma, dank voor de gesprekken die niet over het proefschrift gingen.

Lieve papa en mama, hartelijk dank voor jullie onvoorwaardelijke steun, adviezen en vertrouwen. Zonder jullie had ik dit nooit bereikt. Nu het proefschrift af is, is dat voor jullie denk ik ook een hele zorg minder. Uit de grond van mijn hart, dank jullie wel! 
Curriculum Vitae

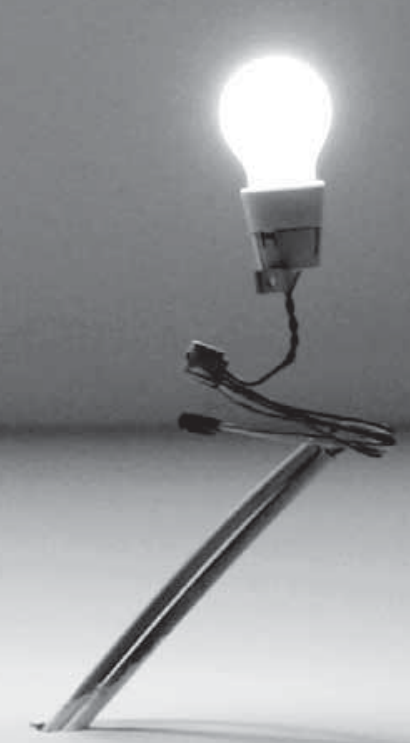





\section{CURRICULUM VITAE}

Marloes van Onna werd op 2 augustus 1982 geboren in Beuningen. Na het behalen van haar gymnasiumdiploma aan het Kandinsky College in Nijmegen, studeerde zij van 2000 tot 2002 Gezondheidswetenschappen aan de universiteit van Maastricht. In 2002 besloot zij Geneeskunde te gaan studeren, omdat zij bij nader inzien toch geen 'onderzoeker' maar 'dokter' wilde worden. Tijdens een keuze-coschap Reumatologie en Maag-, Darm- en Leverziekten in Gent en vervolgens een wetenschappelijke stage op de afdeling Reumatologie in het Maastricht Universitair M edisch Centrum (MUMC) werd haar interesse voor de Reumatologie gewekt. Ze behaalde haar artsenbul in 2008 cum laude.

In 2009 begon zij aan haar vooropleiding Interne Geneeskunde in het MUMC (opleider: Prof. dr. C. Stehouwer). In hetzelfde jaar startte zij eveneens met het onderzoek welk uiteindelijk heeft geresulteerd in dit proefschrift. De resultaten zoals beschreven in dit proefschrift werden gepresenteerd op verschillende nationale en internationale congressen. De vervolgopleiding tot reumatoloog werd in 2012 voortgezet in zowel het MUM C als het Zuyderland Ziekenhuis in Heerlen (opleiders: Prof. dr. S. van der Linden, Dr. D. Vosse en Dr. R. Peeters).

Sinds 2015 werkt zij als staflid Reumatologie in het MUM C. 
